Pontifícia Universidade C Católica

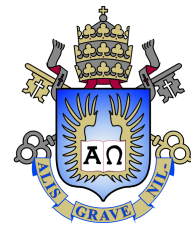

Eduardo Gonçalves Costa Amaral

Essays in Monetary Policy with Risky Assets

Tese de Doutorado

Thesis presented to the Programa de Pós-graduação em Economia of the Departmento de Economia of PUC-Rio in partial fulfillment of the requirements for the degree of Doutor em Economia.

Advisor: Prof. Carlos Viana de Carvalho 


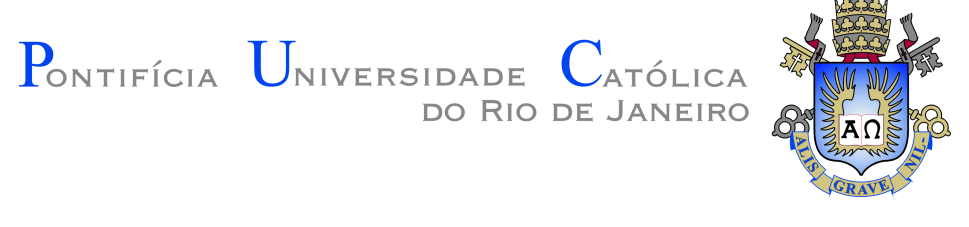

Eduardo Gonçalves Costa Amaral

\title{
Essays in Monetary Policy with Risky Assets
}

Thesis presented to the Programa de Pós-graduação em Economia da PUC-Rio in partial fulfillment of the requirements for the degree of Doutor em Economia. Approved by the Examination Committee:

\author{
Prof. Carlos Viana de Carvalho \\ Advisor \\ Departamento de Economia - PUC-Rio
}

Prof. Eduardo Zilberman

Departamento de Economia - PUC-Rio

Prof. Tiago Couto Berriel

Departamento de Economia - PUC-Rio

Prof. Eduardo Henrique de Mello Motta Loyo

BTG

Prof. Ricardo A. M. R. Reis

Department of Economics - LSE

Rio de Janeiro, October the 4th, 2021 
All rights reserved.

\section{Eduardo Gonçalves Costa Amaral}

Majored in Industrial Engineering by the Federal University of Rio de Janeiro (Rio de Janeiro, Brazil), now holds a Ph.D. degree in Economics from PUC-Rio. During his Ph.D. studies he was a visiting researcher of the Department of Economics of the London School of Economics.

Bibliographic data

Amaral, Eduardo Gonçalves Costa

Essays in Monetary Policy with Risky Assets / Eduardo Gonçalves Costa Amaral; advisor: Carlos Viana de Carvalho. $-2021$.

238 f: il. color. ; $30 \mathrm{~cm}$

Tese (doutorado) - Pontifícia Universidade Católica do Rio de Janeiro, Departamento de Economia, 2021.

Inclui bibliografia

1. Economia - Teses. 2. Política Monetária. 3. Ativo de Política Arriscado. 4. Taxa Natural de Juros. 5. Limite Fiscal. 6. Mudança Endógena de Regime. I. Carvalho, Carlos Viana de. II. Pontifícia Universidade Católica do Rio de Janeiro. Departamento de Economia. III. Título. 


\section{Acknowledgments}

To my advisor, Carlos Viana de Carvalho, for his helpful guidance throughout this long journey, and to Professor Ricardo Reis for generously receiving me during my split Ph.D. studies as a visiting research student of the London School of Economics.

To the other members of the Examination Committee - Loyo, Berriel, and Dudu - for their insightful and inspired comments on this thesis. It was a delight to hear from them.

To all my colleagues at PUC-Rio and at the LSE for sharing with me the burden and also the most fun steps of my studies.

To the Central Bank of Brazil for sponsoring this degree through its amazing postgraduate program, and to CAPES for partially financing my split Ph.D. studies at the London School of Economics.

To the Department of Economics of PUC-Rio, who at the very start made that phone call after the ANPEC exam inviting me for its masters program, and who after the first year believed I could move straight to its Ph.D. program.

To my sister, for her encouragement and example.

Above all, to my parents for their unconditional love and support. 


\section{Abstract}

Amaral, Eduardo Gonçalves Costa; Carvalho, Carlos Viana de (Advisor). Essays in Monetary Policy with Risky Assets. Rio de Janeiro, 2021. 238p. Tese de Doutorado - Departamento de Economia, Pontifícia Universidade Católica do Rio de Janeiro.

This dissertation presents three chapters addressing issues pertaining to monetary policy. Chapter 1 evaluates the problem of conducting monetary policy with risky assets in a simple neo-Wicksellian monetary model. I show that monetary policy's power w.r.t prices and inflation reduces as it can only be conditionally active in the presence of policy-asset risk. Moreover, uncompensated risk premium induces an inflationary bias, as well as default probability and inflation are positively correlated, the same sign of empirical correlations usually found. These results constitute a novel argument in favor of a more hawkish stance in case of a fiscal or political crisis, which helps to explain "monetary policy conservatism" in risky economies. Chapter 2 endogenizes policy-asset risk as a fiscal risk and studies its transmission. I lay out a two-agent New-Keynesian (TANK) model with endogenous fiscal limits in which the central bank operates through defaultable bonds, and then calibrate it to a large emerging economy, Brazil. I find that by ignoring policy-asset risk the central bank reinforces the unpleasant coincidence of higher inflation, real, and nominal interest rates in the equilibrium distribution of the model, what emerges as the result of endogenous expectations of a severe recession in case of default. Additionally, accommodating policy-asset risk induces positive correlation between default risk and inflation. From a policy perspective, these results raise serious concerns about the evaluation of monetary policy stance in default-risky economies, while shed new light on the long-standing discussion about why policy rates have been exceptionally high in Brazil after the Real Plan. Finally, Chapter 3 responds to a recent controversy on the actual presence of a real interest rate transmission channel in New-Keynesian models, as the addition of endogenous capital is consistent with real rates moving in any direction after a monetary shock. I show that this identification problem can be circumvented by the inclusion of another ingredient as prevalent as capital itself in middle-scale models: interest-rate smoothing.

\section{Keywords}

Monetary Policy; Risky Policy Asset; Natural Interest Rate; Fiscal Limit; Endogenous Regime Switching. 


\section{Resumo}

Amaral, Eduardo Gonçalves Costa; Carvalho, Carlos Viana de. Ensaios de Política Monetária com Ativos Arriscados. Rio de Janeiro, 2021. 238p. Tese de Doutorado - Departamento de Economia, Pontifícia Universidade Católica do Rio de Janeiro.

Esta dissertação é composta por três capítulos que abordam questões relacionadas à política monetária. O Capítulo 1 avalia o problema de conduzir política monetária com ativos arriscados em um simples modelo neoWickselliano. Eu mostro que a potência da política monetária com relação a preços e inflação se reduz uma vez que ela só pode ser condicionalmente ativa na presença de risco subjacente ao ativo de política monetária. Além disso, prêmio de risco não compensado induz viés inflacionário, e há correlação positiva entre probabilidade de calote e inflação, do mesmo sinal que se costuma encontrar em dados empíricos. Esses resultados constituem um argumento novo em favor de uma política monetária mais vigilante em caso de crise fiscal ou política, o que ajuda a explicar o "conservadorismo da política monetária" em economias arriscadas. O capítulo 2 endogeniza risco no ativo de política monetária como risco fiscal e estuda sua transmissão. Eu desenvolvo um modelo novo-Keynesiano de dois agentes (TANK) com limites fiscais endógenos no qual o banco central opera através de títulos com risco de calote, e calibro para uma grande economia emergente, Brasil. Eu encontro que, ao ignorar o risco subjacente ao ativo de política monetária, o banco central reforça a "coincidência desagradável" de taxas mais altas de juros real, nominal e inflação na distribuição de equilíbrio do modelo, o que surge como o resultado de expectativas endógenas de recessões severas em caso de calote. Outrossim, acomodar risco de ativo de política induz correlação positiva entre risco de calote e inflação. Do ponto de vista de política, esses resultados lançam dúvidas quanto à correta avaliação da rigidez da política monetária em economias com risco de calote soberano, enquanto também lançam nova luz sobre a antiga discussão de por que a taxa básica de juros foi excepcionalmente alta no Brasil após o Plano Real. Finalmente, o Capítulo 3 responde à controvérsia recente sobre a presença, de fato, de um canal de transmissão de taxa de juros real nos modelos novo-Keynesianos, uma vez que adição de capital endógeno é consistente com a taxa real se movendo em qualquer direção após um choque monetário positivo. Eu mostro que esse problema de identificação pode ser contornado pela inclusão de outro ingrediente tão comum em modelos de tamanho médio quanto o próprio capital: suavização de taxa de juros.

\section{Palavras-chave}


Política Monetária; Ativo de Política Arriscado; Taxa Natural de Juros; Limite Fiscal; Mudança Endógena de Regime. 


\section{Table of contents}

1 Interest, Prices, and Risk $\quad 15$

$\begin{array}{lll}1.1 & \text { Introduction } & 15\end{array}$

$\begin{array}{lll}1.2 & \text { Related literature } & 21\end{array}$

1.3 Theoretical background 23

$\begin{array}{lll}\text { 1.3.1 Wicksell's monetary theory } & 23\end{array}$

1.3.2 Neo-Wicksellian monetary theory 24

1.4 Neo-Wicksellian monetary theory with risky policy assets 29

$\begin{array}{lll}1.4 .1 & \text { A defaultable bond } & 29\end{array}$

$\begin{array}{ll}\text { 1.4.2 The policy asset as a defaultable bond } & 29\end{array}$

1.4.3 Monetary policy with risk in the policy asset under inflation targeting 31

$\begin{array}{ll}\text { 1.4.4 The inflation bias } & 37\end{array}$

$\begin{array}{ll}\text { 1.5 Testable implications of the model } & 39\end{array}$

1.5.1 Model simulation $\quad 40$

1.5.2 Empirical validation 41

$\begin{array}{lll}1.6 & \text { Conclusion } & 48\end{array}$

2 An Unpleasant Coincidence for Monetary Policy: Risky Assets and Fiscal Limits $\quad 49$

2.1 Introduction 49

2.2 Related literature $\quad 54$

2.3 Closed economy with default-risky policy assets 57

2.3.1 Households $\quad 58$

2.3.1.1 Ricardian households $\quad 58$

$\begin{array}{ll}\text { 2.3.1.2 Non-Ricardian households } & 60\end{array}$

$\begin{array}{lll}\text { 2.3.2 } & \text { Final goods sector } & 61\end{array}$

2.3.3 Intermediate goods sector $\quad 62$

$\begin{array}{lll}2.3 .4 & \text { Government } & 63\end{array}$

2.3.5 Defaultable bonds 64

$\begin{array}{lll}\text { 2.3.6 Monetary policy } & 65\end{array}$

$\begin{array}{lll}2.3 .7 & \text { Equilibrium } & 68\end{array}$

2.3.8 Solution $1^{\text {st }}$ step: the model as a single regime with flexible prices 70

2.3.9 Solution $2^{\text {nd }}$ step: fiscal limits and default probability $\quad 72$

2.3.10 Solution $3^{\text {rd }}$ step: regime switching with endogenous probabilities 75

2.4 Calibration and simulation of the model $\quad 79$

$\begin{array}{lll}2.4 .1 & \text { Calibration } & 79\end{array}$

2.4.2 Simulation of the fiscal limits 86

$\begin{array}{ll}2.4 .3 \text { Equilibrium distribution } & 95\end{array}$

$\begin{array}{lll}\text { 2.4.3.1 Variables distribution } & 96\end{array}$

$\begin{array}{ll}\text { 2.4.3.2 Rules comparison } & 97\end{array}$

2.4.4 Bringing inflation back to the model 103

$\begin{array}{lll}2.5 & \text { Conclusion } & 112\end{array}$ 
3 On the Mechanics of New-Keynesian Models:

Smoothing the Capital Controversy Out 114

$\begin{array}{lll}3.1 & \text { Introduction } & 114\end{array}$

$\begin{array}{lll}3.2 & \text { Related literature } & 117\end{array}$

$\begin{array}{lll}3.3 & \text { New-Keynesian model before and after capital } & 119\end{array}$

$\begin{array}{lll}\text { 3.3.1 Canonical closed economy } & 119\end{array}$

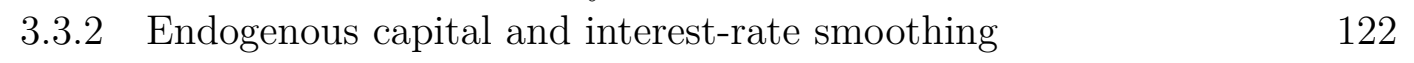

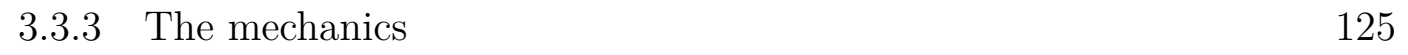

$\begin{array}{ll}\text { 3.3.4 Impulse response functions } & 128\end{array}$

$\begin{array}{lll}3.3 .4 .1 & \text { The identification problem } & 129\end{array}$

$\begin{array}{lll}\text { 3.3.4.2 Fixing with high interest-rate smoothing } & 130\end{array}$

3.3.4.3 Fixing with low interest-rate smoothing and small adjustment cost 131

$\begin{array}{lll}3.4 \text { Conclusion } & 132\end{array}$

A Appendix: Chapter 1 143

A.1 Estimation of the real neutral rate using univariate filters 143

A.2 Model derivation under a price-level targeting rule 146

A.2.1 Neo-Wicksellian model with price-level targeting 146

A.2.2 Monetary policy with risk in the policy asset under price-level targeting 149

A.2.3 The high-price-level bias 153

$\begin{array}{lll}\text { A.3 Propositions and proofs } & 155\end{array}$

$\begin{array}{lll}\text { A.4 A default-risky cashless economy } & 158\end{array}$

A.5 Monetary policy targets the risky rate using safe assets 163

$\begin{array}{lll}\text { A.6 Monetary policy power } & 166\end{array}$

A.7 Testable implications of the model: correlations 172

$\begin{array}{lll}\text { A.7.1 Inflation targeting } & 172\end{array}$

$\begin{array}{lll}\text { A.7.2 Price-level targeting } & 174\end{array}$

$\begin{array}{lll}\text { A.7.3 Country-specific correlations } & 177\end{array}$

$\begin{array}{lll}\text { A.7.4 Alternative measures of risk } & 182\end{array}$

$\begin{array}{lll}\text { A.7.5 CDS data source } & 189\end{array}$

B Appendix: Chapter 2 192

B.1 Steady state of the model 192

$\begin{array}{ll}\text { B.2 Log-linearized model } & 195\end{array}$

$\begin{array}{ll}\text { B.2.1 Equations } & 195\end{array}$

B.3 Estimation of the single-regime model 198

$\begin{array}{lll}\text { B.4 Policy rules and stability } & 206\end{array}$

B.5 Impulse response functions 211

$\begin{array}{ll}\text { B.6 Welfare } & 217\end{array}$

$\begin{array}{ll}\text { B.7 Additional analyses } & 224\end{array}$

B.7.1 Correlation between $\Pi_{t}$ and $\mathbb{E}_{t} \mathcal{D}_{t+1} \quad 224$

B.7.2 Welfare of Ricardian and non-Ricardian households 229

B.7.2.1 Sensitivity analysis under $\overline{\mathcal{D}} \approx 0 \% \quad 230$

$\begin{array}{ll}\text { B.7.2.2 Sensitivity analysis under } \overline{\mathcal{D}}=2 \% & 232\end{array}$

$\begin{array}{ll}\text { B.7.2.3 Sensitivity analysis under } \overline{\mathcal{D}}=5 \% & 234\end{array}$

B.8 Endogenous regime-switching DSGE solution strategy 236 


\section{List of figures}

$\begin{array}{lll}\text { Figure 1.1 } & \text { Real neutral rates estimated by univariate filters } & 17\end{array}$

Figure 1.2 Inflation under neo-Wicksellian monetary theory $\left(\phi^{\pi}=\right.$

1.1) 28

Figure 1.3 Inflation under neo-Wicksellian monetary theory $\left(\phi^{\pi}=\right.$ $1.2)$

Figure 1.4 Inflation under neo-Wicksellian monetary theory augmented with policy-asset default $\left(\phi^{\pi}=1.08\right)$

Figure 1.5 Inflation under neo-Wicksellian monetary theory augmented with policy-asset default $\left(\phi^{\pi}=1.15\right)$

Figure 1.6 Correlation between the default probability and inflation under inflation targeting: $\operatorname{Corr}\left(r_{t}^{n}, \mathbb{E}_{t} \mathcal{D}_{t+1}\right)=0$

Figure 1.7 Scatter plot of pooled emerging economies: nominal interest rate, inflation, and default risk

Figure 1.8 Scatter plot of pooled advanced economies: nominal interest rate, inflation, and default risk

Figure 1.9 Empirically estimated Taylor rules

Figure 2.1 Brazilian historical data

Figure 2.2 Inflation targeting with risky assets 68

Figure 2.3 Stylized Laffer curves

Figure 2.4 Example of peak of the Laffer curve binding in the simulated model

$\begin{array}{lll}\text { Figure 2.5 Goodness of fit of the logistic approximation } & 77\end{array}$

Figure 2.6 Actual stacked Brazilian government expenses $\quad 82$

Figure 2.7 Actual stacked Brazilian government revenues 83

Figure 2.8 The neutral real interest rate and the fiscal limit cdf $\quad 88$

Figure 2.9 Fiscal limits at different steady states: PDFs (left panels) and CDFs (right panels)

Figure 2.10 Fiscal limits at different shock persistence coefficients: PDFs (left panels) and CDFs (right panels)

Figure 2.11 Fiscal limits at different shock volatility coefficients: PDFs (left panels) and CDFs (right panels)

Figure 2.12 Fiscal limits after changing selected parameters: PDFs (left panels) and CDFs (right panels)

Figure 2.13 Ergodic distribution of selected endogenous variables far and near the fiscal limit

Figure 2.14 Stylized representation of the effect of policy-asset default risk on equilibrium

Figure 2.15 Ergodic distribution of selected endogenous variables under different monetary policy rules far from the fiscal limit

Figure 2.16 Ergodic distribution of selected endogenous variables under different monetary policy rules near the fiscal limit

Figure 2.17 Ergodic distribution of the policy rate and of inflation under different monetary policy rules near the fiscal limit 
Figure 3.1 Output and inflation elasticity to a monetary shock

Figure 3.2 Decomposition of the effect of capital to $\hat{R}_{t}$ from a monetary shock when $\frac{\bar{K}}{\bar{Y}}=5.5, \rho^{i}=0$, and $\kappa=0$

Figure 3.3 Decomposition of the effect of capital to $\hat{R}_{t}$ from a monetary shock when $\frac{\bar{K}}{\bar{Y}}=5.5, \rho^{i}=0$, and $\kappa=0.1$

Figure 3.4 Decomposition of the effect of capital to $\hat{R}_{t}$ from a monetary shock when $\frac{\bar{K}}{\bar{Y}}=5.5, \rho^{i}=0.5$, and $\kappa=0$

Figure 3.5 Decomposition of the effect of capital to $\hat{R}_{t}$ from a monetary shock when $\frac{\bar{K}}{\bar{Y}}=5.5, \rho^{i}=0.5$, and $\kappa=0.1$

Figure 3.6 Impulse response function to a 1-standard-deviation monetary shock under $\rho^{m}=0, \rho^{i}=0, \frac{\bar{K}}{\bar{Y}}=5.5$, and $\kappa=0$

Figure 3.7 Impulse response function to a 1-standard-deviation monetary shock under $\rho^{m}=.50, \rho^{i}=0, \frac{\bar{K}}{\bar{Y}}=5.5$, and $\kappa=0$

Figure 3.8 Impulse response function to a 1-standard-deviation monetary shock under $\rho^{m}=0, \rho^{i}=0.9, \frac{\bar{K}}{\bar{Y}}=5.5$, and $\kappa=0$

Figure 3.9 Impulse response function to a 1-standard-deviation monetary shock under $\rho^{m}=.50, \rho^{i}=0.9, \frac{\bar{K}}{\bar{Y}}=5.5$, and $\kappa=0$

Figure 3.10 Impulse response function to a 1-standard-deviation monetary shock under $\rho^{m}=0, \rho^{i}=0.5, \frac{\bar{K}}{\bar{Y}}=5.5$, and $\kappa=0.1$

Figure 3.11 Impulse response function to a 1-standard-deviation monetary shock under $\rho^{m}=.50, \rho^{i}=0.5, \frac{\bar{K}}{\bar{Y}}=5.5$, and $\kappa=0.1$

Figure A.1 Advanced Economies: Real neutral rates (\% per annum) estimated by univariate filters

Figure A.2 Emerging Economies: Real neutral rates (\% per annum) estimated by univariate filters

Figure A.3 The price level under neo-Wicksellian monetary theory $(\phi=0.1)$

Figure A.4 The price level under neo-Wicksellian monetary theory $(\phi=0.2)$

Figure A.5 The price level under neo-Wicksellian monetary theory augmented with policy-asset risk $(\phi=0.08)$

Figure A.6 The price level under neo-Wicksellian monetary theory augmented with policy-asset risk $(\phi=0.15)$

Figure A.7 Monetary policy power under inflation targeting: $\operatorname{Corr}\left(r_{t}^{n}, \mathbb{E}_{t} \mathcal{D}_{t+1}\right)=-1$

Figure A.8 Monetary policy power under inflation targeting: $\operatorname{Corr}\left(r_{t}^{n}, \mathbb{E}_{t} \mathcal{D}_{t+1}\right)=-0.5$

Figure A.9 Monetary policy power under inflation targeting: $\operatorname{Corr}\left(r_{t}^{n}, \mathbb{E}_{t} \mathcal{D}_{t+1}\right)=0$

Figure A.10 Monetary policy power under inflation targeting: $\operatorname{Corr}\left(r_{t}^{n}, \mathbb{E}_{t} \mathcal{D}_{t+1}\right)=0.5$

Figure A.11 Monetary policy power under inflation targeting: $\operatorname{Corr}\left(r_{t}^{n}, \mathbb{E}_{t} \mathcal{D}_{t+1}\right)=1$

Figure A.12 Correlation between the default probability and inflation under inflation targeting: $\operatorname{Corr}\left(r_{t}^{n}, \mathbb{E}_{t} \mathcal{D}_{t+1}\right)=1$ 
Figure A.13 Correlation between the default probability and inflation under inflation targeting: $\operatorname{Corr}\left(r_{t}^{n}, \mathbb{E}_{t} \mathcal{D}_{t+1}\right)=0.5$

Figure A.14 Correlation between the default probability and inflation under inflation targeting: $\operatorname{Corr}\left(r_{t}^{n}, \mathbb{E}_{t} \mathcal{D}_{t+1}\right)=-0.5$

Figure A.15 Correlation between the default probability and inflation under inflation targeting: $\operatorname{Corr}\left(r_{t}^{n}, \mathbb{E}_{t} \mathcal{D}_{t+1}\right)=-1$

Figure A.16 Correlation between the default probability and the price level under price level targeting: $\operatorname{Corr}\left(r_{t}^{n}, \mathbb{E}_{t} \mathcal{D}_{t+1}\right)=1$

Figure A.17 Correlation between the default probability and the price level under price level targeting: $\operatorname{Corr}\left(r_{t}^{n}, \mathbb{E}_{t} \mathcal{D}_{t+1}\right)=0.5$

Figure A.18 Correlation between the default probability and the price level under price level targeting: $\operatorname{Corr}\left(r_{t}^{n}, \mathbb{E}_{t} \mathcal{D}_{t+1}\right)=0$

Figure A.19 Correlation between the default probability and the price level under price level targeting: $\operatorname{Corr}\left(r_{t}^{n}, \mathbb{E}_{t} \mathcal{D}_{t+1}\right)=-0.5$

Figure A.20 Correlation between the default probability and the price level under price level targeting: $\operatorname{Corr}\left(r_{t}^{n}, \mathbb{E}_{t} \mathcal{D}_{t+1}\right)=-1$

Figure A.21 Scatter plot of emerging economies: nominal interest rate, inflation, and default risk (Part 1)

Figure A.22 Scatter plot of emerging economies: nominal interest rate, inflation, and default risk (Part 2)

Figure A.23 Scatter plot of emerging economies: nominal interest rate, inflation, and default risk (Part 3 )

Figure A.24 Scatter plot of advanced economies: nominal interest rate, inflation, and default risk (Part 1)

Figure A.25 Scatter plot of advanced economies: nominal interest rate, inflation, and default risk (Part 2)

Figure A.26 Scatter plot of pooled emerging economies: nominal interest rate, inflation, and LCCS

Figure A.27 Scatter plot of pooled advanced economies: nominal interest rate, inflation, and LCCS

Figure A.28 Scatter plot of emerging economies: nominal interest rate, inflation, and LCCS (Part 1)

Figure A.29 Scatter plot of emerging economies: nominal interest rate, inflation, and LCCS (Part 2)

Figure A.30 Scatter plot of emerging economies: nominal interest rate, inflation, and LCCS (Part 3)

Figure A.31 Scatter plot of advanced economies: nominal interest rate, inflation, and LCCS (Part 1)

Figure A.32 Scatter plot of advanced economies: nominal interest rate, inflation, and LCCS (Part 2)

Figure B.1 Data before demeaning used for estimation

Figure B.2 Prior and posterior distributions of estimated parameters 201

Figure B.3 Curvature at the mode of the posterior distribution of the estimated parameters

Figure B.4 PSRF of the estimated parameters 203

Figure B.5 Smoothed shocks from the estimated model 203

Figure B.6 Observed and smoothed variables after estimation 204

Figure B.7 Variance decomposition of the estimated model 205 
Figure B.8 Parameter stability: policy instrument is risky, but CB targets $r_{t}^{R F}$ under $\overline{\mathcal{D}}=0 \%$

Figure B.9 Parameter stability: policy instrument is risky, and CB targets the risky rate under $\overline{\mathcal{D}}=0 \%$

Figure B.10 Parameter stability: policy instrument is risky, but CB targets $r_{t}^{R F}$ under $\overline{\mathcal{D}}=5 \%$

Figure B.11 Parameter stability: policy instrument is risky, and CB targets the risky rate under $\overline{\mathcal{D}}=5 \%$

Figure B.12 (Regime 1)-specific impulse response function of selected variables to 1 std. shocks

Figure B.13 (Regime 2)-specific impulse response function of selected variables to 1 std. shocks

Figure B.14 Regime-specific impulse response functions of $\Pi_{t}$ to 1 std. shocks

Figure B.15 Regime-specific impulse response functions of $i_{t}$ to 1 std. shocks

Figure B.16 Welfare comparison

Figure B.17 Ergodic distribution of selected endogenous variables under different monetary policy rules near the fiscal limit $\left(2^{\text {nd }}\right.$ order approximation)

Figure B.18 Correlation between $\Pi_{t}$ and $\mathbb{E}_{t} \mathcal{D}_{t+1}$ under different $\overline{\mathcal{D}}$ and policy rules

Figure B.19 Correlation between $\Pi_{t}$ and $\mathbb{E}_{t} \mathcal{D}_{t+1}$ under Rule 1 with $\overline{\mathcal{D}}=5 \%$

Figure B.20 Correlation between $\Pi_{t}$ and $\mathbb{E}_{t} \mathcal{D}_{t+1}$ under Rule 2 with $\overline{\mathcal{D}}=5 \%$

Figure B.21 Correlation between $\Pi_{t}$ and $\mathbb{E}_{t} \mathcal{D}_{t+1}$ under Rule 3 with $\overline{\mathcal{D}}=5 \%$

Figure B.22 Correlation between $\Pi_{t}$ and $\mathbb{E}_{t} \mathcal{D}_{t+1}$ under Rule 4 with $\overline{\mathcal{D}}=5 \%$ 


\section{List of tables}

Table $1.1 \quad$ Inflation bias (p.p.) with $\delta=0.05 \quad 38$

Table 1.2 Inflation bias (p.p.) with $\delta=0.60 \quad 39$

$\begin{array}{lll}\text { Table 2.1 } & \text { Model regimes } & 77\end{array}$

Table 2.2 Calibration of parameters $\quad 80$

Table 2.3 Calibration of steady-state parameters 82

Table 2.4 Summary of parameters estimation 85

Table 2.5 Fiscal limits: sensitivity analysis $\quad 95$

Table 2.6 Bias comparison: $i_{t}$ and $\pi_{t} \quad 102$

Table 2.7 Bias comparison: $r_{t}$ and $r_{t}^{\text {Gov }} \quad 102$

Table 2.8 Simulated means: $\overline{\mathcal{D}}=2 \% ; r_{t}^{n}$ in the intercept 105

Table 2.9 Simulated means (Regime 1): $\overline{\mathcal{D}}=2 \% ; r_{t}^{n}$ in the intercept 106

Table 2.10 Simulated means ( $2^{\text {nd }}$ Order): $\overline{\mathcal{D}}=2 \% ; r_{t}^{n}$ in the intercept 107

Table 2.11 Simulated means: $\overline{\mathcal{D}}=2 \% ; r_{t}^{n}$ in the intercept; and $\delta^{T F P}=0$

Table 2.12 Simulated means (exogenous regime-switching): $\overline{\mathcal{D}}=2 \%$;

$r_{t}^{n}$ in the intercept 111

Table 2.13 Simulated means: $\overline{\mathcal{D}}=2 \% ; r_{t}^{n}$ in the intercept; and $\gamma^{N R}=0112$

Table 3.1 Parameter sweep with $\frac{\bar{K}}{\bar{Y}}=5.5, \delta=0.025$, and $\kappa=0.0 \quad 124$

Table 3.2 Parameter sweep with $\frac{\bar{K}}{\bar{Y}}=5.5, \delta=0.025$, and $\kappa=0.1 \quad 124$

Table 3.3 Parameter sweep with $\frac{\bar{K}}{\bar{Y}}=5.5, \delta=0.025$, and $\kappa=0.5 \quad 125$

Table A.1 Filters: Summary of the data sample 144

Table A.2 Price-level bias (p.p.) with $\delta=0.05 \quad 154$

Table A.3 Price-level bias (p.p.) with $\delta=0.60 \quad 154$

Table A.4 CDS data source: part $1 \quad 190$

Table A.5 CDS data source: part $2 \quad 190$

Table A.6 CDS data source: part $3 \quad 191$

Table B.1 Summary of observables' statistics before demeaning 199

Table B.2 Sensitivity analysis of aggregate welfare under $\overline{\mathcal{D}} \approx 0 \% \quad 221$

Table B.3 Sensitivity analysis of aggregate welfare under $\overline{\mathcal{D}}=2 \% \quad 222$

Table B.4 Sensitivity analysis of aggregate welfare under $\overline{\mathcal{D}}=5 \% \quad 223$

Table B.5 Sensitivity analysis of Ricardian welfare under $\overline{\mathcal{D}} \approx 0 \% \quad 230$

Table B.6 Sensitivity analysis of Non-Ricardian welfare under $\overline{\mathcal{D}} \approx 0 \% 231$

Table B.7 Sensitivity analysis of Ricardian welfare under $\overline{\mathcal{D}}=2 \% \quad 232$

Table B.8 Sensitivity analysis of Non-Ricardian welfare under $\overline{\mathcal{D}}=2 \% 233$

Table B.9 Sensitivity analysis of Ricardian welfare under $\overline{\mathcal{D}}=5 \% \quad 234$

Table B.10 Sensitivity analysis of Non-Ricardian welfare under $\overline{\mathcal{D}}=5 \% 235$ 


\section{Interest, Prices, and Risk ${ }^{1}$}

Monetary policy is often said to be responsible for setting or targeting the nominal risk-free interest rate of an economy even though it is operated in a risky environment through assets that may be risky. This paper studies how policy-asset risk can be transmitted to monetary policy under a neo-Wisksellian approach. We introduce risk in the policy asset of a partial equilibrium model and show that monetary policy power w.r.t prices and inflation is reduced, as well as a positive correlation between inflation and that risk emerges. Moreover, uncompensated risk premium induces an inflationary bias. These results constitute a novel argument in favor of a more hawkish stance in case of a fiscal or political crisis, since monetary policy can only be conditionally active in the presence of risk in its underlying asset. Overall, monetary policy's activeness depends on whether the central bank sets and targets a risky or a risk-free rate.

Keywords: Monetary Policy, Risky Policy Asset, Natural Interest Rate

JEL Classification: E43, E52, E58, E81

\section{1}

\section{Introduction}

Real ex-ante interest rate spreads between emerging and advanced economies sovereign bonds have been mostly positive throughout the years, implying that there are considerable premia on them. ${ }^{2}$ If emerging bonds had

\footnotetext{
${ }^{1}$ I thank the advising from Carlos Viana de Carvalho, the discussions with Ricardo Reis, the detailed critique from Eduardo Loyo, and the comments by Tiago Berriel, Pedro Henrique da Silva Castro, and Eduardo Zilberman. I also thank Juliano Assunção, Yvan Becard, Márcio Garcia, and Leonardo Rezende for their helpful interventions at PUC-Rio seminars. I gratefully acknowledge the Economics Department of the London School of Economics for its hospitality during the academic year 2018/2019. Beyond the usual disclaimer, I must note that any views expressed herein are mine and not necessarily those of the Banco Central do Brasil or of any of its members. Finally, I also thank the Banco Central do Brasil and CAPES for the financial support, and the Economics Department of PUC-Rio for the opportunity.

${ }^{2} \mathrm{Du}$ and Schreger (2016) calculate for 10 emerging economies between 2005 and 2014 the yield spread of local currency bonds over synthetic local currency risk-free rates constructed with cross-currency swaps, assuming U.S. rates as risk-free. They find that spreads are positive and sizable. Ferreira and León-Ledesma (2007) investigate the real interest parity
} 
the same objective characteristics - such as maturity, coupon structure, and currency denomination - as well as the same desirable features from the perspective of the same marginal investor, then they should represent perfect substitute cash-flows to bonds of advanced economies. This equivalence would lead them to be identically priced in markets with free mobility of capital, rational investors, and no other financial friction. However, that does not seem to be the case, what suggests that the (real) natural interest rate ${ }^{3}$ hereafter defined as the real interest rate consistent with flexible prices, should also differ significantly across emerging and developed economies.

A simple attempt to estimate the natural rate using univariate filters gives us a glimpse of such discrepancy in Figure 1.1. There seems to be comovement, it is true, with most notably a downward trend ${ }^{4}$, but, at least from 2000 to 2020 , the spread is likely to have remained sizable and positive. ${ }^{5}$ The details of this estimation are available in Appendix A.1.

hypothesis empirically in a small unbalanced panel of 5 advanced economies and 5 developing ones, ranging from the early 1970 s to the early 2000s, by conducting unit-root tests. The authors find that while interest rate differentials to the U.S. rate tend to revert to zero in the first group, it reverts to a positive wedge in the second. With an older sample, Mishkin (1984) had already found that real interest rates differed across developed economies after conducting econometric tests on their equality, as well as on an ex-ante version of the purchasing power parity, on the uncovered interest parity condition, and on the unbiasedness of forward rate forecasts of exchange rates.

${ }^{3}$ Some other names for the (real) natural interest rate are (real) neutral interest rate and (real) structural interest rate. This paper will use all of them as synonyms.

${ }^{4}$ Rachel and Smith (2015) find similar results subtracting professional 1-year ahead inflation forecasts, used as a proxy for 10-year inflation expectations, from 10-year nominal government bond yields in a larger sample comprising 20 advanced economies and 17 emerging ones. They also estimate that the global real interest rate would have fallen by 450 bps from 1980 to 2015, of which they can explain 400 bps as follows: lower output growth (-100 bps), demographic forces (-90 bps), higher inequality within countries ( $-45 \mathrm{bps})$, a preference shift towards higher saving by emerging economies after the Asian crisis ( -25 $\mathrm{bps})$, a decline in the relative price of capital goods $(-50 \mathrm{bps})$, a preference shift away from public investment projects $(-20 \mathrm{bps})$, and an increase in the spread between the risk-free rate and the return on capital (-70 bps). From a historical point of view, Schmelzing (2020) finds that real rates have been on a declining trend since the 14 th century at the speed of 0.6-1.6 b.p. per annum using data for countries that compose a large share of advanced economies output in the period.

${ }^{5}$ Beyond visual inspection, a paired-sample t-test of the difference in means between emerging real neutral rates and their advanced counterparts results in the rejection at the $1 \%$ level of the null hypothesis that they are equal in favor of the alternative hypothesis that emerging rates are higher for all aggregations. Moreover, estimating $\operatorname{ARIMA}(0$ to 4,0 to 1,0 to 4$)$ models of the wedges and picking the one with the lowest $\operatorname{BIC}(\operatorname{ARIMA}(2,0,1))$ provides evidence at the $1 \%$ level in favor of such wedge being different from zero for the median of the filters' median. For the other aggregations, the evidence is weaker, though. 


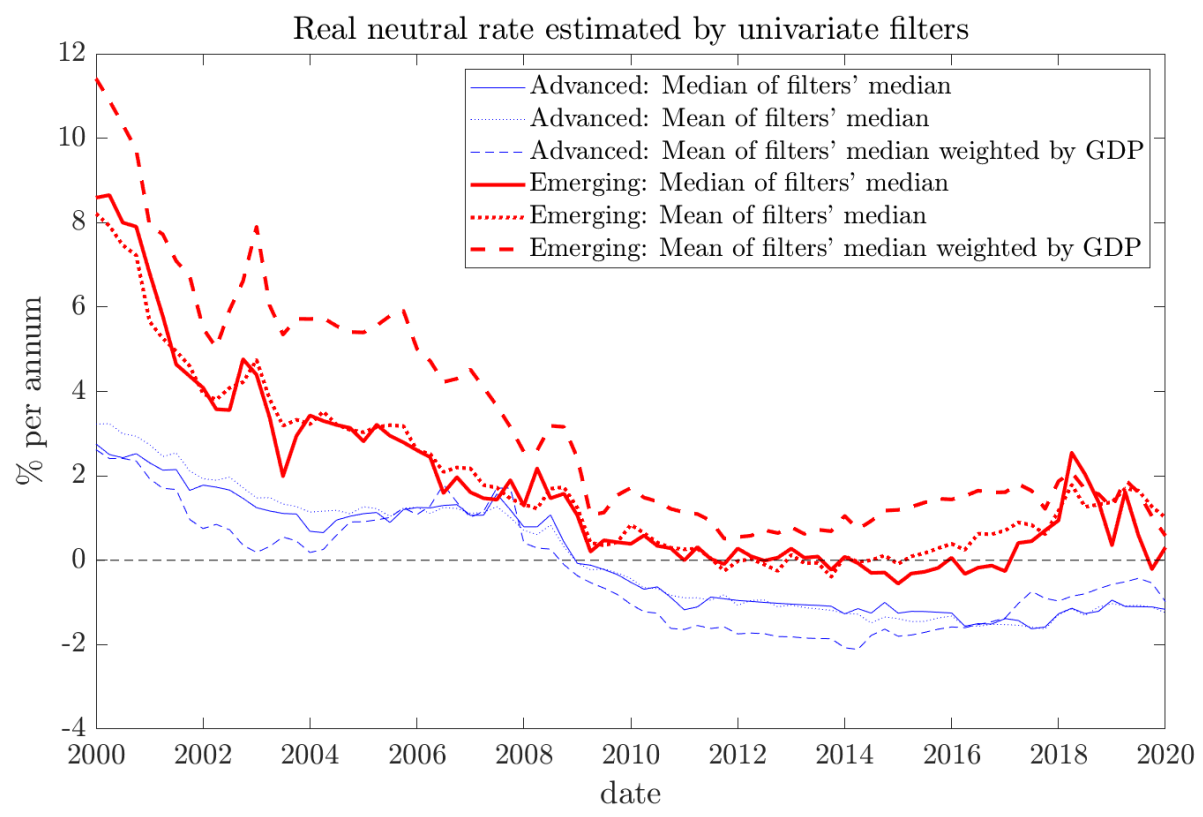

Figure 1.1: Real neutral rates estimated by univariate filters

Moreover, since the natural interest rate constitutes the theoretical reference for the intercept of several monetary policy rules adopted in the NewKeynesian literature (Woodford (2003a); Galí (2015); etc.) and in actual central banking (Taylor and Williams, 2010), there are concerns on the adequacy of prescribing such rules to emerging economies without understanding the dynamics of the natural interest rate wedge. In the specific case of emergingeconomy central banks that target short-term nominal interest rates in local currency, like those which abide by some inflation-targeting regime, that is a particularly relevant theme. For these institutions, setting or targeting nominal interest rates too low/high could ignite capital outflows/inflows with pertinent impacts on the level of domestic prices. This is so as debt sustainability, exchange rate stability, and foreign capital disposal are directly affected by domestic and foreign investors' desire for retaining local assets in their portfolio (Fraga, Goldfajn and Minella, 2003).

All these arguments, raised both in the literature and in actual monetary policymaking, constitute open-economy explanations for the importance of picking the right target for the policy rate. Nonetheless, they frequently ignore that some of the very own assets employed by monetary policy in its monetary operations may be perceived as risky. The exact source of that risk may stem from the credibility of the issuer of the policy asset (i.e. outright or repo operations involving risky federal government bonds $)^{6}$, or still from the fact

${ }^{6}$ Domestic debt denominated in local currency, including short-term federal government bonds, have been defaulted on, de facto and de jure, throughout history, as shown by Reinhart and Rogoff (2009). While the specific case of default via unexpected inflation 
that liquid assets are easy candidates to confiscation in case a government wishes to collect extraordinary revenues or curb inflationary liquidity - as long as the government perceives it as a better choice than the alternatives on the table. $^{7}$ Moreover, in some countries part of government bonds is indexed to the policy rate, configuring an important link of the transmission channel of monetary policy, so that defaulting on them is to some extent defaulting on the policy rate. For the skeptical reader who considers the possibility of default in policy assets only a theoretical curiosity, it may be helpful to note that a financial asset with risk of retroactive tax is priced alike a defaultable bond. ${ }^{8}$

If the policy asset is risky, then, how is monetary policy affected? This is a question that we believe has been neither properly posed nor addressed in the literature, not even in the realm of a closed economy. Some further complications, however, exist for monetary policy. First of all, the natural interest rate is non-observable. Secondly, episodes of exacerbate risk in the policy asset shall have a severe impact on business activity in general. Once we take these hurdles into consideration, it is possible to conclude that in the presence of risk, investors will demand a premium for investing in risky assets, as well as will rebalance their portfolio to hedge against undesirable fluctuations of wealth. ${ }^{9}$

In this paper, the mechanism through which risk influences monetary policy is put under scrutiny. First, we expand a partial equilibrium closedhas received some attention from the literature - most notably, Miller, Paron and Wachter (2020) directly associates the downward trend observed in Figure 1.1 to the stabilization of inflation in many countries in the same period, which would have shrunk inflation premia the possibility of default de facto in domestic currency is still mostly discredited, in denial of the empirical evidence. Focusing on local-currency defaults of large emerging economies, there is Brazil in 1990 (broad confiscation of financial assets), Russia in 1998-99 (suspension of payments of Treasuries), and Turkey in 1999 (retroactive withholding tax on financial assets). In a more extreme example, Ghana in 1979 implemented a monetary reform in which the exchange rate from old to new banknotes was worse than for bank deposits (currency wealth confiscation).

${ }^{7}$ In 1990, Brazil implemented the Collor Plan, a monetary reform intended to contain a hyperinflation process perceived as the result of excessive liquidity in the economy. Among its measures, it temporarily confiscated financial resources that amounted to up to $80 \%$ of the M4 (M1 plus all financial assets), or approximately 30\% of the country's GDP at that time (Pastore, 1991).

${ }^{8}$ Default can be seen as a stochastic retroactive tax on wealth. In that sense, when adopted, it is like if the fiscal policy is going an extra mile to balance the budget. One actual example of that kind of confiscation would be the Turkish local-currency default of 1999. A Letter of Intent of the government of Turkey addressed to the IMF on December 9, 1999, in the context of its request for financial support, implausibly explained: "Finally, a withholding tax on government securities issued before December 1, 1999 has been introduced to reduce the windfall gain accruing to securities holders from the reduction in inflation and interest rates in 2000." Önal and Erçel (1999).

${ }^{9}$ For instance, an expected reaction of households to an increase in uncertainty about the future is to expand their (precautionary) savings, so that they can better smooth out consumption through time. De Paoli and Zabczyk (2013) incorporate this feature into a New-Keynesian model. 
economy monetary model found in Woodford (2003a, sec. 4.3 of ch. 1) to encompass risk in the asset used by monetary policy. We find that in that case the power of monetary policy w.r.t. inflation is reduced at the same time that the price level is higher than in an otherwise identical scenario. The same applies to inflation in case of inflation targeting. These results in conjunction generate a novel argument in favor of more hawkish monetary policy in case of, say, a fiscal or political crisis, which we believe is the main contribution to the literature of this study. Finally, we find that assuming that the policy asset is defaultable and that the central bank accommodates such risk to some extent is enough to generate virtually any positive correlation between inflation and default risk, a feature that is found in empirical data. If expanded this connection between default risk and inflation to an open economy, it could potentially offer an additional explanation for why some countries experience a positive correlation between currency risk and default risk. In that case, causality would flow from default risk to inflation risk to currency risk, and not from default risk to currency risk to inflation risk, as usually assumed in the literature through an uncovered interest rate parity equation. ${ }^{10}$

A simple way of giving the reader the intuition behind our results can be achieved starting from the basics of monetary policy conducted with interest rate rules in a linearized model. Given, at any period $t$, the real natural interest rate, $r_{t}^{n}$, and the time-varying intercept of the policy rule, $\bar{\iota}_{t}$, the nominal policy rate, $i_{t}$, and the inflation expectation for the next period, $\pi_{t, t+1}^{e}$, are simultaneously determined by the Fisher equation and the central bank (CB) policy rule: ${ }^{11}$

$$
\begin{aligned}
i_{t} & =r_{t}^{n}+\pi_{t, t+1}^{e} \\
i_{t} & =\bar{\iota}_{t}+\gamma \pi_{t, t+1}^{e}
\end{aligned} \quad \Rightarrow \quad r_{t}^{n}-\bar{\iota}_{t}=(\gamma-1) \pi_{t, t+1}^{e}
$$

Note that by the Taylor principle - required for the determination of inflation in a model like this - the coefficient $(\gamma-1)$ must be positive, what leads to a positive correlation between $r_{t}^{n}-\bar{\iota}_{t}$ and $\pi_{t, t+1}^{e}$. In this paper, we develop the idea that the policy asset is risky, so there is a wedge, $\Phi_{t}$, between the rate of

\footnotetext{
${ }^{10}$ Examples of New-Keynesian models which follow this approach are Justiniano and Preston (2010) and de Carvalho and Vilela (2015). In Blanchard (2004), the exchange-rate pass-through to inflation is essential to generate his fiscal dominance result. For a list of competing explanations for the positive correlation, check Lowenkron and Garcia (2005).

${ }^{11}$ Without loss of generality, we implicitly assume that the inflation target is zero. Assuming otherwise or that the policy rule reacts to current inflation changes the dynamic of prices, but not our results.
} 
that asset and the risk-free rate.

$$
\begin{gathered}
i_{t}=r_{t}^{n}+\Phi_{t}+\pi_{t, t+1}^{e} \\
i_{t}=\bar{\iota}_{t}+\gamma \pi_{t, t+1}^{e}
\end{gathered} \quad \Rightarrow \quad\left(r_{t}^{n}+\Phi_{t}\right)-\bar{\iota}_{t}=(\gamma-1) \pi_{t, t+1}^{e}
$$

Then, an important insight comes from the fact that inflation expectation is not only a function of $\left(r_{t}^{n}-\bar{\iota}_{t}\right)$, but also of the risk premium demanded to hold the policy asset. If the central bank does not compensate the policy-asset risk in its choice for $\bar{\iota}_{t}$, then it introduces a bias in inflation expectations. Here, we will focus on the case where $\Phi_{t}>0$, which leads to an inflationary bias, but a negative wedge is also possible in case investors are willing to pay for a convenience yield.

As we develop, in this paper, a partial equilibrium monetary model, we suppose that the implicit fiscal policy is kept passive, using the terminology of Leeper (1991), at all times. ${ }^{12}$ We show that, even though introducing default risk in the underlying asset of monetary policy reduces its activeness in directing inflation, the insight from Leeper (1991) for that macroeconomic stability only requires a mismatching active/passive combination of fiscal and monetary policy remains unchanged under very mild conditions for the default probability stochastic process.

The rest of this paper is structured as follows. Section 2 presents related literature. Section 3 exposes the theoretical background of neo-Wicksellian models. Section 4 introduces policy-asset risk. Section 5 exposes some testable implications. Finally, Section 6 concludes. In Appendix A.1, we describe the calculation of univariate filters for the neutral real rate; Appendix A.2 derives the model under price-level targeting; Appendix A.3 provides all proofs for this paper; Appendix A.4 adapts a canonical cashless flexible-price model to show that it can underpin this paper's model; Appendix A.5 analyzes the case of targeting a risky rate with safe assets; Appendix A.6 simulates the model to investigate the power of monetary policy; and Appendix A.7 gives more details on testable implications of the model.

\footnotetext{
${ }^{12}$ Monetary policy is not constrained by the fiscal one, while the latter automatically adjusts to any given trajectory for the price level, so that the real value of government liabilities equals the present value of all its present and future real surpluses. In Appendix A.4, we derive a simple adaptation of the canonical cashless flexible-price model of Woodford (2003a, ch. 2, sec. 1) with a balanced-budget fiscal rule to show that it can underpin this paper's model.
} 


\section{2 \\ Related literature}

In the literature, this paper can be seen as an extension of Woodford (2003a)'s interpretation of Wicksell (1898)'s work on the natural interest rate and its relation with monetary policy. The introduction of risk in the policy asset of a neo-Wicksellian model is our main contribution.

As of the consequences of taming inflation with defaultable assets, this paper is more closely related to Bi, Leeper and Leith (2018), which investigates for the case of a closed economy how the role of monetary policy in an inflationtargeting regime conducted with risk-free assets changes when default risk is not negligible. They employ a New-Keynesian model with fixed intercept Taylor rules, and find that, on the one hand, if the central bank targets the risk-free rate, by presumably controlling a risk-free instrument, it can still manage to bring inflation to the target after a contractionary monetary shock while persistently depressing output. On the other hand, if the central bank targets the (default-) risky interest rate, by implicitly controlling a risk-free instrument whose rate passes through to the risky one, it will be as if it had lifted the inflation target above the publicly announced one, inflating away the government debt. Remarkably, the authors argue that monetary policy activeness increases at the same time that their model points out to a positive link between inflation and default risk. ${ }^{13}$ Commenting on that paper, Reis (2018) notes that the intercept of the risky Taylor rule actually lacks an adjustment for default risk, biasing its results. In Appendix A.5 of our paper, we provide the adequate fix, and find that the effective inflation target now coincides with the announced one, weakening the relation between inflation and default risk in that model. Moreover, activeness still increases, but it is only due to the fact that the policy asset remains risk-free, since policy-asset default risk would also reduce monetary policy power in that paper. Differently from Bi, Leeper and Leith (2018), this paper focuses on the role played by default risk embedded in the monetary policy asset. More strikingly, this paper models the policy asset as a defaultable bond and defines a policy rule that specifically targets the return of the bond in case the issuer repays the debt. We leave general equilibrium considerations for a companion paper.

As we show that neglecting significant policy-asset risk is not without consequences for a central bank's mandate, this paper contributes to the literature on the implications of mismeasurement and model misspecification

\footnotetext{
${ }^{13}$ We interpret that, in a Taylor-like rule, activeness is measured by the effective coefficient on its reaction terms, usually on inflation. The more active, the more elastic is the policy rate to deviations from the steady state, what should also reduce inflation volatility, implying higher monetary policy power w.r.t. inflation.
} 
for monetary policy. Orphanides and Williams (2002) seek to find policy rules that are robust to the uncertainty in the precise estimation of natural rates, both of interest and unemployment. The authors find that policies that underestimate such uncertainty end up generating higher costs, in terms of stabilizing inflation and unemployment, than policies that tend to overestimate it. This finding tilts preference toward policy strategies that act as uncertainty is greater than baseline estimations, such as, for example, rules that react to first differences instead of deviations from natural levels. In Orphanides and Williams (2008), the same authors extend the analysis to when agents do not know the complete structure of the economy and instead must learn through forecasting models updated every period, finding additional evidence in favor of a "conservative" approach. Although our paper does not elaborate on welfare considerations, it presents a new source of mismeasurement and misspecification that challenges the optimal control of monetary policy.

Despite we assume that implicit fiscal policy is passive, this paper still relates to the literature on the interaction between fiscal and monetary policy when debt is risky. Schabert and Van Wijnbergen (2014) find that, if the default probability process is allowed to depend on the debt level in a reduced form, a weak feedback mechanism from debt surprises to the primary surplus associated with active monetary policy jeopardizes macroeconomic stability, a situation described in Blanchard (2004). Despite that, the authors show analytically that active monetary policy can still contribute to stabilization if the slope of fiscal feedback intensity increases with the default probability, by increasing the passiveness of fiscal policy. Concerning their policy recommendation, our finding that default risk may endogenously reduce monetary policy activeness introduces a soothing channel that could counterbalance the need of draconian fiscal consolidation under the Blanchard effect.

Still on the same topic, Bonam and Lukkezen (2019) study how fiscal policy's cyclicality affects equilibrium stability and uniqueness. They show analytically in a closed-economy New-Keynesian model that, after growing budget deficits, debt-elastic interest rates increase in response to a, now, higher default-risk premium, crowding out consumption. The latter, by its turn, decreases inflation requiring a reduction of interest rates. These effects lead to the shrinkage of the parameter space that supports macroeconomic stability, what can be avoided by adopting either a more aggressive fiscal consolidation or a more active monetary policy, or yet both. They conclude that procyclical fiscal policies are more prone to deliver macroeconomic stability. Here, again, our endogenous channel through which default risk reduces monetary policy activeness may be relevant, as their policy recommendations 
could be reinforced by it.

In Bonam and Lukkezen (2019)'s model, risk is contractionary, implying a negative correlation between default risk and inflation, while in Schabert and Van Wijnbergen (2014) it is expansionary, implying in correlation with the opposite sign. We show in Section 1.5 that, to the extent in which localcurrency risk can be proxied by usual country-risk measures, empirical data go in favor of positive correlation for inflation-targeting emerging economies. In our model, such a positive correlation emerges naturally as the central bank reacts only to to the natural real rate and to inflation, ignoring that the policy asset is risky.

Finally, this paper may also be marginally correlated with the unpleasant monetarist arithmetic of Sargent and Wallace (1981); the tight money paradox of Loyo (1999), in which a bounded equilibrium is only obtained after either monetary or fiscal policy stops playing "chicken"; as well as with the fiscal theory of the price level (FTPL) of Sims (1994); Woodford (1994); Uribe (2006), who, like Blanchard (2004), analyze the interaction of monetary policy under an active fiscal policy regime in the definition of Leeper (1991). We leave for further research how the endogenous reduction in monetary policy activeness w.r.t. inflation due to policy-asset risk affects their results. As far as we know, this paper is the first to explore that channel under the mix of active monetary policy and passive fiscal policy (not explicitly modeled), or under any other mix. In a companion paper, we endogenize the risk in the policy asset as a fiscal risk.

\section{3}

\section{Theoretical background}

In this section, we offer a "crash course" on the basics of Wicksell's monetary theory, describing Woodford (2003a)'s mathematization of it, to afterward incorporate policy-asset risk to the neo-Wicksellian model.

\subsection{1}

\section{Wicksell's monetary theory}

In 1898, Knut Wicksell published his seminal book "Interest and Prices: A Study of the Causes Regulating the Value of Money", in which he introduced the concept of a natural interest rate. For him, in an economy based on pure credit, such that money as we know did not exist, and all exchanges and loans were conducted through real capital goods, there would be a unique interest rate with the particular property of clearing the market for these goods. In that economy, this interest rate, named by him as the natural interest rate, 
would be determined in an efficient market by the marginal productivity of real capital goods. In his own words:

THERE is a certain rate of interest on loans which is neutral in respect to commodity prices, and tends neither to raise nor to lower them. This is necessarily the same as the rate of interest which would be determined by supply and demand if no use were made of money and all lending were effected in the form of real capital goods. It comes to much the same thing to describe it as the current value of the natural rate of interest on capital (Wicksell, 1898, p. 102).

Going from a pure credit to a cash economy means that there are, now, two types of assets, money (or financial capital) and real capital goods. It is trivial to think that the existence of two assets may give birth to an exchange rate, i.e., $n$ units of money for 1 unit of capital. This exchange rate is the price of capital, which means that the interest rate on loans with money (Wicksell called the "money rate") and the interest rate on loans with real capital goods can be compared.

For Wicksell, in an otherwise constant world, arbitrage would bring these interest rates to become equal, stabilizing the price of capital. However, in the presence of a money-rate setter with deep pockets or the ability to create them as required, say a contemporaneous central bank, such an equalization would fail to happen. Wicksell envisioned that whenever the money rate was higher than the natural rate, the same arbitrageurs of before would seek to exchange real capital goods for money, forcing the price of real capital to go down (deflation) indefinitely while the difference in the rates remained. Likewise, when the money rate was lower than the natural one, arbitrageurs would seek to convert money into real capital, forcing the price of real capital to go up (inflation) indefinitely until the money-rate setter changed its mind. Since the world is not constant, or more precisely, the factors that affect the natural rate or the money-rate setter's mind, prices in the actual economy fluctuate, alternating inflationary with deflationary periods - beware that Wicksell had in mind the price history available at his time, the nineteenth century.

\subsection{2}

\section{Neo-Wicksellian monetary theory}

A little more than a century after Wicksell's seminal book, Michael Woodford synthesized what he called the neo-Wicksellian monetary theory. Inspired by the fact that central banks around the world had largely abandoned 
monetary aggregate targets in favor of interest rate rules that depended on inflation, the so-called Taylor rules ${ }^{14}$, as well as the prospect that electronic payment media were to become increasingly more popular, Woodford saw the similarity between this new reality and the work of Wicksell on the price level dynamics. In his own words:

"(...) Wicksell's approach is a particularly congenial one for thinking about our present circumstances - a world of purely fiat currencies in which central banks adjust their operating targets for nominal interest rates in response to perceived risks of inflation, but pay little if any attention to the evolution of monetary aggregates - to say nothing of the one to which we may be headed, in which monetary frictions become negligible", (Woodford, 2003a, p. 49).

Woodford (2003a) illustrates in a monetary partial equilibrium model the way a central bank can determine the equilibrium price level without any consideration for money supply and demand. The model laid out in Chapter 1 Section 4.3 of the reference, and adapted here for inflation targeting, can be systematically exposed as follows. Take assumptions (1.1) to (1.5) as valid.

Assumption 1.1 (Flexible prices) at every period t prices are fully flexible.

Assumption 1.2 (Exogenous real interest rate) the equilibrium real interest rate $r_{t}$ is determined only by exogenous real factors affecting saving and investment; it is also the natural one because of Assumption 1.1, $r_{t} \equiv r_{t}^{n}$. Overall, it follows an exogenous process $\left\{r_{j}\right\}_{j=t}^{\infty}$.

Assumption 1.3 (Rational agents) at every period $t$ agents form forwardlooking rational expectations about the future using all the information set available at period $t$.

Assumption 1.4 (Fisher equation) at every period the Fisher equation is valid.

Assumption 1.5 (Central bank sets the nominal interest rate) at every period the central bank successfully sets the nominal interest rate, $i_{t}$.

The Fisher equation can be written up to a first-order approximation in its log-linear form as

$$
\mathbb{E}_{t} \pi_{t+1}=i_{t}-r_{t}^{n}
$$

${ }^{14}$ Taylor (1993) estimates an interest rate rule for the Alan Greenspan's chairmanship at the Federal Reserve as a function of inflation and of a measure of output gap. Rules of this kind have been known as Taylor rules. 
where $\mathbb{E}_{t}$ is the rational expectations operator conditional on all information available at the end of time $t, \pi_{t}$ is the log of the gross inflation at period $t, r_{t}^{n}$ is the equilibrium real rate of interest (and the natural one) at period $t$, while $i_{t}$ is the short-term nominal interest rate at period $t$. Since the central bank sets $i_{t}$, and $r_{t}^{n}$ is exogenously determined, the common way of interpreting this equation as an identity can now be replaced by its understanding as an equilibrium condition between aggregate saving (supply of capital) and investment (demand for capital). In other words, at every instant $t$, the price level that clears the capital goods market (and equates saving and investment) is the one that results from the inflation rate expectation given by equation (1-3).

Now, assume the central bank sets $i_{t}$ for a risk-free asset such that $\pi_{t}$ and $i_{t}$ should move in the same direction, and targeted inflation is zero. The central bank is able to do so by setting the nominal interest rate paid by a risk-free asset, a usual assumption whose importance will be made clearer later in this paper. For a derivation of the same model under a price-level-target rule (or Wicksellian rule), check Appendix A.2.

Assumption 1.6 (Taylor risk-free policy rule) there is a central bank that sets the nominal interest rate of a risk-free asset, $i_{t}$, through a Taylor rule of the type $i_{t}=\bar{\iota}_{t}+\phi^{\pi}\left(\pi_{t}-\bar{\pi}\right)$, where $\left\{\bar{\iota}_{j}\right\}_{j=t}^{\infty}$ is an exogenous process for a time-varying intercept determined independently of the evolution of prices which may or may not be correlated with $\left\{r_{j}^{n}\right\}_{j=t}^{\infty} ; \bar{\pi}$ is the log of the gross inflation target; and $\phi^{\pi}>1$.

Without loss of generality, hereafter, we set $\bar{\pi}=0$. Inserting Assumption 1.6 into the Fisher relation (1-3) to eliminate $i_{t}$, we obtain the law of movement of the equilibrium inflation:

$$
\pi_{t}=\alpha^{\pi} \mathbb{E}_{t} \pi_{t+1}+\alpha^{\pi}\left(r_{t}^{n}-\bar{\iota}_{t}\right)
$$

where $\alpha^{\pi} \equiv \frac{1}{\phi^{\pi}}$ is a coefficient that satisfies $0<\alpha^{\pi}<1$. If the process $\left\{r_{t}^{n}, \bar{\iota}_{t}\right\}$ is bounded then $\pi_{t}$ is unique and bounded ${ }^{15}$, obtained by iterating forward equation (1-4), which gives us

$$
\pi_{t}=\sum_{j=0}^{\infty} \alpha^{\pi j+1} \mathbb{E}_{t}\left(r_{t+j}^{n}-\bar{\iota}_{t+j}\right)
$$

As a consequence, the equilibrium inflation will fluctuate in a bounded interval around its long-run average value:

\footnotetext{
${ }^{15}$ Proof follows the same procedure as the one available in Woodford (2003a)'s Appendix A.4. for the price-level-target case.
} 


$$
\bar{\pi} \equiv \frac{\overline{r^{n}}-\bar{\imath}}{\phi^{\pi}-1}
$$

where $\bar{\pi}, \overline{r^{n}}$, and $\bar{\iota}$ are the long-run average of the net inflation, of the natural interest rate, and of the time-varying intercept, respectively.

The behavior of Woodford (2003a)'s simple model adapted to inflationtargeting is summarized in Figure $1.2\left(\phi^{\pi}=1.1\right)$ and Figure $1.3\left(\phi^{\pi}=1.2\right)$, in which all panels are plotted assuming an economy starting from the steady state at period $t=0$, whose only shocks are the ones specified in each panel, and that $\bar{\iota}_{t}=\overline{r^{n}}$ at all periods unless otherwise stated. The panels can be synthesized as follows:

- There is no distinction in this model between the equilibrium price level and the price level since prices are flexible. If $\bar{\iota}_{t}=r_{t}^{n} \forall t$, then neither the price level nor inflation ever leaves its steady-state value (top-left panel and red line of bottom-right panel of Figure 1.2);

- An expected increase (decrease) in the equilibrium real rate at any time from $t=1$ to $t=\infty$ will increase (decrease) equilibrium prices and inflation today (top-right panel of Figure 1.2). If the sequence of shocks is anticipated at period $t=1$ (blue line), the increase (decrease) of the inflation rate is larger than if shocks are individually seen as MIT shocks $^{16}$ (red line);

- An expected tightening (loosening) of the policy rule, represented in the model by a raise (reduction) of the rule's intercept, at any time from $t=1$ to $t=\infty$ will decrease (increase) equilibrium prices and inflation today (bottom-left panel of Figure 1.2). Here, rational expectations play a role again, since if the sequence of shocks is anticipated by the agents (blue line), the reduction (increase) of the inflation rate is more intense than if they consider shocks to be individually MIT shocks (red line);

- $r_{t}^{n}$ is a sufficient statistic for how real factors affect $p_{t}$ in the model as any additional information about real variables does not expand the information set. By closely tracking the natural interest rate, monetary policy is able to stabilize prices and inflation (red line in bottom-right panel of Figure 1.2) when $\left\{r_{t}^{n}\right\}$ follows a stochastic process. Any intercept that differs from the natural interest rate will fail to stabilize at all periods the inflation rate, where the specific combination of a stationary $\left\{r_{t}^{n}\right\}$ with an intercept fixed at the steady-state value of $r_{t}^{n}$ results in the inflation rate fluctuating around the target (blue line);

\footnotetext{
${ }^{16} \mathrm{An}$ MIT shock is an unexpected shock, usually inflicted at the deterministic steady-state equilibrium, that once it happens it is not expected to happen again by the agents.
} 
- The higher (lower) the reaction coefficient $\phi^{\pi}$ of the policy rule, the more reduced (augmented) is the intensity of deviations from the inflation target. One can see this by comparing the panels of Figure 1.2, whose $\phi^{\pi}=1.1$, with the respective panels of Figure 1.3, whose $\phi^{\pi}=1.2$.
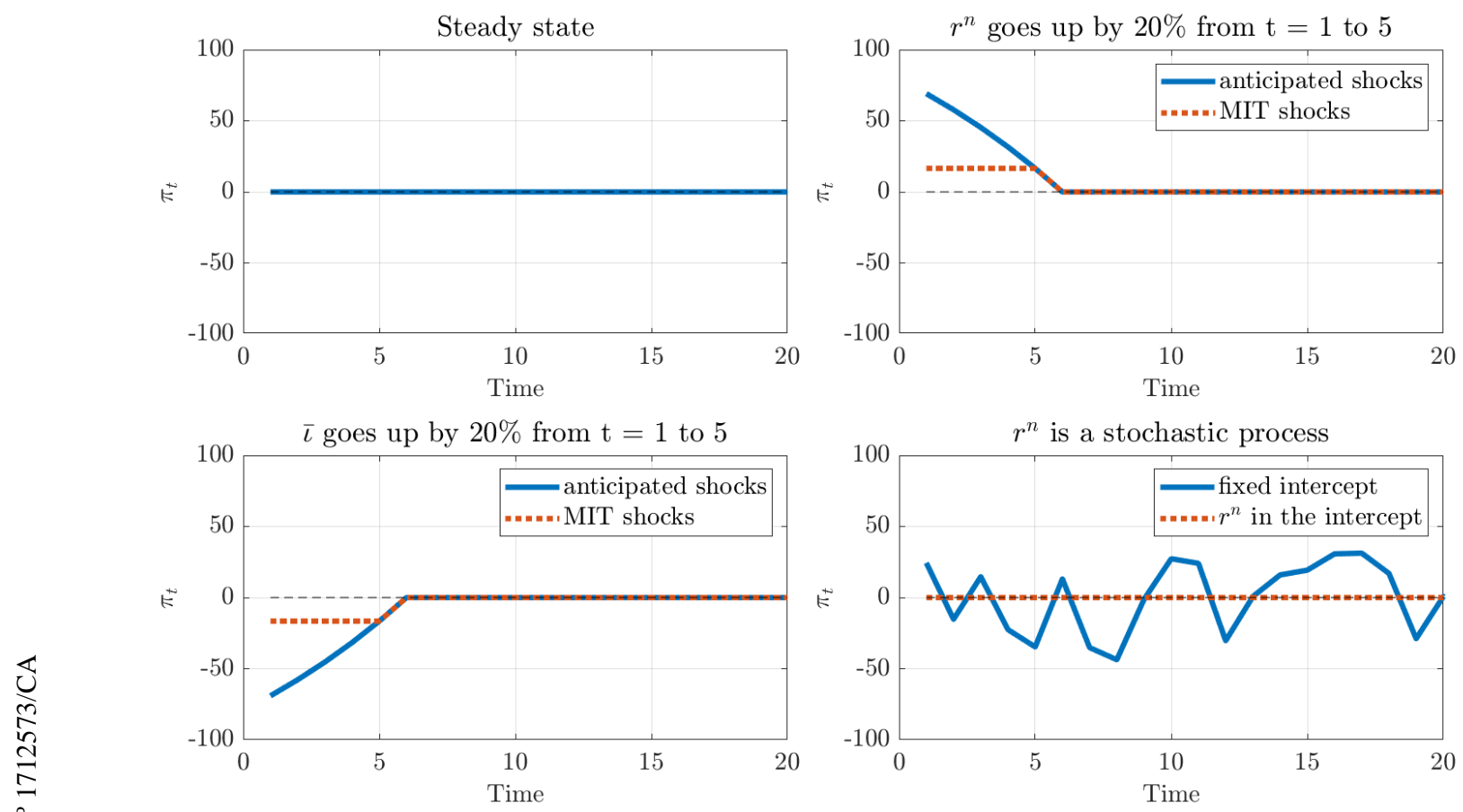

Figure 1.2: Inflation under neo-Wicksellian monetary theory $\left(\phi^{\pi}=1.1\right)$
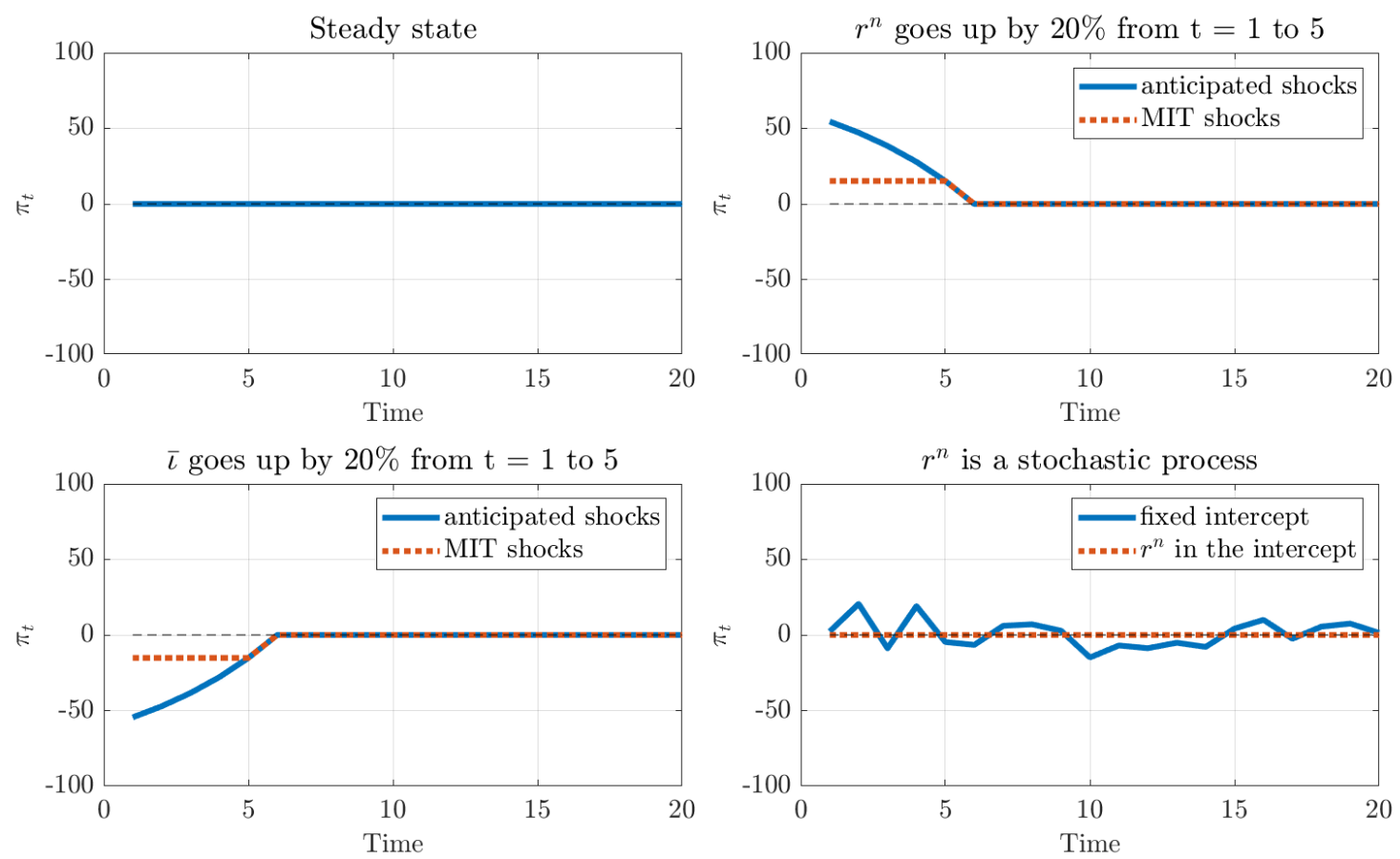

Figure 1.3: Inflation under neo-Wicksellian monetary theory $\left(\phi^{\pi}=1.2\right)$ 


\section{4}

\section{Neo-Wicksellian monetary theory with risky policy assets}

Proceeding with the monetary model of Section 1.3.2, we advance substituting the risk-free policy asset for a defaultable bond, so as to incorporate policy-asset risk into the model.

\subsection{1}

\section{A defaultable bond}

Duffie and Singleton (1999) model recursively the arbitrage-free value of a defaultable bond whose probability of default and recovery rate in case of default are given by processes independent of the value, $V_{t}$, of the defaultable claim itself. Under discrete time, they provide the following expression for the value of that defaultable bond ${ }^{17}$

$$
V_{t}\left(1+i_{t}^{R F}\right)=\left(1-\mathbb{E}_{t}^{Q} \mathcal{D}_{t+1}\right) \mathbb{E}_{t}^{Q}\left(V_{t+1}\right)+\mathbb{E}_{t}^{Q} \mathcal{D}_{t+1} \omega_{t+1}
$$

where $i_{t}^{R F}$ is the risk-free net nominal interest rate at period $t ; \mathbb{E}_{t}^{Q} \mathcal{D}_{t+1}$ is the conditional probability of default under a risk-neutral probability measure $Q$ between periods $t$ and $t+1$ given the information available at period $t$ and that no default has happened until that same period; while $\omega_{t+1}$ is the recovery value in case of default measured in the same unit of account as $V_{t}$. Moreover, Duffie and Singleton (1999) prove that if we impose that the risk-neutral expected recovery rate $\mathbb{E}_{t}^{Q} \omega_{t+1}$ is given by $\left(1-L_{t}\right) \mathbb{E}_{t}^{Q}\left(V_{t+1}\right)$, where $L_{t}$ is an adapted process $^{18}$ bounded by 1 , a case known as recovery of market value (RMV), we can price a default-risky nominal return $i_{t+1}^{R}$ as

$$
1=\left(1-\mathbb{E}_{t}^{Q} \mathcal{D}_{t+1}\right) \frac{1+i_{t+1}^{R}}{1+i_{t}^{R F}}+\mathbb{E}_{t}^{Q} \mathcal{D}_{t+1} \frac{1+i_{t+1}^{R}}{1+i_{t}^{R F}}\left(1-L_{t}\right)
$$

where $i_{t+1}^{R} \approx i_{t}^{R F}+\mathbb{E}_{t}^{Q} \mathcal{D}_{t+1} L_{t}$. Furthermore, there is no restriction for $\mathbb{E}_{t}^{Q} \mathcal{D}_{t+1}$ or $L_{t}$ to not depend on or to not be correlated with $i_{t}^{R F}$. Building the bridge between finance and macroeconomics, this means that both processes can depend on the state vector of the model.

\subsection{2}

\section{The policy asset as a defaultable bond}

As it is often the case, the central bank of our model operates monetary policy through open market operations, by selling and buying federal govern-

\footnotetext{
${ }^{17}$ After adapting notation, rearranging terms, and undoing an exponential approximation of the risk-free return.

${ }^{18} \mathrm{~A}$ stochastic process $X$ is adapted iif for every realization and every $t, X_{t}$ is known at time $t$.
} 
ment bonds, which we will assume are outright operations for simplicity. ${ }^{19}$ These operations allow the central bank to target the liquidity and the interest rate of short-term financial markets ${ }^{20}$, which, by their turn, will impact, through the expectations hypothesis, medium to long-term credit markets (not modeled here) on which the real economy relies on. This transmission mechanism is usually assumed to be risk-free at the beginning of the yield curve, since the central bank and federal government bonds are also usually assumed to enjoy a safe status. Nonetheless, governments have defaulted on domestic debt in the past, including local-currency liabilities - as extensively listed by Reinhart and Rogoff (2009). If agents with rational expectations forecast a future scenario with probability greater than zero in which the asset used by the central bank to conduct monetary policy fails to reward $i_{t}$, then policy assets become risky.

Continuing with our model, to a world in which assumptions (1.1) to (1.5) hold, we add the no-arbitrage hypothesis for pricing the policy asset as a defaultable bond. From Cochrane (2009),

Assumption 1.7 (No-arbitrage hypothesis) Given a payoff space $X$ and pricing function $p(x)$, every payoff $x$ that is always nonnegative, $x \geq 0$ (almost surely), and positive, $x>0$, with some positive probability, has positive price, $p(x)>0$.

We are, now, ready to depart from the risk-free assumption. Let us say policy assets are expected to remunerate at a deterministic gross rate $\left(1+i_{t}\right)$ with expected repayment probability $\left(1-\mathbb{E}_{t} \mathcal{D}_{t+1}\right)$, and expected to remunerate at a non-deterministic gross rate $\left(1+i_{t}\right)\left(1-\mathbb{E}_{t} \delta_{t+1}\right)$ with expected default probability $\mathbb{E}_{t} \mathcal{D}_{t+1}$. That way, the payoff is uncertain only in the case that the issuer of the policy asset defaults on the asset. This is closer to the actual situation faced by a real central bank that conducts monetary policy through open-market operations using government bonds. In that sense, the central bank can only set the nominal interest paid by the policy asset in case of repayment by the issuer, having no control over its outcome in case of default, which will ultimately be determined by the fiscal authority. We define, next, the interest rate demanded in equilibrium for holding that asset.

\footnotetext{
${ }^{19}$ In the case of a central bank that conducts monetary policy paying an interest rate on reserves instead of outright transactions or repos, the default risk of the specific issuer is analogous. If not the federal government who can directly default on the debt, the central bank may hypothetically confiscate either part or the total of the reserves.

${ }^{20}$ As part of the new non-conventional monetary policy toolbox developed after the Great Recession, repos with longer maturities and even with foreign-currency assets have become more common.
} 
Definition 1.1 A net risky policy-asset interest rate, $i_{t}^{\text {Risky }}$, is a net nominal interest rate that in a market under no-arbitrage hypothesis satisfies the identity:

$$
\begin{gathered}
\mathbb{E}_{t}^{Q}\left(1+i_{t+1}^{\text {Risky }}\right)=\left[\left(1-\mathbb{E}_{t}^{Q} \mathcal{D}_{t+1}\right)\left(1+i_{t}\right)+\mathbb{E}_{t}^{Q} \mathcal{D}_{t+1}\left(1+i_{t}\right)\left(1-\delta_{t+1}\right)\right]= \\
\left(1-\mathbb{E}_{t}^{Q} \mathcal{D}_{t+1} \delta_{t+1}\right)\left(1+i_{t}\right)
\end{gathered}
$$

where $i_{t}$ is the net risky policy-asset interest rate in case of non-default; $\mathcal{D}_{t+1}$ is the probability that the risky policy asset will default at maturity; and $\delta_{t+1}$ is the haircut in case of default.

Additionally, we have to restrain the policy default probability distribution to be independent of the current value of the bond. Note that we allow $\mathcal{D}_{t}$ and $\delta_{t}$ to be correlated, like in Duffie and Singleton (1999).

Assumption 1.8 (Policy default is exogenous to the price of the bond) The default probability, $\mathcal{D}_{t}$, and the haircut, $\delta_{t}$, embedded in the risky policyasset interest rate, $i_{t}^{\text {Risky }}$, follow distributions independent of the current value of the bond, while the latter is normalized to 1.

As we work with a log-linearized model, we have no additional loss in focusing only in up to first-order effects of default. Therefore, risk-neutral probabilities coincide with objective ones, and risk-neutral returns are just mathematical expected returns.

\subsection{3}

\section{Monetary policy with risk in the policy asset under inflation targeting}

We derive, next, the partial equilibrium monetary model with risk in the policy asset under an inflation-targeting rule by building on previous assumptions (1.1) to (1.5), as well as (1.7) (no arbitrage), and (1.8) (policy default is exogenous to the price of the bond). We redefine the Taylor rule of Assumption 1.6 to reflect the risk in the policy asset with Assumption 1.9.

Assumption 1.9 (Taylor risky policy rule) the central bank sets the nominal interest rate of a risky asset, $i_{t}$, through a Taylor rule of the type $i_{t}=\bar{\iota}_{t}+\phi^{\pi}\left(\pi_{t}-\bar{\pi}\right)$, where $\left\{\bar{\iota}_{j}\right\}_{j=t}^{\infty}$ is an exogenous process for a time-varying intercept determined independently of the evolution of prices which may or may not be correlated with $\left\{r_{j}^{n}\right\}_{j=t}^{\infty} ; \bar{\pi}$ is the log of the gross inflation target; and $\phi^{\pi}>\frac{1}{1-\mathbb{E}_{t} \mathcal{D}_{t+1} \delta_{t+1}}$ for all $t$.

Again, we normalize the net inflation target to $\bar{\pi}=0$. Having set the independence of the policy asset default probability, then the expected net 
return of the policy asset in line with Definition 1.1 is

$$
\mathbb{E}_{t} i_{t+1}^{\text {Risky }}=\left(1-\mathbb{E}_{t} \mathcal{D}_{t+1} \delta_{t+1}\right) i_{t}-\mathbb{E}_{t} \mathcal{D}_{t+1} \delta_{t+1}
$$

Next, relying on Assumption 1.7 of no arbitrage opportunities, nominal returns must equalize in expectations

$$
i_{t}^{R F}=\mathbb{E}_{t} i_{t+1}^{\text {Risky }}
$$

where, as before, $i_{t}^{R F}$ is the risk-free net nominal interest rate.

Substituting the policy rule of Assumption 1.9 into the policy asset expected return (1-9) and then through the no-arbitrage condition (1-10) into the Fisher equation (1-3), we obtain the equilibrium inflation in the riskypolicy-asset economy

$$
\begin{array}{r}
\pi_{t}=\sum_{j=0}^{\infty} \Upsilon_{j+1}^{\pi} \mathbb{E}_{t}\left(r_{t+j}^{n}-\left(1-\mathbb{E}_{t} \mathcal{D}_{t+j+1} \delta_{t+j+1}\right) \bar{\iota}_{t+j}+\mathbb{E}_{t} \mathcal{D}_{t+j+1} \delta_{t+j+1}\right) \\
\Upsilon_{j+1}^{\pi} \equiv \Pi_{k=1}^{j+1}\left(\frac{1}{\left(1-\mathbb{E}_{t} \mathcal{D}_{t+k} \delta_{t+k}\right) \phi^{\pi}}\right) \quad \forall j \geq 0
\end{array}
$$

For $\pi_{t}$ to exist and be unique, the process $\left\{r_{t}^{n}, \mathcal{D}_{t}, \delta_{t}, \bar{\iota}_{t}\right\}$ must be bounded and more assumptions must be made about $\left\{\mathcal{D}_{t}\right\},\left\{\delta_{t}\right\}$, and $\phi^{\pi}$. Imposing further that $\phi^{\pi}>\frac{1}{1-\mathbb{E}_{t} \mathcal{D}_{t+1} \delta_{t+1}}$ for all $t,{ }^{21}$ and that for all $t$ there is at least one infinite sequence $k_{n} \subset[1, \infty)$ such that $0 \leq \mathbb{E}_{t} \mathcal{D}_{t+k} \delta_{t+k}<1$ in that sequence is sufficient for assuring determinacy since we have already assumed that the object $\left\{\mathcal{D}_{t}\right\}$ represents a probability and $\left\{\delta_{t}\right\}$ a fraction, which implies that $0 \leq\left\{\mathcal{D}_{t} \delta_{t}\right\}<1$ for all $t$. These conditions assure for all $t$ that $0<\frac{1}{\left(1-\mathbb{E}_{t} \mathcal{D}_{t+k} \delta_{t+k}\right) \phi^{\pi}}<1$ for at least one infinite sequence $k_{n} \subset[1, \infty)$. Overall, determinacy is guaranteed under rather mild restrictions. For one, when full (not partial) default is expected at the next period with certainty at all periods, the policy-asset market simply collapses. In that extreme case, $\mathbb{E}_{t} \mathcal{D}_{t+k} \delta_{t+k}=1$ for all $t$ and all $k$, such that we have an explosive process. For two, assuming that all sequences of $k_{n} \subset[1, \infty)$ such that $0 \leq \mathbb{E}_{t} \mathcal{D}_{t+k} \delta_{t+k}<1$ are finite imposes that after a certain $k=\tilde{k}$ the risky policy asset becomes strictly a full confiscation ad eternum by the government, what is quite unrealistic. For three, such sufficient requirements for determinacy already preclude full default to be expected for certain at any amount of periods into the future, since otherwise would require $\phi^{\pi}>\infty$. In short, when agents expect full default at any period into the future, inflation is not determined under an inflation-targeting rule. Finally, note that under the implicit assumption that $\phi^{\pi}$ is time-invariant these

\footnotetext{
${ }^{21}$ Under rational expectations, this also imposes $\phi^{\pi}>\frac{1}{1-\mathbb{E}_{t} \mathcal{D}_{t+k} \delta_{t+k}}$ for all $t$ and all $k$.
} 
are not only sufficient but also necessary conditions. Allowing $\phi^{\pi}$ to vary in time would allow for equilibrium determinacy even with lower values of $\phi^{\pi}$ at some periods. ${ }^{22}$

Proposition 1.1 (Inflation determinacy under inflation targeting) $A$ bounded process $\left\{r_{t}^{n}, \mathcal{D}_{t}, \delta_{t}, \bar{\iota}_{t}\right\}$, a monetary policy rule such as the one proposed in Assumption 1.9 with $\phi^{\pi}>\frac{1}{1-\mathbb{E}_{t} \mathcal{D}_{t+1} \delta_{t+1}}$ for all $t$, the fact that $\mathcal{D}_{t}$ is a process that represents a probability and $\delta_{t}$ is a process that represents a fraction, and the condition that for all $t$ there is at least one infinite sequence $k_{n} \subset[1, \infty)$ such that $0 \leq \mathbb{E}_{t} \mathcal{D}_{t+k} \delta_{t+k}<1$ in that sequence are necessary and sufficient conditions so that equilibrium inflation exists and it is unique.

Proof. Available in Appendix A.3.

Now, we prove which intercept for the Taylor rule is able to stabilize inflation at all periods. The equivalent proof for a central bank that targets the price level is developed in Proposition A.2.

\section{Proposition 1.2 (Optimal intercept under inflation targeting)}

Monetary policy is able to stabilize inflation through operations with the risky asset if it can track the sequence of natural interest rates $\left\{r_{t+j}^{n}\right\}_{j=0}^{\infty}$, the sequence of one-period-ahead policy-default probabilities $\left\{\mathcal{D}_{t+j+1}\right\}_{j=0}^{\infty}$, the sequence of one-period-ahead expected haircuts $\left\{\delta_{t+j+1}\right\}_{j=0}^{\infty}$, and it credibly adopts at period $t$ a Taylor rule with the sequence of time-varying intercepts $\left\{\bar{\iota}_{t+j}\right\}_{j=0}^{\infty} \equiv\left\{\frac{r_{t+j}^{n}+\mathbb{E}_{t} \mathcal{D}_{t+j+1} \delta_{t+j+1}}{1-\mathbb{E}_{t} \mathcal{D}_{t+j+1} \delta_{t+j+1}}\right\}_{j=0}^{\infty}$.

Proof. Available in Appendix A.3.

From the equilibrium inflation equation (1-11) and Figures $1.4\left(\phi^{\pi}=\right.$ $1.08)$ and $1.5\left(\phi^{\pi}=1.15\right)$, one can see that default expectations affect inflation in four ways:

- First, it directly changes the inflation rate in the present: $\Upsilon_{j+1}^{\pi}>$ $\alpha^{\pi j+1} \quad \forall j \geq 0$, the higher the default probability, the higher the inflation rate (top-left panel of Figure 1.4).

- Second, it reduces the power of monetary policy w.r.t. prices and inflation (middle-right panel of Figure 1.4): $\frac{\left(1-\mathbb{E}_{t} \mathcal{D}_{t+j+1} \delta_{t+j+1}\right)}{\Pi_{k=1}^{j+1}\left[\left(1-\mathbb{E}_{t} \mathcal{D}_{t+k} \delta_{t+k}\right) \phi^{\pi}\right]} \bar{l}_{t+j}<\frac{1}{\Pi_{k=1}^{j+1}\left[\phi^{\pi}\right]} \bar{l}_{t+j} \quad \forall \mathbb{E}_{t} \mathcal{D}_{t+1} \delta_{t+1}>0$. In Appendix

${ }^{22}$ Davig and Leeper (2007) study the case in which the value of $\phi^{\pi}$ switches according to different monetary regimes, and also find that the Taylor principle does not have to be attended at every regime for a New-Keynesian model to be determined. Schabert (2010) finds that an interest rate policy rule makes prices indeterminate when the government can default on the debt, but that is only because he does not have an additional equation for default probability to close the model. Here, we assume it is exogenous. 
A.6, we simulate the model for different correlations between $r_{t}^{n}$ and $\mathbb{E}_{t} \mathcal{D}_{t+1}$, and conclude that the power reduction in monetary policy is robust even when considered the whole time-sequence of expected default probabilities. One way of seeing the inflationary bias that policy-asset risk introduces is to compare the multiplier of $r_{t+j}^{n}, \Upsilon_{t, j+1}^{\pi}$, with the multiplier of $\bar{\iota}_{t+j}, \Upsilon_{t, j+1}^{\pi}\left(1-\mathbb{E}_{t} \mathcal{D}_{t+j+1} \delta_{t+j+1}\right)$, and note that the first one is larger for any positive $\mathbb{E}_{t} \mathcal{D}_{t+j+1} \delta_{t+j+1}$.

- Third, the expected haircut term amplifies the reduction of power of monetary policy, as the higher $\mathbb{E}_{t} \mathcal{D}_{t+j+1} \delta_{t+j+1}$ the higher is the inflation rate in equilibrium (bottom-left panel at Figure 1.4). Nevertheless, its effect is numerically dominated in reasonable calibrations, where $\left(1-\mathbb{E}_{t} \mathcal{D}_{t+j+1} \delta_{t+j+1}\right) \gg \mathbb{E}_{t} \mathcal{D}_{t+j+1} \delta_{t+j+1}$.

- Fourth, monetary policy is no longer able to stabilize inflation at all periods by just tracking $\left\{r_{t}^{n}\right\}$; it has to track a function of the natural interest rate, the default probability, and the haircut (Proposition 1.2). Despite that, note that even though tracking $\left\{r_{t}^{n}\right\}$ does not fully stabilize inflation, it does reduce its volatility under the assumption of independence between $\left\{r_{t}^{n}\right\}$ and $\left\{\mathcal{D}_{t}\right\}$ (bottom-right panel of Figure A.5).

- Finally, by comparing the panels of Figure 1.4) $\left(\phi^{\pi}=1.08\right)$ with their equivalents in Figure $1.5\left(\phi^{\pi}=1.15\right)$, one can see the consequence of increasing $\phi^{\pi}$. Considering only the trajectory of inflation, the effects of conducting monetary policy with defaultable bonds can be consistently attenuated with a more hawkish stance. 

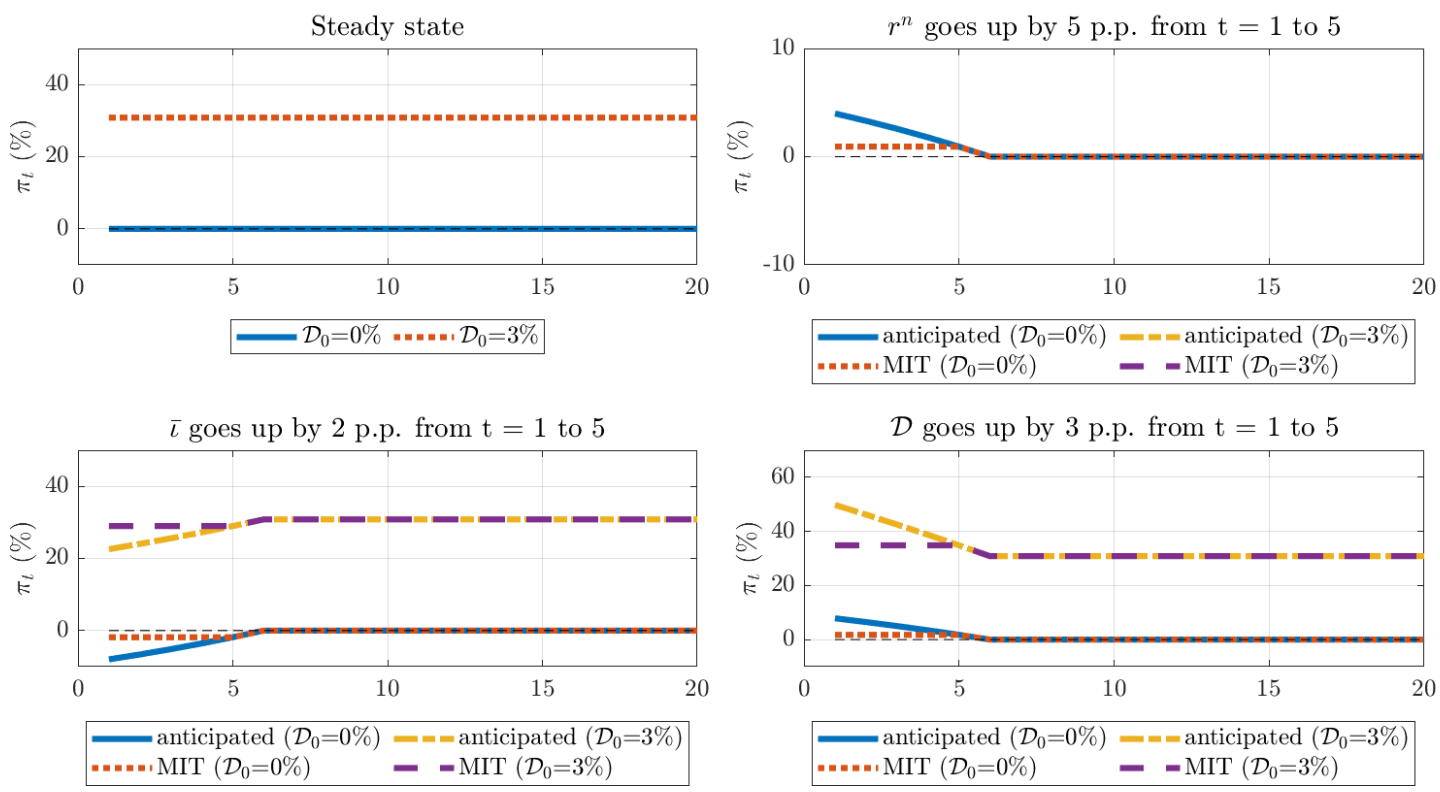

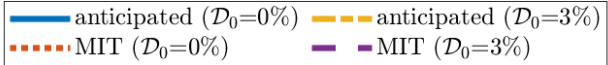

$\delta$ goes up by 20 p.p. from $\mathrm{t}=1$ to 5
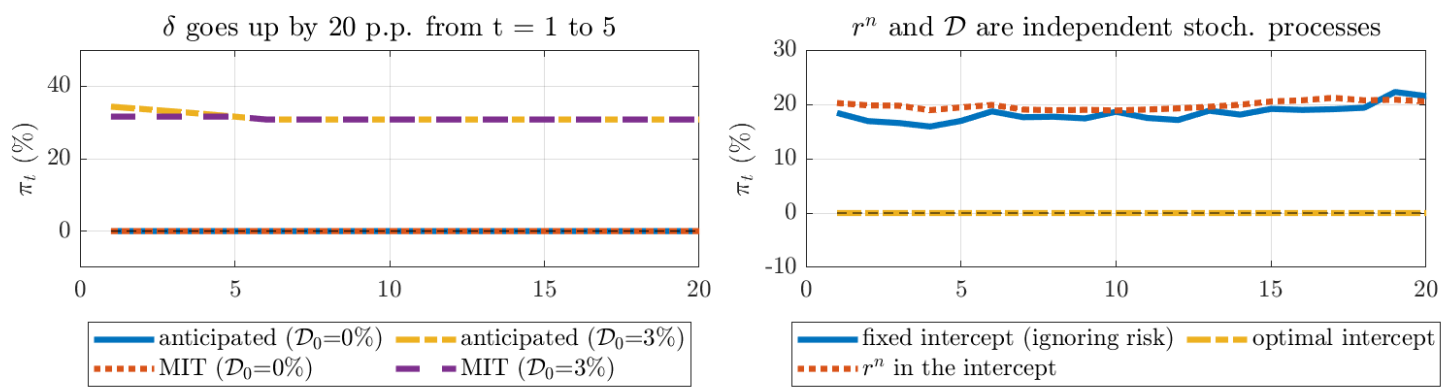

Figure 1.4: Inflation under neo-Wicksellian monetary theory augmented with policy-asset default $\left(\phi^{\pi}=1.08\right)$ 

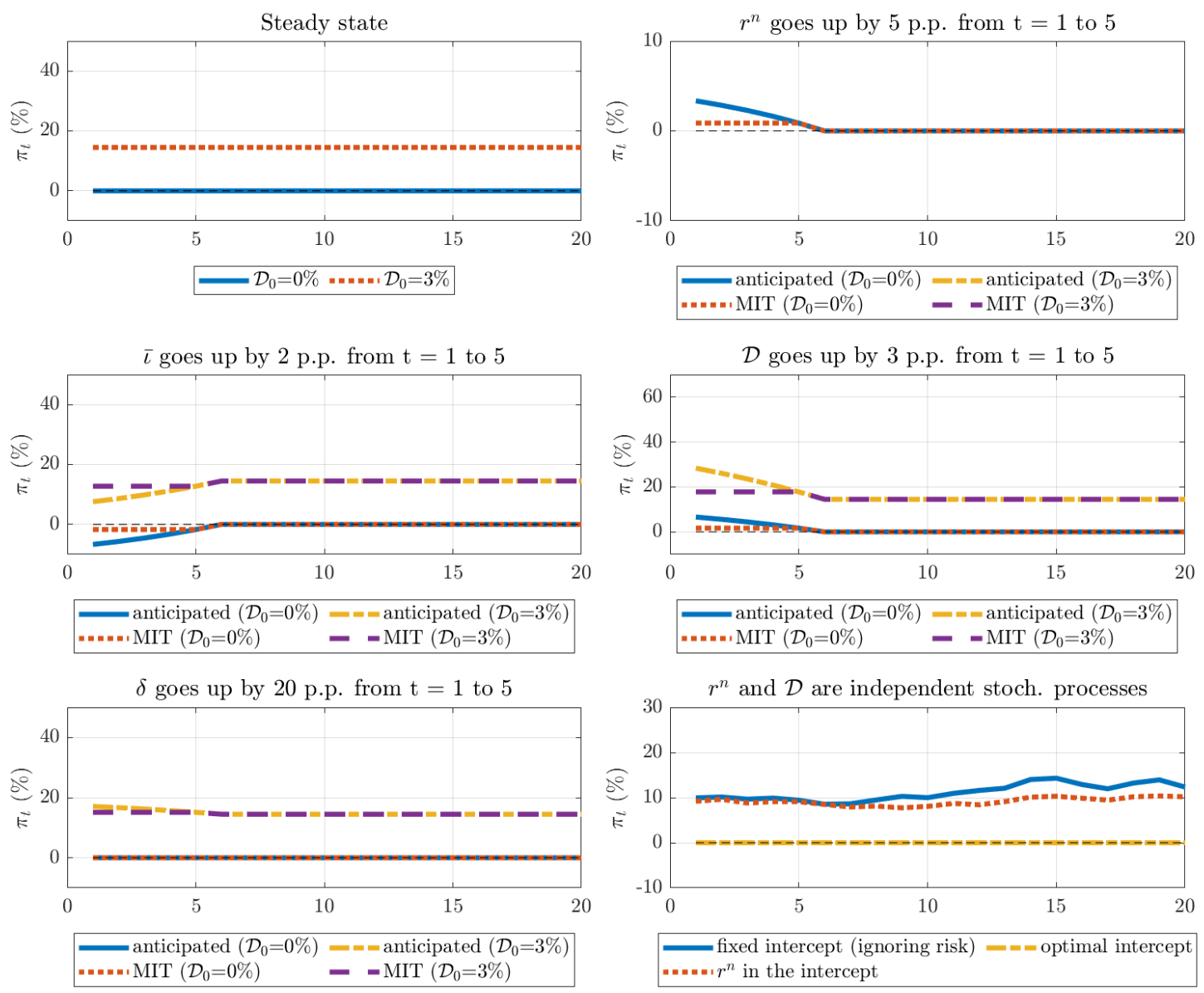

Figure 1.5: Inflation under neo-Wicksellian monetary theory augmented with policy-asset default $\left(\phi^{\pi}=1.15\right)$

The intuition for why the risk level of the asset used by monetary policy matters is straightforward after we have built this model. Starting from the end of period $t$, let us say that a continuum of states can represent all possible states of nature that can happen at period $t+1$. Only in those future states where there is no default of the policy asset is that the central bank can determine the ex-post return obtained by an investor who holds that asset. In all other states, in which the policy asset defaults, the return obtained with the policy asset is partially independent of the action of the central bank, and, therefore, monetary policy must be weaker compared to a scenario where the policy asset has no risk. The firepower of a traditional model central bank relies on its capacity of setting a nominal return of reference in all future states. After introducing risk in the policy asset, the latter is no longer true. Rationalizing in terms of an active vs. passive monetary policy à la Leeper (1991), we have that when the policy asset carries risk of default, monetary policy is only active conditional to the repayment of the debt by the issuer, and, thus, default risk makes it "less active". 
As far as we know, the reduction of the power of monetary policy w.r.t. prices and inflation in case of a surge in the perceived risk of the policy asset, such as what happens with risky debt during political or fiscal crises, is a new argument in favor of raising interest rates during such episodes in the literature. An obvious caveat, though, is that so far we have worked with only a partial equilibrium model. The interaction of interest rates with the trajectory of the debt is a fundamental mechanism that can revert this conclusion. In Appendix A.4, we derive a simple adaptation of the somewhat larger cashless flexible-price model of Woodford (2003a, ch. 2, sec. 1) under the assumption of a balanced-budget fiscal rule and show how our partial equilibrium defaultrisky cashless model dialogues well with the microfoundations of canonical neo-Wicksellian models. When fiscal policy is passive à la Leeper (1991), as we implicitly assume here, this is a result that we believe may survive in more realistic set-ups.

\subsection{4}

\section{The inflation bias}

Conducting monetary policy with risky assets under inflation targeting partially disconnects the unconditional mean of inflation from the central bank's target. We show this, next, by recovering the recursive formulation of (1-11) and taking the unconditional mean of both sides of that equation. Up to first order, these are the results.

$$
\begin{array}{r}
\mathbb{E} \pi=\Upsilon^{\pi}\left(\mathbb{E} r^{n}-(1-\mathbb{E} \mathcal{D} \delta) \mathbb{E} \bar{\iota}+\mathbb{E} \mathcal{D} \delta+\mathbb{E} \pi\right) \quad \text { where } \Upsilon^{\pi} \equiv\left(\frac{1}{(1-\mathbb{E} \mathcal{D} \delta) \phi^{\pi}}\right) \\
\mathbb{E} \pi=\frac{\Upsilon^{\pi}}{1-\Upsilon^{\pi}}\left(\mathbb{E} r^{n}-(1-\mathbb{E} \mathcal{D} \delta) \mathbb{E} \bar{\iota}+\mathbb{E} \mathcal{D} \delta\right) \\
\mathbb{E} \pi=\frac{1}{(1-\mathbb{E} \mathcal{D} \delta) \phi^{\pi}-1}\left(\mathbb{E} r^{n}-(1-\mathbb{E} \mathcal{D} \delta) \mathbb{E} \bar{\iota}+\mathbb{E} \mathcal{D} \delta\right)
\end{array}
$$

To make explicit the inflation bias, we assume that the intercept of the policy rule is the same of the canonical model, that is $\mathbb{E} \bar{\iota}=\mathbb{E} r^{n}$, and we obtain

$$
\mathbb{E} \pi=\underbrace{\frac{\mathbb{E} \mathcal{D} \delta}{(1-\mathbb{E} \mathcal{D} \delta) \phi^{\pi}-1}\left(1+\mathbb{E} r^{n}\right)}_{\text {inflation bias }}
$$

which will collapse to the inflation target $(\bar{\pi}=0)$ only when $\mathbb{E} \mathcal{D} \delta=0$, that is, only when the policy asset is non-defaultable, showing that the canonical case is nested here. As long as $r^{n}>-1$, the inflation bias is positive for any positive 
default probability lower than 1 if $\phi^{\pi}>\frac{1}{1-\mathbb{E} \mathcal{D} \delta}$. In case monetary policy is less active to the point that $\phi^{\pi}<\frac{1}{1-\mathbb{E} \mathcal{D} \delta}$, the inflation bias is negative, while when the expression is evaluated with equality the bias is indeterminate, just like inflation itself. If full confiscation is all to be expected $(\mathbb{E} \mathcal{D} \delta=1)$, inflation is not determined as it requires $\phi^{\pi}>\infty$. Finally, note that the bias reduces with the size of $\phi^{\pi}$, suggesting that more active monetary policy can mitigate it. The bias also increases with the default probability and reduces with the recovery rate. It is important to note that as long as inflation is determined the bias tilts inflation upward, but it does not make it accelerate.

So, how large is the inflation bias? Under the near-optimal intercept rule $\left(\mathbb{E} \bar{\iota}=\mathbb{E} r^{n}\right)$, Tables 1.1 and 1.2 calculate that variable in percentage points for some combinations of $\mathbb{E} \mathcal{D} \delta$ and $\phi^{\pi}$, arbitrarily assuming $\mathbb{E} r^{n}=4 \%$, for $\delta=0.05$ and $\delta=0.6$, respectively. For policy rules with low values of $\phi^{\pi}$, the bias is not negligible at all, while for rules with relatively high values of $\phi^{\pi}$ it is mostly attenuated.

Overall, conducting monetary policy with risky assets under inflation targeting results in a non-accelerating inflationary bias, which can be sizable if the central bank opts for being only slightly active. Our interpretation of this result is that central banks of risky economies, when taking the temperature of the room in the monetary market, may end up heuristically picking high values of $\phi^{\pi}$ as these values are more likely to bring inflation to the target more often, even when the calibration of the policy rule's intercept is not quite accurate and there is considerable uncertainty on the estimation of the natural real interest rate. This last result could explain a certain preference of risky-economy central banks for higher inflation-reaction coefficients in their policy rules, as such a parametric range is more likely to successfully meet their mandate w.r.t. inflation. Alternatively, these central banks could opt to raise the intercept itself, signaling a more permanent change in how monetary policy is conducted. Both strategies constitute what some may call "conservatism" of monetary policy, but, in reality, they may be required to deliver inflation on the target in risky economies.

Table 1.1: Inflation bias (p.p.) with $\delta=0.05$

\begin{tabular}{l|ccccc}
\hline \hline & $\phi^{\pi}=1.2$ & $\phi^{\pi}=1.5$ & $\phi^{\pi}=2.0$ & $\phi^{\pi}=2.5$ & $\phi^{\pi}=3.0$ \\
\hline $\mathcal{D}=0.0 \%$ & 0.0 & 0.0 & 0.0 & 0.0 & 0.0 \\
$\mathcal{D}=2.5 \%$ & 0.7 & 0.3 & 0.1 & 0.1 & 0.1 \\
$\mathcal{D}=5.0 \%$ & 1.3 & 0.5 & 0.3 & 0.2 & 0.1 \\
$\mathcal{D}=7.5 \%$ & 2.0 & 0.8 & 0.4 & 0.3 & 0.2 \\
$\mathcal{D}=10.0 \%$ & 2.7 & 1.1 & 0.5 & 0.3 & 0.3 \\
\hline \hline
\end{tabular}


Table 1.2: Inflation bias (p.p.) with $\delta=0.60$

\begin{tabular}{l|ccccc}
\hline \hline & $\phi^{\pi}=1.2$ & $\phi^{\pi}=1.5$ & $\phi^{\pi}=2.0$ & $\phi^{\pi}=2.5$ & $\phi^{\pi}=3.0$ \\
\hline $\mathcal{D}=0.0 \%$ & 0.0 & 0.0 & 0.0 & 0.0 & 0.0 \\
$\mathcal{D}=2.5 \%$ & 8.6 & 3.3 & 1.6 & 1.1 & 0.8 \\
$\mathcal{D}=5.0 \%$ & 19.0 & 6.9 & 3.3 & 2.2 & 1.6 \\
$\mathcal{D}=7.5 \%$ & 32.0 & 10.8 & 5.1 & 3.4 & 2.5 \\
$\mathcal{D}=10.0 \%$ & 48.8 & 15.2 & 7.1 & 4.6 & 3.4 \\
\hline \hline
\end{tabular}

\section{5}

\section{Testable implications of the model}

Our expansion of the neo-Wicksellian model with the inclusion of risk in the underlying asset of monetary policy allows for some testable implications. Under inflation targeting, inflation and inflation expectation should be positively correlated with policy-asset risk, whereas in case a good measure of $\mathbb{E}_{t} \delta_{t+1}$ were constructed it should also be positively correlated with inflation. Moreover, inflation volatility should reduce with larger values of $\phi^{\pi}$, like in the canonical model, but risky economies should have a harder time to achieve that result. ${ }^{23}$

In Section 1.1, we showed how the combination of the Fisher equation with an interest rate rule already revealed the predicted correlation between inflation and policy-asset risk. A possible counterfactual set-up would consist in a risk-free policy asset rate, $i_{t}$, and a central bank which still reacts to the risk wedge. Suppose an "unnecessarily reactive" central bank.

$$
\begin{gathered}
i_{t}=r_{t}^{n}+\pi_{t, t+1}^{e} \\
i_{t}=\bar{\iota}_{t}+\Phi_{t}+\gamma \pi_{t, t+1}^{e}
\end{gathered} \quad \Rightarrow \quad r_{t}^{n}-\left(\bar{\iota}_{t}+\Phi_{t}\right)=(\gamma-1) \pi_{t, t+1}^{e}
$$

As long as $r_{t}^{n}-\left(\bar{\iota}_{t}+\Phi_{t}\right)<0$, the correlation between policy-asset risk and inflation expectation is negative, at odds with what is commonly found in empirical data for emerging economies. Although unusual this set-up, we must remember that $r_{t}^{n}$ is not observable by the central bank, and that for very low levels of risk premium or even negative ones (convenience yields), this scenario could actually come up. In this section, we test the empirical implications of our model and show that, while developed economies tend to present correlation indistinguishable from zero, negative correlations are not impossible. Most importantly, if emerging central banks "unnecessarily" reacted

\footnotetext{
${ }^{23}$ In case of price-level targeting, actual and expected prices should be positively correlated with policy-asset risk, while inflation volatility should reduce with larger values of $\phi$, observing the same caveat for risky economies.
} 
to risk perceptions, than the correlation with inflation should be negative. We show, next, that this is not the case.

\subsection{1}

\section{Model simulation}

To show these correlations in the model under inflation targeting, we assume that both the real natural interest rate and the expected default probability at the next period follow independent normal $\operatorname{AR}(1)$ processes from which we simulate 10,000 vectors containing 100 periods each. Figure 1.6 shows the dispersion of these variables for three different values of $\phi^{\pi}(1.2$, 1.5, and 2.0) under three different monetary policy rules: intercept is fixed at the steady-state value ${ }^{24}$, intercept tracks the real natural rate, and intercept tracks $r_{t}^{n}$ adjusting by the risk underlying the policy asset. Note that for the first policy rule, both variables are somewhat positively correlated. When the central bank tracks $r_{t}^{n}$, this increases the positive correlation between $\mathbb{E}_{t} \mathcal{D}_{t+1}$ and $\pi_{t}$. Finally, when the central bank tracks $r_{t}^{n}$ adjusting by the risk in the policy asset, the correlation disappears. As we transition through the rules in that same order (from the second to the fourth column in the picture) inflation dispersion is increasingly reduced until virtually zero, showing the benefits of updating the policy rule intercept according to the evolution of $r_{t}^{n}$ and $\mathbb{E}_{t} \mathcal{D}_{t+1}$. Moreover, concerning the activeness of monetary policy w.r.t. inflation, the higher the $\phi^{\pi}$ the higher is the correlation. All these results are robust to the sign of the correlation between $r_{t}^{n}$ and $\mathbb{E}_{t} \mathcal{D}_{t+1}$ as can be seen in Appendix A.7, where we also show the simulation results for the price-level targeting regime.

${ }^{24}$ We impose $\overline{\mathcal{D}}=0$. 


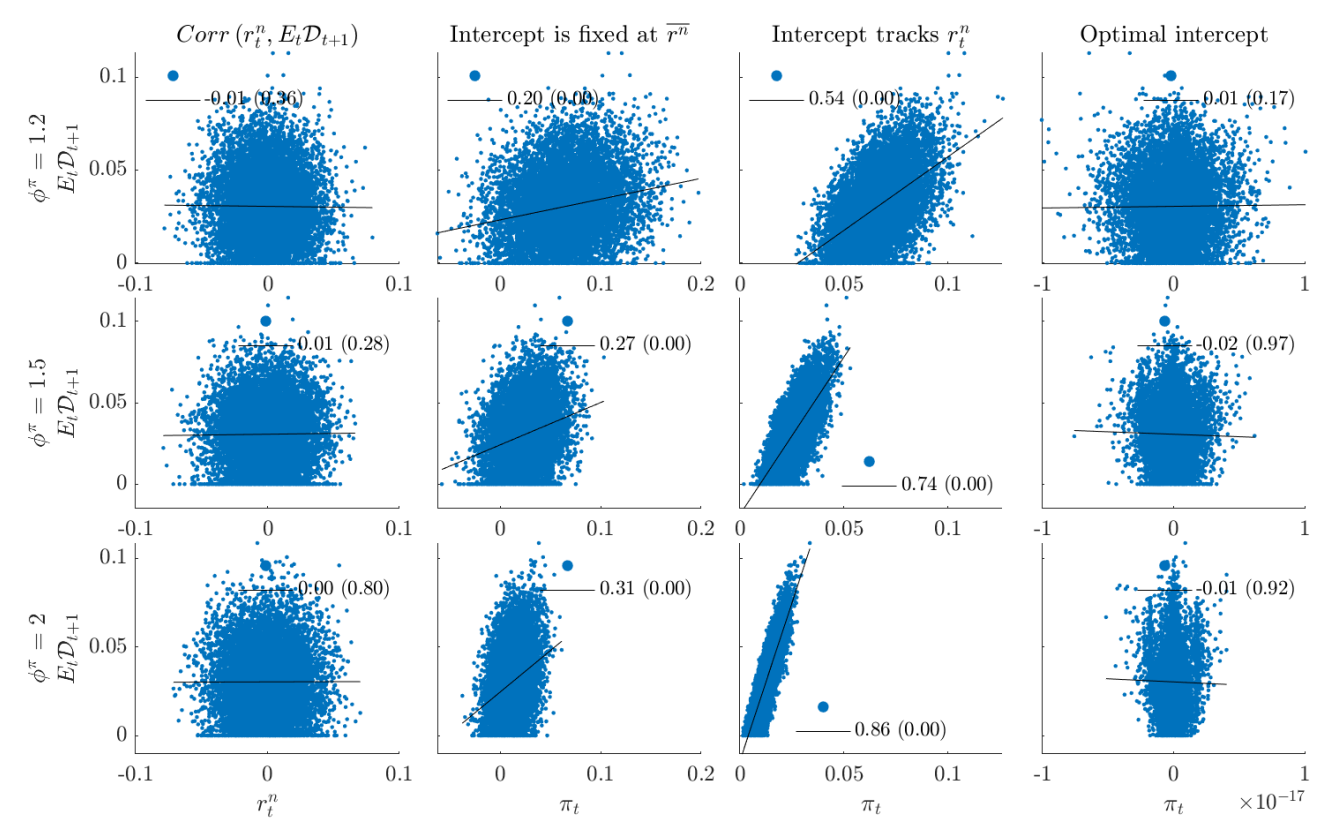

Note: p-values between parentheses.

Figure 1.6: Correlation between the default probability and inflation under inflation targeting: $\operatorname{Corr}\left(r_{t}^{n}, \mathbb{E}_{t} \mathcal{D}_{t+1}\right)=0$

\section{5 .2 \\ Empirical validation}

The theoretical predictions of our model are actually empirically found by Galli (2020) in a set of 10 large emerging economies ${ }^{25}$ in the period 2004Q12018Q4, although for some countries data start later. In his analysis, besides actual inflation data, he uses CDS data as an indicator of default risk, and fixed-for-fixed Cross-Currency Swaps (XCSs) for representing the expected depreciation of the local currency against the U.S. dollar, which, by its turn, he interprets as a proxy for expected inflation. He concludes that, first, countries with high default risk also exhibit high inflation and high expected inflation levels; second, within each country at a quarterly frequency, he finds positive pairwise correlations between default risk and actual inflation, default risk and inflation risk, as well as default risk and exchange rate depreciation. What is away from Galli (2020)'s scope, but is important in this paper, is that of the 10 countries in the sample 9 of them have adopted the inflation-targeting regime during at least part of the interval analyzed. ${ }^{26}$ In that line, Arellano et al.

${ }^{25}$ Brazil (1999), Colombia (1999), Indonesia (2005), Mexico (2001), Malaysia, Poland (1998), Russia (2014), Thailand (2000), Turkey (2006), and South Africa (2000), where the year in parentheses is the one in which each country adopted the inflation-targeting regime.

${ }^{26}$ Malaysia, which adopted an "inflation-anchoring" regime in the same period, is the only exception. Under that regime, the central bank does not target a specific price index, adopting a more discretionary attitude toward price stability. 
(2018) also find positive pairwise correlations between nominal interest rates, inflation, and default risk analyzing a sample of quarterly data from 2004-2017 comprehending the 10 inflation-targeting emerging countries that compose the JP-Morgan Emerging Market Bond Index (EMBI), which, by its turn, is used as the measure of default risk. ${ }^{27}$

As our model extends the very basic framework of neo-Wicksellian models, so important for the inflation-targeting rationale, the aforementioned empirical facts can be reconciled with the inflation-targeting regime without the need of adding to the model money and a seignorage channel through which defaulting on the debt and later inflating the economy would play complementary roles like in Galli (2020). Moreover, also different from what is done in Arellano et al. (2018), where these positive correlations are obtained by merging the small-open-economy New-Keynesian model of Gali and Monacelli (2005) with the strategic sovereign default RBC model of Arellano (2008), we get the same sign for the correlations still in the realm of a closed-economy flexible-price model. To conclude, embedding monetary policy's underlying asset with risk is sufficient for generating correlations with the same sign as the data.

We conduct, now, our own empirical exercise on the subject. Collecting a CDS dataset of emerging economies from Bloomberg ${ }^{28}$ and merging it with the same data we used for plotting Figure 1.1 - our estimation of the natural interest rate of emerging and advanced economies using univariate filters - we can calculate for each country in the sample the contemporaneous four-quarter moving correlation between quarterly-mean nominal policy rates, Q/(Q-4) CPI inflation, and a measure of risk. For emerging economies, we use 5-year CDS in USD (usually the most liquid), while for advanced economies we opt for the 1-year nominal interest rate spread w.r.t. to 1-year nominal U.S. Treasuries, as CDS contracts are not liquid for these economies. ${ }^{29}$ We show the correlations from pooling these observations in Figures 1.7 (emerging economies) and 1.8 (advanced economies). Country-specific correlations are available in Appendix A.7. Our sample ranges from 2000Q1 to 2019Q4, and includes 12 of the 20 largest emerging economies, in addition to 7 of the 20 largest developed economies, where the missing countries were due to lack of data. ${ }^{30}$ We opt

${ }^{27}$ The EMBI spread is measured as the difference in yields between USD-denominated emerging-economy government bonds and a comparable U.S. government bond. Arellano et al. (2018)'s sample comprises Brazil, Chile, Colombia, Indonesia, Korea, Mexico, Peru, Philippines, Poland, and South Africa.

${ }^{28}$ Data source description is available in Appendix A.7.

${ }^{29}$ Even though CDS data reflect the insurance premium on debt issued in USD, they are widely used by financial market practitioners as a general measure of country risk.

${ }^{30}$ We adopted a small arbitrary minimum threshold: 10 available observations. 
to remove outliers identified as observations more than three scaled median absolute deviations (MAD) from the median as such extreme values can have a large effect on correlations. ${ }^{31}$

We find that the regression coefficient between inflation and default risk is significantly positive at the $5 \%$ level for the aggregate of emerging economies. ${ }^{32}$ Furthermore, for the aggregate of advanced economies no linear relation is found between inflation and default risk, reinforcing that for that group default risk may be perceived as too small to influence prices. Besides, aggregate results are robust to country-fixed effects, whereas adopting inflation targeting is positively correlated with significant reduction of the level of default risk for emerging economies. In Appendix A.7, we reproduce this exercise using Du and Schreger (2016)'s measure of 5-year local-currency credit spread, which arguably controls for exchange-rate expectations and exchange-rate risk, and confirm the robustness of the difference in correlation pattern between emerging and advanced economies. From a country-specific perspective, the sign and the significance of correlations may vary from country to country depending on the risk measure chosen. However, the pattern that default risk in emerging economies tends to exhibit positive correlation with inflation while in advanced ones that correlation is mostly non-significant (or negative) remains for any of these risk measures.

\footnotetext{
${ }^{31}$ The scaled MAD formula is given by $c^{*}$ median(abs(A-median $\left.\left.(\mathrm{A})\right)\right)$, where $\mathrm{A}$ is the vector of observations, and $\mathrm{c}=-1 /\left(\operatorname{sqrt}(2)^{*} \operatorname{erfcinv}(3 / 2)\right)$.

${ }^{32}$ Replacing CDS spreads by 1 -year nominal interest rate spreads increases significance up to the $1 \%$ level.
} 

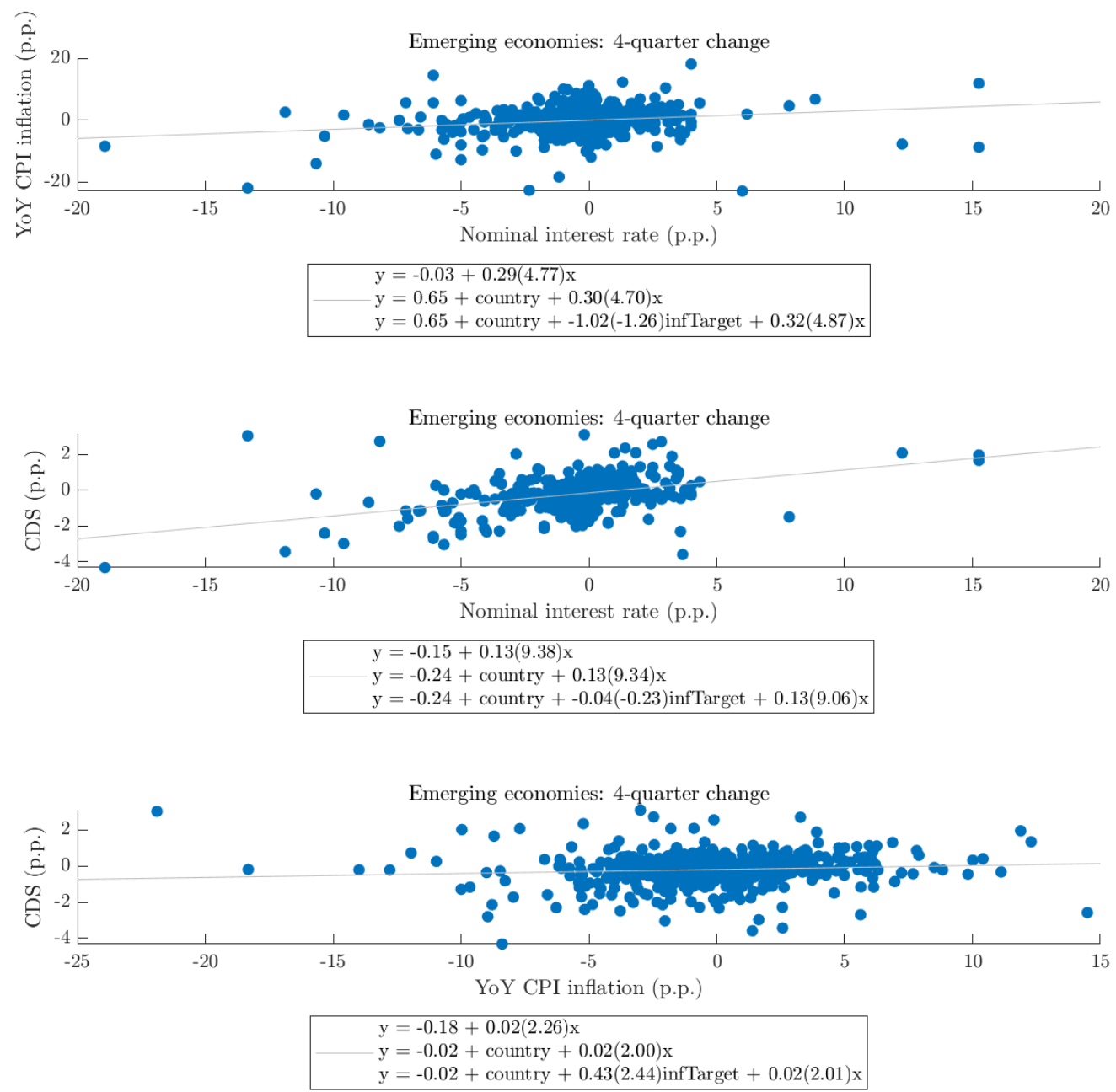

Note: between parentheses are t-statistics; "country" is a country-fixed effect; "infTarget" is a dummy that equals 1 when inflation targeting is adopted at the observation.

Figure 1.7: Scatter plot of pooled emerging economies: nominal interest rate, inflation, and default risk 

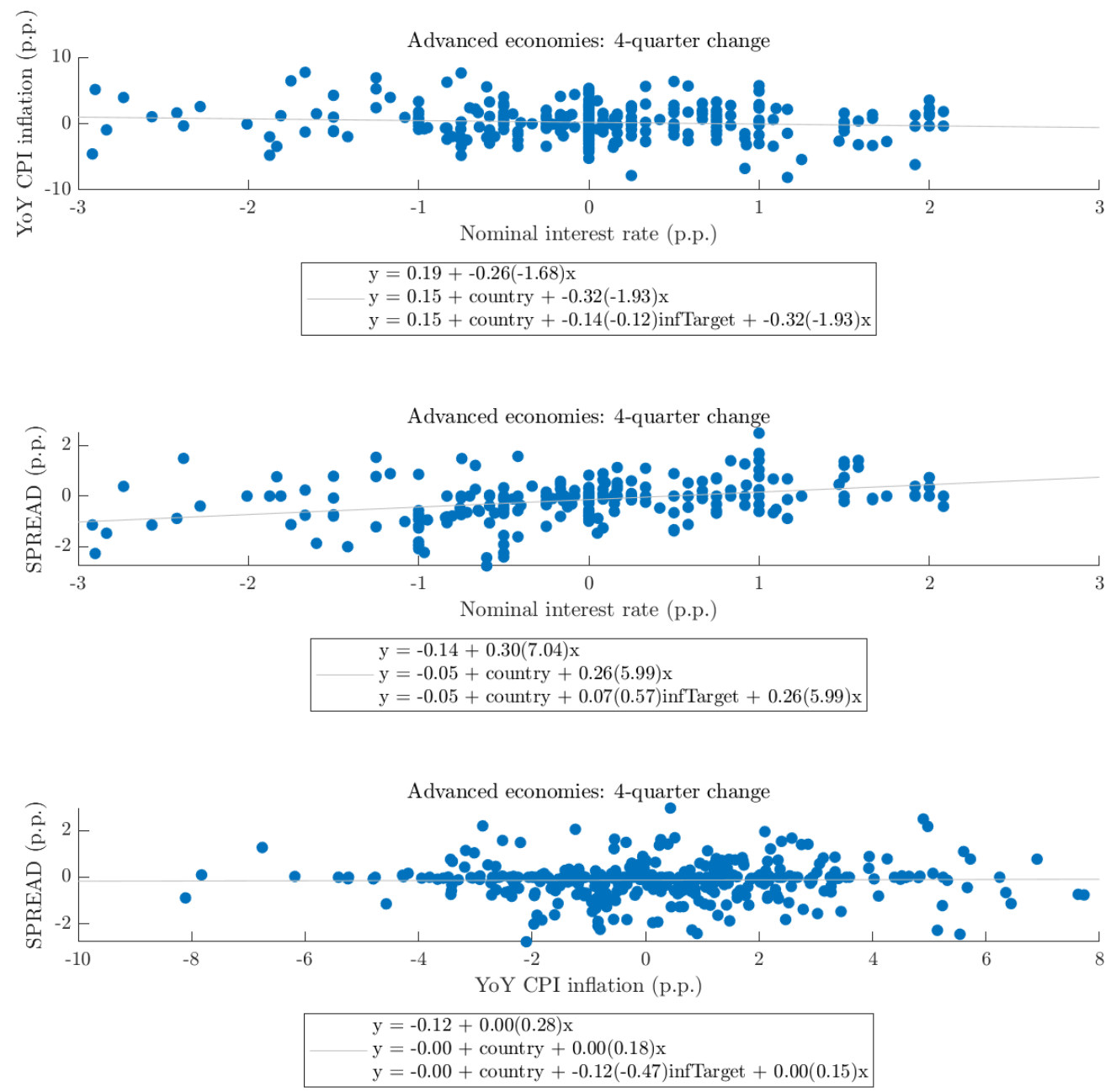

Note: between parentheses are t-statistics; "country" is a country-fixed effect; "infTarget" is a dummy that equals 1 when inflation targeting is adopted at the observation.

Figure 1.8: Scatter plot of pooled advanced economies: nominal interest rate, inflation, and default risk

The last testable implication that we explore is the one that relates inflation volatility with the inflation response coefficient, $\phi^{\pi}$, in the policy rule. Our model predicts that increasing $\phi^{\pi}$ reduces that volatility, but when the policy asset is risky, it should occur with less intensity, because monetary policy power is attenuated by the default probability. To verify that prediction, we estimate four different Taylor rules using OLS for an unbalanced panel of 27 countries, not necessarily inflation-targeters. ${ }^{33}$ Even though the Taylor

${ }^{33}$ We start from a sample with the 20 largest advanced and the 20 largest emerging economies, classified like in Appendix A.1. Countries without data available for the sample period are excluded. The remaining economies are the following. Advanced economies: Canada (CA), Hong Kong (HK), Israel (IL), Japan (JP), Norway (NO), South Korea (KR), Sweden (SE), United Kingdom (GB), United States (US). Emerging economies: Argentina 
rule's endogeneity implies that regressors are correlated with the error term, resulting in an asymptotic bias, Carvalho, Nechio and Tristao (2019) argue that such a bias should be small since monetary policy shocks explain only a small fraction of the variance of the regressors usually employed in this type of rule. Quarterly data is obtained from the IMF-IFS and it ranges from 2000Q1 to 2019Q4. For $\pi_{t}$, we use CPI YoY inflation, while for $i_{t}$, we use the quarterly mean of the annual nominal rate on 1-year Treasury Bills. We plot results in Figure 1.9. Each panel is a scatter plot of estimated coefficient $\phi^{\pi}$ against the standard-deviation of CPI inflation under a different specification for the Taylor rule: no trend nor smoothing (top-left panel), smoothing (topright panel), trend (bottom-left paenl), and trend and smoothing (bottom-right panel). The reason for including a linear trend is to allow that real natural interest rates may have been declining during the sample period, as we have seen in Figure 1.1.

The graphs confirm our model's prediction. Inflation volatility does reduce with the size of $\phi^{\pi}$, evidenced by the declining best-fit lines estimated, whereas emerging (risky) economies enjoy higher inflation volatility than advanced (risk-free) ones for the same $\phi^{\pi}$ values, shown by the positive shift between the respective lines. It does not go without notice that estimated $\phi^{\pi}$ values without smoothing are mostly lower than 1 , in apparent contradiction with the Taylor principle. To a great extent, this is explained by the fact that central banks tend to smooth interest rates out across the business cycle, a point already made by Clarida, Gali and Gertler (1999). The $\phi^{\pi}$ values in the graphs with smoothing (not displayed) are much more likely to attend the Taylor principle. Additionally, our Taylor rules still miss some of the elements to which central banks respond, i.e. output gaps and time-varying inflation targets. It is also possible that our selected series do not strongly positively correlate with the exact indicators tracked by each country's central bank. Above all, this exercise sought to demonstrate broad stylized facts, more than to obtain precise estimations.

(AR), Bangladesh (BD), Brazil (BR), Colombia (CO), Chile (CL), China (CN), Egypt (EG), India (IN), Indonesia (ID), Malaysia (MY), Mexico (MX), Nigeria (NG), Phillipines (PH), Poland (PL), Russia (RU), Saudi Arabia (SA), South Africa (ZA), Thailand (TH). Moreover, we exclude Turkey (TR) from the sample because it is clearly an outlier. 

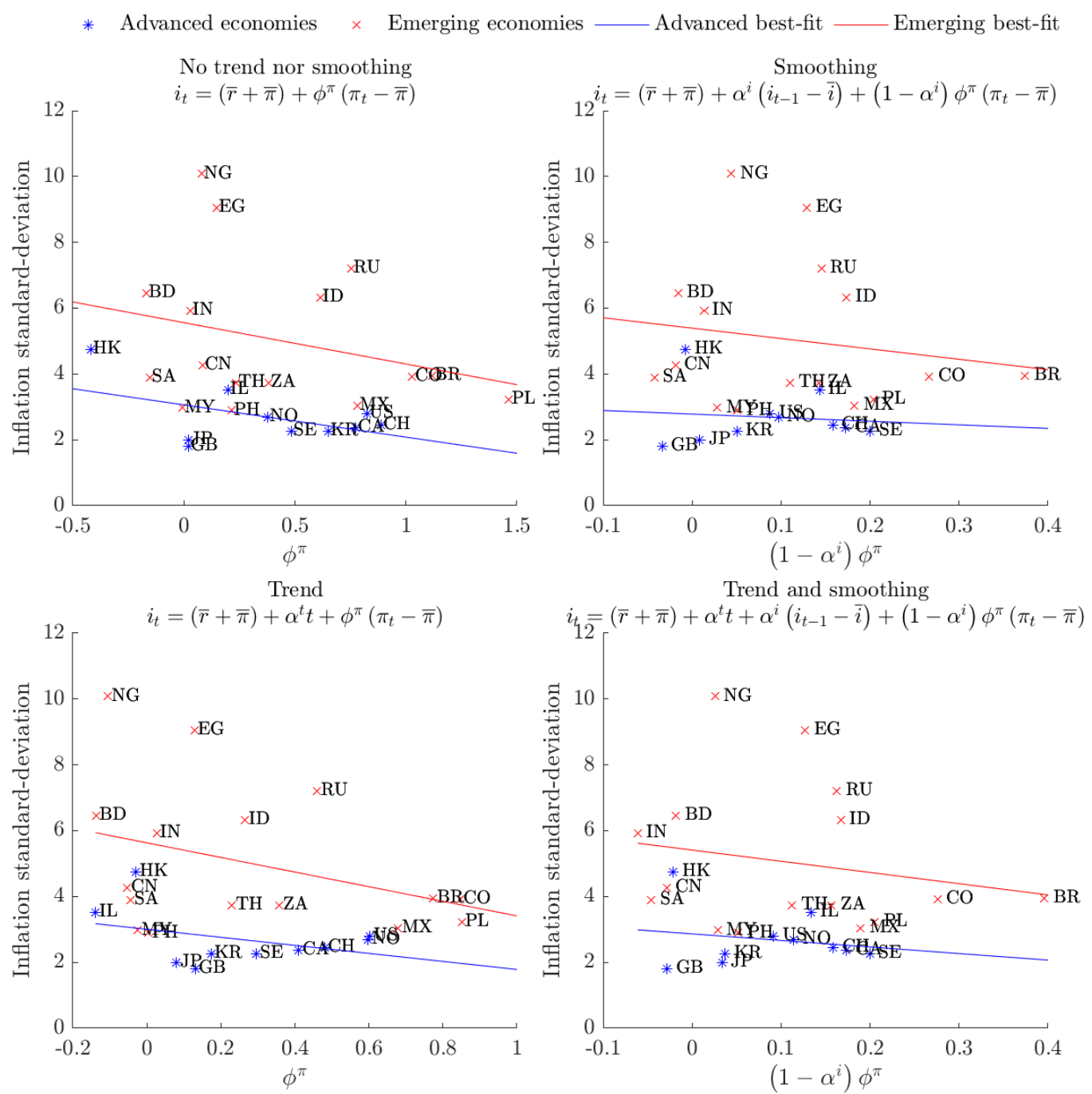

Note: estimation is done with OLS (ordinary least squares). Data sample ranges from 2000Q1 to 2019Q4. We use the CPI YoY inflation $\left(\pi_{t}\right)$ and the quarterly mean of the annual nominal rate on Treasury Bills $\left(i_{t}\right)$, both collected from the IMF-IFS. The Treasury Bills we use are local-currency 1-year-maturity federal government bonds, and the panel is unbalanced. $(\bar{r}+\bar{\pi})$ is the intercept of each regression; $\alpha^{i}$ is the smoothing coefficient; $\alpha^{t}$ is the time-trend coefficient; $t$ is a linear time trend; $\phi^{\pi}$ is the inflation-reaction coefficient; and $\bar{x}$ is the sample mean of any variable $x$. Advanced economies: Canada (CA), Hong Kong (HK), Israel (IL), Japan (JP), Norway (NO), South Korea (KR), Sweden (SE), United Kingdom (GB), United States (US). Emerging economies: Argentina (AR), Bangladesh (BD), Brazil (BR), Colombia (CO), Chile (CL), China (CN), Egypt (EG), India (IN), Indonesia (ID), Malaysia (MY), Mexico (MX), Nigeria (NG), Phillipines (PH), Poland (PL), Russia (RU), Saudi Arabia (SA), South Africa (ZA), Thailand (TH).

Figure 1.9: Empirically estimated Taylor rules 


\section{6 \\ Conclusion}

The assumption that monetary policy is conducted through risk-free instruments may be unrealistic for an emerging economy whose central bank targets inflation. This paper showed using a cashless closed-economy model with flexible prices that when the policy instrument is modeled as risky the power of monetary policy w.r.t the price level and inflation is reduced compared to a counterfactual without that risk. Moreover, uncompensated policy-asset risk distinguishes the unconditional mean of the price level, or inflation, from its target, resulting in a bias that induces a more aggressive reaction from the central bank. That reaction ultimately consists of either adopting a Taylor rule more elastic to inflation, or with a higher estimation for the unobserved real natural rate in the intercept, or both. This phenomenon perceived by some pundits in risky economies as "monetary policy conservatism" is actually necessary to bringing inflation to the target in the presence of risk in the policy asset.

By modeling the policy asset as a defaultable bond instead of a risk-free asset, monetary policy is not only less active, but it also becomes conditionally active to the issuer repaying its debt. Ignoring that fact leads to non-optimal monetary policy inducing positive correlation between default risk and inflation, what we showed is consistent with empirical data. That correlation, frequently motivated in the literature as an exchange rate transmission, emerges here without the need of opening the economy. In the context of active monetary policy combined with passive fiscal policy, our results represent a novel argument in favor of a more hawkish stance for monetary policy in the event of a fiscal or political crisis. Under the light of our results, central banks in the disposal of some independence should consider switching to remunerated deposits to mitigate exposure to government default risk.

The fact that the underlying asset of monetary policy can carry significant risk raises challenges to emerging economy central banks that have so far been either neglected or treated as of little relevance by the literature. This paper is a first attempt to tackle such challenges. However, many questions remain open. For instance, what other mechanisms allow policy-asset risk to interacting with the natural interest rate? How do nominal frictions can affect our results? Does the reduction of power we find for monetary policy remains relevant in a quantitative general equilibrium model? These and other questions we leave for future research. 


\section{An Unpleasant Coincidence for Monetary Policy: Risky Assets and Fiscal Limits ${ }^{1}$}

What if the government can default on monetary policy assets? This paper studies how sovereign default risk transmits to monetary policy depending on the policy instrument's credit risk. We lay out a two-agent New-Keynesian (TANK) model with endogenous fiscal limits and then calibrate it to a large emerging economy, Brazil. We find that endogenous expectations of a severe recession in case of default push inflation, real, and nominal policy rates higher in the equilibrium distribution of the model. By ignoring risk in the policy asset, the central bank reinforces that unpleasant coincidence. From a policy perspective, these results raise concerns on the evaluation of monetary policy stance in default-risky economies, while arguably solve a long-standing conundrum of the Brazilian economy.

Keywords: Monetary Policy, Risky Policy Asset, Natural Interest Rate, Fiscal Limit, Default in Domestic Currency, Endogenous Regime-Switching, Collor Plan, Real Plan

JEL Classification: D81, E43, E52, E58, E63

\section{1}

\section{Introduction}

What does change once we assume that the government can default on assets targeted by the central bank? This is the exact opposite assumption to the one adopted by usual monetary policy models. Although government debt

${ }^{1}$ I thank the advising from Carlos Viana de Carvalho, the discussions with Ricardo Reis, the comments of Juliano Assunção, Yvan Becard, Tiago Berriel, Pedro Henrique da Silva Castro, Marcio G. P. Garcia, Eduardo Loyo, Marina Perrupato, Leonardo Rezende, and Eduardo Zilberman. An early version of this project received very helpful comments from Miguel Bandeira, Jordi Galí, Xitong Hui, Daniel Albuquerque Maranhão De Lima, and Bilal Tabti. I gratefully acknowledge the Economics Department of the London School of Economics for its hospitality during the academic year 2018/2019. Beyond the usual disclaimer, I must note that any views expressed herein are mine and not necessarily those of the Banco Central do Brasil or of any of its members. Finally, I also thank the Banco Central do Brasil and CAPES for the financial support, and the Economics Department of PUC-Rio for the opportunity. 
is sometimes modeled as risky, the monetary authority is mostly supposed to have risk-free nominal targets which it implements with risk-free instruments. After all, central banks with their deep pockets can always issue more money on demand. This is basically the essence of monetary policy in canonical New-Keynesian models (i.e., Galí (2015); Woodford (2011)). In this paper, we flip that assumption up-side-down and model the policy instrument as a defaultable bond carrying the same risk of default as that of the government. The motivation for doing so is straight-forward. For one, in most countries, the central bank is part of the general government, enjoying different degrees of $d e$ facto independence. For two, emerging economy central banks often go to the open market with a portfolio of assets issued by the federal government. For three, and perhaps most important, domestic defaults including those of debt denominated in domestic currency have happened in the past, as Reinhart and Rogoff (2009) and Beers and de Leon-Manlagnit (2019) have built databases of such cases. ${ }^{2}$

We develop a two-agent New-Keynesian (TANK) model with distortionary taxes and endogenous fiscal limits, à la Bi (2012), conjugated with a central bank that targets the rate of government defaultable bonds. We model both Ricardian and non-Ricardian (hand-to-mouth) agents to reproduce the environment of emerging economies, in which access to financial assets, including those directly influenced by the central bank's rate, may be quite limited. This heterogeneity may have important implications for welfare, since only the first type of agent suffers a direct wealth loss in case of default, while both types share the updated tax burden for the new debt trajectory as well as the indirect costs of default which we model as a recessionary shock. ${ }^{3}$ Additionally, we assume a positive spill-over of government expenses to productivity as a way to obtain empirically-motivated positive correlation between the first and output. Our nominal frictions are two as they come from the fact that the government issues exclusively nominal debt at the same time that prices are sticky.

${ }^{2}$ As Reinhart and Rogoff (2009, p. 111) put: "In fact, our reading of the historical record is that overt de jure defaults on domestic public debt, though less common than external defaults, are hardly rare. Our data set includes more than 70 cases of overt default (compared to 250 defaults on external debt) since 1800. These de jure defaults took place via a potpourri of mechanisms, ranging from forcible conversions to lower coupon rates to unilateral reduction of principal (sometimes in conjuction with a currency conversion) to suspension of payments".

${ }^{3}$ Although an economic recession increases the likelihood that default happens, defaulting by itself is associated with an additional negative shock. Both stylized facts are captured by our model and are empirically validated by Reinhart and Rogoff (2009, p. 129)'s estimations of an average $8 \%$ cumulative decline of output in the three-year run-up of a domestic default crisis, in addition to a $4 \%$ average decline on the very year of the default event. From a theoretical point of view, as D'Erasmo and Mendoza (2016) show, default must be costly for the government to warrant why it most often than not repays its debt. 
Inflation works as a wealth tax on Ricardian agents, who detain all sovereign bonds, at the same time that it reduces expected taxation levied on all agents in the future. Furthermore, since prices are sticky, real interest rates in this model may be different from natural ones, their flexible-price counterparts. We study two policy rules: (1) targeting the real risk-free rate using risky assets; and (2) targeting the risk-adjusted rate using risky assets. Finally, since our economy contains two non-excluding nonlinearities for the government, taxing at the peak of the Laffer curve and reaching the fiscal limit (ultimately partially defaulting on debt), we adopt Maih (2015)'s regime-switching approach, in which transition probabilities are allowed to be endogenous.

After calibrating the model to a large emerging economy perceived as having not irrelevant default risk, Brazil ${ }^{4}$, and which credibly abides by the inflation-targeting regime in the present, despite having defaulted on localcurrency-denominated liabilities in the past, we confirm that ignoring such a risk when embedded in the monetary policy asset has potential to put in check the central bank's mandate, since we find that this attitude reinforces the unpleasant coincidence of high real and nominal policy rates while it delivers inflation above the target in the ergodic distribution of the model. ${ }^{5} \mathrm{~A}$ longstanding discussion in Brazil revolves around why the country experienced that coincidence after the end of its hyperinflation period, as can be seen in Figure 2.1. ${ }^{6}$ Since the Real Plan of July 1994, inflation has been mostly moderate for an emerging economy, but at the expense of considerably high nominal policy rates, resulting in equivalently high ex-post real interest rates. ${ }^{78}$ The successful monetary reform was preceded four years before by the Collor Plan,

\footnotetext{
${ }^{4}$ Brazil's indicators of default risk are sizable no matter you measure it using CDS (credit default swap) rates, EMBI+ spreads, or using Du and Schreger (2016)'s measure of credit risk on local-currency denominated sovereign debt. Meanwhile, it has accumulated more than 20 years of experience with inflation targeting, being arguably successful on that goal for it has actually delivered inflation inside the previously communicated target range in most of these years. Despite the stability of the last decades, Reinhart and Rogoff (2009, p. 116) point out that Brazil has defaulted on domestic debt in, at least, two occasions: 1986-1987 and 1990. In the first episode, debt previously issued as inflation-indexed forcibly lost the previously agreed indexation, and in the second episode, the government partially froze private financial assets in the context of the Collor Plan.

${ }^{5}$ We consider rates to be empirically high when they are so compared to the rest of the world at the same period. In the model, when they exceed their deterministic-steady-state values in the benchmark regime.

${ }^{6}$ Franco (2017, p. 726-745) exposes a detailed account of that discussion.

${ }^{7}$ Bacha (2010) associates the persistence of ex-post real interest rates in Brazil with some inherited attributes from the high-inflation period such as high levels of price indexation, net debt to output, earmarked credit, as well as limitations to currency convertibility. He also points out to the unrelenting political tension that stems out from that discrepancy w.r.t the rest of the world and which blurs the government's strategy to repay its debt.

${ }^{8}$ Ex-ante real interest rates calculated with inflation expectations drawn from professional survey or from financial market data are available for the inflation targeting period and exhibit a similar pattern, BCB (2017).
} 
in which the government partially froze private financial assets to contain what a recently-elected government considered excessive liquidity in the economy and blamed for the out-of-control inflationary process. ${ }^{9}$ In the middle panel of Figure 2.1, one can note that ex-post real interest rates turned out very negative right after the confiscation amid a pronounced recession $(-4.3 \%$ YoY GDP in 1990). However, some time before the Real Plan it had already converged to a higher level than before the Collor Plan, around the same level it maintained in the first years after the Real Plan, until the implementation of the inflation-targeting regime in June 1999. That last regime change also contemplated the floating of the exchange rate and the adoption of annual fiscal surplus targets, ultimately setting up the so-called "macroeconomic tripod". ${ }^{10}$ In the middle and bottom panels of Figure 2.1, one can see that ex-post real interest rates, nominal interest rates, and inflation engage together in a sluggish downward trend after the Real Plan, which arguably reflects the slow improvement of Brazil's fundamentals in addition to the fading memory of its government's attempts to break tacit and legal contracts. Our modeling approach of default as the partial confiscation of Ricardian agents' financial wealth conjugated with a severe recession guards some resemblance with what happened in Brazil during the Collor Plan at the same time that it points out to a potential source of misspecification in emerging-economy models which neglect policy-asset default risk. While default by itself is a bad deal for the bondholders, the negative repercussions that it entails is what really drives real interest rates significantly up in the model, even at low levels of expected default probability. Whether the central bank accommodates or not that risk in its policy rule is what, eventually, pushes inflation above the target. From a quantitative point of view, we do not try to exactly replicate the empirical moments of the post-Real period, but rather to demonstrate that default risk is able to generate some of its still intriguing features.

Overall, our simple dynamic stochastic general equilibrium (DSGE) model provides a new closed-economy explanation for why nominal interest rates, and real interest rates, of emerging economies may be observed as higher than their advanced economies counterparts. By ignoring the risk in monetary policy's underlying asset, central banks miss the adequate intercept of the policy rule, generating undesirable price fluctuations today and expected into

${ }^{9}$ Pastore (1991) points out that $80 \%$ of the M4 (M1 plus all financial assets), approximately $30 \%$ of the Brazilian GDP at that time, became unavailable to their holders for 18 months, after which they were released in up to 12 installments with interest and inflation correction. The confiscation threshold was set at financial resources above $\mathrm{NCz} \$ 50,000$, which as of July $31^{\text {st }} 2021$ amounts to around BRL 19,500 or USD 3,800 inflation-adjusted.

${ }^{10}$ Bevilaqua and Loyo (2005) give a detailed account of this transition and the early years of the inflation-targeting regime in Brazil. 

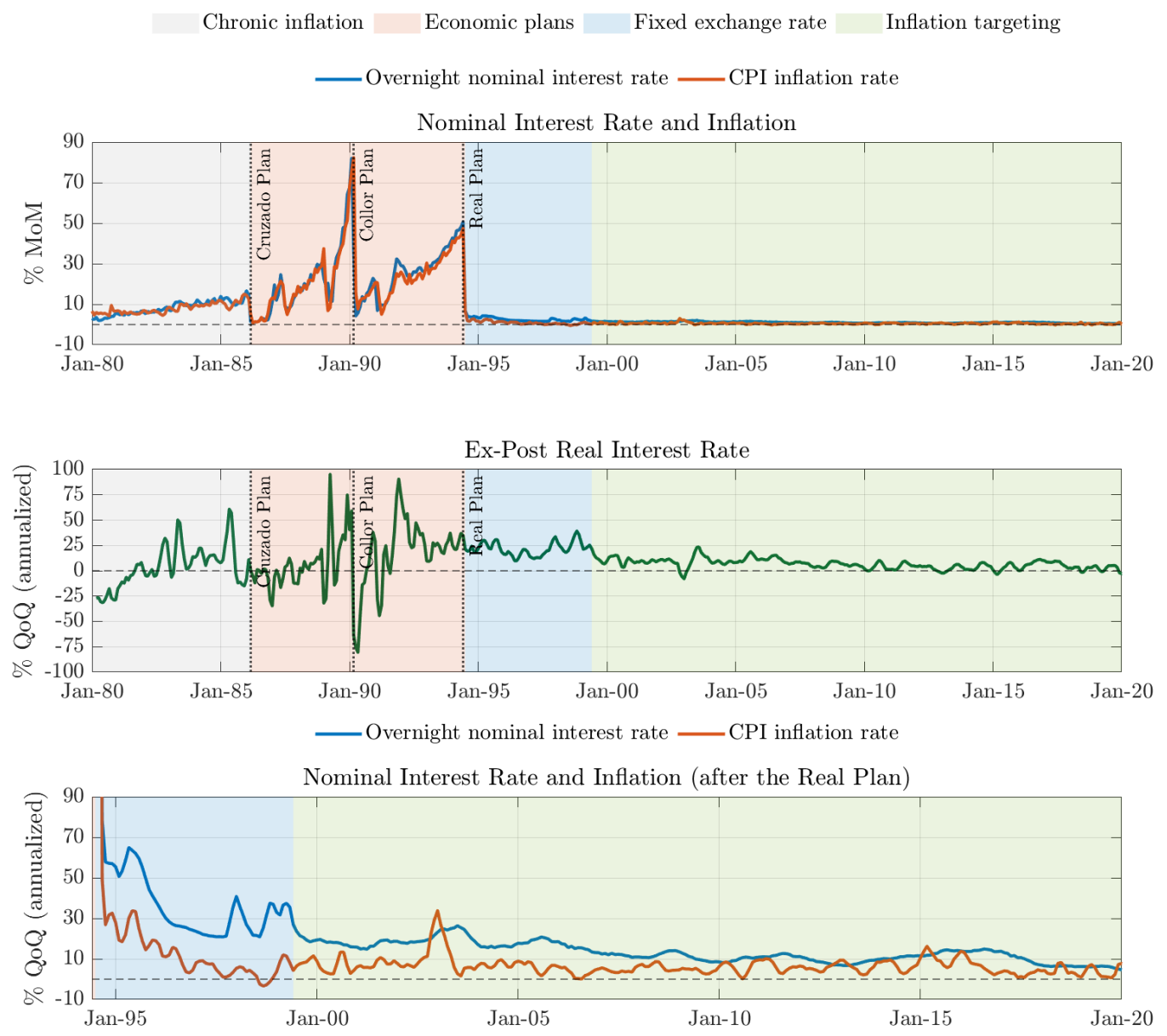

Note: The four periods identified are dated as follows: Chronic inflation (Jan-1980 to Feb-1986), Economic plans (Mar-1986 to Jun-1994), Fixed exchange rate (Jul-1994 to May-1999), and Inflation targeting (Jun-1999 onward). The Cruzado Plan is dated as of Mar-1986; the Collor Plan as of Mar-1990; and the Real Plan as of Jun-1994. Constructed with data from IPEADATA. Overnight nominal policy rate is series "Taxa de juros - Over / Selic - acumulada no mês". CPI inflation rate is series "Preços - IPCA - geral". The ex-post real interest rate series is calculated from the previous ones.

Figure 2.1: Brazilian historical data 
the future. In that sense, the model rationalizes an argument in favor of that, in case of, say, a fiscal or political crisis, the central bank should raise the nominal policy rate or reduce it by less than if its instrument was risk-free, considering the adverse effects of the crisis over the economic activity. Needless to say that such a type of reaction is commonly seen in practice, even though most often reasoned as an attempt to contain capital flights to abroad. Moreover, a central bank that credibly commits itself to always update the policy rule intercept to changes in default risk is able to stabilize inflation on the target, at the same time that it may deliver lower nominal and real interest rates throughout time.

In a companion paper, we expand Wicksell (1898)'s partial-equilibrium flexible-price monetary model as interpreted by Woodford (2011) with defaultable bonds being used as monetary policy assets. There, we find that, in such a setting, monetary policy power w.r.t. prices is reduced, and the central bank ends up raising nominal interest rates more than it would if policy assets were risk-free. This outcome can only be undone in case the central bank adopts, with credibility, a particular nominal interest rate rule with a time-varying intercept that adjusts itself to default-risk variations underlying the policy asset. Moreover, by ignoring the riskiness of its own asset, the policy rule will generate a positive correlation between expected default risk and inflation, a testable implication of the model consistent with empirical data collected from both (risk-free) advanced and (risky) emerging economies.

This paper proceeds as follows. Section 2 presents the related literature. Section 3 describes our model with risky assets and fiscal limits, as well as explains the solution method. Section 4 calibrates and simulates the model to the Brazilian economy. Section 5 makes considerations about welfare. Finally, Section 6 concludes. Appendix B.1 derives the steady state; Appendix B.2 lists the log-linearized equations; Appendix B.3 describes the estimation of some parameters; Appendix B.4 tests the stability of the model; Appendix B.5 plots impulse response functions; Appendix B.6 makes welfare considerations; Appendix B.7 provides additional analyses; and Appendix B.8 gives technical details on the endogenous regime-switching solution method.

\section{2}

\section{Related literature}

In the literature, this paper is more closely related to Bi, Leeper and Leith (2018), which investigates for the case of a closed economy with fiscal limits how the inflation-targeting regime is affected when the monetary policy rule targets the interest rate on default-risky sovereign bonds, instead of on riskfree assets. The authors employ a New-Keynesian model with fixed-intercept 
Taylor rules, and find that, on the one hand, if the central bank targets the risk-free rate, it can still manage to bring inflation to the target after a contractionary monetary shock, although persistently depressing output. On the other hand, if the central bank targets the default-risky interest rate, it would be as if it had lifted the inflation target. ${ }^{11}$ Differently from Bi, Leeper and Leith (2018), in this paper, we allow the intercept of the policy rules to vary in order to reflect the evolution of default risk. Additionally, we specify both Ricardian and non-Ricardian agents, for they will be affected differently by an episode of default, in a set-up more similar to an emerging economy. We also take a different approach to solving the model, as well as explore the ergodic distribution induced by each policy rule, in addition to sketching some welfare considerations.

Still in the realm of New-Keynesian models with fiscal limits, Battistini, Callegari and Zavalloni (2019) endogenize the interaction of the latter's distribution with different policy rules and the zero-lower-bound. Bi, Shen and Yang (2020), by their turn, keep monetary policy conditional to a given fiscal limit distribution, as we do in this paper, but introduce capital and long-term debt to evaluate interest rate normalization on the exit of the zero-lower-bound in the United States.

As this paper deals with the interaction between inflation and government debt default risk, it can be related to papers which explore that dimension, even though central bank operations are still seen as risk-free by them. Bonam and Lukkezen (2019) look into how pro-cyclical fiscal policy when debt is risky may put in check the inflation-targeting regime inside a closed-economy NewKeynesian framework, while Schabert and Van Wijnbergen (2014) analyze the consequences of having a not very responsive fiscal rule in an open-economy New-Keynesian model. Both papers emphasize that default risk makes it more likely that monetary policy is constrained by fiscal policy. Arellano, Bai and Mihalache (2020), by their turn, combine the open-economy NewKeynesian framework of Gali and Monacelli (2005) with the literature on strategic external sovereign default of Arellano (2008), and find that default risk amplifies monetary frictions by bringing tension to monetary policy that, in the end, leads to inflation and nominal interest rates being even more volatile, as well as the latter to positively co-move with default risk. Turning to our model, when the central bank accommodates policy-asset default risk it generates correlations with the same sign still in the realm of a closed economy.

Expanding the literature on strategic default to domestic sovereign debt,

\footnotetext{
${ }^{11}$ Reis (2018) points out that adjusting the intercept of the policy rule to the risk premium
} embedded in the risky rate brings inflation back to the target. 
D'Erasmo and Mendoza (2016) propose a theory based on distributional incentives across heterogeneous agents to show how positive debt can be sustained in equilibrium when defaulting is costly, a situation we reproduce in this paper under the fiscal limits approach by differentiating Ricardian from non-Ricardian households. Deviating somewhat from default risk, but still facing the question of inflation credibility when the central bank can inflate the debt, a problem latent in this paper that we abstract from by assuming the central bank is credible and always abides by its policy rule (excepting for random monetary shocks), there is Aguiar et al. (2014). The authors propose a model to explain why less developed economies who have joined the Eurosystem enjoyed significantly lower interest rates on their sovereign debt after that event, which the authors rationalize as gains of credibility in the conduction of monetary policy.

In the implementation of government default risk in our model, we follow Bi, Shen and Yang (2020); Bi, Leeper and Leith (2018); Bi, Shen and Yang (2016) and Bi (2017), for we adopt the stochastic fiscal limit mechanism proposed in Bi (2012). By this approach, a government subject to a Laffer curve may be forced to default on its debt at any period with a probability inferred from the distribution of future shocks in the economy. Differently from the literature of sovereign default led by Eaton and Gersovitz (1981) and Arellano (2008), the preferences of the government are not explicitly modeled, so that default happens not because the government prefers to, or is strategic doing so, but because the trajectory of debt becomes unsustainable given fiscal limitations, namely, an exogenous process for government expenses combined with an endogenous cap on government revenues. For a more empirical perspective, an attempt to calculate market-priced fiscal limits using CDS time series and a semi-structural model is developed in Pallara and Renne (2019).

A similar approach to modeling fiscal limits, but with less emphasis on its distribution, can also be found in Davig, Leeper and Walker (2010) and Davig, Leeper and Walker (2011), who focus on policy uncertainty stemming from the risk that monetary policy may switch from active to passive, in Leeper (1991)'s definition, when under fiscal stress, allowing for the central bank to inflate the debt. A feature both these works share with the present paper is that regime switching happens with endogenous probability. Nonetheless, the mentioned papers provide global solutions obtained through the monotone map method of Coleman (1991), while in this paper we provide locally-approximated solutions by employing the regime-switching method described in Maih (2015).

Although this work always assumes active monetary policy and passive 
fiscal policy, it can be marginally correlated to the well-established literature that assumes different combinations, either more in line with the fiscal theory of the price level and fiscal dominance, like in Sargent and Wallace (1981), Sims (1994), Woodford (1995), Cochrane (1998), Blanchard (2004), and Uribe (2006), or with the non-existence of a bounded equilibrium, like in Loyo (1999). Two of them deserve special attention in reason of also taking Brazil as a motivating case, although covering completely different periods. Blanchard (2004) tells us a story of hikes in the policy rate increasing real interest rates and, as a consequence, the stock of default-risky government debt. As the latter is related to significantly higher default probability, a higher policy rate is not enough to make domestic debt more attractive, on the contrary, it leads to a real depreciation of the domestic exchange rate which is further transmitted into higher inflation - a situation of fiscal dominance for which monetary policy has its hands tied to decrease inflation. Differently from Blanchard (2004), in this paper the exchange rate channel is absent and inflation only depends on the central bank's reaction both to it and to default risk - a situation better described as of monetary dominance. Particularly contrasting with Loyo (1999), while he tells a story of accelerating inflation and policy rates, we tell a story about their persistence at high levels. In this paper, the central bank may never go for the rescue of the indebted government while, by committing to always adjust the intercept of the policy rule to the default risk underlying its instrument, it can still deliver inflation on the target. Overall, monetary policy is conditionally active to the government repaying its debt, but still active, while fiscal policy is always passive. If, by any chance, the government has to default, it confiscates part of the Ricardian agents wealth, whereas the economy's TFP suffers a persistent negative shock.

\section{3}

\section{Closed economy with default-risky policy assets}

We present a DSGE model of a sticky-price closed economy composed of households and firms with both a fiscal and a monetary authority. Households are of two types, Ricardians and non-Ricardians. The first type invests her savings in defaultable nominal government bonds. There is no investment in capital in this economy, for it is assumed fixed across firms at all periods.

The central bank conducts monetary policy through open-market operations with government bonds abiding by a nominal interest rate rule. To allow for default risk in the policy asset of this economy, we impose that the fiscal authority is constricted by private perceptions of its stochastic fiscal limit, as in Bi (2012) and Bi, Leeper and Leith (2018), what implies that at any period 
$t$ there is a non-zero probability that the government will only repay partially its maturing debt at period $t+1$. Consequently, investors charge a default premium for holding government bonds. Default, in addition to confiscation, coincides with a negative TFP shock, but it is costless otherwise, in the sense that both the fiscal authority and the central bank do not suffer any sanction and still maintain their access to the bond market after defaulting. The fiscal authority levies time-varying distortionary taxes on labor and profit income, at the same time that it makes fixed lump-sum transfers to all households. ${ }^{12}$

To turn the calculation of the fiscal limits computationally faster, we adopt ingredients so as to keep the global solution of the model analytical under flexible prices even after we have added government to it. First, we specialize the one-period utility function to be of the GHH type (Greenwood, Hercowitz and Huffman, 1988), eliminating income effects from the labor supply, what facilitates aggregation of Ricardian and non-Ricardian agents. Second, we adopt a Cobb-Douglas production function with constant marginal returns to labor. ${ }^{13}$

\subsection{1}

\section{Households}

At every period $t$, there is a continuum of households indexed by $i \in[0,1]$ split into two types: Ricardians (optimizing) and non-Ricardians (rule-ofthumb). $\gamma^{N R}$ represents the fraction of the latter in the continuum. The aggregate consumption of this economy, $C_{t}$, is given by

$$
C_{t}=\left(1-\gamma^{N R}\right) C_{t}^{R}+\gamma^{N R} C_{t}^{N R}
$$

where $C_{t}^{R}$ and $C_{t}^{N R}$ are, respectively, the amounts consumed by each Ricardian and non-Ricardian representative household.

\subsubsection{1}

\section{Ricardian households}

The fraction $\left(1-\gamma^{N R}\right)$ of Ricardian households can be consolidated into a representative Ricardian household, who seeks to maximize her value function (2-2) subject for all $t$ to her nominal budget constraint (2-3) and to her solvency

\footnotetext{
${ }^{12}$ Lump-sum transfers will be particularly useful in our calibration strategy as they will be calculated as to ensure that debt is stable at the steady state given the empirical calibration of other fiscal variables.

${ }^{13}$ The combination of Cobb-Douglas production function in which labor has diminishing marginal returns with traditional separable power utility in a model with government impedes a global analytical solution of the model, as it would require the use of approximation or numerical methods inside each iteration of the calculation of the fiscal limits. Although perfectly doable, we opted here to keep the model as tractable as possible, while still obtaining sensible impulse response functions.
} 
constraint (2-4) in order to avoid Ponzi-schemes. We assume that when the government buys goods in the market, it somehow generates positive utility to households, perhaps through the provision of public goods. ${ }^{14}$

$$
\begin{gathered}
\mathbb{E}_{0} \sum_{t=0}^{\infty} \beta^{t} \frac{1}{1-\sigma}\left(C_{t}^{R}+\alpha_{G} G_{t}-\eta \frac{N_{t}^{1+\chi}}{1+\chi}\right)^{1-\sigma} \\
P_{t} C_{t}^{R}+\frac{P_{t} B_{t}}{1+i_{t}} \leq\left(1-\delta_{t}\right) P_{t-1} B_{t-1}+\left(1-\tau_{t}\right)\left(W_{t} N_{t}+P_{t} D_{t}\right)+P_{t} Z_{t} \\
\lim _{T \rightarrow \infty} \mathbb{E}_{t}\left[\beta^{T-t} \frac{\left(C_{T}^{R}+\alpha_{G} G_{T}-\eta \frac{N_{T}^{1+\chi}}{1+\chi}\right)^{-\sigma}}{\left(C_{t}^{R}+\alpha_{G} G_{t}-\eta \frac{N_{t}^{1+\chi}}{1+\chi}\right)^{-\sigma}} \frac{\left(1-\delta_{T}\right) B_{T}}{P_{T}}\right] \geq 0
\end{gathered}
$$

where $\beta \in(0,1)$ is the subjective discount factor; $\sigma$ is the inverse of the elasticity of intertemporal substitution; $\eta$ is a parameter that regulates the disutility of labor; and $\chi$ is the inverse of the Frisch elasticity of labor supply. Evaluated all at period $t, C_{t}^{R}$ is the amount consumed by the Ricardian household; $P_{t}$ is the price of the consumption good; $N_{t}$ is the number of hours worked; $W_{t}$ is the nominal wage paid for hours worked; and $D_{t}$ is the dividend paid by the representative firm to the representative household as the latter ultimately owns all firms. Concerning the portfolio of assets, $B_{t}$ is the amount of the one-period discounted risky nominal bond purchased at the end of period $t$; and $i_{t}$ is the net interest rate on the risky one-period nominal bond to be paid at period $t+1$. Concerning the government-related parameters, $\alpha_{G}$ controls how public consumption provides utility to the households. When $\alpha_{G}>0$, government consumption substitutes for private consumption; when $\alpha_{G}=1$, it is a perfect substitute; and if $\alpha_{G}<0$ it complements. ${ }^{15}$ Finally, $\delta_{t}$ is a timevarying function that indicates default according to a rule to be defined, but which is going to be positive in case of default, and zero otherwise.

\footnotetext{
${ }^{14}$ In the calculation of the fiscal limits, the nominal rigidities will be turned off. In that flexible-price scenario, simply introducing government expenses and applying a positive shock to it would crowd out private consumption to such an extent that output would decrease instead of increase in the short-run, contrary to the usual empirical evidence. Mechanisms often introduced to induce short-run positive correlation between $\Delta G_{t}$ and $\Delta Y_{t}$ such as nominal rigidities would add a new state variable to our model, turning the fiscal limits calculation computationally more demanding. Defining part of households as handto-mouth helps to dump the short-run negative impact on output, but it is not enough to change its sign. We opt, then, to put government consumption inside of the utility function of the households, a specification able to induce empirically validated short-run positive correlations between $G_{t}$ and other real variables in an environment with nominal rigidities, as shown by Fève and Sahuc (2017), with the advantage of not adding a new state variable. Despite that, what will, eventually, make output to respond positively to a public consumption expansion in the flexible-price version of our model is the modification of the production function described ahead.

${ }^{15}$ For a list of papers which play with this parameter, check Fève and Sahuc (2017).
} 
The optimization of the Ricardian household with respect to $C_{t}^{R}, N_{t}$, and $B_{t}$ results, respectively, in conditions (2-5), (2-6), and (2-7)

$$
\begin{gathered}
U_{C, t}=\lambda_{t} P_{t} \\
U_{N, t}=-\lambda_{t}\left(1-\tau_{t}\right) W_{t} \\
\frac{\lambda_{t}}{\mathbb{E}_{t} \lambda_{t+1}}=\beta\left(1+i_{t}\right)\left(1-\mathbb{E}_{t} \delta_{t+1}\right)
\end{gathered}
$$

where $U_{C, t}$ and $U_{N, t}$ are, in order, the marginal utility of consumption and of labor in period $t$; and $\lambda_{t}$ is the Lagrange multiplier of the household's budget constraint in the same period. Note that we pick a tax on wages on purpose, because it distorts the optimal choice of the households when compared to their choice when such a tax does not exist. Higher taxes reduce household's after-tax real return per worked hour, discouraging labor supply. This feature will generate a curve of revenues for the government against the tax rate $\tau_{t}$ that is concave in its valid domain of $[0,1]$, the so-called Laffer curve. This will be important further ahead when we define default conditions in the model.

After specializing the one-period utility function adopted, the CPOs of the representative Ricardian household are given by the optimal labor supply (2-8) in addition to the Euler condition (2-10), valid for all $t$. The solvency constraint is binding and takes the form of the transversality condition (2-11), also valid in all periods. Hereafter, we define the stochastic discount factor of the Ricardian household at period $t$ for a risk-free real flow at period $t+1$, $M_{t, t+1}$, by equation (2-9), where $r_{t}^{R F}$ is the net real interest rate on that flow.

$$
\begin{aligned}
& \frac{W_{t}}{P_{t}}=\frac{1}{\left(1-\tau_{t}\right)} \eta N_{t}^{\chi} \\
& M_{t, t+1} \equiv \frac{1}{1+r_{t}^{R F}}=\mathbb{E}_{t}\left[\beta\left(\frac{C_{t+1}^{R}+\alpha_{G} G_{t+1}-\eta \frac{N_{t+1}^{1+\chi}}{1+\chi}}{C_{t}^{R}+\alpha_{G} G_{t}-\eta \frac{N_{t}^{1+\chi}}{1+\chi}}\right)^{-\sigma}\right] \\
& \frac{1}{1+i_{t}}=\mathbb{E}_{t}\left[\beta\left(1-\delta_{t+1}\right)\left(\frac{C_{t+1}^{R}+\alpha_{G} G_{t+1}-\eta \frac{N_{t+1}^{1+\chi}}{1+\chi}}{C_{t}^{R}+\alpha_{G} G_{t}-\eta \frac{N_{t}^{1+\chi}}{1+\chi}}\right)^{-\sigma} \frac{P_{t}}{P_{t+1}}\right] \\
& \lim _{T \rightarrow \infty} \mathbb{E}_{t}\left[\beta^{T-t} \frac{\left(C_{T}^{R}+\alpha_{G} G_{T}-\eta \frac{N_{T}^{1+\chi}}{1+\chi}\right)^{-\sigma}}{\left(C_{t}^{R}+\alpha_{G} G_{t}-\eta \frac{N_{t}^{1+\chi}}{1+\chi}\right)^{-\sigma}} \frac{\left(1-\delta_{T}\right) B_{T}}{P_{T}}\right]=0
\end{aligned}
$$

\subsubsection{2}

\section{Non-Ricardian households}

The fraction $\gamma^{N R}$ of non-Ricardian, rule-of-thumb, households can be consolidated into a representative non-Ricardian household, who consumes all 
her income at every period since it has no access to assets, bonds, or dividends. She also takes prices and nominal wages as given, while she maximizes the utility flow (2-12) subject for all $t$ to her nominal budget constraint (2-13).

$$
\begin{gathered}
\mathbb{E}_{0} \sum_{t=0}^{\infty} \beta^{t} \frac{1}{1-\sigma}\left(C_{t}^{N R}+\alpha_{G} G_{t}-\eta \frac{\left(N_{t}^{N R}\right)^{1+\chi}}{1+\chi}\right)^{1-\sigma} \\
P_{t} C_{t}^{N R}=\left(1-\tau_{t}\right) W_{t} N_{t}^{N R}+P_{t} Z_{t}
\end{gathered}
$$

where $N_{t}^{N R}$ is her number of hours worked. As we assume both household types have the same GHH specification for the utility function, they supply the same amount of labor in equilibrium, $N_{t}=N_{t}^{N R} \forall t$. One can note this by comparing the non-Ricardian CPO for the labor supply (2-14) with the Ricardian (2-8)

$$
\frac{W_{t}}{P_{t}}=\frac{1}{\left(1-\tau_{t}\right)} \eta N_{t}^{N R \chi}
$$

\subsection{2}

\section{Final goods sector}

At every period $t$, there is a continuum of competitive firms indexed by $j$ willing to produce a homogeneous final good composed of differentiated goods produced by a continuum of monopolistic firms indexed by $k$. The final good aggregation technology has a CES form and it is given by

$$
Y_{j, t}=\left(\int_{0}^{1} y_{k, t}^{\frac{\theta-1}{\theta}} \mathrm{d} k\right)^{\frac{\theta}{\theta-1}}
$$

where $\theta$ is the elasticity of demand for each intermediate firm's good.

In the final sector, each firm $j$ minimizes its cost generating the following demand curve for the intermediate good of firm $\mathrm{k}$.

$$
Y_{k, t}=\left(\frac{P_{k, t}}{P_{t}}\right)^{-\theta} Y_{t}
$$

The associated price index to the final good is presented next.

$$
P_{t}=\left(\int_{0}^{1} P_{k, t}^{1-\theta} \mathrm{d} k\right)^{\frac{1}{1-\theta}}
$$

Finally, the representative final sector firm's output, and this economy's output, is easily obtained by symmetry

$$
Y_{t}=\int_{0}^{1} Y_{j, t} \mathrm{~d} j=Y_{j, t}
$$




\subsection{3}

\section{Intermediate goods sector}

At every period $t$, there is a continuum of monopolistic firms indexed by $k$ willing to produce a differentiated good. Each of them hires households in the amount of $N_{k, t}$ working hours at that period. These firms make use of the following technology, (2-19), where $Y_{k, t}$ is the production of firm $k$ at period $t$, and $A_{t}$ represents the common TFP process of all firms also at the same period. We assume that the stock of capital belongs directly to the firms and that its amount is equally fixed across them at all periods at the level of $\bar{K} \cdot{ }^{16}$ Additionally, we include a capital enhancement effect motivated by public consumption ${ }^{17}$, where $\gamma_{G \Psi} \in[0,1)$ is the output elasticity with respect to government expenditures.

$$
Y_{k, t}=A_{t}\left(\frac{G_{t}}{\bar{G}}\right)^{\gamma_{G \Psi}} \bar{K} N_{k, t}
$$

Note that this production function implies constant returns to scale, so all intermediate firms optimize by seeking to employ the same amount of input factors. The TFP, $A_{t}$, follows the exogenous process

$$
\log \left(\frac{A_{t}}{\bar{A}}\right)=\rho_{A} \log \left(\frac{A_{t-1}}{\bar{A}}\right)+\sigma_{A} \varepsilon_{t}^{A}-\underbrace{\mathbb{1}_{B_{t-1}>\mathcal{B}_{t}} \delta^{\mathrm{TFP}}}_{\text {loss in case of default }}
$$

where $\rho_{A} \in[0,1)$ is a parameter that controls the persistence of the shocks; $\sigma_{A}$ is their standard deviation; while $\varepsilon_{t}^{A}$ is i.i.d. $\mathcal{N}(0,1)$. The last term of the equation, $\mathbb{1}_{B_{t}>\mathcal{B}_{t+1}} \delta^{\mathrm{TFP}}$, is the product of an indicator function that the government has defaulted on the debt by a productivity loss parameter, $\delta^{\mathrm{TFP}}$. At last, $\mathcal{B}_{t}$ is the fiscal limit drawn at period $t$, as it will be explained further ahead in this paper.

The marginal cost of the intermediate firm, $\mathrm{MC}_{t}$, is identical across all firms of that type, and can be obtained by dividing the cost of one unit of labor by its marginal product. Note that since the production function is linear in labor, the marginal product does not depend on the amount of labor employed. At period $t$, the marginal cost is expressed by

\footnotetext{
${ }^{16}$ We keep the constant in the model because it is going to help us with the steady-state calibration. Otherwise, we would have to find a real-world value for $\bar{A}$, the TFP at the steady state.

${ }^{17}$ Barro (1990) argues that private inputs are not a close substitute for public ones and warrants the specification of nonrival public services in the firm-specific production function in terms that it is indifferent whether the government buys a flow of output from the private sector (infrastructure, defense, etc.), which is later offered to the firms to fulfill their private demand, or that the goverment itself carries on the production as long as they share the same production function. Maršál, Kaszab and Horvath (2017) adopt a similar idea in a DSGE model under a more complex specification of public expenditures.
} 


$$
\mathrm{MC}_{t}=\frac{W_{t}}{P_{t}} \frac{1}{A_{t}\left(\frac{G_{t}}{\bar{G}}\right)^{\gamma_{G \Psi}} \bar{K}}
$$

Each period, the intermediate firm $k$ solves the optimization problem (222) through which she maximizes profits subject to sticky prices à la Rotemberg (1982), where $\phi^{C}$ is a parameter that calibrates the price adjustment cost, and $\bar{\Pi}$ is the steady-state gross inflation,

$$
\max _{P_{k, t}} \sum_{h=0}^{\infty} M_{t, t+h}\left(P_{k, t} Y_{k, t}-\mathrm{MC}_{t} P_{t} Y_{k, t}-\frac{\phi^{C}}{2}\left(\frac{P_{k, t}}{P_{k, t-1}} \frac{1}{\bar{\Pi}}-1\right)^{2} P_{t} Y_{t}\right)
$$

subject to (2-16), taking $P_{t}, W_{t}$ and $Y_{t}$ as given. After imposing symmetry, the $\mathrm{CPO}$ of the representative intermediate firm is the non-linear New-Keynesian Phillips curve under Rotemberg prices, which is given by

$$
(1-\theta)+\theta \mathrm{MC}_{t}-\phi\left(\frac{\Pi_{t}}{\bar{\Pi}}-1\right) \frac{\Pi_{t}}{\bar{\Pi}}+\phi^{C} M_{t, t+1}\left(\frac{\Pi_{t+1}}{\bar{\Pi}}-1\right) \frac{\Pi_{t+1}}{\bar{\Pi}} \frac{Y_{t+1}}{Y_{t}}=0
$$

Monopoly profit at any period $t$ is immediately transferred as dividends, $D_{t}$, to the Ricardian households, who own the shares of the firms.

$$
D_{t} \equiv Y_{t}-\mathrm{MC}_{t} Y_{t}-\frac{\phi^{C}}{2}\left(\frac{\Pi_{t}}{\bar{\Pi}}-1\right)^{2} Y_{t}
$$

\subsection{4}

\section{Government}

The government is limited by the following budget constraint

$$
\frac{P_{t} B_{t}}{1+i_{t}}+\tau_{t}\left(W_{t} N_{t}+P_{t} D_{t}\right) \geq\left(1-\delta_{t}\right) P_{t-1} B_{t-1}+P_{t} G_{t}+P_{t} Z_{t}
$$

where $B_{t}$ is real debt at the end of period $t ; \tau_{t}$ is a time-varying tax rate applied to labor and dividend income; $G_{t}$ is real government expenditure; and $Z_{t}$ is real lump-sum government transfers to the households. The default discount, $\delta_{t}$, shall be interpreted here not as a partial default in the stock of bonds, but as a partial default on the promised nominal return of all of them, for we impose that the government cannot discriminate bondholders. The government constraint can be rewritten in real terms resulting in

$$
\frac{B_{t}}{\left(1+i_{t}\right)}+T_{t} \geq\left(1-\delta_{t}\right) \frac{B_{t-1}}{\Pi_{t}}+G_{t}+Z_{t}
$$

where $T_{t} \equiv \tau_{t}\left(\frac{W_{t}}{P_{t}} N_{t}+D_{t}\right)$ is real tax revenue. Government expenditure, by its turn, follows an exogenous $\mathrm{AR}(1)$ process that also depends on lagged output: ${ }^{18}$

${ }^{18} \mathrm{Bi}$, Shen and Yang (2016) also allow government expenditure to react to output with a lag, which is intended to capture its procyclicality observed in some emerging economies, especially in Latin America, as Gavin and Perotti (1997) find. There is also evidence of fiscal 


$$
\log \left(\frac{G_{t}}{\bar{G}}\right)=\rho_{G G} \log \left(\frac{G_{t-1}}{\bar{G}}\right)+\rho_{G Y} \log \left(\frac{Y_{t-1}}{\bar{Y}}\right)+\sigma_{G} \varepsilon_{t}^{g}
$$

where $\left|\rho_{G G}\right|<1 ;\left|\rho_{G Y}\right|<1 ; \sigma_{G}$ is the standard deviation of the shocks; and $\varepsilon_{t}^{g} \sim$ i.i.d. $N(0,1) .{ }^{19}$ Additionally, we fix transfers at all periods such that $Z_{t}=\bar{Z}$. To restrain indebtedness, fiscal policy abides by a debt-target rule ${ }^{20}$

$$
\log \left(\frac{\tau_{t}}{\bar{\tau}}\right)=\rho_{\tau} \log \left(\frac{\tau_{t-1}}{\bar{\tau}}\right)+\gamma_{\tau} \log \left(\frac{B_{t-1}}{\bar{B}} \frac{\bar{Y}}{Y_{t-1}}\right)
$$

where $\left|\rho_{\tau}\right|<1 ; \gamma_{\tau}>0$ is a policy parameter that measures the sensitivity of tax rates to the debt level at the previous period - the higher its value, the more passive fiscal policy should be.

From the government budget constraint holding with equality in equilibrium, we get the law of movement of real debt at the end of period $t$.

$$
B_{t}=\left(1+i_{t}\right)\left(\left(1-\delta_{t}\right) \frac{B_{t-1}}{\Pi_{t}}+G_{t}+Z_{t}-T_{t}\right)
$$

\subsection{5}

\section{Defaultable bonds}

Here, we extend the work of Duffie and Singleton (1999) on defaultable bonds to our economy. We define the net interest rate demanded in equilibrium for holding government bonds that carry default risk, the net risky interest rate, as follows.

Definition 2.1 A net risky interest rate, $i_{t}$, is a net nominal interest rate that in a market under no-arbitrage hypothesis satisfies the identity:

$$
\begin{gathered}
\mathbb{E}_{t}^{Q}\left(1+i_{t}\right)=\left[\left(1-\mathbb{E}_{t}^{Q} \mathcal{D}_{t+1}\right)\left(1+i_{t}\right)+\mathbb{E}_{t}^{Q} \mathcal{D}_{t+1}\left(1+i_{t}\right)\left(1-\delta_{t+1}\right)\right]= \\
\left(1-\mathbb{E}_{t}^{Q} \mathcal{D}_{t+1} \delta_{t+1}\right)\left(1+i_{t}\right)
\end{gathered}
$$

where $\mathbb{E}_{t}^{Q}$ is expectations under a risk-neutral probability measure $Q, i_{t}$ is the net interest rate in case of non-default; $\mathcal{D}_{t+1}$ is the probability that the risky asset will default at maturity; and $\delta_{t+1}$ is the haircut in case of default.

procyclicality at the state level in Brazil, as Sturzenegger and Werneck (2006) and Arena and Revilla (2009) point out.

${ }^{19}$ Having already defined all the required terms, the firm-specific production function can be cast in terms of its labor demand, its autoregressive components, and the shocks as follows: $Y_{k, t}=\bar{A} \bar{K}\left[\left(\frac{A_{t-1}}{\bar{A}}\right)^{\rho_{A}}\left(\frac{G_{t-1}}{\bar{G}}\right)^{\rho_{G G} \gamma_{G \Psi}}\left(\frac{Y_{t-1}}{\bar{Y}}\right)^{\rho_{G Y} \gamma_{G \Psi}}\right]\left[e^{\sigma^{A} \varepsilon_{t}^{A}+\gamma_{G \Psi} \sigma_{G} \varepsilon_{t}^{G}-\mathbb{1}_{B_{t-1}}>\mathcal{B}_{t} \delta^{\mathrm{TFP}}}\right] N_{k, t}$.

${ }^{20} \mathrm{We}$ deviate a little from the literature on fiscal limits (i.e. Bi (2012) Bi, Shen and Yang (2016) and Bi, Leeper and Leith (2018)) in the sense that we maintain the tax rate dependence on $B_{t-1}$ even in the event of a default, instead of replacing it by the effectively repaid debt at that period. We are not aware of systematic empirical evidence that governments reduce taxes at the same period that they default. For instance, in the Collor Plan, a new tax on financial operations (IOF) was introduced, taxes were linked to inflation, and the prices of some public services were raised. 
In our model, assuming no arbitrage opportunities, and then applying the definition of net risky interest rate (2.1), we have that

$$
\left(1+i_{t}^{R F}\right)=\mathbb{E}_{t}^{Q}\left(1+i_{t}\right)=\operatorname{Pr}^{Q}\left(B_{t} \leq \mathcal{B}_{t+1}\right)\left(1+i_{t}\right)+\operatorname{Pr}^{Q}\left(B_{t}>\mathcal{B}_{t+1}\right)\left[\left(1-\delta_{t+1}\right)\left(1+i_{t}\right)\right]
$$

where $i_{t}^{R F}$ is the net risk-free nominal interest rate, $\operatorname{Pr}^{Q}(X)$ represents the risk-neutral probability that the event $X$ will happen. Moreover, we can define $\mathcal{D}_{t+1} \equiv \mathbb{1}_{\left(B_{t}>\mathcal{B}_{t+1}\right)}$. With these definitions, we can rewrite (2-30),

$\mathbb{E}_{t}^{Q}\left(1+i_{t}\right)=\left(1-\mathbb{E}_{t}^{Q} \mathcal{D}_{t+1} \delta_{t+1}\right)\left(1+i_{t}\right) \quad \Rightarrow \quad \Phi_{t} \equiv \frac{1}{\left(1-\mathbb{E}_{t}^{Q} \mathcal{D}_{t+1} \delta_{t+1}\right)}=\frac{\left(1+i_{t}\right)}{\mathbb{E}_{t}^{Q}\left(1+i_{t}\right)}$

where $\Phi_{t}$ is the time-varying gross default premium demanded for holding the risky government bond, or, equivalently, the greatest premium the Ricardian agent is willing to pay at period $t$ to avoid default risk.

\subsection{6 \\ Monetary policy}

The central bank targets the gross inflation $\bar{\Pi}$, abiding by a nominal interest rate rule (2-32), which it implements through open-market operations with government risky bonds. All rules react to current period inflation deviation from the target with coefficient $\phi^{\pi}$, and to output deviation from the steady state with coefficient $\phi^{Y}$, in addition to a monetary shock process, $\mathcal{M}_{t}$. We also allow the central bank to smooth out the interest rate trajectory by adding a 1-period lag component with coefficient $\phi^{i}$. Finally, what distinguishes each rule is the choice for a different stochastic process for the time-varying intercept, $\bar{\iota}_{t} \cdot{ }^{21}$

$$
i_{t}=\left(1+i_{t-1}\right)^{\phi^{i}}\left(\left(1+\bar{\iota}_{t}\right) \bar{\Pi}\left(\frac{\Pi_{t}}{\bar{\Pi}}\right)^{\phi^{\pi}}\left(\frac{Y_{t}}{\bar{Y}}\right)^{\phi^{Y}}\right)^{1-\phi^{i}} e^{\mathcal{M}_{t}}-1
$$

where the monetary shock process, $\mathcal{M}_{t}$, is given by

$$
\mathcal{M}_{t}=\rho_{M} \mathcal{M}_{t-1}+\sigma_{M} \varepsilon_{t}^{M}
$$

${ }^{21}$ Woodford (2001) discusses the optimality of interest rate rules with time-varying intercepts which closely track the real natural interest rate for the sake of consistency with an equilibrium where both the inflation rate and the output gap are stable. These last two variables show up in the microfounded loss function derived from a simple New-Keynesian model - the variance of inflation is a proxy for the variance of output dispersion across individual firms whereas the output gap represents the deviation of aggregate output from its efficient level. 
such that $\rho_{M} \in[0,1)$ is a parameter that controls the persistence of the shocks; $\sigma_{M}$ is their standard deviation; and $\varepsilon_{t}^{M}$ is i.i.d. $\mathcal{N}(0,1)$.

When the policy rule is implemented with risk-free assets and the central bank targets a risk-free rate (the canonical case), the rule that always hits the inflation target is the one whose intercept always tracks $r_{t}^{R F}$, without smoothing, and no monetary shock. As we assume in this model that policy assets are defaultable, the central bank must, then, also neutralize the evolution of the default premium over the $r_{t}^{R F}$ to achieve the same result. To understand how operating monetary policy with risky assets compares to the canonical case, it is helpful to start from the static case. After substituting the optimal intercept into the interest rate rule (2-32), and evaluating it at the deterministic steady state, we obtain the monetary policy rule at that point, which can be decomposed as in equation (2-34), where $\overline{r^{n}}$ is the natural interest rate at the steady state, whose value is the same of the risk-free real interest rate at the steady state, and $\bar{\Phi} \approx-\log (1-\bar{\delta})$ is the steady-state gross default premium demanded on the policy asset.

$$
\bar{i}=\frac{1}{\beta(1-\bar{\delta})} \bar{\Pi}-1=\left(1+\overline{r^{n}}+\bar{\Phi}\right) \bar{\Pi}-1
$$

Note how the existence of policy-default risk adds a policy-default premium to the natural interest rate. Therefore, compared to managing monetary policy with risk-free assets, resorting to risky ones instead results in higher nominal policy rates at the steady state. Later, we will show how simulating default risk can amplify this effect far beyond its deterministic steady-state value.

In the presence of other financial assets in the market, such as government bonds, but not only, the expectations channel shall discipline the interest rate of such assets as well, while at the same time they may be more informative of monetary conditions than an overnight rate available to, perhaps, only some selected agents. Kulish (2007) remembers us that the expectations channel works in both directions, and shows that a central bank that operates and targets the interest rate of long-term assets is still able to bring inflation to the target, as long as it follows an approximate version of the Taylor principle. The reasoning here is similar. Under the no-arbitrage assumption, the expectations channel operates through time but also through the safety dimension of the assets, allowing the $\mathrm{CB}$ to bring inflation to the target by operating or targeting a risky asset, as long as it adequately adjusts its policy rule to that fact. Assuming that the policy asset is a defaultable government bond or that the CB implicitly operates safe overnight deposits (not modeled) but adopts an explicit interest rate rule for defaultable government bonds end up being the same here, for we do not explicitly model the balance sheet of 
the $\mathrm{CB}$, following the tradition of the canonical New-Keynesian model. We present, now, our two monetary policy rules, characterized each by a different process for the intercept, $\left\{\bar{t}_{t}\right\}$. Later in the paper, we will allow the natural real rate to be in the intercept, approximating our rules to those in the literature and in actual policy-making.

\section{Rule 1: Risky policy asset, but the CB ignores default-risk dynamics}

The policy asset is a defaultable government bond, but the $\mathrm{CB}$ ignores the dynamics of that risk. It assumes that the mean level of the default premium is part of the real natural interest rate. Not a far-fetched assumption, we believe, since such a rate is non-observable in the real world due to the prevalence of sticky prices. Remember, the reader, that being right about the mean also means being right about interest rates at the deterministic steady state.

$$
\bar{\iota}_{t}=r_{t}^{R F}+\bar{\Phi}
$$

\section{Rule 2: Risky policy asset, and the CB perfectly tracks default-risk dynamics}

The policy asset is a defaultable government bond, and the CB adjusts the intercept of the policy rule to neutralize the dynamics of that risk. It knows that the default premium is not part of the real natural interest rate. This rule may be too much to ask from central banks, since it requires loads of informational content quite challenging to observe: the default-risk premium and the risk-free real interest rate.

$$
\bar{\iota}_{t}=r_{t}^{R F}+\Phi_{t}
$$

To explain how adjusting the intercept works, we turn off the monetary shock in the model, in addition to setting $\phi^{Y}=0$ and $\phi^{i}=0$. Then, we plot in Figure 2.2 the simulated transition from a set-up in which $\overline{\mathcal{D}} \approx 0 \%$ (left panels) to a set-up in which $\overline{\mathcal{D}}=5 \%$ (second column of panels), considering that the net inflation target, $\bar{\pi}$, is calibrated to $4.5 \%$ (annualized). In this transition, we do not fix the wedge of risk premium, $\bar{\Phi}$, that emerges at the deterministic steady state when the policy asset is risky. The ergodic mean of inflation leaves the (degenerated) inflation target and reaches $5.1 \%$ at the same time that a negative output gap, defined as $Y_{t}^{\text {Gap }} \equiv \frac{Y_{t}-Y_{t}^{n}}{Y_{t}^{n}}$, where $Y_{t}^{n}$ is the flexible-price output, emerges. Now, inflation is spread over a long range, since the intercept is not able to accommodate the effect of remaining stochastic shocks on the 
evolution of the default premium. In the third column of panels, we fix the wedge at the deterministic steady state as defined in Rule 1 . Inflation gets closer to the target, but it is still far from it as the dynamics of default risk are not compensated. This is the adequate fix from a deterministic perspective, since if we turn off the shocks and the risk of regime transition, it would successfully set inflation on the target. The output gap turns a bit more negative, but its relation with inflation is rule-dependent. In the last panel, we assume that the central bank, now, tracks the default-risk premium, $\Phi_{t}$, as defined in Rule 2 . Note that inflation is degenerated at its target while the output gap is zero once again. In this case, monetary shock is the only shock capable of introducing volatility to inflation (and to the output gap). To sum up, the nuts and bolts of our model do not preclude the existence of a divine coincidence - a term coined by Blanchard and Galí (2007) - as there is no trade-off between the stabilization of inflation and the stabilization of the welfare-relevant output gap.

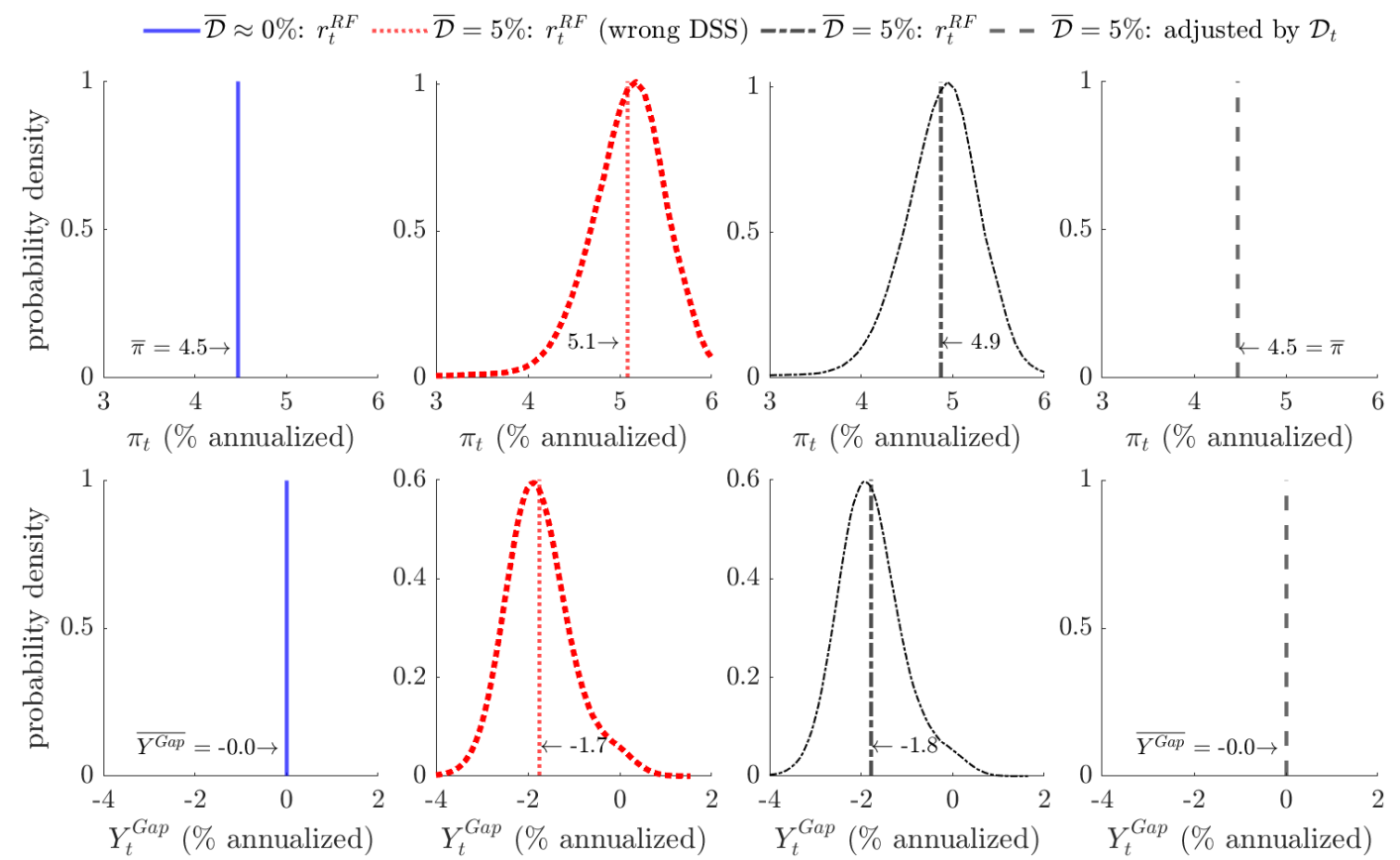

Figure 2.2: Inflation targeting with risky assets

\subsection{7 \\ Equilibrium}

As we have seen, the policy asset in this economy may actually be a government bond in whose market the central bank intervenes with deep pockets. Nevertheless, bonds are priced by the stochastic discount factor of the Ricardian household, making the latter indifferent about holding them, so we impose that in equilibrium all bonds issued by the government are sold to 
her.

$$
B_{t}^{\text {demand }}=B_{t}^{\text {supply }} \quad \forall t
$$

It is important to note that the Ricardian agent incorporates into her expectations the fact that her and only her will have to save enough to hold all the government's debt in her portfolio. This is an equilibrium selection that, although common in models with fiscal policy, it excludes the possibility that the Ricardian agent refuses to finance the government as long as the debt level to be repaid at the current period is lower or equal to the current draw of the stochastic fiscal limit (described in section 2.3.9). In case it is not, default happens, what can be understood as either the refusal of the private agents in financing the government, or the refusal of the government to repay its debt, or both. In our specific model, it also excludes the possibility that Ricardian agents behave like non-Ricardian ones even if that behavior would improve their welfare.

The real asset, by its turn, is a private asset available in zero-net-supply and as such its market-clearing condition demands that the net position of the representative Ricardian household on that asset always equals zero by construction.

$$
\mathcal{A}_{t}=0 \quad \forall t
$$

Now, after imposing previous market-clearing conditions, we aggregate the budget constraint of the households (2-3) with the budget constraint of the government (2-26) and the dividends definition (2-24), and then evaluate the resulting constraint in equilibrium to obtain the resources constraint of our economy

$$
Y_{t}=C_{t}+G_{t}+\frac{\phi^{C}}{2}\left(\frac{\Pi_{t}}{\bar{\Pi}}-1\right)^{2} Y_{t}
$$

We have all set to define the recursive competitive equilibrium of this economy.

Definition 2.2 (Equilibrium) A recursive competitive equilibrium of this economy is an initial distribution of $\left\{B_{i, 0}\right\}$ across individual households indexed by $i \in[0,1]$, a set of exogenous processes $\{A, G\}$, a set of prices $\left\{r, \frac{W}{P}, P\right\}$, a set of policy functions for individual households $\left\{C_{i}, N_{i}, B_{i}\right\}$, a factor demand policy for individual intermediate firms $\left\{N_{k}\right\}$ indexed by $k \in[0,1]$, budget-feasible government policies $\{B, \tau, Z, \delta\}$, stochastic fiscal limits $\{\mathcal{B}\}$, and a monetary policy rule $\{i\}$ such that the following conditions hold:

(a) Aggregation: $Y_{t}=\int_{0}^{1} Y_{i, t} d i$ and $C_{t}=\int_{0}^{1} C_{i, t} d i$ in all t, washing out idiosyncratic uncertainty;

(b) Optimality for the households: solves the representative Ricardian household's optimization problem, and the representative non-Ricardian household's budget constraint is satisfied with equality; 
(c) Optimality for intermediate firms: solves the representative intermediate firm's optimization problem;

(d) Optimality for final-sector firms: solves the representative final-sector firm's optimization problem;

(e) Labor-market clearing: $N_{t}=\int_{0}^{1} N_{i, t}$ di in all $t$;

(f) Asset-market clearing: $B_{t}^{\text {demand }}=\int_{0}^{1} B_{i, t} d i=B_{t}^{\text {supply }}$ in all $t$;

(g) Government's budget constraint is satisfied in all $t$;

(h) Good-market clearing: $Y_{t}=C_{t}+G_{t}+\frac{\phi^{C}}{2}\left(\frac{\Pi_{t}}{\bar{\Pi}}-1\right)^{2} Y_{t}$ in all $t$.

\subsection{8}

\section{Solution $1^{\text {st }}$ step: the model as a single regime with flexible prices}

Our solution strategy is composed of three steps. In this first step, we assume that prices are flexible and solve the model as a function of $\tau_{t}$ and $\delta_{t}$, the variables directly related to the two nonlinearities in our model, caused by, respectively, the peak of the Laffer curve and the fiscal limit. In the second step, we will describe how the fiscal limit can be reached and how the default probability is calculated from the solution derived in the first step. For such a calculation, we follow $\mathrm{Bi}$, Leeper and Leith (2018), and assume that the central bank always keeps inflation at the target, what eliminates the effect of sticky prices and of explicit monetary policy, warranting the flexible-price solution derived in the first step. Finally, in the third and last step of the algorithm, we segregate the nonlinearities as different regimes of a regimeswitching model, where in each regime the sticky-price version of the model is solved after linearization.

Now, we proceed imposing flexible prices, what turns our economy temporarily into a RBC (real business cycle) model. We can obtain a closed expression for the labor quantity in equilibrium by equating the labor supply (2-8) with the CPO of the firm (2-23) through eliminating real wages, $\frac{W_{t}}{P_{t}}$, after replacing the expression for the marginal cost (2-21).

$$
N_{t}=\left(\frac{(\theta-1)}{\theta} \frac{\left(1-\tau_{t}\right)}{\eta} \bar{K}\left(\frac{G_{t}}{\bar{G}}\right)^{\gamma_{G \Psi}} A_{t}\right)^{\frac{1}{\chi}}
$$

Real wage in equilibrium is straightforward and given by the CPO of the firm (2-23), after replacing the expression for the marginal cost (2-21). Turning to the output in equilibrium, we can obtain it by substituting the labor quantity in equilibrium (2-40) into the production function (2-19):

$$
Y_{t}=\left(\frac{(\theta-1)}{\theta} \frac{\left(1-\tau_{t}\right)}{\eta}\right)^{\frac{1}{\chi}}\left(\bar{K}\left(\frac{G_{t}}{\bar{G}}\right)^{\gamma_{G \Psi}} A_{t}\right)^{1+\frac{1}{\chi}}
$$


Aggregate households' consumption of private goods in equilibrium can, now, be obtained by inserting (2-19) into the resources constraint:

$$
C_{t}=\left(\frac{(\theta-1)}{\theta} \frac{\left(1-\tau_{t}\right)}{\eta}\right)^{\frac{1}{\chi}}\left(\bar{K}\left(\frac{G_{t}}{\bar{G}}\right)^{\gamma_{G \Psi}} A_{t}\right)^{1+\frac{1}{\chi}}-G_{t}
$$

For obtaining the consumption in equilibrium of each type of household, we proceed as follows. The non-Ricardian household consumes all its income, so her consumption comes directly from her budget constraint.

$$
C_{t}^{N R}=\left(\frac{(\theta-1)}{\theta} \frac{1}{\eta}\right)^{\frac{1}{\chi}}\left(\left(1-\tau_{t}\right) \bar{K}\left(\frac{G_{t}}{\bar{G}}\right)^{\gamma_{G \Psi}} A_{t}\right)^{1+\frac{1}{\chi}}+\bar{Z}
$$

The Ricardian type, by her turn, will consume what is left from the aggregate consumption after subtracting the consumption of the non-Ricardian type.

$$
\begin{aligned}
C_{t}^{R} & =\frac{1}{1-\gamma^{N R}}\left[\left(\frac{(\theta-1)}{\theta} \frac{\left(1-\tau_{t}\right)}{\eta}\right)^{\frac{1}{\chi}}\left(\bar{K}\left(\frac{G_{t}}{\bar{G}}\right)^{\gamma_{G \Psi}} A_{t}\right)^{1+\frac{1}{\chi}}-G_{t}\right. \\
& \left.-\gamma^{N R}\left(\left(\frac{(\theta-1)}{\theta} \frac{1}{\eta}\right)^{\frac{1}{\chi}}\left(\left(1-\tau_{t}\right) \bar{K}\left(\frac{G_{t}}{\bar{G}}\right)^{\gamma_{G \Psi}} A_{t}\right)^{1+\frac{1}{\chi}}+\bar{Z}\right)\right]
\end{aligned}
$$

Next, total government revenue in equilibrium is obtained by substituting the equilibrium expressions for $N_{t}, \frac{W_{t}}{P_{t}}$, and $D_{t}$ into the definition of real taxes.

$$
T_{t}=\tau_{t}\left(\frac{(\theta-1)}{\theta} \frac{\left(1-\tau_{t}\right)}{\eta}\right)^{\frac{1}{\chi}}\left(\bar{K}\left(\frac{G_{t}}{\bar{G}}\right)^{\gamma_{G \Psi}} A_{t}\right)^{1+\frac{1}{\chi}}
$$

Finally, we can obtain an expression for the real natural interest rate as a function of the state vector and of the tax rate policy rule. We proceed by inserting the Ricardian consumption and the labor expressions, both in equilibrium, into the real bond Euler of the Ricardian household (2-9) ${ }^{22}$

$r_{t}^{n}=-1+\frac{1}{\beta} \mathbb{E}_{t}\left[\left(\frac{C_{t+1}^{R}\left(A_{t+1}, G_{t+1}\right)+\alpha_{G} G_{t+1}-\frac{\eta}{1+\chi}\left(\frac{(\theta-1)}{\theta} \frac{\left(1-\tau_{t+1}\right)}{\eta} \bar{K}\left(\frac{G_{t+1}}{\bar{G}}\right)^{\gamma_{G \Psi}} A_{t+1}\right)^{\frac{1+\chi}{\chi}}}{C_{t}^{R}\left(A_{t}, G_{t}\right)+\alpha_{G} G_{t}-\frac{\eta}{1+\chi}\left(\frac{(\theta-1)}{\theta} \frac{\left(1-\tau_{t}\right)}{\eta} \bar{K}\left(\frac{G_{t}}{\bar{G}}\right)^{\gamma_{G \Psi}} A_{t}\right)^{\frac{1+\chi}{\chi}}}\right]\right.$

Moreover, we can obtain the policy asset real interest rate, $r_{t}$ in equilibrium, by substituting the market-clearing condition into the Euler of the Ricardian household and then substituting the latter into the Fisher equation. We derive here the more general case, when the policy asset is defaultable and the recovery rate in case of default is allowed to be different from zero. In case the policy asset were risk-free, one would just have to set $\mathbb{E}_{t} \mathcal{D}_{t+1}=0 \forall t$.

${ }^{22}$ We keep $C^{R}$ explicit to avoid cluttering the equation. 


$$
\begin{array}{r}
r_{t}=-1+\frac{1}{\beta} \mathbb{E}_{t}\left[\left[1-\mathcal{D}_{t+1} \bar{\delta}\right]^{-1}\right. \\
\left(\frac{C_{t+1}^{R}\left(A_{t+1}, G_{t+1}\right)+\alpha_{G} G_{t+1}-\frac{\eta}{1+\chi}\left(\frac{(\theta-1)}{\theta} \frac{\left(1-\tau_{t+1}\right)}{\eta} \bar{K}\left(\frac{G_{t+1}}{\bar{G}}\right)^{\gamma_{G \Psi}} A_{t+1}\right)^{\frac{1+\chi}{\chi}}}{C_{t}^{R}\left(A_{t}, G_{t}\right)+\alpha_{G} G_{t}-\frac{\eta}{1+\chi}\left(\frac{(\theta-1)}{\theta} \frac{\left(1-\tau_{t}\right)}{\eta} \bar{K}\left(\frac{G_{t}}{\bar{G}}\right)^{\gamma_{G \Psi}} A_{t}\right)^{\frac{1+\chi}{\chi}}}\right]
\end{array}
$$

The natural interest rate depends on the fiscal policy, as well as on the technological growth. In addition to that, the government default risk will indirectly interact with $r_{t}^{n}$ through its effect on the evolution of indebtedness, which by its turn will affect $\tau_{t}$ under the fiscal policy rule adopted. As a consequence, monetary policy is affected by the risk of default even when it is operated with risk-free assets. Additionally, what it comes to $r_{t}$, it is clear that the expected haircut on the debt, $\mathbb{E}_{t} \delta_{t+1}$, introduces a wedge over the real natural interest rate compared to when it is nil. Overall, the policy asset real interest rate will be greater than the real natural one whenever there is the perception of default risk $\left(\mathbb{E}_{t} \delta_{t+1}>0\right)$, and the difference between both rates is a default premium.

\subsection{9}

\section{Solution $2^{\text {nd }}$ step: fiscal limits and default probability}

Having solved the model as a function of $\tau_{t}$ and $\delta_{t}$ in the previous step, we are ready to describe how the fiscal limits and the default probability interact in the model.

At the beginning of every period, an effective fiscal limit $\mathcal{B}$ is drawn from the fiscal limit distribution $\mathcal{B}^{*}\left(\overline{\mathcal{B}}, \sigma_{\mathcal{B}}^{2}\right)$, where $\overline{\mathcal{B}}$ is its mean and $\sigma_{\mathcal{B}}$ its standard deviation, and compared to the real debt maturing at that same period, $B_{t-1}$. If the effective fiscal limit is greater than or equal to the debt level, the government repays the debt in its entirety, so that $\delta_{t}=0$. Otherwise, it defaults on a fraction of the outstanding debt, so that $\delta_{t}=\bar{\delta}$.

$$
\delta_{t}=\left\{\begin{array}{lll}
\bar{\delta} \in(0,1] & \text { if } \quad & B_{t-1}>\mathcal{B}_{t} \\
0 & \text { if } \quad & B_{t-1} \leq \mathcal{B}_{t}
\end{array}\right.
$$

The fiscal limit adopted here is the private sector's perception of that limit as in Bi (2012), but adapted to the state vector of our model, ${ }^{23}$ and under

${ }^{23} \mathrm{Bi}(2012)$ specifies a Markov-switching process for transfers $Z_{t}$, and estimates $\delta_{t}$ using the empirical distribution of actual default rates - defined as the product of the ratio of defaulted debt to total debt by the haircut on the defaulted debt - of emerging economies from 1998 to 2005 as compiled by Sturzenegger and Zettelmeyer (2008). Bi, Leeper and Leith (2018), who also adopt the fiscal limit approach, include an additional political discount that follows a Markov-switching process aiming to shift the distribution of the fiscal limit 
the assumption that the central bank maintains inflation at the target at all times, like in Bi, Leeper and Leith (2018). ${ }^{24}$ There are at least two features in favor of that approach against the strategic default framework of Eaton and Gersovitz (1981) and Arellano (2008). First, it makes explicit that debt ratios are not the only factor that affects the private perception of a country's default probability. Present and expected future fiscal policies matter as well as growth prospects, what makes this feature aligned to the empirical fact that sovereign spreads and credit ratings are not linear univariate functions of debt ratios. ${ }^{25}$ Second, more than strategic from the point-of-view of a benevolent government, the default decision carries an erratic political component, which goes in favor of modeling it as a stochastic event. ${ }^{26}$ Motivated by that, the effective fiscal limit $\mathcal{B}$ of our economy is drawn from the distribution (2-49).

$$
\mathcal{B}^{*}\left(A_{t}, G_{t}\right) \sim \sum_{t=0}^{\infty} \underbrace{\beta^{t} \frac{U_{c}^{\max }\left(A_{t}, G_{t}\right)}{U_{c}^{\max }\left(A_{0}, G_{0}\right)}}_{\begin{array}{c}
\text { stochastic discount factor } \\
\text { at the peak of the Laffer curve }
\end{array}} \underbrace{\left(T^{\max }\left(A_{t}, G_{t}\right)-G_{t}-Z_{t}\right)}_{\text {primary balance }}
$$

Note that the fiscal limit is the sum of all expected primary balances from today into the future discounted at the peak of the Laffer curve. That specific point, $\left(\tau_{t}^{\max }, T_{t}^{\max }\right)$, gives us the tax rate that maximizes tax revenue, $\tau_{t}^{\max }\left(A_{t}, G_{t}\right)$, and the maximum revenue that the government can raise, $T_{t}^{\max }\left(A_{t}, G_{t}\right)$. The Laffer curve combined with the fiscal rule imply that if government expenses or transfers exhibit an upward trend, they will eventually push the tax rate to reach $\tau_{t}^{\max }$. This is an example of how the default probability increases under the fiscal limit mechanism. The specification of our model, with its structural parameters and exogenous processes, guarantees a unique mapping between the state vector and the peak of the Laffer curve.

To obtain an expression for $\tau_{t}^{\max }$, we derive the tax revenue in equilibrium, $T_{t}$, with respect to $\tau_{t}^{\max }$

to the left and increase its standard-deviation along the debt-to-output axis, so as to match empirical moments of risk premium. We abstract from both features since they are not necessary to our model.

${ }^{24}$ Battistini, Callegari and Zavalloni (2019) turn the fiscal limits endogenous to monetary policy by solving their sticky-price model through numerical methods, since with nominal rigidity there is no analytical solution.

${ }^{25}$ The literature on the determinants of sovereign spreads (in foreign or local-currencydenominated bonds) is as old as at least Edwards (1986). Overall, it finds that determinants can be hardly generalized as each country spread seems to be sensitive to a different set of variables in each time period.

${ }^{26}$ Schabert and Van Wijnbergen (2014) make the case that Bayesian strategies like this one are optimal in some policy game set ups, for which Pastine (2002) is an analogous example of how introducing uncertainty into the central bank decision of when to abandon a fixed-exchange rate can avoid otherwise predictable speculative attacks. 


$$
\begin{array}{r}
T_{t}=\tau_{t}\left(\frac{W_{t}}{P_{t}} N_{t}+D_{t}\right)=\tau_{t}\left(\frac{(\theta-1)}{\theta} \frac{\left(1-\tau_{t}\right)}{\eta}\right)^{\frac{1}{\chi}}\left(\bar{K}\left(\frac{G_{t}}{\bar{G}}\right)^{\gamma_{G \Psi}} A_{t}\right)^{1+\frac{1}{\chi}} \\
\frac{\partial T_{t}}{\partial \tau_{t}}=\left[\left(\frac{(\theta-1)}{\theta} \frac{\left(1-\tau_{t}\right)}{\eta}\right)^{\frac{1}{\chi}}-\frac{(\theta-1)}{\theta} \frac{1}{\eta} \frac{1}{\chi} \tau_{t}\left(\frac{(\theta-1)}{\theta} \frac{\left(1-\tau_{t}\right)}{\eta}\right)^{\frac{1}{\chi}-1}\right]=0 \\
\tau_{t}^{\max }=\frac{\chi}{1+\chi}
\end{array}
$$

Therefore, in our model, a government willing to maximize its revenue will always set $\tau_{t}=\frac{\chi}{1+\chi}$, a result that is independent of the state of the economy. The maximum tax revenue, on the contrary, does depend on the state of the economy.

$$
T_{t}^{\max }\left(A_{t}, G_{t}\right)=\frac{\chi}{1+\chi}\left(\frac{(\theta-1)}{\theta} \frac{\left(1-\frac{\chi}{1+\chi}\right)}{\eta}\right)^{\frac{1}{\chi}}\left(\bar{K}\left(\frac{G_{t}}{\bar{G}}\right)^{\gamma_{G \Psi}} A_{t}\right)^{1+\frac{1}{\chi}}
$$

To give the reader a glimpse of our model's Laffer curve, in Figure 2.3, we plot the tax revenue against the tax rate for three different values of $\chi$ $(0.50,0.75,1.00)$ and different values for $\eta$ and $A_{t}$. Additionally, for the only purpose of this exercise, $\bar{K}$ is calibrated to 1.0 , whereas $\theta \rightarrow \infty$ as in perfect competition, and we set $G_{t}=\bar{G}$. Vertical-dotted lines cross at the maximum revenue for the Laffer curve with the same color. It is possible to see on all panels that the higher is the Frisch elasticity of labor $\left(\frac{1}{\chi}\right)$, the lower is the maximum capacity of the government to tax this economy. At the same time, comparing the left panel with the middle one, a lower disutility of labor, $\eta$, incentivizes work and increases the maximum tax revenue. Finally, comparing the left panel with the right one, lower productivity shrinks fiscal capacity.
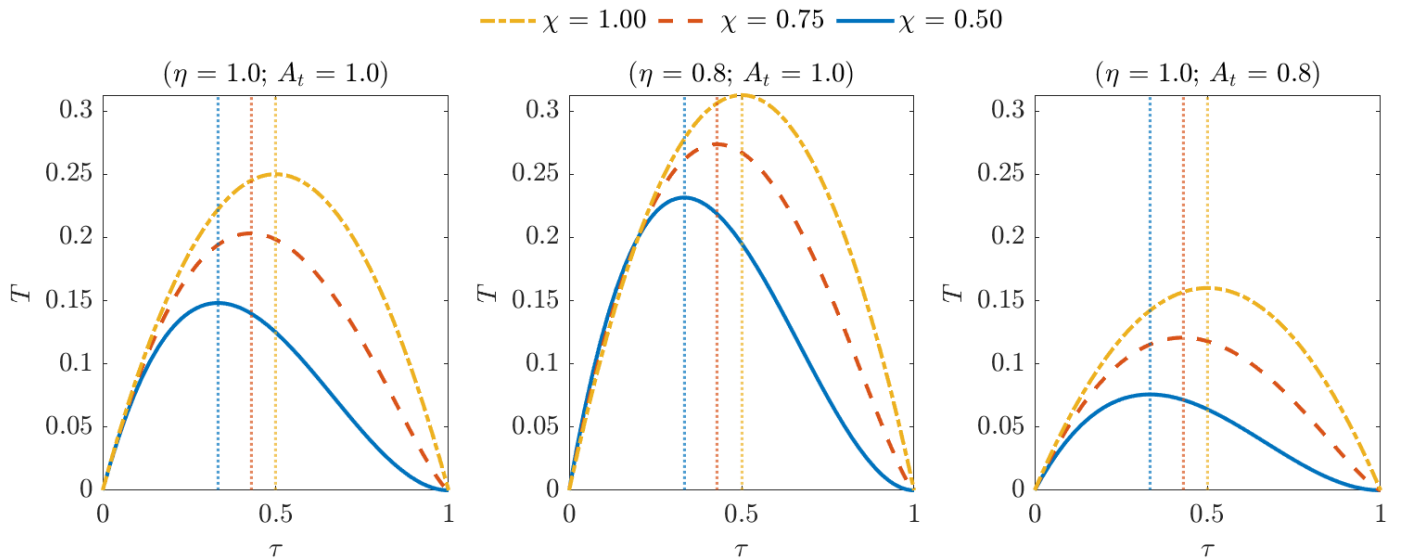

Note: vertical-dotted lines cross at the maximum of each curve with the same color.

Figure 2.3: Stylized Laffer curves

As there is a unique mapping between the state vector and $\tau_{t}^{\max }$ as well 
as between the state vector and $T_{t}^{\max }$, it is possible to obtain the distribution of the fiscal limit, $\mathcal{B}_{t}^{*}$, as a function of the state vector through Monte Carlo simulation. Moreover, by comparing such a distribution with the level of debt at the end of any period, we can calculate the conditional default probability, $\operatorname{Pr}\left(B_{t}>\mathcal{B}_{t+1}\right)_{t}$, at any horizon into the future.

\subsubsection{0}

\section{Solution $3^{\text {rd }}$ step: regime switching with endogenous probabilities}

In this last step of our solution algorithm, the model is solved using the endogenous regime-switching method described in Maih (2015). ${ }^{27}$ This approach is warranted by the fact that our model contains two nonlinearities, namely, taxing at the peak of the Laffer curve and defaulting on government debt when the fiscal limit is endogenously reached.

The constraint at the peak of the Laffer curve is straightforward. Whenever the prescribed unrestricted tax rule for $\tau_{t}$, (2-28), should exceed $\tau_{t}^{\max }$, we impose that $\tau_{t}=\tau_{t}^{\max }$, like an occasionally-binding constraint. ${ }^{28}$ As the transition probability for the next period must be set at the end of the period before, we pose a shadow tax rate, $\tau_{t}^{\text {sdw }}$, which anticipates what would be the unrestricted tax rate in the next period were not for the tax constraint. This is the object that will be compared to the rate at the peak of the Laffer curve to define whether the binding probability in the next period is either 1 or $0 .^{29}$ In Figure 2.4, we show an example of situation in which this constraint is binding extracted from a random simulation of the model at the benchmark calibration of section 2.4.1. Note that the accumulation of debt is matched by successive hikes of the tax rate until the latter reaches the rate that maximizes the government revenue. In the example, debt starts reducing after some time along with the next-period default probability, allowing for the easing of the tax rate.

${ }^{27}$ We use the Matlab toolbox RISE (Rationality In Switching Environments) developed by Junior Maih, to whom we thank immensely for the generosity of making it available and free of charge.

${ }^{28}$ We simplify here by setting $\tau_{t}^{\max }$ to its flexible-price value at all periods, as in equation $(2-50)$.

${ }^{29}$ Our modeling device allows for the peak of the Laffer curve to be actually breached after an unexpectedly dire sequence of shocks, but when that happens, in reason of the slow-moving nature of the tax policy rule and the binding constraint, the tax rate will hover around the peak until recede as it faces an "occasionally binding resistance". This kind of mechanism can be seen as is in the same family of other threshold-type mechanisms such as the ones present in Davig et al. (2006) and Chang, Maih and Tan (2019). For more examples of how to model occasionally binding constraints as regime switches with RISE, check Binning and Maih (2017). 

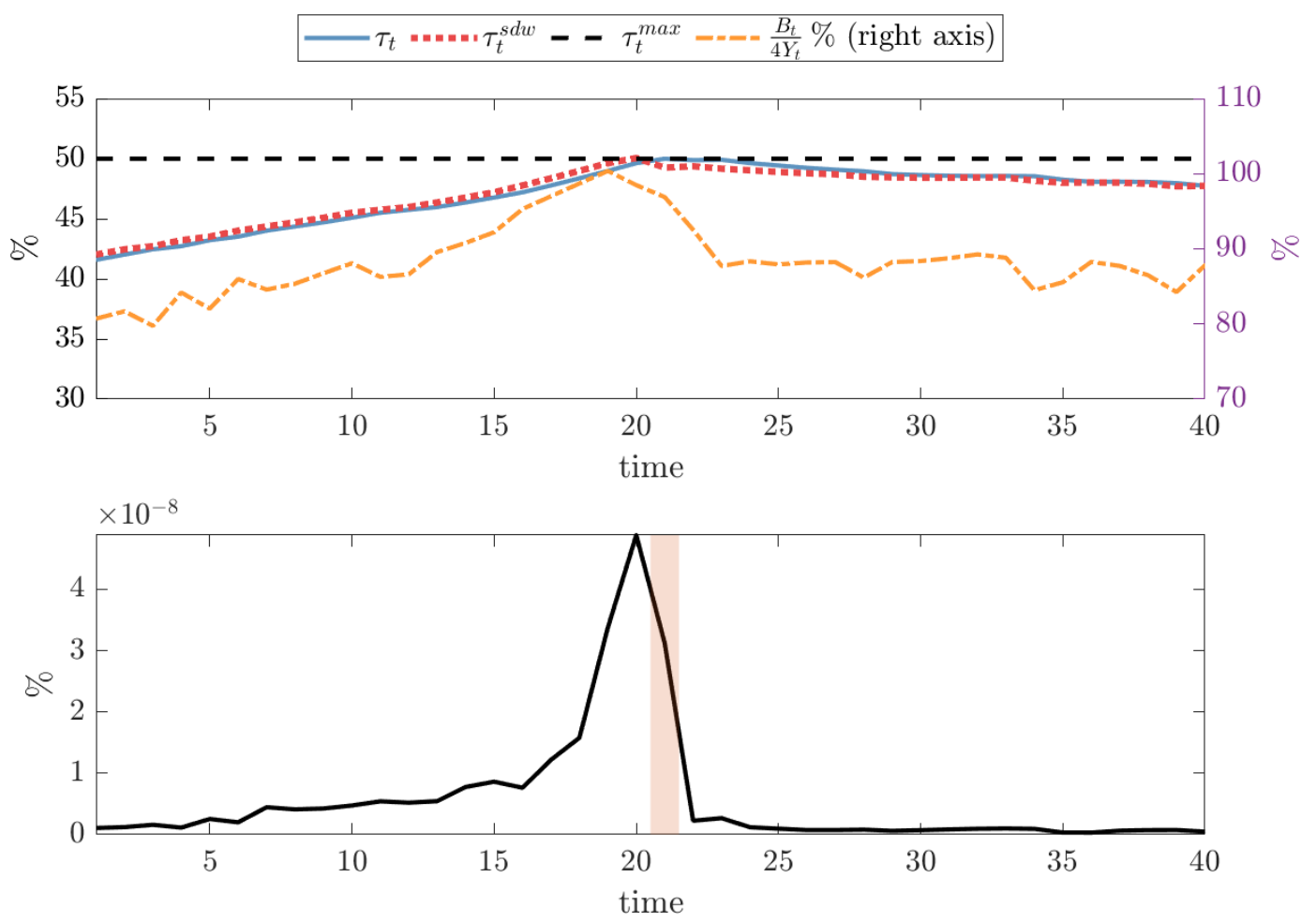

\begin{tabular}{|llll|}
\hline - Prob. of default binding & Regime 2 & Regime 3 & Regime 4 \\
\hline
\end{tabular}

Note: prob. of default binding refers to default happening the next period. No filling in the bottom graph indicates Regime 1.

Figure 2.4: Example of peak of the Laffer curve binding in the simulated model

The fiscal limit constraint, by its turn, is imposed through an approximation. We regress separately the distributions for the mean and for the standard deviation of the fiscal limits, both obtained in the second step of the solution, on their respective state-vector deviations from the steady state. Note that the state variables that the fiscal limit depends on have the same steady-state value across all regimes. By proceeding this way, we obtain one reduced form equation for the mean and one for the standard deviation of the fiscal limit. The latter, then, can be incorporated into the regime-switching model at any period as a stochastic draw of a normal distribution whose mean and standard deviation are given by their respective reduced form equation. ${ }^{30}$ At any period, the probability of reaching the fiscal limit is endogenously updated by the equation (2-52), where $\gamma_{0}, \gamma_{b}, \gamma_{a}$, and $\gamma_{g}$ are parameters calibrated from the fiscal limits calculated at the second step of the solution method. Figure 2.5 exhibits the goodness of fit of that approximation.

${ }^{30}$ The standard-deviation reduced-form equation is not actually necessary in the model. We append it just for completeness. 

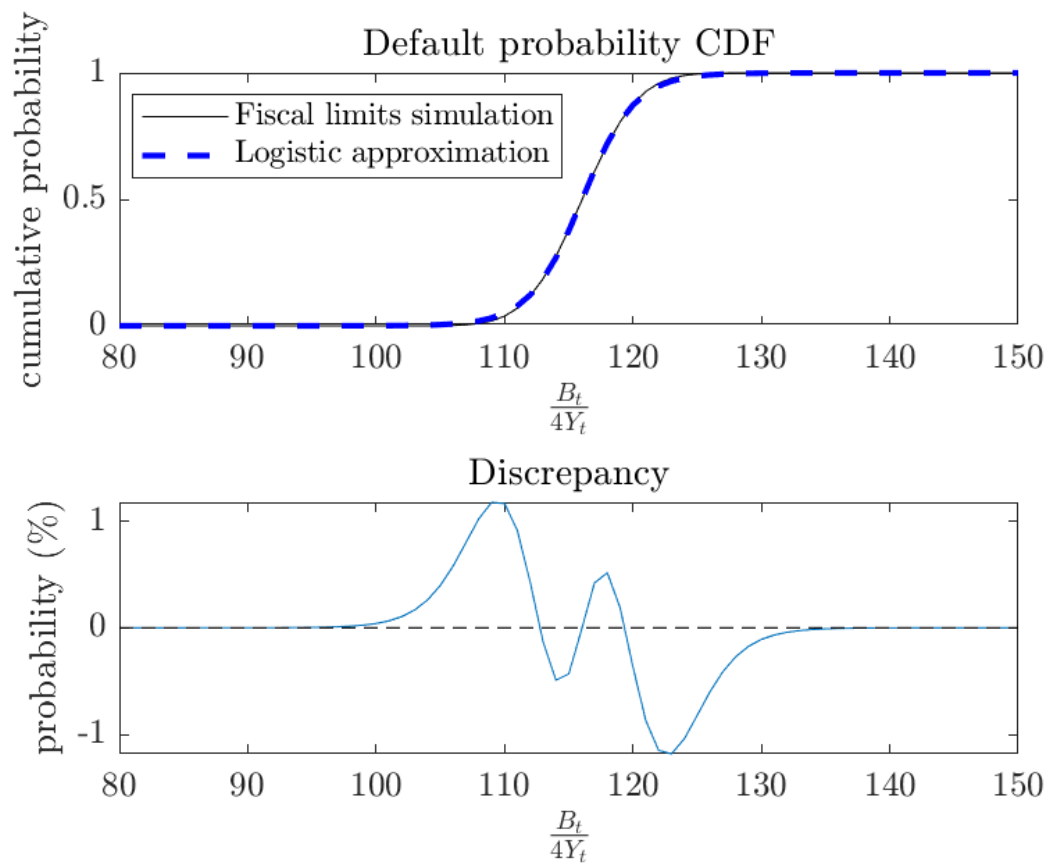

Figure 2.5: Goodness of fit of the logistic approximation

Note: top panel compares the cumulative probability distribution of the fiscal limits simulation against the logistic approximation; bottom panel plots the arithmetic difference between approximation and simulation values.

The combination of the two nonlinearities generates four regimes in our model, as exposed in Table 2.1.

\begin{tabular}{|c|c|c|}
\hline \multicolumn{1}{c|}{} & Below $\tau^{\max }$ & At $\tau^{\max }$ \\
\hline Below fiscal limit & Regime 1 & Regime 2 \\
\hline Reached fiscal limit & Regime 3 & Regime 4 \\
\hline
\end{tabular}

Table 2.1: Model regimes

Regime 1 is our starting point for solving and simulating the model, since fiscal limits clearly have not been reached for Brazil in the recent period. No default has happened, and the country can finance itself through debt with relative ease, relying both on domestic and foreign investors (not modeled here). Besides, efforts for increasing the tax burden do not seem to have been preempted by the idea that it will reduce total government revenue, but mostly for political reasons. 
Regime 2 takes place when the peak of the Laffer curve is reached. This will happen when the stock of debt grows way beyond its steady-state level. The tax rate is, then, constrained to be equal to the rate that maximizes the government revenue, so that the debt can follow a trajectory that reduces the likelihood of default. Note that although monetary policy still has en effect on the trajectory of the debt in this regime, it is not able to indirectly affect the tax rate, and, through that channel, affect other real variables such as output, consumption and the employment level. ${ }^{31}$

Regime 3 occurs when the government defaults on the debt before its taxing capacity is exhausted. Although an unlikely event if the steady state is calibrated far from the fiscal limit, this may still happen in the model due to the stochastic character of this restriction. There is always a chance that a very large shock will be inflicted in that economy. The tax rate, which reacts with a lag to the inherited stock of debt, may suffer a large drop in the next period if the debt to be repaid in the future becomes much lower. As we calibrate the steady-state debt closer to the fiscal limit, this regime becomes more frequent.

Finally, Regime 4 represents default when the economy has already reached its taxation capacity. This is the case when a sequence of adverse shocks results in a large accumulation of debt. At some (stochastic) point, the government has to default. After that event, in reason of the lower debt level, the tax rate will be adjusted with a lag to below the peak of the Laffer curve, unless the debt level is so high that even after the haircut its sustainability still requires maximum taxation. An extremely high debt-to-output level - for the calibrated economy - would lead to a succession of default events happening near the peak of the Laffer curve until debt became sustainable again; a case of "debt intolerance" resulting in a "serial defaulteer", to employ the language of Reinhart, Rogoff and Savastano (2003). ${ }^{32}$

The regime-switching solution strategy consists of first log-linearizing the model around each regime-specific non-stochastic steady state, and then applying the algorithm exposed in Maih (2015) and summarized in Appendix B.8. The list of log-linearized equations is available in Appendix B.2.

\footnotetext{
${ }^{31}$ Despite that, as long as this regime is not absorbing, monetary policy still affects these variables through the agents' expectation of regime-switching in the future, a channel that exists even under flexible prices. Since prices are sticky in our model, two real effects of monetary policy coexist in this regime: the price adjustment costs, and the regime-switching expectations.

${ }^{32}$ The same observations about the real effects of monetary policy made for Regime 2 also apply here.
} 


\section{4}

\section{Calibration and simulation of the model}

We calibrate and simulate the model for Brazil, a country whose sovereign premium on its debt has been considerably high throughout the years. This fact makes that country an adequate candidate for our policy-default-risky model. ${ }^{33}$ Furthermore, the Central Bank of Brazil adopted an explicit inflationtargeting regime in June 1999, and, since then, it conducts monetary policy mainly through repo operations involving federal government securities. With respect to fiscal policy, also since 1999 the country has pursued primary surplus targets, but with somewhat less success than it has met its inflation ones. As our tax rule establishes a debt-to-output target instead, we leave a more detailed representation of the Brazilian fiscal policy for further research.

In our calibration strategy described ahead, we partially estimate the flexible-price single-regime version of the model with Bayesian methods for calibrating the fiscal limits. In Appendix B.4, we test the stability of the model with that calibration under each policy rule and for different levels of default probability at the deterministic steady-state. Additionally, in Appendix B.5, we analyze the impulse response functions of the model; in Appendix B.6, we discuss welfare far and near the fiscal limit for a small set of policy rules; and in Appendix B.7 we discuss how the policy rule can entail correlations with different signs between inflation and default probability.

\subsection{1 \\ Calibration}

We proceed with the parameterization of our model, relying on the calibration and estimation (posterior mean) of De Castro et al. (2015), unless otherwise stated. Our calibration is summarized in Table 2.2 and Table 2.3. Estimated parameters are listed in Table 2.4, while more details on the estimation procedure are available in Appendix B.3. The steady state is derived in Appendix B.1.

\footnotetext{
${ }^{33}$ For more on that choice, we redirect the reader to footnote 4 .
} 


\begin{tabular}{lll}
\hline \hline Parameter & Description & Value \\
\hline$\beta$ & time discount factor & 0.989 \\
$\eta$ & disutility of labor & varies \\
$\chi$ & inverse of the Frisch elasticity of labor & 1.0 \\
$\bar{N}$ & steady-state labor supply & $1 / 3$ \\
$k_{Y}$ & capital-to-quarterly-output ratio & 18.0 \\
$\gamma^{N R}$ & fraction of non-Ricardian households & 0.40 \\
$\gamma_{\tau}$ & tax-rate elasticity to the debt level & 0.108 \\
$\bar{\delta}_{\delta_{t}>0}$ & debt haircut in case of default & 0.05 \\
$\bar{\Pi}$ & gross inflation target & 1.011 \\
$\delta^{\mathrm{TFP}}$ & TFP loss at the impact of default & 0.0238 \\
$\theta$ & elasticity of substitution between intermediate goods & 11 \\
$\phi^{C}$ & price adjustment cost & 100 \\
$\rho_{\tau}$ & tax-rate autoregressive coefficient & 0.862 \\
\hline \hline
\end{tabular}

Table 2.2: Calibration of parameters

The time discount factor, $\beta$, is set to 0.989 ; the inverse of the Frisch elasticity of labor, $\chi$, is set to $1.0 .^{34}$ The disutility of labor, $\eta$, is calibrated so that labor supply equals $1 / 3$ at the steady state, as is common in the literature, while $k_{Y}$, the fraction $\frac{\bar{K}}{\bar{Y}}$, is calibrated to 18.0 , calculated from the Penn World Table database, whose methodology is described in Feenstra, Inklaar and Timmer (2015). ${ }^{35}$. Moreover, the fraction of non-Ricardian households is calibrated to $\gamma^{N R}=0.40$. Since the model in De Castro et al. (2015) does not have defaultable bonds, we resort to other sources. We calibrate the haircut in case of default, $\bar{\delta}_{\delta_{t}>0}$, to 0.05 (20\% annually) like Bi, Leeper and Leith (2018) to emphasize that even small haircuts can generate quantitatively relevant results. Additionally, we calibrate the TFP loss in case of default, $\delta^{\mathrm{TFP}}$, so it is consistent with a $4.3 \%$ annual output loss, which is the yearly contraction of Brazilian real GDP in 1990, the year of the Collor plan, obtained from the IBGE (Brazilian Institute of Geography and Statistics) ${ }^{36}$ Finally, we calibrate the elasticity of substitution between intermediate goods, $\theta$, to 11 , and the price adjustment cost parameter, $\phi^{C}$, to $100 .{ }^{37}$

${ }^{34}$ In De Castro et al. (2015) this parameter is not identified in the estimation, so they pick 1.0 as it is inside the range of values in the literature.

${ }^{35}$ The 1999-2017 average value of annual capital stock divided by $1 / 4$ of annual real GDP, both measured at constant national prices in millions of 2011 U.S. Dollars.

${ }^{36}$ From the log-linearized version of the equation of output in equilibrium (2-41), we compute the size of the TFP shock at period 1 that $\sum_{t=1}^{4}\left(1+\frac{1}{\chi}\right)\left(\log \left(A_{t}\right)-\log (\bar{A})\right)=$ $(1-0,043)$.

${ }^{37}$ De Castro et al. (2015) adopts Calvo pricing and estimates the frequency of non- 
Turning to the steady-state parameters, we calculate $\bar{A}$ so that $\bar{Y}=1.0$. To calibrate fiscal variables, we use annual Brazilian data from the Government Finance Statistics (GFS) of the IMF, available only for the period 2006-2018 (Figure 2.6 and 2.7). Total government expenses averaged $42.4 \%$ of GDP in the period. Of this total, the sum of compensation of employees, the use of goods and services, the consumption of fixed capital, and other expenses averaged $20.6 \%$ of GDP, which we use to calibrate $\frac{\bar{G}}{\bar{Y}}$. The sum of subsidies, grants expense, and social benefits averaged $14.2 \%$ of GDP in the same period, which we use to calibrate the value of government transfers at the steady state, $\frac{\bar{R}}{\bar{Y}}$. The remaining difference is given to interest expenses, which averaged $8.1 \%$ in that time range. Steady-state tax rate when maximum tax rate restriction is not binding, $\bar{\tau}_{\tau_{t}<\tau_{t}^{\max }}$, is set to $39.1 \%$, which is the mean fraction of total government revenues to GDP in the period. Finally, debt to output ratio at the steady state, $\frac{\bar{B}}{\bar{Y}}$, is calibrated to $248 \%$ of quarterly output, or $61.9 \%$ of annual output using data for gross debt from the Central Bank of Brazil (BCB). ${ }^{38}$ As our model is a closed economy, we assume that international reserves are either nil or that they cannot be used for the purpose of debt repayment. ${ }^{39}$ With BCB and GFS data, we estimate equation (2-28), using a linear regression, and we get $\gamma_{\tau}=0.108$ and $\rho_{\tau}=(0.552)^{\frac{1}{4}}=0.862 .^{40}$

optimizing firms at any period to be 0.74 for freely-set prices. Using Keen and Wang (2007)'s first-order equivalence between Calvo and Rotemberg pricing, our calibration would imply a frequency of 0.73 .

${ }^{38}$ In 2007, the methodology for calculating the gross debt of the general government published by the Central Bank of Brazil changed. While the old series is available in the sample from 2001M12 to 2019M12, the new series covers 2006M12 onward. We opt to interpolate both series by estimating values from 2001M12 to 2006M11 through adding to the old series the mean difference between then.

${ }^{39}$ Calibrating for net debt instead of gross debt would not affect our results qualitatively as the debt level does not enter in the calculation of the fiscal limits. One can easily interpret $B_{t}$ as the net debt level and assume that international reserves are fixed at any specific level. In fact, as we will show that the calibrated steady-state gross debt is already compatible with virtually zero default probability, substituting it for the lower steady-state net debt would not entail any additional dynamics to the model. Moreover, the tax rate elasticity to the net debt, calculated with IMF World Economic Outlook data, is $\gamma_{\tau}=0.109$, roughly the same as for the gross debt. At least for the estimated period, adopting net debt instead of gross debt is just a negative level shift in the default probability associated with any value of $B_{t}$.

${ }^{40} \mathrm{Bi}$, Shen and Yang (2016) estimate $\gamma_{\tau}=0.047$ for Argentina using Bayesian methods in a sample covering 2004Q1:2015Q2. Ramirez and Wright (2017) calculate fiscal limits for 18 economies in Central America and the Caribbean while calibrating $\gamma_{\tau}$ between 0.26 (Guatemala) and 0.69 (Belize). Overall, we assess that our calibration is in line with the literature, although it should be taken with a grain of salt. 
Chapter 2. An Unpleasant Coincidence for Monetary Policy: Risky Assets and Fiscal Limits

\begin{tabular}{lll}
\hline \hline Parameter & Description & Value \\
\hline $\bar{Z}$ & steady-state government transfers & $0.142 \bar{Y}$ \\
$\bar{G}$ & steady-state government expenses & $0.206 \bar{Y}$ \\
$\bar{\tau}_{\tau_{t}<\tau_{t}^{\max }}$ & steady-state tax rate & 0.391 \\
$\bar{Y}$ & steady-state output & 1.0 \\
$\bar{B}$ & steady-state debt & 2.48 \\
$\bar{P}$ & steady-state price level & 1.0 \\
\hline \hline
\end{tabular}

Table 2.3: Calibration of steady-state parameters

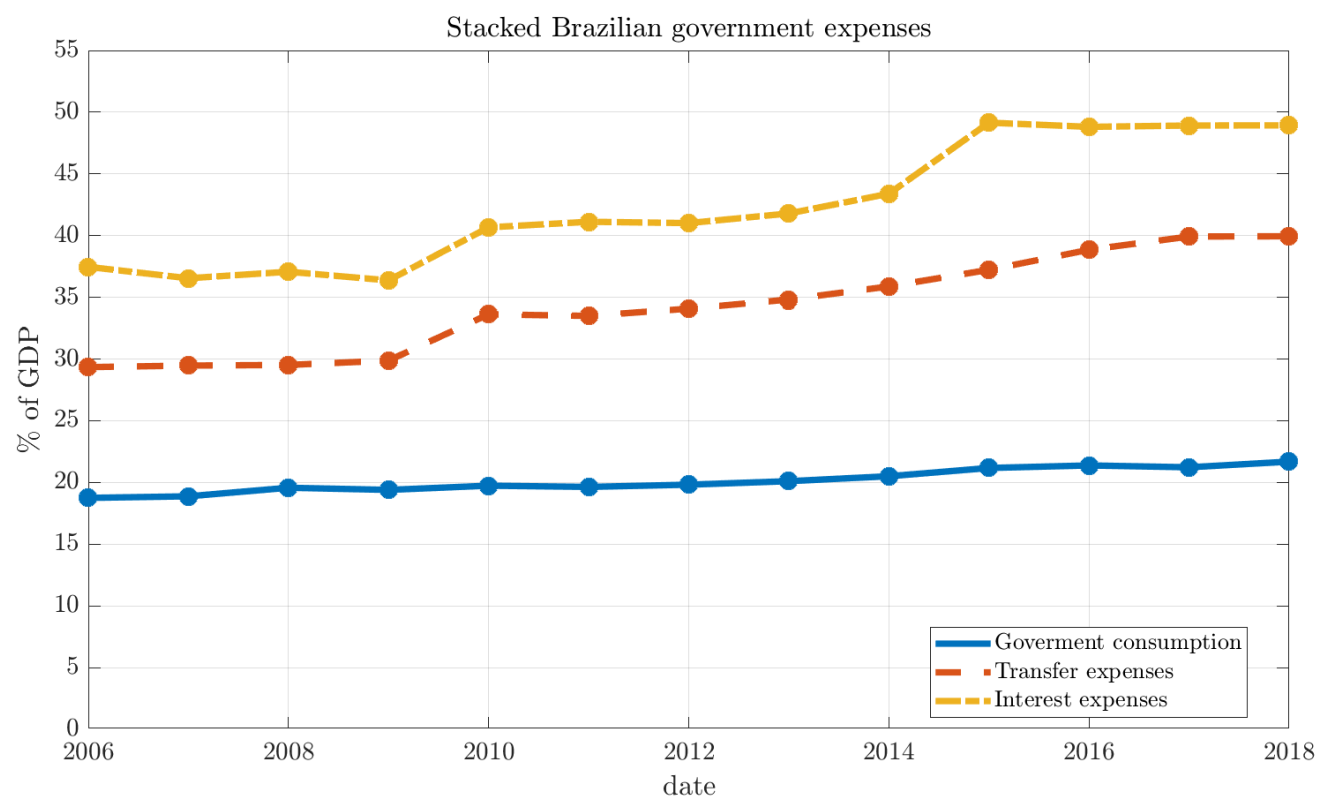

Figure 2.6: Actual stacked Brazilian government expenses 


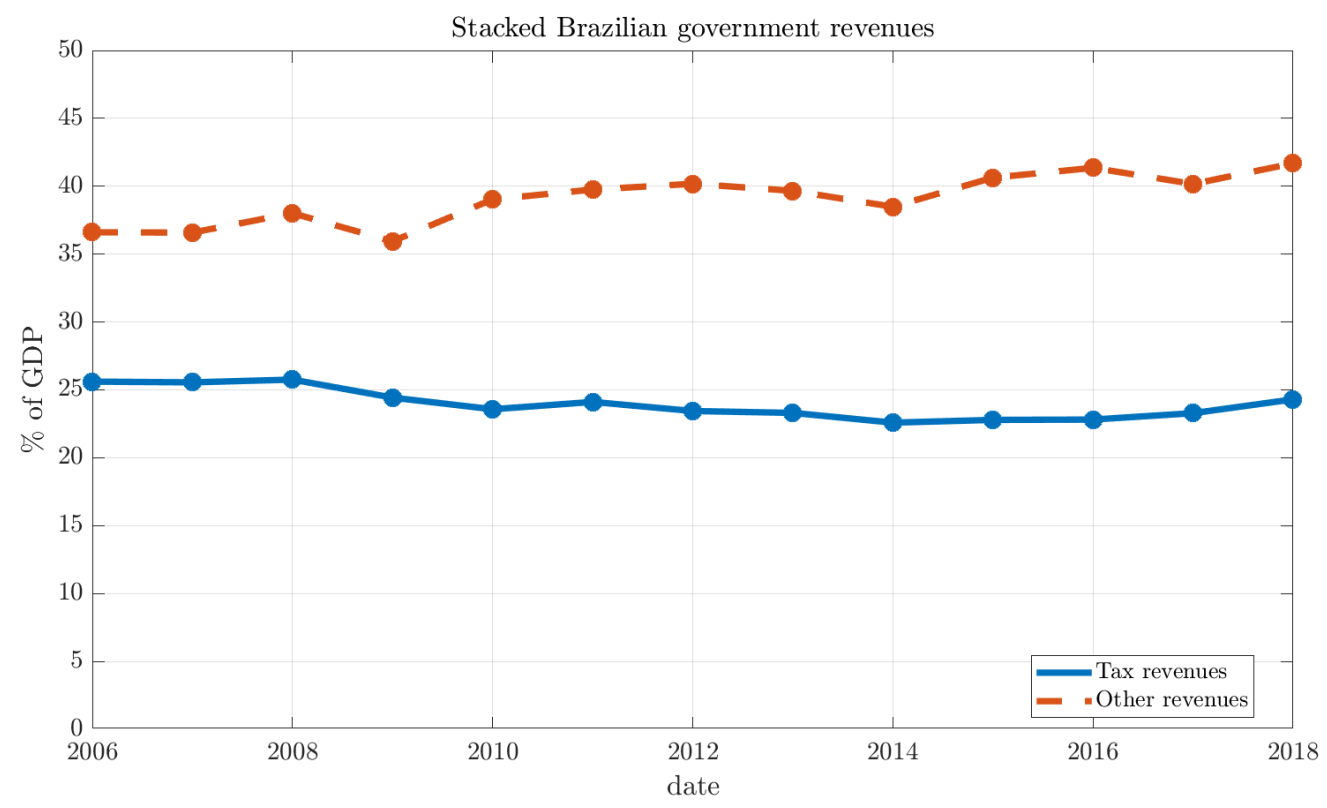

Figure 2.7: Actual stacked Brazilian government revenues

We conduct a Bayesian estimation, as described in Appendix B.3, of some parameters of the flexible-price single-regime version of the model, that is, supposing that its two non-linearities are never binding nor expected to bind. ${ }^{41}$ Specifically for estimation, we opt for allowing time preferences to evolve according to an $\mathrm{AR}(1)$ stochastic process, ${ }^{42}$

$$
\log \left(\frac{\beta_{t}}{\beta}\right)=\rho^{\beta} \log \left(\frac{\beta_{t-1}}{\beta}\right)+\sigma^{\beta} \varepsilon_{t}^{\beta}
$$

where $\rho^{\beta} \in[0,1)$ measures its persistence; $\sigma^{\beta}$ is the standard deviation of the shocks; and $\varepsilon_{t}^{\beta}$ is i.i.d. $\mathcal{N}(0,1)$.

The posterior mean of the inverse of the elasticity of intertemporal substitution, $\sigma$, is estimated to be 2.132 , larger than the 1.3 estimated by De Castro et al. (2015). We, as them, find that this parameter is poorly identified in the data.

Concerning the externalities of public expenditure in the model, we obtain $\alpha_{G}=0.551$, implying substitutability between government and private consumption, ${ }^{43}$ and $\gamma_{G, \Psi}=0.160$, so that a positive spill-over to firms' total factor productivity guarantees that the public expenditure multiplier is larger than 1 in the short-run.

${ }^{41} \mathrm{~A}$ full Bayesian estimation of the regime-switching model would require more complex estimation techniques, such as the ones employed by Bi and Traum (2012) and Bi and Traum (2014).

${ }^{42}$ There is a noticeable linear trend in the data for nominal interest rates. As in our estimation we prefer to demean it instead of applying an HP filter, so as not to introduce spurious cycles, this preferences process helps us to capture that trend.

${ }^{43}$ Fève and Sahuc (2017) estimates it to be -1.51 (posterior mean) for the euro area. 
In the realm of monetary policy, we estimate the central bank reaction to deviations from the inflation target, $\phi^{\pi}$, to be 2.965. Additionally, $\bar{\Pi}$ is calibrated to 1.011, which results roughly in an annual net inflation target of $4.5 \%$, whereas $\phi^{Y}$ and $\phi^{i}$ are estimated to be 0.020 and 0.783 , respectively.

In the specific estimation of the remaining exogenous processes, we obtain from posterior means $\rho^{A}=0.933$ and $\sigma_{A}=0.005 .{ }^{44}$ Concerning the preference shock, we find $\rho_{\beta}=0.966$ and $\sigma_{\beta}=0.004$. For the monetary shock process, we obtain $\rho_{\mathcal{M}}=0.232$ and $\sigma_{\mathcal{M}}=0.004$ (annualized 0.016). At last, for the government expenses shock, we obtain $\rho_{G G}=0.795, \rho_{G Y}=0.132$, and $\sigma_{G}=0.013 .^{45}$

\footnotetext{
${ }^{44}$ This calibration implies that the likelihood of a TFP shock at least as bad as the one associated with a default event is of $1.72 \%$, an otherwise rare disaster indeed.

${ }^{45}$ If our estimation had found that $G_{t}$ significantly reacts to output deviation from the steady state with a lag, it could reduce to a large extent the parameter space for which the model has a solution. This shows how sensitive the specification of government expenses can be to models with fiscal limits.
} 


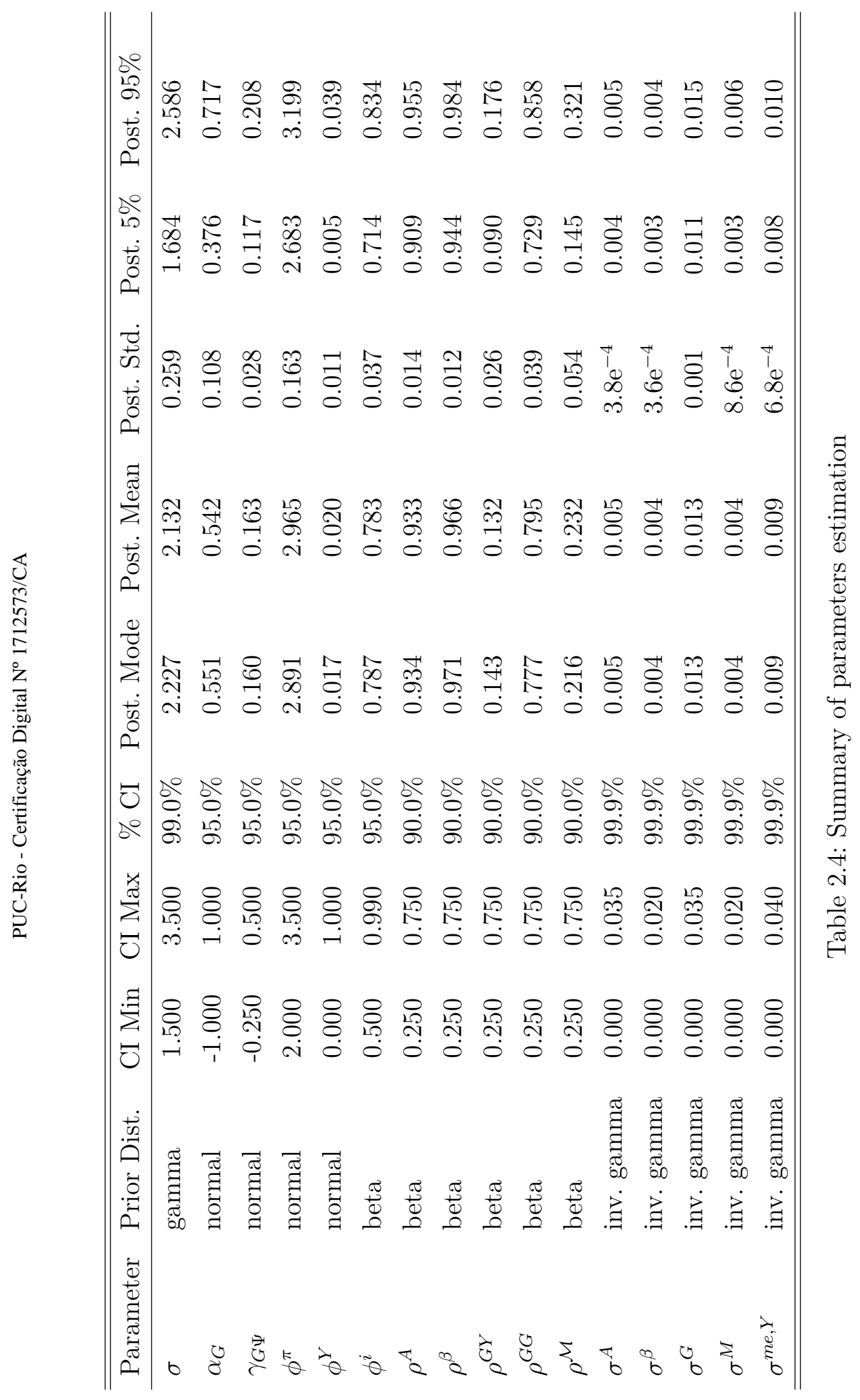




\section{4 .2}

\section{Simulation of the fiscal limits}

Like in Bi (2012), we explore how economic fundamentals affect the fiscal limit by finding the conditional distribution of that limit under different assumptions. The specification of the shocks as processes with infinite support (normal distributions) allows for the default probability to be always present and different from zero, as the possibility that an extremely large shock inflicts our model economy is always positive. It is important to note, though, that the fiscal limits computed here are extremely sensitive to our parameterization. For instance, small changes to the elasticity of labor supply, from 1 to $1 / 1.3$ could shift the distribution to the right by more than $100 \%$ of output. Besides, we opt for turning off the preferences shock, as we had already done when of the definition of the fiscal limit (2-49), for such a stochastic shock harshly increases both the mean and the standard deviation of the fiscal limit distribution, leading to implausible results. These are critical limitations of our approach to modeling fiscal limits, and therefore, we prefer to focus on their qualitative features.

The algorithm can be summarized as follows. We approximate the possible values of each exogenous variable with a discrete state vector of size $S$ obtained using the Tauchen (1986) method. Then, for each possible combination of states, we conduct $N=150,000$ Monte Carlo simulations. In each simulation, we randomly draw as many vectors of size $\left(T_{F L}+T_{\text {burn-in }}, 1\right)$ as the number of shock processes we have; where $T_{F L}=200$ is the number of periods ahead that we use in the summation of the fiscal limit expression, and $T_{\text {burn-in }}=200$ is the number of initial shocks that we discard. Next, like in $\mathrm{Bi}$, Leeper and Leith (2018), we approximate the empirical distribution of fiscal limits by a normal distribution, finding its respective mean and standard deviation, which we attribute to each specific combination of states. As the fiscal limit is, by definition, the maximum level of debt that the government can support without defaulting, in each iteration the model is solved assuming that at every period $\delta_{t}=0$ and $\tau_{t}=\tau_{t}^{\max }=\tau^{\max }$.

Our calibration indicates that the deterministic steady state of the Brazilian economy at the recent period was situated far from the fiscal limit until at least $2019 .{ }^{46}$ Figure 2.8 depicts at the top panel how the annualized

\footnotetext{
${ }^{46}$ Some important caveats should be raised here. First, our approach to calibration is agnostic w.r.t the source of risk premium embedded on Brazilian interest rates, and we do not try to directly match its respective moments, except for $\beta$, which summarizes the deterministic discount of the future. Second, the calibrated period exhibits a pronounced downward trend for interest rates, which we interpret generically as slow improvement of fundamentals, but that we do not try to replicate in this paper. Third, one way of shifting to the left the distribution of the fiscal limits at the steady state along the debt-to-output axis
} 
neutral real interest rate of steady state changes as we pick a higher debt-tooutput ratio. Vertical-dashed lines indicate actual and projected ratios at the end of the respective labeled years $(2013,2016,2019,2020,2022)^{47}$. Verticaldotted lines indicate the same but for net debt. The curve is steady until around $110 \%$, but it grows exponentially after that mark, reaching a top plateau after $125 \%$ at the time-discounted recovery rate of steady state. The graph at the bottom panel exhibits the cumulative probability distribution of the fiscal limit being lower or equal to the same range of debt-to-output ratios of the top panel. Default probability remains negligible until around 105\%, but grows quickly after it. ${ }^{48}$ As a consequence of that switching nature, even a numerically low default probability can levy a heavy interest rate burden on such an economy. It is important to remember that the steady state we calculate here depends on the calibration of the model, especially of our choice for $\beta$. It could very well be that, during the period analyzed, the Brazilian economy already presented significant default risk in the eyes of the marginal investor, so our value for $\beta$ is biased and actually includes some default premium. This fragility of our calibration only reinforces that we should focus on the qualitative aspects of the results presented here.

is by assuming that the government is more impatient than households, perhaps in reason of political motives, a common assumption in the sovereign default literature.

${ }^{47} 2013,2016$, and 2019 are actual values. 2020 and 2022 are projections made by the IFI (Instituto Fiscal Independente) on 17th of November 2020.

${ }^{48} \mathrm{Bi}$ (2017) calibrates a simple RBC model with fiscal limits to Brazil and finds that default probability starts growing meaningfully after debt-to-output ratio reaches $110 \%$ (by visual inspection of her plotted results). Not such a different result from ours. 


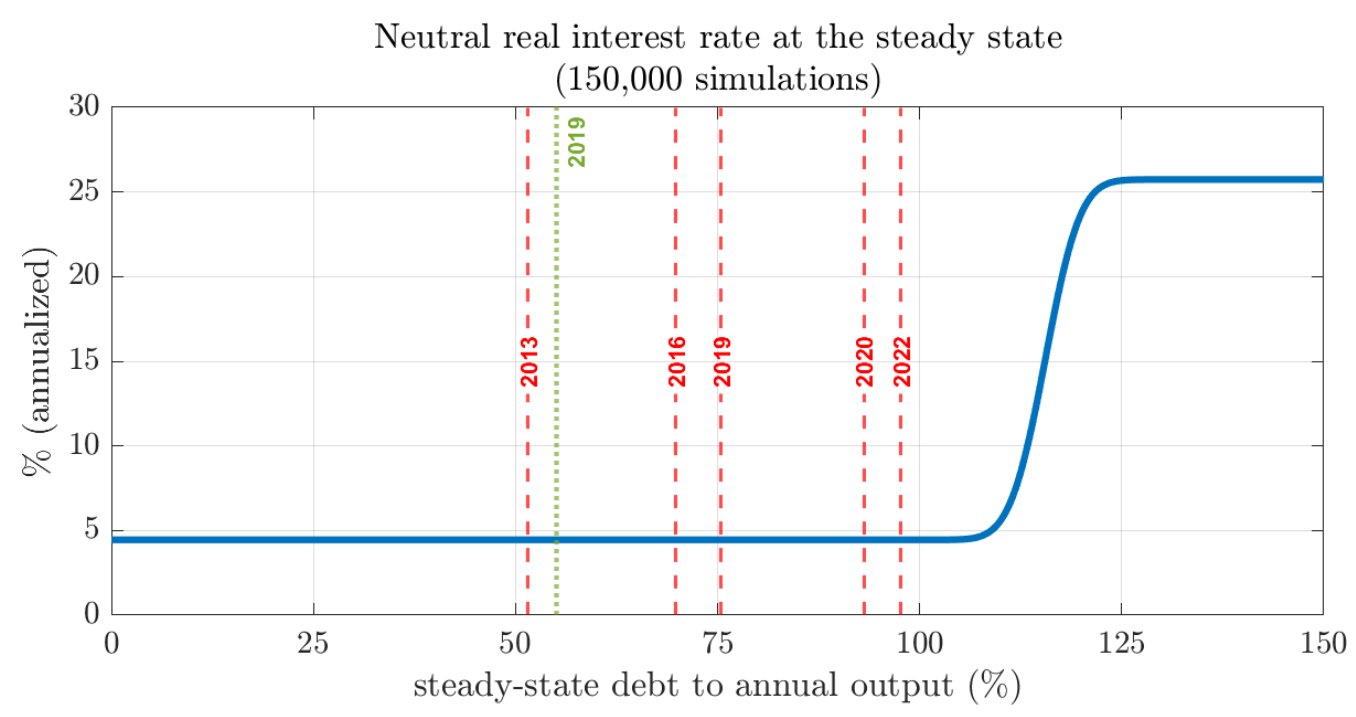

Fiscal limit cdf (150,000 simulations)

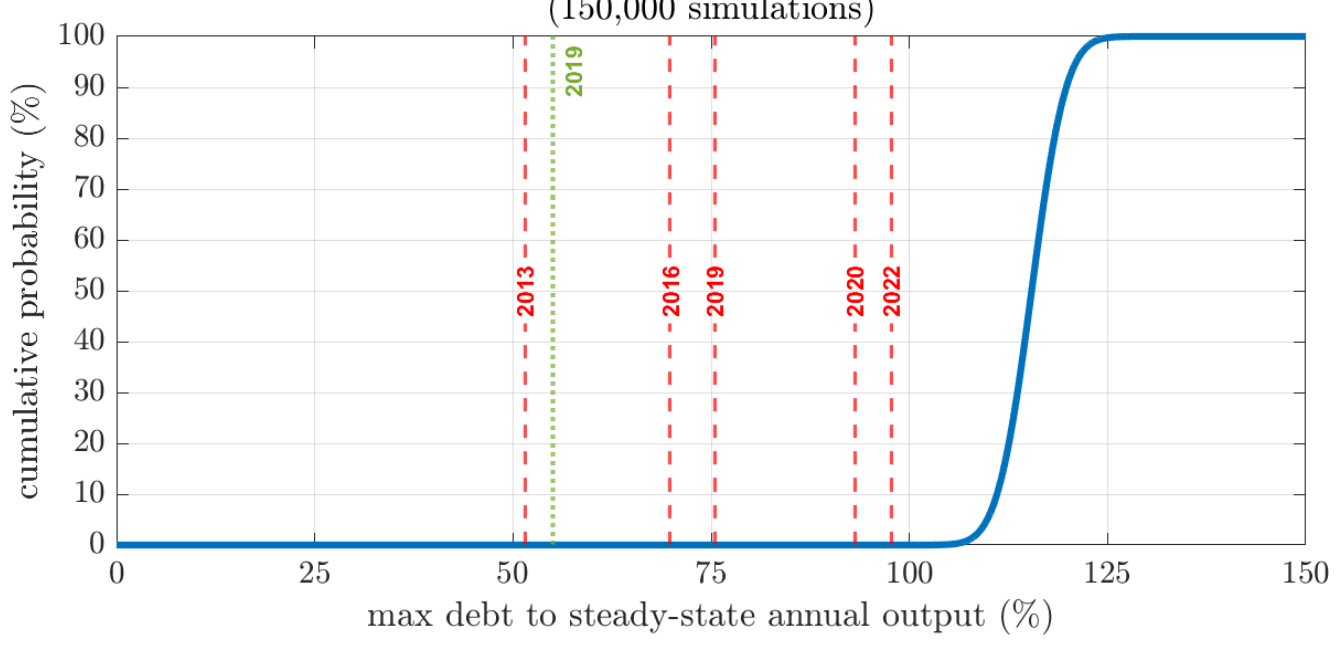

Note: Vertical-dashed lines indicate actual and projected ratios of the gross debt at the end of the respective labeled years, where 2013, 2016, and 2019 are actual values, while 2020 and 2022 are projections made by the IFI (Instituto Fiscal Independente) on 17th of November 2020. Vertical-dotted lines indicate actual net debt at the end of the respective label years.

Figure 2.8: The neutral real interest rate and the fiscal limit cdf

To understand how the fiscal limit is affected by state variables, we plot its distribution at different steady-state values in Figure 2.9. On the left panels of the figure, we plot the PDFs, and, on the right panels, we plot the respective CDFs. It is possible to see on the top panels that increasing the steady-state value of productivity, $\bar{A}$, amplifies the fiscal space of the government as it turns less likely that the latter will have to default on its debt. Under our calibration, an increase of $1 \%$ of $\bar{A}$, ceteris paribus, increases the median of the fiscal limit distribution by $0.15(4 \bar{Y})$, while a symmetrical reduction of $\bar{A}$ reduces the same measure by $0.14(4 \bar{Y})$. This shows how during an economic recession 
the fiscal limit shrinks. On the second row, by its turn, we can see that the higher the steady-state level of government expenses, the lower is its fiscal space, what is represented by a shift to the left of the density function. Under our calibration, a 1 p.p. increase of $\frac{\bar{G}}{\bar{Y}}$, ceteris paribus, is enough to reduce the median of the distribution by $0.18(4 \bar{Y})$. This large effect reflects the fact that, as the tax rate is already set at the peak of the Laffer curve, augmenting further government expenses severely endangers fiscal sustainability. Finally, at the bottom panel, we plot how changing the discount factor of the households can have a huge impact on fiscal limits. Reducing the steady-state discount factor by 0.25 quarterly p.p. (1 p.p. annually) shifts the distribution to the left by $0.17(4 \bar{Y})$. The effect is clearly non-linear in the value of the parameter, as increasing the discount factor by the same amount shifts the distribution to the right by $0.39(4 \bar{Y})$. The coexistence of very low real interest rates with large debt-to-output ratios in low-risk developed economies is, thus, consistently predicted by the fiscal limits methodology. 

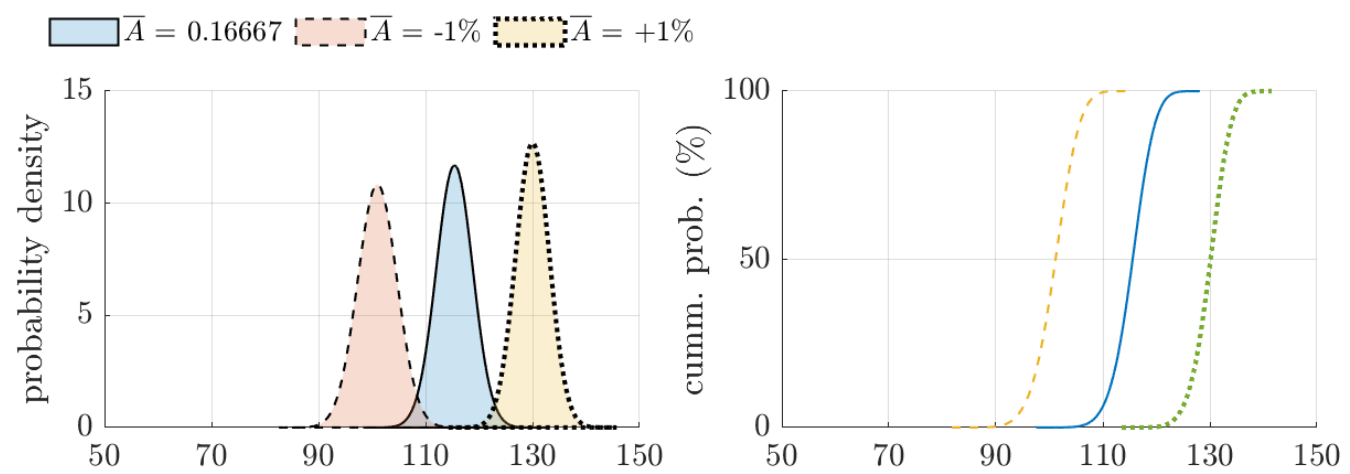

$\square \bar{G}=0.206:-, \bar{G}=-1 \% \bar{Y} ; \ldots . . . . . . \bar{G}=+1 \% \bar{Y}$
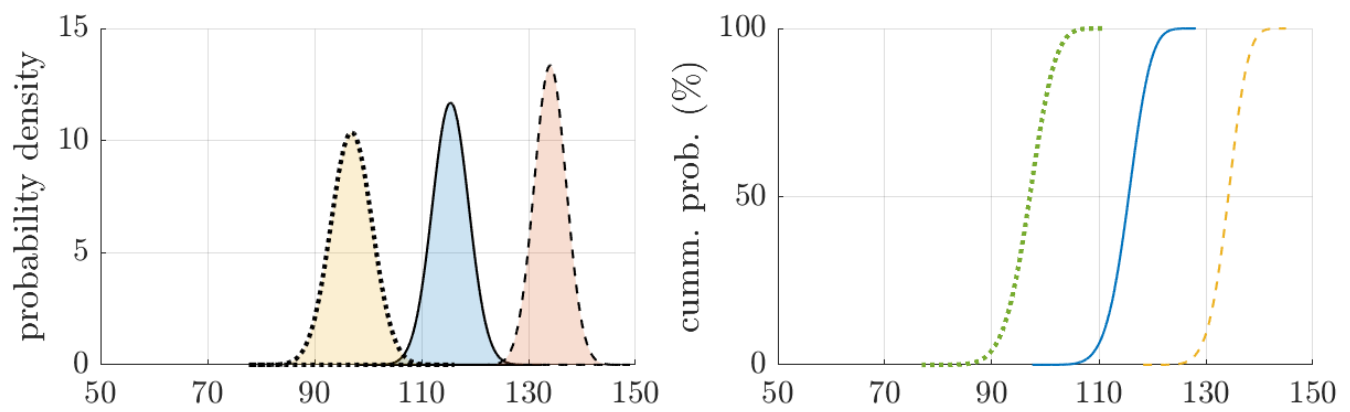

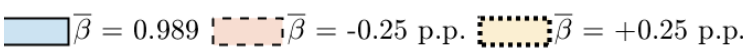
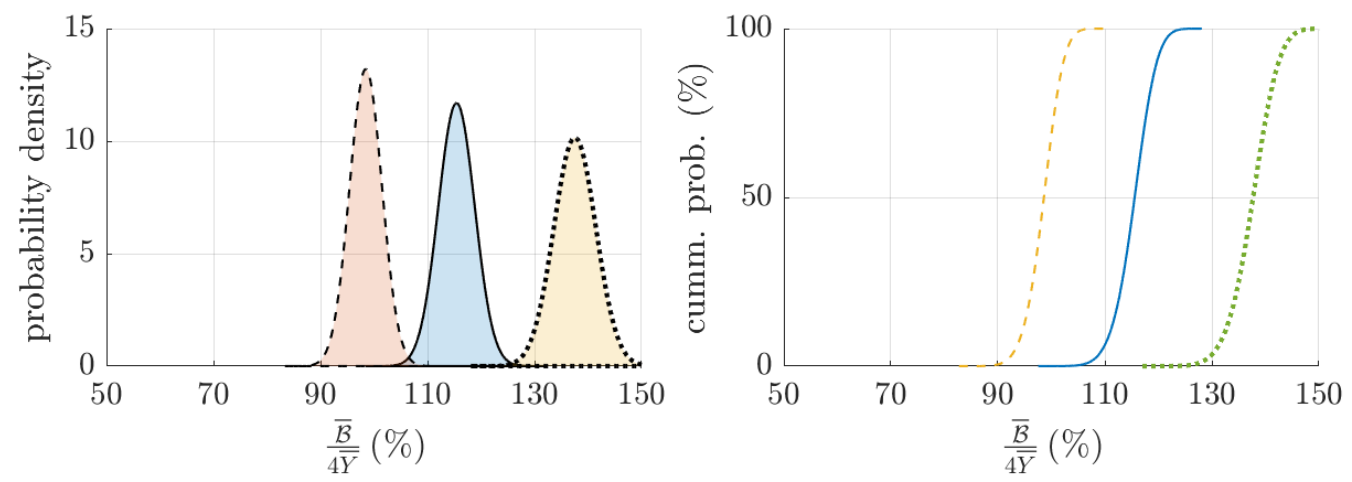

Figure 2.9: Fiscal limits at different steady states: PDFs (left panels) and CDFs (right panels)

In Figures 2.10 and 2.11, we expand the previous analysis to different values of the parameters that govern either the persistence or the standard deviation of the shocks. On the top panels of both figures, the effect of raising any of $\rho_{A}$ or $\sigma_{A}$ over the density distribution is that it gets more spread, what means that default becomes more likely at lower debt-to-output ratios. On the remaining panels, we can see that due to the role that government expenses play in our model, changes in the persistence or the size of a shock to it will only affect the fiscal limit in case the correlation with lagged output changes. The more pro-cyclical public expenditure is, the lower is the risk of default. Changing the role performed by government expenses in the model may overturn our results, so that is a very sensitive feature of the model. 
Finishing the sensitivity analysis of our model's fiscal limits, in Figure 2.12 , we plot how they change when we calibrate different values for some selected parameters: $\gamma_{G \Psi}, \alpha_{G}$, and $\gamma^{N R}$. As one can see, a higher spillover from government expenses to productivity shifts the fiscal limit distribution to the left at the same time that it flattens it. Remember that a negative shock to government expenses also reduces the effective productivity of that economy, making it harder for the government to collect enough taxes to repay the debt. Concerning $\alpha_{G}$, a negative value of this parameter implies complementarity between the consumption of private and public goods. This tends to shift the fiscal limit distribution to the left. The opposite happens when that parameter is positive, for now consumption of private and public goods are substitutes. We interpret changes in $\alpha_{G}$ as agents becoming satisfied with less consumption in the second scenario, and, therefore, more willing to postpone consumption. Changes in $\gamma^{N R}$, by its turn, regulates the fraction of agents able to finance the government. When $\gamma^{N R}=0$, all agents are Ricardian, what shifts the fiscal limits distribution to the right. The opposite happens as $\gamma^{N R}$ gets larger.

In Table 2.5 we list the mean/median and the standard deviation of all distributions plotted in Figures 2.9, 2.10, and 2.11. 

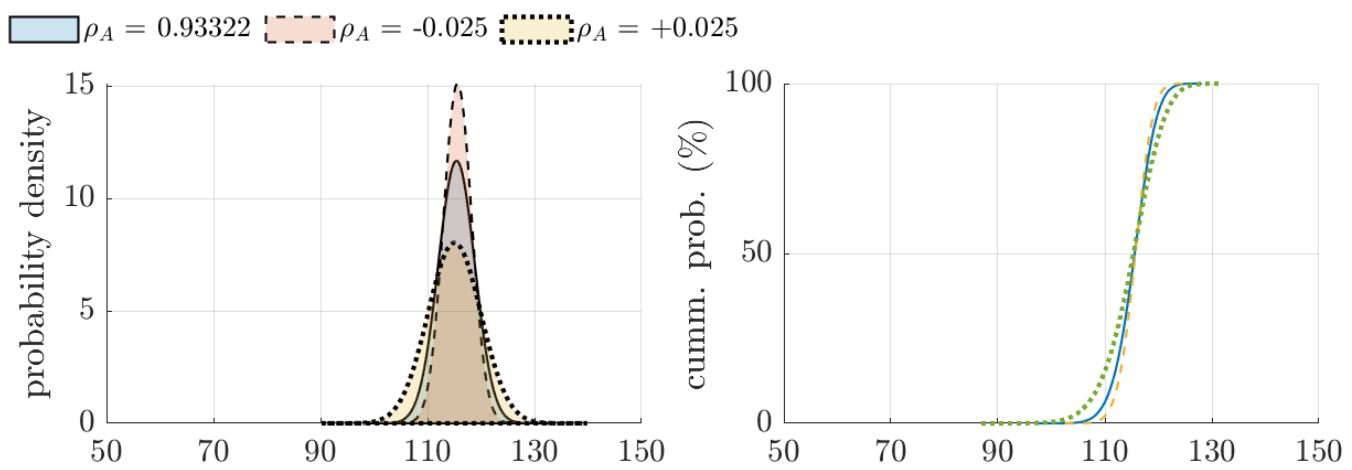

$\square \rho_{G G}=0.79493:-\rho_{G G}=-0.025: \ldots . . . . . . . . . . \rho_{G G}=+0.025$
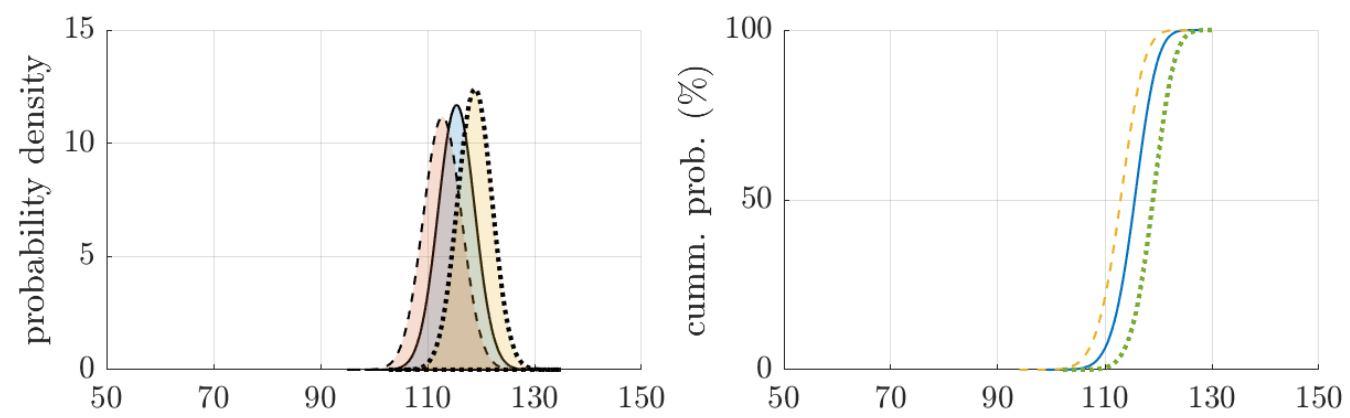

$\square \rho_{G Y}=0.13201$ L
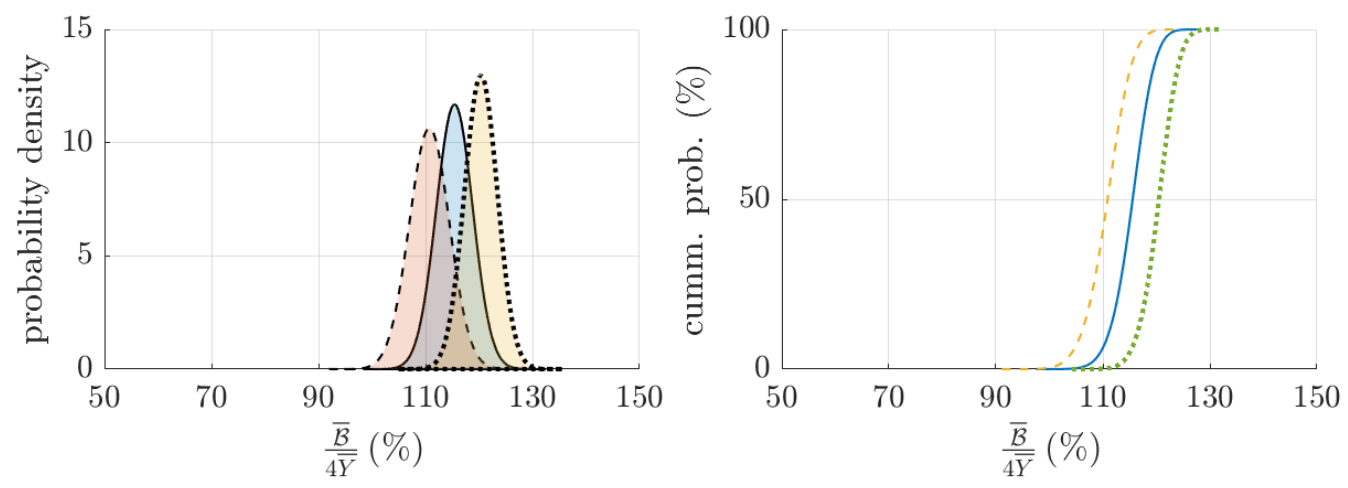

Figure 2.10: Fiscal limits at different shock persistence coefficients: PDFs (left panels) and CDFs (right panels) 
Chapter 2. An Unpleasant Coincidence for Monetary Policy: Risky Assets and

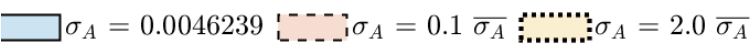
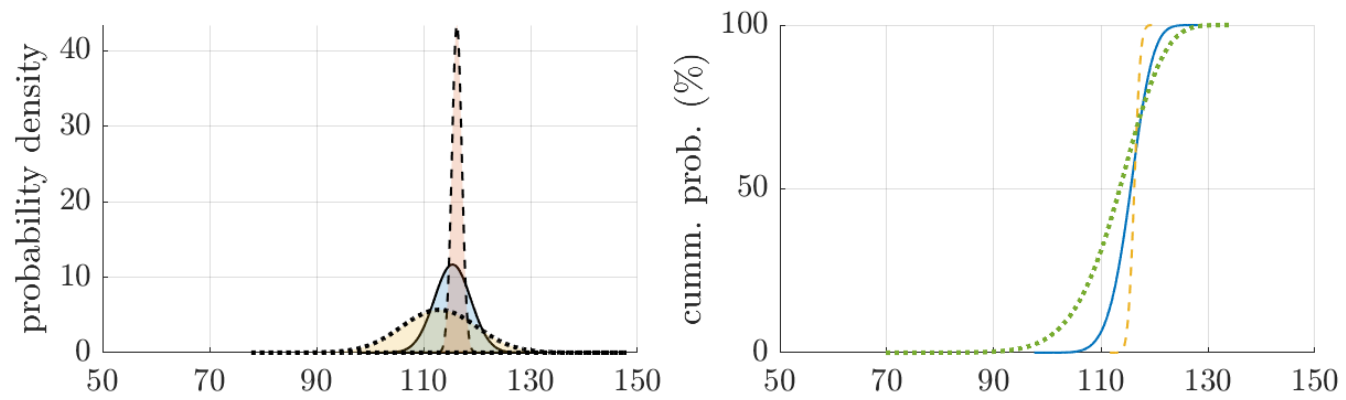

$\square \sigma_{G}=0.013013:-\sigma_{G}=0.1 \overline{\sigma_{G}} \ldots \ldots . . . . . . . . .6 \sigma_{G}=2.0 \overline{\sigma_{G}}$
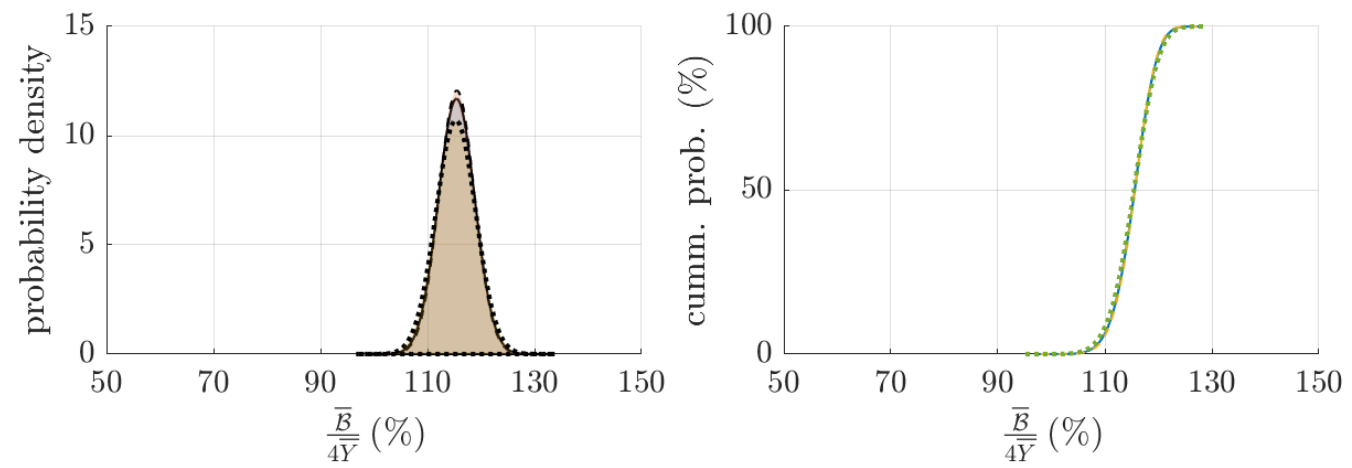

Figure 2.11: Fiscal limits at different shock volatility coefficients: PDFs (left panels) and CDFs (right panels) 
Chapter 2. An Unpleasant Coincidence for Monetary Policy: Risky Assets and

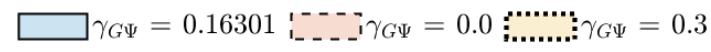
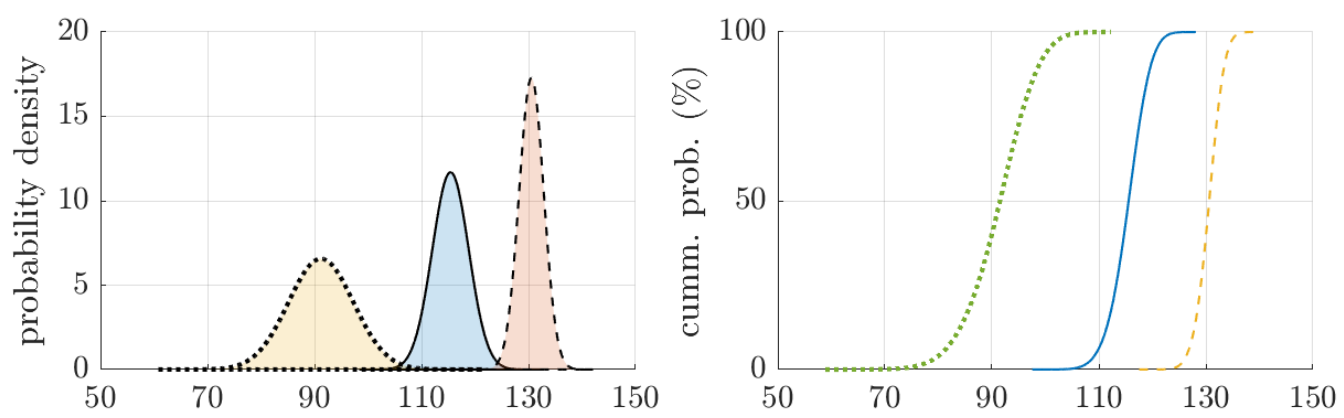

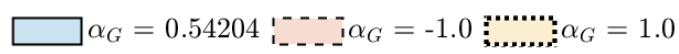
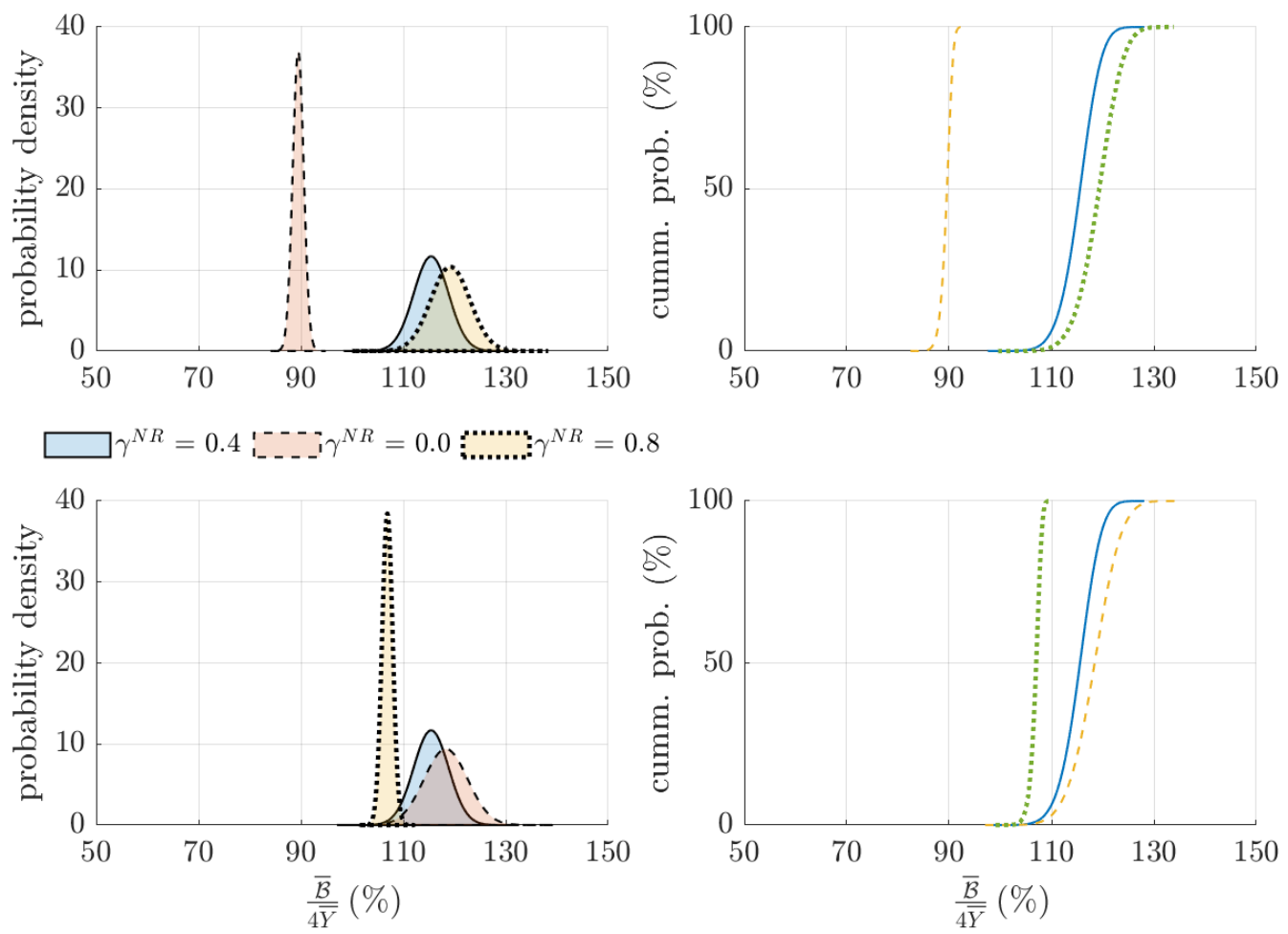

Figure 2.12: Fiscal limits after changing selected parameters: PDFs (left panels) and CDFs (right panels) 
Chapter 2. An Unpleasant Coincidence for Monetary Policy: Risky Assets and

\begin{tabular}{l|ccc|ccc|cccc}
\hline \hline & \multicolumn{2}{|l|}{ Medium Low } & High & \multicolumn{2}{|c|}{ Medium } & Low & High & Medium Low & High \\
& Param. & Param. & Param. & $\mu$ & $\mu$ & $\mu$ & $\sigma$ & $\sigma$ & $\sigma$ \\
& & & & $(\% 4 \bar{Y})$ & $(\% 4 \bar{Y})$ & $(\% 4 \bar{Y})$ & $(\% 4 \bar{Y})$ & $(\% 4 \bar{Y})$ & $(\% 4 \bar{Y})$ \\
\hline $\bar{A}$ & 0.167 & 0.165 & 0.168 & 115.6 & 101.2 & 130.1 & 3.4 & 3.7 & 3.1 \\
$\bar{G}$ & 0.206 & 0.196 & 0.216 & 115.6 & 134.2 & 97.1 & 3.4 & 3.0 & 3.8 \\
$\bar{\beta}$ & 0.989 & 0.987 & 0.991 & 115.6 & 98.6 & 137.7 & 3.4 & 3.0 & 3.9 \\
$\rho_{A}$ & 0.933 & 0.908 & 0.958 & 115.6 & 115.7 & 115.3 & 3.4 & 2.6 & 5.0 \\
$\rho_{G G}$ & 0.795 & 0.770 & 0.820 & 115.6 & 112.9 & 119.0 & 3.4 & 3.6 & 3.2 \\
$\rho_{G Y}$ & 0.132 & 0.107 & 0.157 & 115.6 & 110.9 & 120.5 & 3.4 & 3.8 & 3.1 \\
$\sigma_{A}$ & 0.005 & 0.000 & 0.009 & 115.6 & 116.2 & 113.5 & 3.4 & 0.9 & 7.0 \\
$\sigma_{G}$ & 0.013 & 0.001 & 0.026 & 115.6 & 115.6 & 115.4 & 3.4 & 3.3 & 3.7 \\
$\gamma_{G \Psi}$ & 0.163 & 0.000 & 0.300 & 115.6 & 130.6 & 91.5 & 3.4 & 2.3 & 6.1 \\
$\alpha_{G}$ & 0.542 & -1.000 & 1.000 & 115.6 & 89.6 & 119.3 & 3.4 & 1.1 & 3.8 \\
$\gamma^{N R}$ & 0.400 & 0.000 & 0.800 & 115.6 & 118.4 & 107.0 & 3.4 & 4.3 & 1.0 \\
\hline \hline
\end{tabular}

Table 2.5: Fiscal limits: sensitivity analysis

\subsection{3}

\section{Equilibrium distribution}

We analyze, here, the equilibrium distribution of the model by drawing stochastic shocks for 4 Markov chains with 330,000 periods each, where the first 30,000 periods are discarded. The unconditional distributions are obtained from piling up all periods of all chains. To make clear the differences between the monetary policy rules, we simplify them by turning off the interest rate smoothing and the dependency on the output gap. In all simulation periods, the model is solved around the current regime-specific non-stochastic steadystate.

Still, one important caveat must be raised in the interpretation of the following results. As we have simplified the policy rules, they will not necessarily induce similar distributions as their fully specified versions. Besides, as our calibration relies on the Bayesian estimation of the (default-risk-free) single-regime flexible-price version of the model, the estimated parameters may be biased, and, therefore, may not be very close approximations to their equivalent values had we estimated the full regime-switching model. Despite all that, we believe the qualitative results we present shall remain valid under more precise calibrations. 


\subsubsection{1}

\section{Variables distribution}

One of the questions we seek to answer in this paper is whether the existence of default risk underlying the policy asset influences the distribution of inflation and nominal interest rates in a given economy. It is an empirical fact that emerging (risky) economies tend to adopt higher nominal policy rates at the same time that their inflation process is perceived as more volatile in comparison with advanced (risk-free) economies. Our approach sheds some light on that topic.

First, in Figure 2.13, we plot the unconditional ergodic distribution of selected variables under the risk-adjusted policy rule far from the fiscal limit, at our benchmark calibration, and near the fiscal limit, at a steady-state debt level consistent with $1 \%$ default risk as calculated from the fiscal limits. In addition to the common monetary dominance, some differences stand out. For one, the higher $\frac{\bar{B}}{\bar{Y}}$ makes taxation at the peak of the Laffer curve much more likely. The transition between regimes leads output, consumption and employment to exhibit multimodality, higher volatility, and lower means, three undesirable features of pushing the economy towards its fiscal limit. Despite the higher average tax rate, government revenue is lower in reason of the depressed tax base, at the same time that $\mathbb{E} \frac{G_{t}}{Y_{t}}$ is higher in reason of the lower output. It is easy to conclude that, in this model, welfare reduces near the fiscal limit, what warrants an important policy recommendation against expanding the debt level near it. Note that, as we plot default-adjusted policy rule environments, inflation successfully averages around the central bank's target no matter the presence or not of significant default risk, where deviations from the target are due to unexpected monetary shocks. The policy rate, by its turn, exhibits both higher mean and volatility when default risk is significant. Note also that negative interest rates become more likely in that case, as we have not imposed a zero or effective lower bound for the policy rate in the model. 

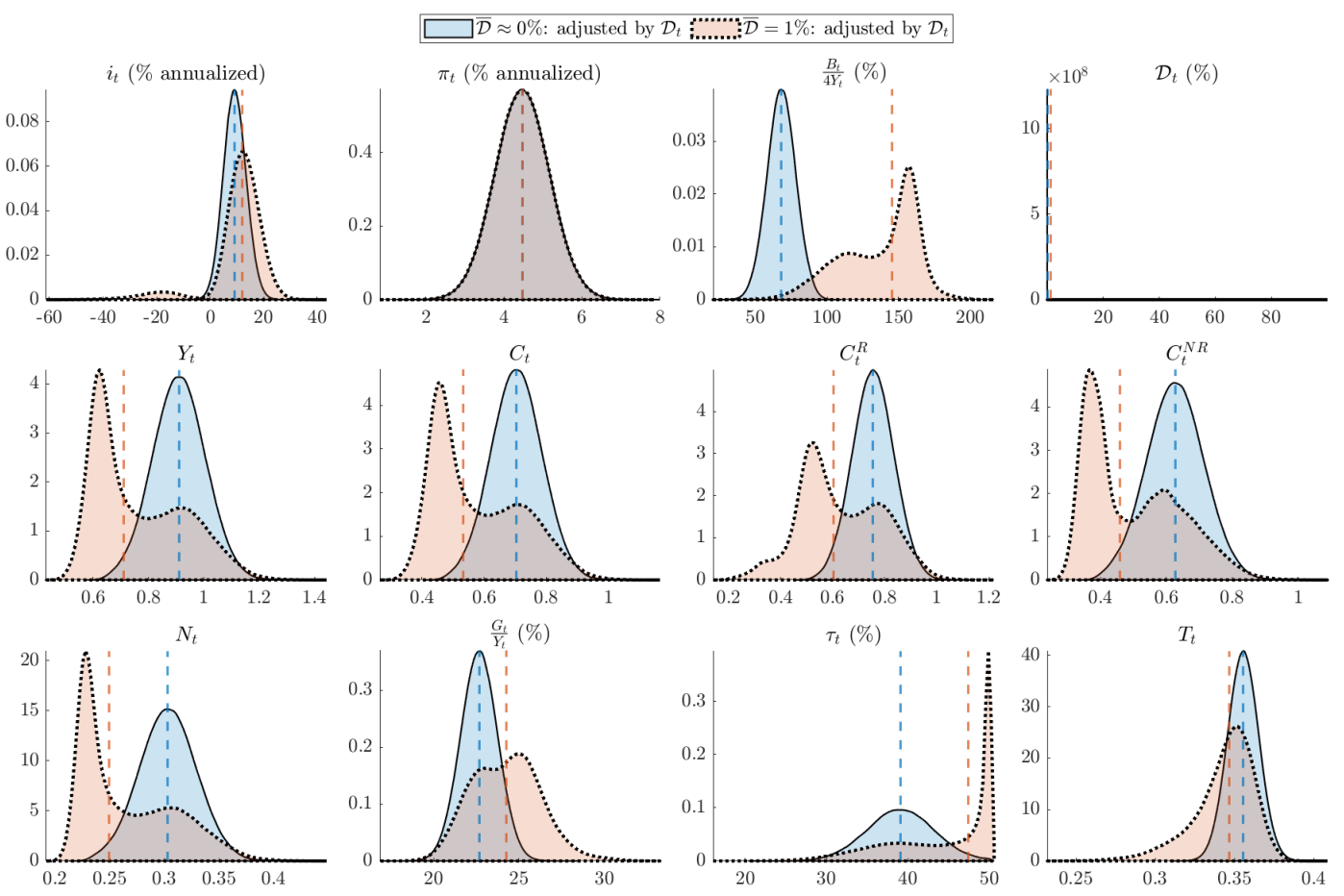

Note: Each vertical line is at the median of the distribution with the same color. Horizontal axis indicates the values of the variables, while the vertical axis indicates the probability density of each value. Density functions are estimated with the Epanechnikov kernel.

Figure 2.13: Ergodic distribution of selected endogenous variables far and near the fiscal limit

\subsubsection{2 \\ Rules comparison}

We move to the comparison across the policy rules. In Figure 2.15, we plot both of them under the benchmark calibration. As one can observe, the policy rules are hardly distinguishable in that case. Then, in Figure 2.16, we plot the same variables near the fiscal limit ( $2 \%$ default probability). The multimodality of some variables stand out, but switching rules impact more the distributions of the policy rate and of inflation. In Figure 2.17, we separate theses variables and plot the consequence of pushing the economy even closer to the fiscal limit, at a debt level consistent with $5 \%$ default probability. When the central bank ignores default risk, both $\pi_{t}$ and $i_{t}$ are higher compared to when it decides to fully offset default risk. Under our calibration, conducting monetary policy with risky assets and accommodating default risk results in the average annualized policy rate being 0.2 p.p. higher (0.6 p.p. excluding negative policy rates) than when the central bank offsets default risk. At the same time, annualized inflation is 0.2 p.p. higher ( 0.3 excluding negative policy rates) than the inflation target. Remember that, in the non-stochastic steady state, 
all rules hit the target with success. It is only when shocks are activated and regime-switching is allowed (default and taxation risk) that such divergences between the studied rules appear. Figure 2.14 plots the aforementioned result using stylized curves for the Fisher relation and the Taylor rule both in their risk-free and default-risk adjusted versions. The left panel represents Rule 1, when the central bank ignores the policy asset default risk, whereas the right panel represents Rule 2, when the central bank adjusts its policy rule to that risk. We have not specified an effective-lower-bound for the Taylor rules as risky economies are less likely to visit that constraint, but if we had the graphs would change in two ways. First, there would be also a deflationary equilibrium in which the effective-lower-bound is binding. Second, the inflationary bias of the policy-asset default risk would be to some extent offset by the deflationary bias of the effective-lower-bound, where the last bias is described in Hills, Nakata and Schmidt (2019) as existing at both the risky steady state and at the unconditional mean.

—_Fisher Relation - - Risk-Adjusted Fisher Relation —— Taylor Rule - - Risk-Adjusted Taylor Rule
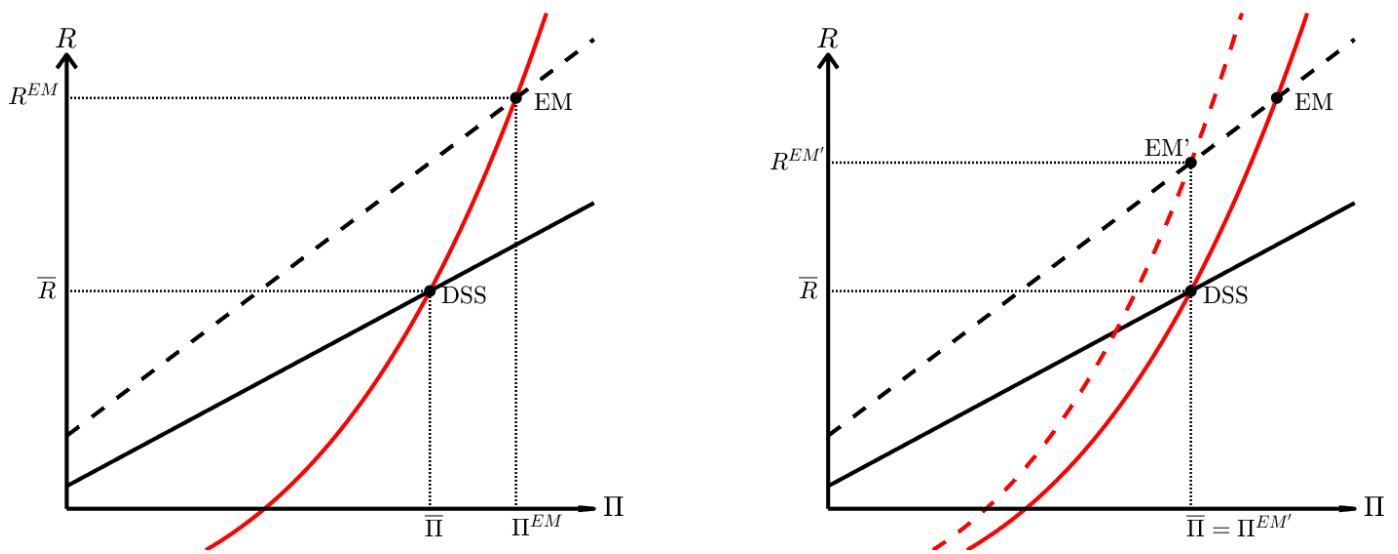

Note: Left panel represents Policy Rule 1, when the central bank ignores the policy asset default risk, whereas right panel represents a switch from that rule to Policy Rule 2, when the central bank adjusts its policy rule to that risk. $R$ is the gross nominal policy rate and $\Pi$ is gross inflation. Variables with an overbar represent targets or deterministic values. DSS stands for deterministic steady state, while EM stands for ergodic mean.

Figure 2.14: Stylized representation of the effect of policy-asset default risk on equilibrium

The summary of our comparison is tabulated in Table 2.6, while Table 2.7 shows that, with inflation under control, real interest rates $\left(r_{t}\right.$ and $\left.r_{t}^{\text {Gov }}\right)$ are the amplified variables. Important to note that, as we raise the default probability, both the risk-free and the default-risky real interest rate demanded in equilibrium increase. This result is engendered by consumption smoothing under incomplete markets of the type modeled here, where only part of the 
households are able to buy (partial) insurance against income fluctuations. ${ }^{49}$ Our regime-switching set-up in which defaulting triggers nasty recessions drives its magnitude, as will be shown in Section 2.4.4.

Above all, our results suggest that assuming default risk in the underlying policy asset may have numerically relevant implications for monetary policy. Since our solution method includes the linearization of the model, we rely to some extent on certainty equivalence ${ }^{50}$, what excludes excessive risk premia due to the risk-aversion of the agents. Having this in mind gives us a glimpse that, in periods of financial distress, the divergence between the policy rules should be even larger.
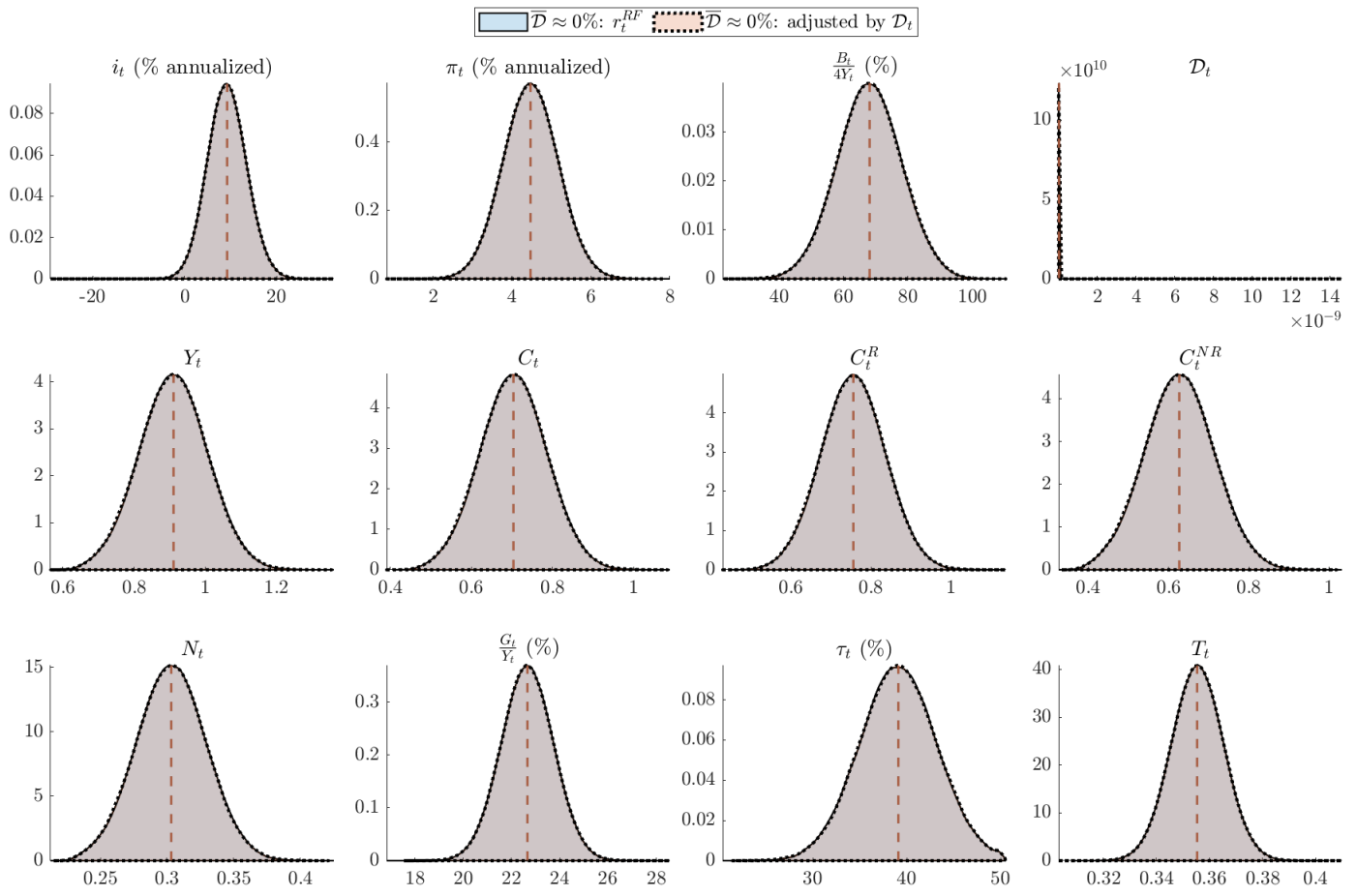

Note: Each vertical line is at the median of the distribution with the same color. Horizontal axis indicates the values of the variables, while the vertical axis indicates the probability density of each value. Density functions are estimated with the Epanechnikov kernel.

Figure 2.15: Ergodic distribution of selected endogenous variables under different monetary policy rules far from the fiscal limit

\footnotetext{
${ }^{49}$ Kocherlakota (2015) singles out a similar result in the incomplete market class of models of Bewley (1986) and Aiyagari (1994) - solved with global methods - where additional supply of public debt is not completely offset by corresponding additional demand due to borrowing constraints, resulting in the increase of the long-run neutral real interest rate.

${ }^{50}$ Regime-switching models are not usually certainty-equivalence models since the decision rule that solves the stochastic problem may differ from the one that solves the nonstochastic problem. Specifically, this paper's model violates the property that $\mathbb{E}\left(\varepsilon_{t+1} \mid x_{t}\right)=0$, where $x_{t}$ is the state vector. For instance, being close to the fiscal limit increases the likelihood of a negative TFP shock $\left(\delta^{T F P}>0\right)$.
} 

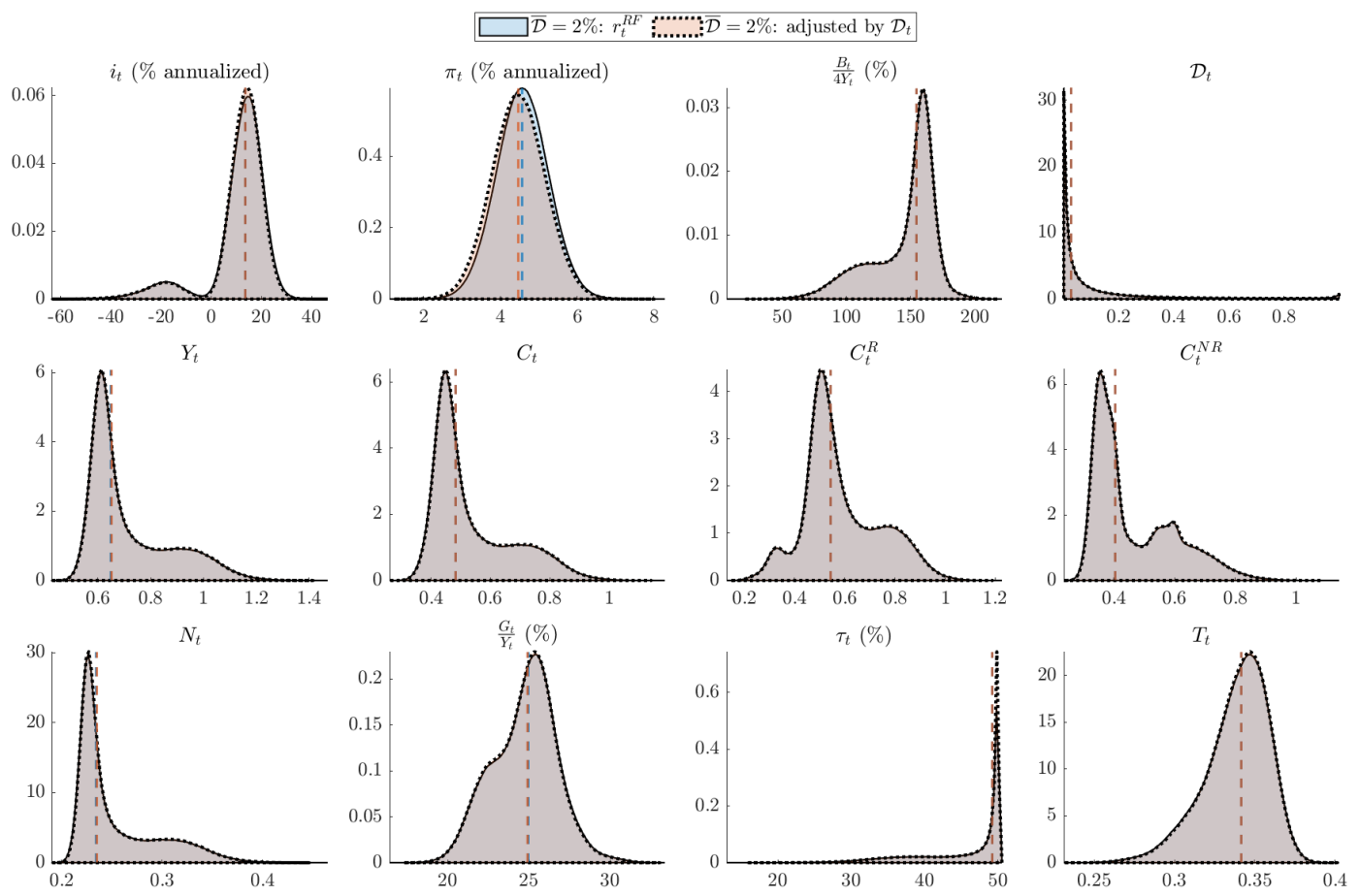

Note: Each vertical line is at the median of the distribution with the same color. Horizontal axis indicates the values of the variables, while the vertical axis indicates the probability density of each value. Density functions are estimated with the Epanechnikov kernel.

Figure 2.16: Ergodic distribution of selected endogenous variables under different monetary policy rules near the fiscal limit 
All observations

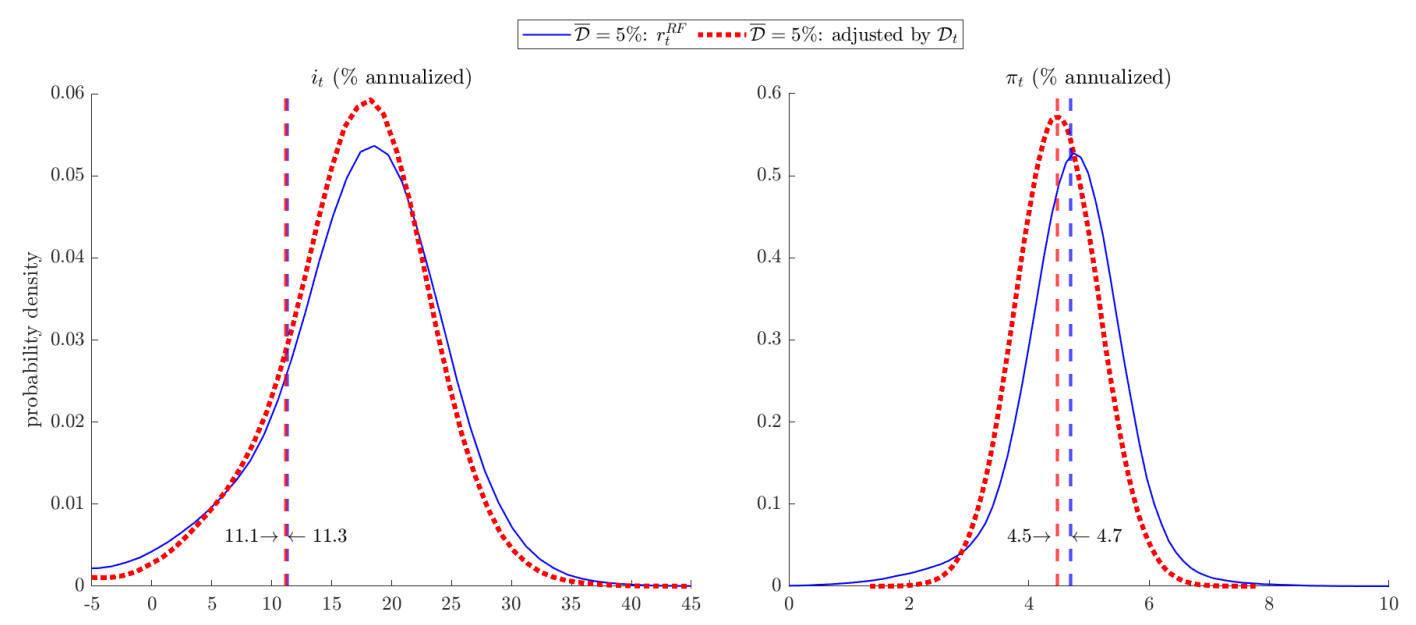

Only observations in which the policy rate is above zero

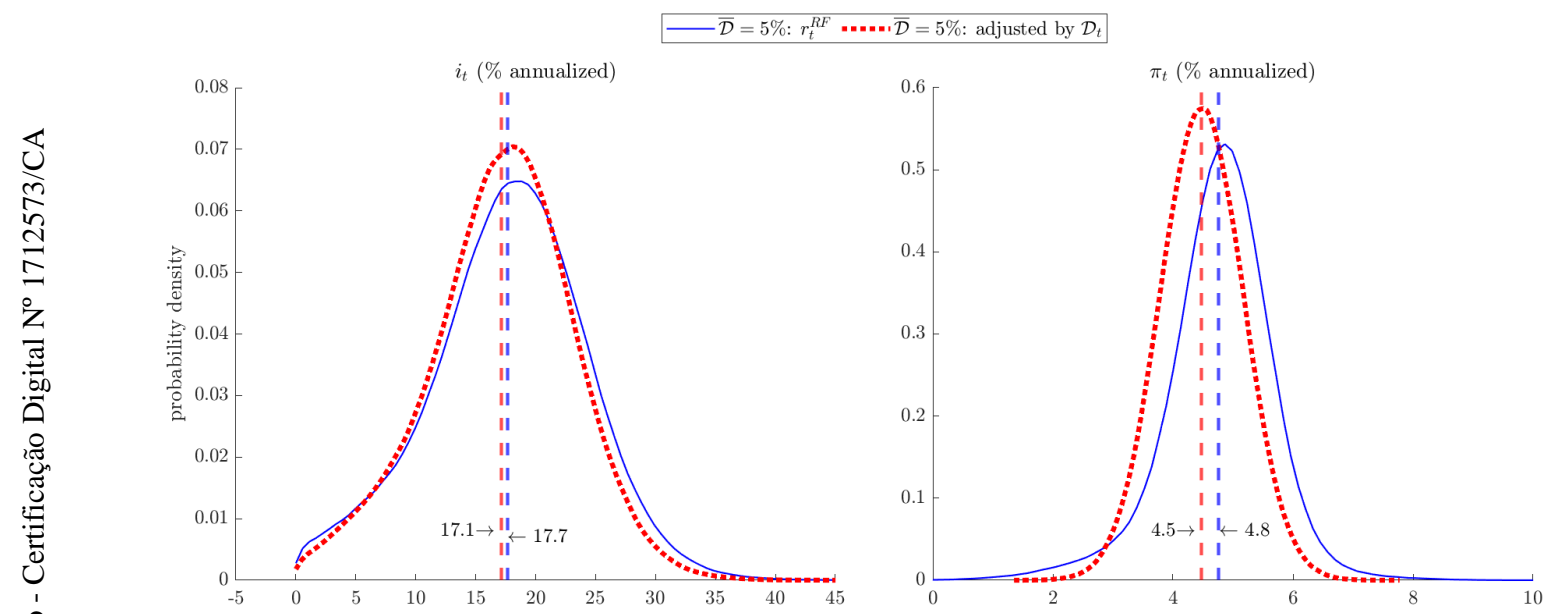

Note: Each vertical line is at the mean of the distribution with the same color. Horizontal axis indicates the values of the variables, while the vertical axis indicates the probability density of each value. Density functions are estimated with the Epanechnikov kernel.

Figure 2.17: Ergodic distribution of the policy rate and of inflation under different monetary policy rules near the fiscal limit 
All observations

\begin{tabular}{l|ccc|ccc}
\hline \hline & \multicolumn{3}{|c|}{$i_{t}(\%$ annualized $)$} & \multicolumn{3}{c}{$\pi_{t}(\%$ annualized $)$} \\
& DSS & EM & Bias & DSS & EM & Bias \\
\hline$\overline{\mathcal{D}}=5 \%: r_{t}^{R F}$ & 9.7 & 11.3 & 1.6 & 4.5 & 4.7 & 0.2 \\
$\overline{\mathcal{D}}=5 \%$ : adjusted by $\mathcal{D}_{t}$ & 9.7 & 11.1 & 1.4 & 4.5 & 4.5 & 0 \\
\hline \hline
\end{tabular}

Only observations in which the policy rate is above zero

\begin{tabular}{l|ccc|ccc}
\hline \hline & \multicolumn{3}{|c|}{$i_{t}(\%$ annualized $)$} & \multicolumn{3}{c}{$\pi_{t}(\%$ annualized $)$} \\
& DSS & EM & Bias & DSS & EM & Bias \\
\hline$\overline{\mathcal{D}}=5 \%: r_{t}^{R F}$ & 9.7 & 17.7 & 8 & 4.5 & 4.8 & 0.3 \\
$\overline{\mathcal{D}}=5 \%$ : adjusted by $\mathcal{D}_{t}$ & 9.7 & 17.1 & 7.4 & 4.5 & 4.5 & 0 \\
\hline \hline
\end{tabular}

Note: DSS stands for deterministic steady state (or non-stochastic) and the ones displayed belong to Regime 1; EM stands for the ergodic mean of a Monte Carlo simulation with 4 Markov Chains including 330,000 periods each, where the first 30,000 periods are discarded as burn-in; while Bias is calculated as the difference between EM and DSS. Displayed values are the means of annualized rates.

Table 2.6: Bias comparison: $i_{t}$ and $\pi_{t}$

All observations

\begin{tabular}{l|ccc|ccc}
\hline \hline & \multicolumn{3}{|c|}{$r_{t}(\%$ annualized $)$} & \multicolumn{3}{c}{$r_{t}^{\text {Gov }}$ (\% annualized $)$} \\
& DSS & EM & Bias & DSS & EM & Bias \\
\hline$\overline{\mathcal{D}}=5 \%: r_{t}^{R F}$ & 5 & 6.1 & 1.1 & 5 & 6.1 & 1.1 \\
$\overline{\mathcal{D}}=5 \%$ : adjusted by $\mathcal{D}_{t}$ & 5 & 6.4 & 1.4 & 5 & 6.4 & 1.4 \\
\hline \hline
\end{tabular}

Only observations in which the policy rate is above zero

\begin{tabular}{l|ccc|ccc}
\hline \hline & \multicolumn{3}{|c|}{$r_{t}(\%$ annualized $)$} & \multicolumn{3}{c}{$r_{t}^{\text {Gov }}$ (\% annualized $)$} \\
& DSS & EM & Bias & DSS & EM & Bias \\
\hline$\overline{\mathcal{D}}=5 \%: r_{t}^{R F}$ & 5 & 12.2 & 7.2 & 5 & 12.2 & 7.2 \\
$\overline{\mathcal{D}}=5 \%$ : adjusted by $\mathcal{D}_{t}$ & 5 & 12.1 & 7.1 & 5 & 12.1 & 7.1 \\
\hline \hline
\end{tabular}

Note: DSS stands for deterministic steady state (or non-stochastic) and the ones displayed belong to Regime 1; EM stands for the ergodic mean of a Monte Carlo simulation with 4 Markov Chains including 330,000 periods each, where the first 30,000 periods are discarded as burn-in; while Bias is calculated as the difference between EM and DSS. Displayed values are the means of annualized rates.

Table 2.7: Bias comparison: $r_{t}$ and $r_{t}^{G o v}$ 


\subsection{4 \\ Bringing inflation back to the model}

So far, we have analyzed rules in which a time-varying intercept mostly neutralizes the (dis)inflationary impact of the other shocks of this economy but the monetary one, namely, the TFP and the government expenditure shocks. In reason of that, these rules represent a monetary policy's commitment with keeping inflation close to the target at every period, preventing long and lasting deviations. Not very realistic, indeed, as real-life central banks tend to have commitments with longer horizons, what gives them some margin to smooth out policy rate adjustments, including their reaction to temporary changes of the equilibrium real rate. ${ }^{51}$

To loose our policy rules so as to unleash inflation, we proceed in two ways. First, we reactivate smoothing in the policy rate by varying its parameter, $\phi^{i}$, from 0.0 (no smoothing) to 0.9 (high smoothing). Second, we replace the risk-free real rate, $r_{t}^{R F}$, by the risk-free natural real rate, $r_{t}^{n}$, in the time-varying intercept. This last change brings our policy rules closer to some of the rules in the literature as the natural rate is the one consistent with flexible prices. ${ }^{52}$

On the importance of the natural rate, Edge, Kiley and Laforte (2008) estimate a New-Keynesian model for the U.S. economy between 1984 and 2004 using Bayesian methods, and compare the story told by the estimated output and interest rate gaps to the actual policy narrative of the period. They find that some high-frequency fluctuations of the business cycle perceived by policymakers as inefficient in the period were, in fact, efficient responses to movements of the estimated natural interest rate. In comparison with Laubach and Williams (2003), they find the natural rate to be even more volatile, what can be explained by its short-term definition in DSGE models. Moreover, the

${ }^{51}$ The Brazilian Central Bank targets annual inflation measured at the end of each calendar year. Other central banks, such as the Bank of England, pursue a rolling 12-month inflation target.

${ }^{52}$ The FED lists five interest rate rules on its website that according to it are illustrative of the many policy rules that have received attention in the academic literature. Among them, four adopt time-varying long-run real interest rates in the intercept, $r_{t}^{L R}$, while the other one follows a first-difference process that should eventually converge to the same intercept. $r_{t}^{L R}$ is defined as "the level of the neutral inflation-adjusted federal funds rate in the longer run that, on average, is expected to be consistent with sustaining inflation at 2 percent and output at its full resource utilization level". In a move to take these rules to the numbers, the FED conducts an exercise in which it calculates that intercept as "the difference between the linearly interpolated quarterly average values of the long-term forecast for the three-month Treasury bill rate and the long-term forecast for inflation of the implicit GDP price deflator from Blue Chip Economic Indicators". This measure is supposed to be a slow-mover, contrasting with the behavior of the natural rate simulated in DSGE models. Available on https://www.federalreserve.gov/monetarypolicy/policy-rules-and-howpolicymakers-use-them.htm as of July 172021. 
authors find that actual market real interest rates seem to be less volatile than the natural one, what could be explained by the central banks' preference for Taylor rules with smooth adjustment. In our exercise, we opt to introduce the natural rate by appending to the model the counterfactual flexible-price equations (2-40), (2-41), (2-44), and (2-46), as well as duplicating (2-27), while renaming each variable with a $n$ superscript. ${ }^{53}$ This way, while we do not ignore the effect of sticky prices in the simulated trajectory of the variables, to some extent we are able to clean the reaction of the central bank to price stickiness. Therefore, temporary deviations from the inflation target emerge more frequently in the model. ${ }^{54}$

We proceed by conducting a Monte Carlo simulation with 4 Markov Chains in which each chain includes 33,000 periods where the first 3,000 are excluded as burn-in. Table 2.8 displays the simulated means for the policy rate, the real interest rate, and inflation, all annualized, in a set-up with $\mathcal{D}=2 \%$ and $r_{t}^{n}$ in the intercept. Different combinations of $\phi^{\pi}$ and $\phi^{i}$ are simulated. Note that $\mathbb{E} i_{t}$ and $\mathbb{E} r_{t}$ are always higher than their value at the deterministic steadystate, while $\mathbb{E} \pi_{t}$ increases exponentially with smoothing. ${ }^{55}$ This result shows that even low levels of default risk can lead to a reality of high policy rates, high real rates, and moderately high inflation. Table 2.9 excludes observations of all regimes but Regime 1 to allow us to make a closer comparison with single-regime models. One can note how the deviation from the deterministic steady state is sizable, which highlights the importance of "hidden" regimes to explain observed levels of variables. In Table 2.10, we present the results of the same set-up, but with the model solved in second order around the deterministic steady state of each regime. Now, there is more than expected loss and regime-switching engendering the unpleasant coincidence, there is also risk-aversion from the households amplifying the phenomenon.

\footnotetext{
${ }^{53}$ Alternatively, the natural rate could have been obtained from the simulation of the flexible-price version of the regime-switching model.

${ }^{54}$ This approach is adopted in Neiss and Nelson (2003) and has the benefit of making the real natural rate an exogenous object, but at the cost of, as Woodford (2011, sec. 3.4 of ch. 5) criticizes, reducing its connection with equilibrium determination in the sticky-price economy.

${ }^{55}$ There is usually no closed-form relation between the ergodic mean of variables in an endogenous regime-switching model and deterministic steady states. Each non-linearity in the model, including asymmetrical shock distributions, may bias equilibrium values to one direction or the other.
} 
Chapter 2. An Unpleasant Coincidence for Monetary Policy: Risky Assets and Fiscal Limits

$i_{t}$ (\% annualized, DSS $\bar{i}=9.7$ in Regime 1$)$

\begin{tabular}{rrrrrrrr}
\hline \hline & $\phi^{i}=0.000$ & $\phi^{i}=0.150$ & $\phi^{i}=0.300$ & $\phi^{i}=0.450$ & $\phi^{i}=0.600$ & $\phi^{i}=0.750$ & $\phi^{i}=0.900$ \\
\hline$\phi^{\pi}=1.00$ & 28.2 & 27 & 23.8 & 21.3 & 18.1 & 14.7 & 10.8 \\
$\phi^{\pi}=1.25$ & 11.7 & 11.4 & 11.5 & 11.4 & 11.5 & 11.8 & 11.1 \\
$\phi^{\pi}=1.50$ & 11 & 10.9 & 10.8 & 10.8 & 11 & 11.1 & 11.1 \\
$\phi^{\pi}=1.75$ & 10.7 & 10.7 & 10.7 & 10.8 & 10.8 & 11 & 11 \\
$\phi^{\pi}=2.00$ & 10.7 & 10.7 & 10.7 & 10.8 & 10.8 & 11 & 11.1 \\
$\phi^{\pi}=2.25$ & 10.8 & 10.7 & 10.7 & 10.7 & 10.7 & 11.1 & 11.1 \\
$\phi^{\pi}=2.50$ & 10.7 & 10.7 & 10.7 & 10.7 & 10.8 & 11 & 11.1 \\
$\phi^{\pi}=2.75$ & 10.8 & 10.6 & 10.7 & 10.7 & 10.8 & 11 & 11.2 \\
$\phi^{\pi}=3.00$ & 10.7 & 10.8 & 10.7 & 10.8 & 10.8 & 11 & 11.1 \\
\hline \hline
\end{tabular}

$r_{t}(\%$ annualized, DSS $\bar{r}=5.0$ in Regime 1)

\begin{tabular}{lrrrrrrr}
\hline \hline & $\phi^{i}=0.000$ & $\phi^{i}=0.150$ & $\phi^{i}=0.300$ & $\phi^{i}=0.450$ & $\phi^{i}=0.600$ & $\phi^{i}=0.750$ & $\phi^{i}=0.900$ \\
\hline$\phi^{\pi}=1.00$ & 6.5 & 6.5 & 6.3 & 6.3 & 6.2 & 6.2 & 5.6 \\
$\phi^{\pi}=1.25$ & 5.8 & 5.7 & 5.7 & 5.7 & 5.8 & 6 & 5.4 \\
$\phi^{\pi}=1.50$ & 6 & 5.9 & 5.9 & 5.9 & 5.9 & 5.9 & 5.4 \\
$\phi^{\pi}=1.75$ & 5.9 & 5.9 & 6 & 6 & 5.9 & 5.9 & 5.4 \\
$\phi^{\pi}=2.00$ & 5.9 & 6 & 5.9 & 6 & 5.9 & 5.9 & 5.4 \\
$\phi^{\pi}=2.25$ & 6 & 6 & 5.9 & 5.9 & 5.9 & 6 & 5.3 \\
$\phi^{\pi}=2.50$ & 6 & 6 & 6 & 6 & 6 & 5.9 & 5.3 \\
$\phi^{\pi}=2.75$ & 6.1 & 5.9 & 6 & 5.9 & 5.9 & 5.9 & 5.3 \\
$\phi^{\pi}=3.00$ & 6 & 6 & 5.9 & 6 & 5.9 & 5.8 & 5.3 \\
\hline \hline
\end{tabular}

$\pi_{t}$ (\% annualized, DSS $\bar{\pi}=4.5$ in Regime 1 )

\begin{tabular}{lrrrrrrr}
\hline \hline & $\phi^{i}=0.000$ & $\phi^{i}=0.150$ & $\phi^{i}=0.300$ & $\phi^{i}=0.450$ & $\phi^{i}=0.600$ & $\phi^{i}=0.750$ & $\phi^{i}=0.900$ \\
\hline$\phi^{\pi}=1.00$ & 20.6 & 19.5 & 16.7 & 14.4 & 11.5 & 8.5 & 5.8 \\
$\phi^{\pi}=1.25$ & 5.3 & 5.3 & 5.4 & 5.4 & 5.6 & 5.9 & 6.3 \\
$\phi^{\pi}=1.50$ & 4.6 & 4.6 & 4.7 & 4.7 & 4.9 & 5.3 & 6.3 \\
$\phi^{\pi}=1.75$ & 4.4 & 4.5 & 4.5 & 4.6 & 4.8 & 5.2 & 6.2 \\
$\phi^{\pi}=2.00$ & 4.4 & 4.4 & 4.5 & 4.6 & 4.8 & 5.2 & 6.3 \\
$\phi^{\pi}=2.25$ & 4.4 & 4.4 & 4.5 & 4.6 & 4.8 & 5.2 & 6.3 \\
$\phi^{\pi}=2.50$ & 4.4 & 4.4 & 4.5 & 4.6 & 4.8 & 5.2 & 6.3 \\
$\phi^{\pi}=2.75$ & 4.4 & 4.4 & 4.5 & 4.6 & 4.8 & 5.2 & 6.3 \\
$\phi^{\pi}=3.00$ & 4.4 & 4.5 & 4.5 & 4.7 & 4.8 & 5.2 & 6.3 \\
\hline \hline
\end{tabular}

Table 2.8: Simulated means: $\overline{\mathcal{D}}=2 \% ; r_{t}^{n}$ in the intercept 
Chapter 2. An Unpleasant Coincidence for Monetary Policy: Risky Assets and Fiscal Limits

$i_{t}$ (\% annualized, DSS $\bar{i}=9.7$ in Regime 1$)$

\begin{tabular}{rrrrrrrr}
\hline \hline & $\phi^{i}=0.000$ & $\phi^{i}=0.150$ & $\phi^{i}=0.300$ & $\phi^{i}=0.450$ & $\phi^{i}=0.600$ & $\phi^{i}=0.750$ & $\phi^{i}=0.900$ \\
\hline$\phi^{\pi}=1.00$ & 28.7 & 27 & 24.2 & 21.8 & 17.8 & 14.8 & 10.6 \\
$\phi^{\pi}=1.25$ & 14.9 & 14.3 & 13.8 & 13.3 & 13 & 12.6 & 11.3 \\
$\phi^{\pi}=1.50$ & 14.2 & 13.6 & 13.2 & 12.5 & 12.2 & 12.1 & 11.4 \\
$\phi^{\pi}=1.75$ & 13.8 & 13.3 & 12.7 & 12.5 & 12.1 & 12 & 11.6 \\
$\phi^{\pi}=2.00$ & 13.7 & 13.4 & 12.8 & 12.5 & 12.2 & 12.1 & 11.6 \\
$\phi^{\pi}=2.25$ & 13.8 & 13.1 & 12.8 & 12.6 & 12.4 & 12.1 & 11.8 \\
$\phi^{\pi}=2.50$ & 13.6 & 13.4 & 12.9 & 12.7 & 12.4 & 12.2 & 12.1 \\
$\phi^{\pi}=2.75$ & 13.7 & 13.3 & 13.1 & 12.7 & 12.4 & 12.1 & 12 \\
$\phi^{\pi}=3.00$ & 13.8 & 13.2 & 12.9 & 12.6 & 12.3 & 12.1 & 12.1 \\
\hline \hline
\end{tabular}

$r_{t}(\%$ annualized, DSS $\bar{r}=5.0$ in Regime 1$)$

\begin{tabular}{rrrrrrrr}
\hline \hline & $\phi^{i}=0.000$ & $\phi^{i}=0.150$ & $\phi^{i}=0.300$ & $\phi^{i}=0.450$ & $\phi^{i}=0.600$ & $\phi^{i}=0.750$ & $\phi^{i}=0.900$ \\
\hline$\phi^{\pi}=1.00$ & 9.8 & 9.3 & 8.7 & 8.3 & 7.6 & 7.5 & 6.8 \\
$\phi^{\pi}=1.25$ & 8.9 & 8.4 & 8 & 7.6 & 7.4 & 7.3 & 7 \\
$\phi^{\pi}=1.50$ & 9 & 8.5 & 8.1 & 7.6 & 7.3 & 7.2 & 6.9 \\
$\phi^{\pi}=1.75$ & 8.8 & 8.4 & 7.9 & 7.7 & 7.3 & 7.2 & 7 \\
$\phi^{\pi}=2.00$ & 8.8 & 8.5 & 8 & 7.8 & 7.5 & 7.3 & 7 \\
$\phi^{\pi}=2.25$ & 8.9 & 8.2 & 8 & 7.8 & 7.6 & 7.2 & 7 \\
$\phi^{\pi}=2.50$ & 8.7 & 8.5 & 8.1 & 7.9 & 7.6 & 7.4 & 7.2 \\
$\phi^{\pi}=2.75$ & 8.9 & 8.4 & 8.3 & 7.9 & 7.6 & 7.2 & 7 \\
$\phi^{\pi}=3.00$ & 8.9 & 8.3 & 8.1 & 7.8 & 7.5 & 7.2 & 7.1 \\
\hline \hline
\end{tabular}

$\pi_{t}(\%$ annualized, DSS $\bar{\pi}=4.5$ in Regime 1$)$

\begin{tabular}{lrrrrrrr}
\hline \hline & $\phi^{i}=0.000$ & $\phi^{i}=0.150$ & $\phi^{i}=0.300$ & $\phi^{i}=0.450$ & $\phi^{i}=0.600$ & $\phi^{i}=0.750$ & $\phi^{i}=0.900$ \\
\hline$\phi^{\pi}=1.00$ & 17.3 & 16.3 & 14.5 & 12.7 & 9.7 & 7.2 & 4.3 \\
$\phi^{\pi}=1.25$ & 5.4 & 5.3 & 5.3 & 5.3 & 5.4 & 5.4 & 4.9 \\
$\phi^{\pi}=1.50$ & 4.7 & 4.7 & 4.7 & 4.7 & 4.8 & 4.9 & 5 \\
$\phi^{\pi}=1.75$ & 4.5 & 4.5 & 4.5 & 4.6 & 4.7 & 4.9 & 5.1 \\
$\phi^{\pi}=2.00$ & 4.5 & 4.5 & 4.5 & 4.6 & 4.7 & 4.9 & 5.2 \\
$\phi^{\pi}=2.25$ & 4.5 & 4.5 & 4.5 & 4.6 & 4.7 & 4.9 & 5.4 \\
$\phi^{\pi}=2.50$ & 4.5 & 4.5 & 4.5 & 4.6 & 4.7 & 5 & 5.5 \\
$\phi^{\pi}=2.75$ & 4.5 & 4.5 & 4.5 & 4.6 & 4.7 & 5 & 5.5 \\
$\phi^{\pi}=3.00$ & 4.5 & 4.5 & 4.5 & 4.6 & 4.7 & 5 & 5.6 \\
\hline \hline
\end{tabular}

Table 2.9: Simulated means (Regime 1): $\overline{\mathcal{D}}=2 \% ; r_{t}^{n}$ in the intercept 
Chapter 2. An Unpleasant Coincidence for Monetary Policy: Risky Assets and Fiscal Limits

$i_{t}$ (\% annualized, DSS $\bar{i}=9.7$ in Regime 1$)$

\begin{tabular}{rrrrrrrr}
\hline \hline & $\phi^{i}=0.000$ & $\phi^{i}=0.150$ & $\phi^{i}=0.300$ & $\phi^{i}=0.450$ & $\phi^{i}=0.600$ & $\phi^{i}=0.750$ & $\phi^{i}=0.900$ \\
\hline$\phi^{\pi}=1.00$ & 3051977.4 & 969350.4 & 252996.6 & 35574.6 & 3155.1 & 4323.7 & 176639.4 \\
$\phi^{\pi}=1.25$ & 16.5 & 16.2 & 16.1 & 16.3 & 16.9 & 18.9 & 32.1 \\
$\phi^{\pi}=1.50$ & 13.5 & 13.2 & 13.1 & 13 & 13.4 & 14.6 & 21.4 \\
$\phi^{\pi}=1.75$ & 12.7 & 12.5 & 12.2 & 12.2 & 12.4 & 13.3 & 17.9 \\
$\phi^{\pi}=2.00$ & 12.4 & 12.2 & 11.9 & 12 & 12 & 12.7 & 16.1 \\
$\phi^{\pi}=2.25$ & 12.3 & 12 & 11.8 & 11.7 & 11.9 & 12.4 & 15.1 \\
$\phi^{\pi}=2.50$ & 12.2 & 11.9 & 11.7 & 11.7 & 11.8 & 12.1 & 14.6 \\
$\phi^{\pi}=2.75$ & 12.2 & 11.8 & 11.7 & 11.6 & 11.7 & 12.1 & 14.1 \\
$\phi^{\pi}=3.00$ & 12.1 & 11.8 & 11.6 & 11.6 & 11.7 & 12 & 13.7 \\
\hline \hline
\end{tabular}

$r_{t}(\%$ annualized, DSS $\bar{r}=5.0$ in Regime 1$)$

\begin{tabular}{rrrrrrrr}
\hline \hline & $\phi^{i}=0.000$ & $\phi^{i}=0.150$ & $\phi^{i}=0.300$ & $\phi^{i}=0.450$ & $\phi^{i}=0.600$ & $\phi^{i}=0.750$ & $\phi^{i}=0.900$ \\
\hline$\phi^{\pi}=1.00$ & 413.3 & 170.4 & 63.7 & 16.9 & 6.1 & 5.3 & 10.6 \\
$\phi^{\pi}=1.25$ & 6.9 & 6.6 & 6.5 & 6.4 & 6.5 & 6.9 & 7.9 \\
$\phi^{\pi}=1.50$ & 6.9 & 6.6 & 6.5 & 6.4 & 6.5 & 6.8 & 7.7 \\
$\phi^{\pi}=1.75$ & 7 & 6.7 & 6.5 & 6.5 & 6.4 & 6.7 & 7.4 \\
$\phi^{\pi}=2.00$ & 7 & 6.8 & 6.6 & 6.5 & 6.5 & 6.6 & 7.3 \\
$\phi^{\pi}=2.25$ & 7 & 6.8 & 6.5 & 6.5 & 6.4 & 6.5 & 7.1 \\
$\phi^{\pi}=2.50$ & 7.1 & 6.8 & 6.6 & 6.5 & 6.5 & 6.5 & 7 \\
$\phi^{\pi}=2.75$ & 7.1 & 6.8 & 6.6 & 6.5 & 6.5 & 6.5 & 7 \\
$\phi^{\pi}=3.00$ & 7.1 & 6.8 & 6.6 & 6.6 & 6.5 & 6.5 & 6.8 \\
\hline \hline
\end{tabular}

$\pi_{t}$ (\% annualized, DSS $\bar{\pi}=4.5$ in Regime 1 )

\begin{tabular}{rrrrrrrr}
\hline \hline & $\phi^{i}=0.000$ & $\phi^{i}=0.150$ & $\phi^{i}=0.300$ & $\phi^{i}=0.450$ & $\phi^{i}=0.600$ & $\phi^{i}=0.750$ & $\phi^{i}=0.900$ \\
\hline$\phi^{\pi}=1.00$ & 2858858.7 & 914789.3 & 241008.9 & 34430.9 & 3045.8 & 4123.1 & 169819.4 \\
$\phi^{\pi}=1.25$ & 8.5 & 8.7 & 8.8 & 9.3 & 10.1 & 12 & 24.5 \\
$\phi^{\pi}=1.50$ & 5.8 & 5.9 & 6.1 & 6.2 & 6.8 & 8.1 & 14.6 \\
$\phi^{\pi}=1.75$ & 5.1 & 5.2 & 5.3 & 5.5 & 5.9 & 6.9 & 11.6 \\
$\phi^{\pi}=2.00$ & 4.9 & 4.9 & 5 & 5.2 & 5.6 & 6.4 & 10 \\
$\phi^{\pi}=2.25$ & 4.7 & 4.8 & 4.9 & 5.1 & 5.4 & 6.1 & 9.1 \\
$\phi^{\pi}=2.50$ & 4.7 & 4.7 & 4.8 & 5 & 5.3 & 5.9 & 8.6 \\
$\phi^{\pi}=2.75$ & 4.6 & 4.7 & 4.8 & 5 & 5.2 & 5.8 & 8.2 \\
$\phi^{\pi}=3.00$ & 4.6 & 4.7 & 4.8 & 4.9 & 5.2 & 5.8 & 7.9 \\
\hline \hline
\end{tabular}

Table 2.10: Simulated means $\left(2^{\text {nd }}\right.$ Order $): \overline{\mathcal{D}}=2 \% ; r_{t}^{n}$ in the intercept

So, what does drive these results? In Table 2.11, we repeat the exercise, but this time eliminating the recession shock in case of default, $\delta^{T F P}=0$. Note how we practically return to the deterministic steady state of Regime 1 for all combinations of $\phi^{\pi}$ and $\phi^{i}$. This sheds light on why default risk is so powerful as to generate previous results. Confiscating resources from the Ricardian households may be (morally) bad, but the recession that it 
elicits is (economically) much worse. Although rare, it is a disaster, and one which increases the likelihood of drawing an extremely negative TFP shock from the latter's, otherwise normal, distribution. In traditional models without regime-switching, that distribution is usually assumed to be symmetrical. This explains why they cannot generate the unpleasant coincidence discussed in this paper. Overall, Ricardian agents suffer a financial wealth loss at the exact time that they need it the most for smoothing their consumption out: at a severe recession.

From the Euler equation of the policy asset (2-10) evaluated at the ergodic mean, one variable that helps to set the wedge w.r.t the deterministic steady state is the expected default probability, whose ergodic mean value increases with the size of $\delta^{T F P}$, since more profound recessions deteriorate by more the fiscal position of the government and also increase the likelihood of reaching the peak of the Laffer curve. In decomposition $(2-54),{ }^{56}$ we make explicit that the covariance between the Ricardian's household one-period utility growth and the expected default probability for the next period should be negative due to default-enacted recession, which allows us to infer that default-risky real interest rates are higher at the ergodic mean in comparison with at the deterministic steady state, since utility at a default event is highly likely to be lower than at the period before of it. ${ }^{57}$ Besides, in reason that default risk makes a regime switch more likely, the volatility of endogenous variables increase, as we have seen in Figure 2.16, what also helps to push upward interest rates at the ergodic mean, making the wedge sizable.

$$
\begin{array}{r}
\mathbb{E}^{E M}\left[\frac{1}{1+r_{t}}\right]=\mathbb{E}^{E M}[\underbrace{\beta}_{\Lambda_{U}} \underbrace{\left(\frac{C_{t+1}^{R}+\alpha_{G} G_{t+1}-\eta \frac{N_{t+1}^{1+\chi}}{1+\chi}}{C_{t}^{R}+\alpha_{G} G_{t}-\eta \frac{N_{t}^{1+\chi}}{1+\chi}}\right)^{-\sigma} \underbrace{\left(1-\delta_{t+1}\right)}_{\Lambda_{D}}]}_{\mathbb{E}^{D S S}\left[r_{t}\right]<\mathbb{E}^{E M}\left[r_{t}\right]} \\
=
\end{array}
$$

So, how important is that regimes switch endogenously? It can be seen in Table 2.12 what happens if the default probability is kept fixed at its deterministic steady-state value (exogenous switching). ${ }^{58}$ Both nominal and

${ }^{56} \mathbb{E}^{E M}$ and $\mathrm{COV}^{E M}$ stand for, respectively, the unconditional expectation and the unconditional covariance operators for the ergodic distribution.

${ }^{57}$ For low values of $\delta^{T F P}$, this relation is less obvious given the distribution of non-TFP shocks.

${ }^{58}$ We maintain the peak of the Laffer curve constraint endogenous in reason that it is modeled like an occasionally binding constraint. 
real policy rates as well as inflation shrink in comparison with Table 2.8. Taking the difference between both tables results in the endogenous component of the total expectations-formation effect, following the terminology of Leeper and Zha (2003) and Chang, Maih and Tan (2019). That effect is induced by changes in the agents' beliefs about regimes. The fact that it is sizable in the model highlights not only the importance of the Lucas (1976) critique, but also the importance of allowing transitions matrices to evolve with the state vector.

$$
\begin{array}{r}
\text { Total effect } \equiv \mathbb{E}^{E M}\left[X_{t}\right]-\mathbb{E}^{E M}\left[X_{t} \mid \text { Regime }_{t}=1 \forall t\right] \\
\text { Endogenous effect } \equiv \mathbb{E}^{E M}\left[X_{t}\right]-\mathbb{E}^{E M}\left[X_{t} \mid \text { Exogenous switching }\right] \\
\text { Exogenous effect } \equiv \text { Total effect }- \text { Endogenous effect }
\end{array}
$$

Finally, what about the heterogeneity of our households? In Table 2.13, we repeat the exercise setting $\gamma^{N R}=0$, so that all households are now Ricardian. ${ }^{59}$ We are, basically, back to similar results as the ones displayed in Table 2.8. This shows that even a representative agent New-Keynesian (RANK) model with regime-switching would be able to reproduce the high levels of policy rate, real interest rate and inflation we find.

\footnotetext{
${ }^{59} \mathrm{~A}$ more rigorous exercise would include recalculating the fiscal limits, which we have showed in this paper it will be displaced to the right along the debt-to-output axis, turning default less likely at any level of debt.
} 
Chapter 2. An Unpleasant Coincidence for Monetary Policy: Risky Assets and Fiscal Limits

$i_{t}$ (\% annualized, DSS $\bar{i}=9.7$ in Regime 1$)$

\begin{tabular}{lrrrrrrr}
\hline \hline & $\phi^{i}=0.000$ & $\phi^{i}=0.150$ & $\phi^{i}=0.300$ & $\phi^{i}=0.450$ & $\phi^{i}=0.600$ & $\phi^{i}=0.750$ & $\phi^{i}=0.900$ \\
\hline$\phi^{\pi}=1.00$ & 9.3 & 9.5 & 9.4 & 9.3 & 9.3 & 9.4 & 9.1 \\
$\phi^{\pi}=1.25$ & 9.3 & 9.2 & 9.2 & 9.1 & 9.2 & 9.2 & 8.9 \\
$\phi^{\pi}=1.50$ & 9.3 & 9.3 & 9.3 & 9.3 & 9.3 & 9.2 & 9 \\
$\phi^{\pi}=1.75$ & 9.3 & 9.3 & 9.5 & 9.3 & 9.3 & 9.2 & 8.9 \\
$\phi^{\pi}=2.00$ & 9.3 & 9.3 & 9.2 & 9.4 & 9.3 & 9.2 & 9 \\
$\phi^{\pi}=2.25$ & 9.4 & 9.3 & 9.4 & 9.3 & 9.3 & 9.3 & 9 \\
$\phi^{\pi}=2.50$ & 9.4 & 9.3 & 9.3 & 9.3 & 9.3 & 9.3 & 9 \\
$\phi^{\pi}=2.75$ & 9.4 & 9.3 & 9.3 & 9.3 & 9.3 & 9.3 & 9.1 \\
$\phi^{\pi}=3.00$ & 9.3 & 9.4 & 9.3 & 9.4 & 9.4 & 9.3 & 9.1 \\
\hline \hline
\end{tabular}

$r_{t}(\%$ annualized, DSS $\bar{r}=5.0$ in Regime 1$)$

\begin{tabular}{lrrrrrrr}
\hline \hline & $\phi^{i}=0.000$ & $\phi^{i}=0.150$ & $\phi^{i}=0.300$ & $\phi^{i}=0.450$ & $\phi^{i}=0.600$ & $\phi^{i}=0.750$ & $\phi^{i}=0.900$ \\
\hline$\phi^{\pi}=1.00$ & 4.6 & 4.7 & 4.7 & 4.7 & 4.6 & 4.7 & 4.4 \\
$\phi^{\pi}=1.25$ & 4.7 & 4.6 & 4.6 & 4.6 & 4.6 & 4.6 & 4.3 \\
$\phi^{\pi}=1.50$ & 4.7 & 4.7 & 4.6 & 4.7 & 4.6 & 4.6 & 4.4 \\
$\phi^{\pi}=1.75$ & 4.6 & 4.6 & 4.8 & 4.7 & 4.6 & 4.6 & 4.4 \\
$\phi^{\pi}=2.00$ & 4.6 & 4.7 & 4.6 & 4.8 & 4.6 & 4.6 & 4.4 \\
$\phi^{\pi}=2.25$ & 4.7 & 4.6 & 4.7 & 4.7 & 4.6 & 4.7 & 4.4 \\
$\phi^{\pi}=2.50$ & 4.7 & 4.7 & 4.6 & 4.7 & 4.6 & 4.7 & 4.4 \\
$\phi^{\pi}=2.75$ & 4.7 & 4.7 & 4.6 & 4.6 & 4.7 & 4.7 & 4.5 \\
$\phi^{\pi}=3.00$ & 4.7 & 4.7 & 4.6 & 4.7 & 4.7 & 4.6 & 4.5 \\
\hline \hline
\end{tabular}

$\pi_{t}$ (\% annualized, DSS $\bar{\pi}=4.5$ in Regime 1 )

\begin{tabular}{rrrrrrrr}
\hline \hline & $\phi^{i}=0.000$ & $\phi^{i}=0.150$ & $\phi^{i}=0.300$ & $\phi^{i}=0.450$ & $\phi^{i}=0.600$ & $\phi^{i}=0.750$ & $\phi^{i}=0.900$ \\
\hline$\phi^{\pi}=1.00$ & 4.4 & 4.5 & 4.5 & 4.4 & 4.4 & 4.4 & 4.6 \\
$\phi^{\pi}=1.25$ & 4.4 & 4.4 & 4.4 & 4.3 & 4.4 & 4.4 & 4.5 \\
$\phi^{\pi}=1.50$ & 4.4 & 4.4 & 4.4 & 4.4 & 4.4 & 4.4 & 4.4 \\
$\phi^{\pi}=1.75$ & 4.4 & 4.4 & 4.5 & 4.4 & 4.4 & 4.4 & 4.4 \\
$\phi^{\pi}=2.00$ & 4.4 & 4.5 & 4.4 & 4.5 & 4.4 & 4.4 & 4.4 \\
$\phi^{\pi}=2.25$ & 4.5 & 4.5 & 4.5 & 4.5 & 4.4 & 4.4 & 4.4 \\
$\phi^{\pi}=2.50$ & 4.5 & 4.5 & 4.5 & 4.5 & 4.5 & 4.4 & 4.5 \\
$\phi^{\pi}=2.75$ & 4.5 & 4.5 & 4.5 & 4.5 & 4.5 & 4.5 & 4.5 \\
$\phi^{\pi}=3.00$ & 4.5 & 4.5 & 4.5 & 4.5 & 4.5 & 4.5 & 4.5 \\
\hline \hline
\end{tabular}

Table 2.11: Simulated means: $\overline{\mathcal{D}}=2 \% ; r_{t}^{n}$ in the intercept; and $\delta^{T F P}=0$ 
Chapter 2. An Unpleasant Coincidence for Monetary Policy: Risky Assets and Fiscal Limits

$i_{t}$ (\% annualized, DSS $\bar{i}=9.7$ in Regime 1$)$

\begin{tabular}{rrrrrrrr}
\hline \hline & $\phi^{i}=0.000$ & $\phi^{i}=0.150$ & $\phi^{i}=0.300$ & $\phi^{i}=0.450$ & $\phi^{i}=0.600$ & $\phi^{i}=0.750$ & $\phi^{i}=0.900$ \\
\hline$\phi^{\pi}=1.00$ & 14.2 & 13.5 & 13 & 12.1 & 11.7 & 10.7 & 9.4 \\
$\phi^{\pi}=1.25$ & 10.5 & 10.4 & 10.7 & 10.4 & 10.3 & 10.1 & 9.5 \\
$\phi^{\pi}=1.50$ & 10 & 10.3 & 10.1 & 10 & 10.2 & 10.1 & 9.5 \\
$\phi^{\pi}=1.75$ & 10.2 & 10.2 & 10.1 & 10.1 & 10 & 10.1 & 9.5 \\
$\phi^{\pi}=2.00$ & 10.1 & 10.2 & 10 & 10 & 10 & 9.9 & 9.5 \\
$\phi^{\pi}=2.25$ & 10.1 & 10 & 9.9 & 10 & 9.9 & 9.9 & 9.4 \\
$\phi^{\pi}=2.50$ & 10 & 9.9 & 10 & 10 & 9.9 & 9.9 & 9.5 \\
$\phi^{\pi}=2.75$ & 10 & 10 & 10 & 10.1 & 10 & 9.9 & 9.5 \\
$\phi^{\pi}=3.00$ & 9.9 & 10 & 9.9 & 10 & 10 & 9.9 & 9.5 \\
\hline \hline
\end{tabular}

$r_{t}(\%$ annualized, DSS $\bar{r}=5.0$ in Regime 1)

\begin{tabular}{lrrrrrrr}
\hline \hline & $\phi^{i}=0.000$ & $\phi^{i}=0.150$ & $\phi^{i}=0.300$ & $\phi^{i}=0.450$ & $\phi^{i}=0.600$ & $\phi^{i}=0.750$ & $\phi^{i}=0.900$ \\
\hline$\phi^{\pi}=1.00$ & 5.3 & 5.2 & 5.2 & 5.2 & 5.2 & 5.1 & 4.6 \\
$\phi^{\pi}=1.25$ & 5.2 & 5.2 & 5.3 & 5.1 & 5.1 & 5.1 & 4.6 \\
$\phi^{\pi}=1.50$ & 5.1 & 5.2 & 5.1 & 5.1 & 5.2 & 5.1 & 4.6 \\
$\phi^{\pi}=1.75$ & 5.2 & 5.3 & 5.2 & 5.2 & 5.1 & 5.2 & 4.7 \\
$\phi^{\pi}=2.00$ & 5.2 & 5.3 & 5.2 & 5.1 & 5.1 & 5.1 & 4.7 \\
$\phi^{\pi}=2.25$ & 5.2 & 5.2 & 5.1 & 5.2 & 5.1 & 5.1 & 4.6 \\
$\phi^{\pi}=2.50$ & 5.2 & 5.1 & 5.2 & 5.2 & 5.1 & 5.2 & 4.7 \\
$\phi^{\pi}=2.75$ & 5.2 & 5.2 & 5.2 & 5.3 & 5.2 & 5.2 & 4.7 \\
$\phi^{\pi}=3.00$ & 5.1 & 5.2 & 5.2 & 5.2 & 5.2 & 5.1 & 4.8 \\
\hline \hline
\end{tabular}

$\pi_{t}$ (\% annualized, DSS $\bar{\pi}=4.5$ in Regime 1$)$

\begin{tabular}{rrrrrrrr}
\hline \hline & $\phi^{i}=0.000$ & $\phi^{i}=0.150$ & $\phi^{i}=0.300$ & $\phi^{i}=0.450$ & $\phi^{i}=0.600$ & $\phi^{i}=0.750$ & $\phi^{i}=0.900$ \\
\hline$\phi^{\pi}=1.00$ & 8.4 & 7.8 & 7.4 & 6.6 & 6.2 & 5.3 & 4.8 \\
$\phi^{\pi}=1.25$ & 5.1 & 5 & 5.1 & 5 & 4.9 & 4.8 & 4.8 \\
$\phi^{\pi}=1.50$ & 4.7 & 4.8 & 4.7 & 4.7 & 4.7 & 4.7 & 4.7 \\
$\phi^{\pi}=1.75$ & 4.7 & 4.7 & 4.7 & 4.7 & 4.6 & 4.7 & 4.8 \\
$\phi^{\pi}=2.00$ & 4.6 & 4.6 & 4.6 & 4.6 & 4.6 & 4.6 & 4.7 \\
$\phi^{\pi}=2.25$ & 4.6 & 4.6 & 4.6 & 4.6 & 4.6 & 4.6 & 4.7 \\
$\phi^{\pi}=2.50$ & 4.6 & 4.5 & 4.6 & 4.6 & 4.6 & 4.6 & 4.7 \\
$\phi^{\pi}=2.75$ & 4.5 & 4.5 & 4.5 & 4.6 & 4.6 & 4.6 & 4.6 \\
$\phi^{\pi}=3.00$ & 4.5 & 4.5 & 4.5 & 4.5 & 4.6 & 4.6 & 4.6 \\
\hline \hline
\end{tabular}

Table 2.12: Simulated means (exogenous regime-switching): $\overline{\mathcal{D}}=2 \% ; r_{t}^{n}$ in the intercept 
Chapter 2. An Unpleasant Coincidence for Monetary Policy: Risky Assets and Fiscal Limits

$i_{t}(\%$ annualized, DSS $\bar{i}=9.7$ in Regime 1$)$

\begin{tabular}{rrrrrrrr}
\hline \hline & $\phi^{i}=0.000$ & $\phi^{i}=0.150$ & $\phi^{i}=0.300$ & $\phi^{i}=0.450$ & $\phi^{i}=0.600$ & $\phi^{i}=0.750$ & $\phi^{i}=0.900$ \\
\hline$\phi^{\pi}=1.00$ & 22.7 & 21.5 & 20.1 & 18.7 & 16.4 & 13.9 & 10.5 \\
$\phi^{\pi}=1.25$ & 12.5 & 12.4 & 12.6 & 12.4 & 12.1 & 11.9 & 10.7 \\
$\phi^{\pi}=1.50$ & 11.6 & 11.7 & 11.5 & 11.6 & 11.6 & 11.4 & 10.8 \\
$\phi^{\pi}=1.75$ & 11.5 & 11.3 & 11.4 & 11.2 & 11.2 & 11.2 & 10.6 \\
$\phi^{\pi}=2.00$ & 11.4 & 11.3 & 11.1 & 11.2 & 11.1 & 11.2 & 10.8 \\
$\phi^{\pi}=2.25$ & 11.2 & 11.1 & 11.2 & 11.1 & 11.1 & 11.2 & 10.6 \\
$\phi^{\pi}=2.50$ & 11.1 & 11.2 & 11 & 11 & 11 & 11 & 10.7 \\
$\phi^{\pi}=2.75$ & 11.1 & 11.1 & 11.2 & 11.2 & 11 & 11.1 & 10.7 \\
$\phi^{\pi}=3.00$ & 11 & 11 & 11.1 & 11.1 & 11.1 & 11.1 & 10.7 \\
\hline \hline
\end{tabular}

$r_{t}(\%$ annualized, DSS $\bar{r}=5.0$ in Regime 1$)$

\begin{tabular}{lrrrrrrr}
\hline \hline & $\phi^{i}=0.000$ & $\phi^{i}=0.150$ & $\phi^{i}=0.300$ & $\phi^{i}=0.450$ & $\phi^{i}=0.600$ & $\phi^{i}=0.750$ & $\phi^{i}=0.900$ \\
\hline$\phi^{\pi}=1.00$ & 6.6 & 6.6 & 6.5 & 6.5 & 6.4 & 6.3 & 5.5 \\
$\phi^{\pi}=1.25$ & 6.2 & 6.2 & 6.3 & 6.2 & 6.1 & 6.1 & 5.3 \\
$\phi^{\pi}=1.50$ & 6.2 & 6.2 & 6.1 & 6.2 & 6.2 & 6 & 5.4 \\
$\phi^{\pi}=1.75$ & 6.3 & 6.1 & 6.2 & 6.1 & 6.1 & 6 & 5.2 \\
$\phi^{\pi}=2.00$ & 6.3 & 6.2 & 6.1 & 6.2 & 6.1 & 6 & 5.4 \\
$\phi^{\pi}=2.25$ & 6.2 & 6.2 & 6.2 & 6.1 & 6.1 & 6 & 5.3 \\
$\phi^{\pi}=2.50$ & 6.2 & 6.3 & 6.1 & 6.1 & 6.1 & 5.9 & 5.3 \\
$\phi^{\pi}=2.75$ & 6.2 & 6.1 & 6.3 & 6.2 & 6 & 6.1 & 5.4 \\
$\phi^{\pi}=3.00$ & 6.1 & 6.1 & 6.2 & 6.2 & 6.1 & 6.1 & 5.4 \\
\hline \hline
\end{tabular}

$\pi_{t}$ (\% annualized, DSS $\bar{\pi}=4.5$ in Regime 1$)$

\begin{tabular}{rrrrrrrr}
\hline \hline & $\phi^{i}=0.000$ & $\phi^{i}=0.150$ & $\phi^{i}=0.300$ & $\phi^{i}=0.450$ & $\phi^{i}=0.600$ & $\phi^{i}=0.750$ & $\phi^{i}=0.900$ \\
\hline$\phi^{\pi}=1.00$ & 15.3 & 14.2 & 12.9 & 11.6 & 9.6 & 7.4 & 5.3 \\
$\phi^{\pi}=1.25$ & 5.9 & 5.9 & 5.9 & 5.9 & 5.7 & 5.7 & 5.6 \\
$\phi^{\pi}=1.50$ & 5.1 & 5.1 & 5.1 & 5.2 & 5.2 & 5.3 & 5.6 \\
$\phi^{\pi}=1.75$ & 4.9 & 4.9 & 4.9 & 4.9 & 5 & 5.1 & 5.6 \\
$\phi^{\pi}=2.00$ & 4.8 & 4.8 & 4.8 & 4.8 & 4.9 & 5 & 5.6 \\
$\phi^{\pi}=2.25$ & 4.7 & 4.7 & 4.7 & 4.8 & 4.8 & 5 & 5.5 \\
$\phi^{\pi}=2.50$ & 4.6 & 4.7 & 4.7 & 4.7 & 4.8 & 4.9 & 5.5 \\
$\phi^{\pi}=2.75$ & 4.6 & 4.6 & 4.7 & 4.7 & 4.8 & 4.9 & 5.5 \\
$\phi^{\pi}=3.00$ & 4.6 & 4.6 & 4.6 & 4.7 & 4.8 & 4.9 & 5.4 \\
\hline \hline
\end{tabular}

Table 2.13: Simulated means: $\overline{\mathcal{D}}=2 \% ; r_{t}^{n}$ in the intercept; and $\gamma^{N R}=0$

\section{5}

\section{Conclusion}

The highly frequent idea that governments can, and will, always print money to repay its debt denominated in domestic currency before choosing to default on it is at odds with economic history, what should raise concerns 
for monetary policy. In this paper, we sought to answer the question of whether conducting monetary policy with such default-risky assets, instead of usually conceived risk-free ones, should matter for a central bank. By employing a relatively simple TANK model with government, nominal debt, and endogenous fiscal limits, we find that not only inflation dynamics is affected, but also monetary policy simultaneously generates higher inflation, real, and nominal policy rates unless the central bank updates the intercept of its policy rule in response to changes in the default-risk premium. This result sheds new light on a long-standing discussion on why Brazil, whose economy we use as reference for calibrating our model, has displayed that unpleasant coincidence, which we explain as motivated by endogenous expectations of severe recessions in episodes of default. The slow attenuation of the coincidence since the Real Plan is supposed to reflect a similarly slow transition between higher and lower long-run default-risk perceptions.

Contrary to the current observation of high debt accumulation in advanced economies which seems to suggest the opposite, the level of debt-tooutput ratio of a country does matter, and the coincidence of high levels of inflation and nominal policy rate may be the symptom of an unpleasant reality indeed. The stance of monetary policy suggested by emerging-economy models which neglect this source of misspecification may, therefore, be misleading. Monitoring policy-asset default risk to distinguish its movements from changes in the unobserved real risk-free rate can help central banks fulfill their mandates, as they may be able to consciously opt to accommodate that risk or not to some extent.

Overall, this paper turns upside-down an assumption prevalent in monetary models and shows that, contrary to Milton Friedman's observation that "inflation is always and everywhere a monetary phenomenon" ${ }^{60}$, it is sometimes simply the lack of confidence in the government (or in the central bank).

${ }^{60}$ In 1970, Milton Friedman gave a now famous lecture named "The Counter-Revolution in Monetary Theory", in which he declared: "It follows from the propositions I have so far stated that inflation is always and everywhere a monetary phenomenon in the sense that it is and can be produced only by a more rapid increase in the quantity of money than in output. However, there are many different possible reasons for monetary growth, including gold discoveries, financing of government spending, and financing of private spending" Friedman (1970). 


\section{3 \\ On the Mechanics of New-Keynesian Models: Smoothing the Capital Controversy Out ${ }^{1}$}

Rupert and Šustek (2019) showed that, once we introduce endogenous capital to the canonical New-Keynesian model (i.e. Woodford (2003a); Galí (2015)), real interest rates may move in any direction after a positive monetary shock. According to them, this would prove that the real interest rate transmission channel of monetary policy is only observational, not structural, in that class of models. In this paper, we expose that such an identification problem for VARs can be circumvented by the inclusion of interest-rate smoothing in the Taylor rule - a feature as prevalent in middle-scale New-Keynesian models as capital itself.

Keywords: Monetary Policy, New-Keynesian Model, Interest-Rate Smoothing

JEL Classification: E43, E52, E58

\section{1 \\ Introduction}

In a recent paper, Rupert and Šustek (2019) challenged the existence of a real interest rate channel of monetary policy transmission in textbook New-Keynesian models (Woodford (2003a); Galí (2015)). They showed that, after we introduce endogenous capital to such models, a positive monetary shock becomes consistent with the real interest rate moving in any direction. ${ }^{2}$ According to the authors, this would prove that the aforementioned channel

${ }^{1}$ I thank the advising from Carlos Viana de Carvalho, and the comments from Eduardo Loyo and Ricardo Reis. I gratefully acknowledge the Economics Department of the London School of Economics for its hospitality during the academic year 2018/2019. Beyond the usual disclaimer, I must note that any views expressed herein are mine and not necessarily those of the Banco Central do Brasil or of any of its members. Finally, I also thank the Banco Central do Brasil and CAPES for the financial support, and the Economics Department of PUC-Rio for the opportunity.

${ }^{2}$ Woodford (2003a, sec. 5.3.3) calls the lack of any effect of variations in private spending upon the economy's productive capacity one of the more obvious omissions in the baseline New-Keynesian model. He observes that although there are calibrations for which introducing endogenous capital results in similar dynamics for output and inflation after a monetary shock, the mechanisms within each model which generate these results are not too closely parallel. 
is only observational, not structural, in that class of models, raising serious concerns on the use of the latter for policy recommendations. ${ }^{3}$ Likewise, assuming that channel for the identification of VARs with sign restrictions would also be problematic. In this paper, we show that this identification problem can be largely circumvented in the relevant parameter range by adding interest-rate smoothing to the Taylor rule - a feature as prevalent as capital in middle-scale New-Keynesian DSGE models (i.e. Smets and Wouters (2003)).

The importance of Rupert and Šustek (2019)'s result is straightforward. Although in general equilibrium all variables are determined simultaneously, every model needs a story to tell, and the common view on the transmission of monetary policy in textbook New-Keynesian models relies on the real interest rate channel, which Ireland (2010) describes as follows:

"A monetary tightening in the form of a shock to the Taylor rule that increases the short-term nominal interest rate translates into an increase in the real interest rate as well when nominal prices move sluggishly due to costly or staggered price setting. This rise in the real interest rate then causes households to cut back on their spending, as summarized by the IS curve. Finally, through the Phillips curve, the decline in output puts downward pressure on inflation, which adjusts only gradually after the shock."

Galí (2015, p. 5) also emphasizes the real interest rate channel when describing the short-run non-neutrality of monetary policy in this class of models:

"As a consequence of the presence of nominal rigidities, changes in short term nominal interest rates (whether chosen directly by the central bank or induced by changes in the money supply) are not matched by one-for-one changes in expected inflation, thus leading to variations in real interest rates. The latter bring about changes in consumption and investment and, as a result, on output and employment, because firms find it optimal to adjust the quantity of goods supplied to the new level of demand. In the long run, however, all prices and wages adjust, and the economy reverts back to its natural equilibrium."

Schematically, we should have that a positive monetary shock $\left(\varepsilon_{t}^{m}\right)$ increases the real interest rate $\left(r_{t}\right)$, because of sticky prices, leading to the

${ }^{3}$ By their view, the apparent consistency of the canonical model with the real interest rate channel would be due to its equivalence to a set-up with infinite capital adjustment costs. 
reduction of consumption $\left(C_{t}\right)$, output $\left(Y_{t}\right)$, and, finally, inflation $\left(\pi_{t}\right)$.

$$
\uparrow \varepsilon_{t}^{m} \Rightarrow \underbrace{\uparrow r_{t}}_{\text {if prices are sticky }} \Rightarrow \downarrow C_{t} \Rightarrow \downarrow Y_{t} \Rightarrow \downarrow \pi_{t}
$$

However, Rupert and Šustek (2019) propose a different story, that they argue would be more consistent with the actual mechanics of the model. The transmission does not operate through a real interest rate channel. First, equilibrium inflation is approximately determined as in a flexibleprice model. ${ }^{4}$ Second, output is pinned down by the New-Keynesian Phillips curve, interpreted here as, given the expected inflation trajectory, firms which cannot adjust prices will change output. Finally, the real rate only reflects the feasibility to keep consumption smooth when income changes. Once the authors introduce endogenous capital in the model, consistency with the real interest rate channel becomes observational, not structural, since a contractionary monetary shock reduces inflation and output, but the real interest rate can move in any direction depending on the parameterization of the shock persistence. After adding capital adjustment costs, the authors conclude that the canonical model, without capital, is simply a limiting case where these costs are infinite. According to this view, we are supposed to have monetary transmission as follows:

$$
\uparrow \varepsilon_{t}^{m} \Rightarrow \downarrow \pi_{t} \Rightarrow \underbrace{\downarrow Y_{t}}_{\text {if prices are sticky }} \Rightarrow \downarrow C_{t} \Rightarrow \underbrace{? r_{t}}_{\begin{array}{c}
\text { depends on the presence } \\
\text { of capital and calibration }
\end{array}}
$$

We adopt the following modeling strategy to challenge the practical relevance of the aforementioned finding. First, we solve the textbook NewKeynesian model of Galí (2015) with capital and interest-rate-smoothing in the Taylor rule to show that the latter can circumvent the identification problem revealed by Rupert and Sustek (2019). Our finding that the real interest rate channel of monetary policy is reestablished with a common ingredient of middle-scale New-Keynesian models weakens the concerns for its correct identification in policy-oriented DSGE or VAR models. Then, we better qualify our result by exploring different combinations of interest-rate smoothing and

${ }^{4}$ In Galí (2015)'s chapter 2, a canonical RBC model is augmented with a fixed-intercept interest rate rule to pin down inflation and, thus, a trajectory for the price level. Current inflation, as a deviation of its steady-state value, is determined by the expected path of real interest rate deviations from the steady state, as long as the Taylor principle is obeyed. Important to note that the steady-state value of the real interest rate and the intercept of the monetary policy rule coincide, assuming a zero inflation target. Woodford (2003a)'s chapter 1 shows the same idea in a partial-equilibrium monetary model where the sequence of real interest rates is exogenous. 
capital adjustment costs. We manage to show that the latter is needed to prevent output from overreacting after a monetary shock.

The next sections of this paper are structured as follows. Section 2 presents the related literature. Section 3 describes, solves, and analyzes the closed-economy New-Keynesian model with endogenous capital. Finally, section 4 concludes.

\section{2}

\section{Related literature}

This paper builds on Rupert and Šustek (2019), who scrutinize the mechanics of canonical New-Keynesian models (i.e. Woodford (2003a); Galí (2015)). They argue that the transmission mechanism of monetary policy in this class of models does not operate through the real interest rate channel, against the conventional view. Actually, equilibrium inflation would be determined similarly to when prices are flexible; output is, then, pinned down by the Phillips curve; and the real rate is just the one that smooths out consumption given the income change. As a consequence, a contractionary monetary shock (a positive shock to the intercept of the policy rule), while it reduces inflation and output, it can coexist with the real rate moving in any direction, depending fundamentally on the persistence of the shock. They make explicit this dynamics by comparing the 3 -equation canonical model with an extension with endogenous capital. The observational similitude of the first model with the real interest rate channel would come from a supposed implicit assumption of infinite capital adjustment costs. Their finding could represent an additional challenge on the identification of VAR models with sign restrictions.

Brault and Khan (2019) modify Rupert and Šustek (2019)'s work to include frictions on changes in the flow of investments instead of on capital adjustment and obtain that the real interest rate always moves in the same direction as the monetary policy shock. That result does not depend on the size of the adjustment cost nor on the persistence of the monetary shock. The authors argue, then, that at least in contemporary (middle-scale) NewKeynesian models, the real interest rate channel is present, a point similar to ours but made with a different ingredient.

The suspicion on the real interest rate channel of New-Keynesian models is not actually new. The seminal work of Kimball (1995) on the derivation of a real business cycle model with sticky prices - he called it Neo-Monetarist already dedicated a whole section to discuss the unlikelihood of that channel. He concludes that, even when investment adjustment costs are introduced, parameter values perceived by him as "plausible" would imply that the real in- 
terest rate increases in response to a monetary expansion. ${ }^{5}$ The "implausible" scenario would show up if either adjustment costs were "too high" or convergence back to the long-run equilibrium after a monetary shock were "too fast" - not unlike what Rupert and Šustek (2019) find. Nonetheless, here lies two distinctions from the Neo-Monetarist model and most New-Keynesian models that followed. First, while Kimball (1995) insisted on portraying monetary policy through a quantity equation with exogenous shocks to the money supply and no endogenous response of it, the New-Keynesian literature has followed the real-world trend of adopting nominal interest rate rules with an endogenous response to inflation. Especially when augmented with smoothing - as we propose in this paper - these last rules put in sharp relief the speed of the convergence back to a long-run equilibrium. Second, the parameterization deemed by him as "plausible" - an investment adjustment cost elasticity of 0.2 and a (labor-constant) elasticity of intertemporal substitution (EIS) for consumption of 0.2 - does not match modern estimations of these models, which find higher values for these parameters. ${ }^{6}$

Our modification of the canonical model is empirically motivated. The presence of significant interest-rate smoothing in the response function of the FED is found by Clarida, Gali and Gertler (1999), for both pre-Volcker (1960:11979:2) and Volcker-Greenspan (19179:3-1996:4) eras, as well as by Coibion and Gorodnichenko (2012), whose results favor that source of policy inertia over serially correlated monetary shocks. Smets and Wouters (2007) estimate a middle-scale New-Keynesian DSGE model with Bayesian methods for the United States and find large interest-rate smoothing (above 0.7) as well as small monetary shock persistence (below 0.3) coefficients. These papers suggest the empirical presence of smoothing through the estimation of either single or multiple equation models, that is, by imposing only little or much informational restriction to the estimation. Nonetheless, a contrasting result can still be found depending on the estimation strategy as Carrillo, Fève and Matheron (2018) demonstrate. Sack and Wieland (2000) and Woodford (2003b), by their turn, show that smoothing policy interest rates may be optimal from a welfare perspective. Despite the fact that such smoothing is a policy choice, we believe that the optimality of high levels of it and the empirical infrequency of low levels of it warrant the case of this paper.

\footnotetext{
${ }^{5}$ The model is linearized and, therefore, we assume a symmetrical response in case of a monetary contraction.

${ }^{6}$ With Bayesian methods, Smets and Wouters (2003) estimate the EIS to be 0.74 for the Euro Area, and Smets and Wouters (2007) estimate 0.68-0.72 for the U.S.. All values are posterior modes.
} 
Chapter 3. On the Mechanics of New-Keynesian Models:

Smoothing the Capital Controversy Out

\section{3}

\section{New-Keynesian model before and after capital}

In this section, we propose and solve a New-Keynesian toy model. First, the canonical version and, then, the model augmented with endogenous capital.

\subsection{1}

\section{Canonical closed economy}

Let us take the example of a closed economy without fiscal policy in which there is a one-period risk-free nominal bond available in zero net supply, and that its central bank adopts a fixed intercept Taylor rule. We expand here on the simplified presentation made by Rupert and Šustek (2019) of the canonical New-Keynesian model of Galí (2015), with minor changes in notation.

The simple model starts with 7 variables: real consumption, $c_{t}$; labor $l_{t}$; real output, $y_{t}$; real wage, $w_{t}$; real marginal cost, $\mathrm{mc}_{t}$; nominal interest rate, $i_{t}$; and inflation, $\pi_{t}$. Over-lined variables represent their steady-state values. There are 6 parameters: the subjective discount factor, $\beta$; the inverse of the elasticity of labor supply, $\eta$; the elasticity of substitution between intermediate goods, $\varepsilon$; the fraction of producers not adjusting prices at any given period, $\theta$; the intercept of the Taylor rule, $i$; and the Taylor-rule coefficient that gauges the central bank's reaction to current inflation, $\nu$. There is also an exogenous monetary shock variable, $\xi_{t}^{m}$.

Assuming a per-period utility function of the form (3-1) and an intermediate goods aggregator like (3-2), the equilibrium conditions of that economy are given by the Euler equation (3-3) in conjunction with equations (3-4) to (3-9), namely the CPO of labor, the production function, the real marginal cost, the New-Keynesian Phillips Curve under Calvo pricing already linearized around a zero steady-state inflation, a Taylor rule, and the market-clearing condition.

$$
\begin{gathered}
u_{t}=\log \left(c_{t}\right)-\frac{l_{t}^{1+\eta}}{1+\eta} \\
y_{t}=\left[\int y(j)^{\varepsilon} \mathrm{d} j\right]^{\frac{1}{\varepsilon}}
\end{gathered}
$$




$$
\left.\begin{array}{r}
\frac{1}{c_{t}}=\beta \mathbb{E}_{t}\left(\frac{1}{c_{t+1}} \frac{1+i_{t}}{1+\pi_{t+1}}\right) \\
\frac{w_{t}}{c_{t}}=l_{t}^{\eta} \\
y_{t}=l_{t} \\
\mathrm{mc}_{t}=w_{t} \\
\pi_{t}=\frac{(1-\theta)(1-\theta \beta)}{\theta}\left(\mathrm{mc}_{t}-\overline{\mathrm{mc}}\right)+\beta \mathbb{E}_{t} \pi_{t+1} \\
i_{t}=i+\nu \pi_{t}+\xi_{t}^{m} \\
y_{t}=c_{t}
\end{array}\right\}
$$

As usual, the previous equilibrium conditions can be simplified to a threeequation system linearized around a steady state $(\bar{\pi}=0, \bar{y}=1)$. This is possible by first linearizing (3-3) and substituting the market-clearing condition (3-9) into it. Then, eliminating (3-9), (3-5), and (3-6) through the substitution of their respective expressions for $c_{t}, l_{t}$, and $w_{t}$ into (3-4), which is later linearized such that $\hat{y}_{t} \equiv \frac{y_{t}-\bar{y}}{\bar{y}}$. Finally, the Taylor Rule (3-8) is rewritten as deviations of the interest rate from its steady-state value such that $\hat{i}_{t}=i_{t}-i$.

$$
\left.\begin{array}{r}
-\hat{y}=-\mathbb{E}_{t} \hat{y}_{t+1}+\hat{i_{t}}-\mathbb{E}_{t} \pi_{t+1} \\
\pi_{t}=\Omega \hat{y}_{t}+\beta \mathbb{E}_{t} \pi_{t+1} \\
\hat{i}_{t}=\nu \pi_{t}+\xi_{t}^{m}
\end{array}\right\}
$$

where

$$
\Omega \equiv \frac{(1+\eta)(1-\theta)(1-\theta \beta)}{\theta}>0
$$

Notice that when prices are fully flexible, $\theta \rightarrow 0$, then $\Omega \rightarrow \infty$, whereas when prices are fixed, $\theta \rightarrow 1$, then $\Omega \rightarrow 0$. As Rupert and Šustek (2019) comment, it is useful to think of $\Omega$ as a weight that gauges the solution coefficients of the system between the fully flexible and the fixed price regime.

We can proceed further by substituting the policy rule (3-12) into (3-10) so that we reduce the system to only two equations:

$$
\left.\begin{array}{r}
-\hat{y}=-\mathbb{E}_{t} \hat{y}_{t+1}+\nu \pi_{t}+\xi_{t}^{m}-\mathbb{E}_{t} \pi_{t+1} \\
\pi_{t}=\Omega \hat{y}_{t}+\beta \mathbb{E}_{t} \pi_{t+1}
\end{array}\right\}
$$

We assume that the monetary shock follows an $\mathrm{AR}(1)$ process given by $\xi_{t}^{m}=\rho^{m} \xi_{t-1}^{m}+\epsilon_{t}^{m}$, where $\rho^{m} \in[0,1)$ and $\epsilon_{t}^{m}$ is i.i.d. $\mathrm{N}(0,1)$. Solving the model with the method of undetermined coefficients, also known as guess-and-verify, by conjecturing $\hat{y}_{t}=a \xi_{t}^{m}$ and $\pi_{t}=b \xi_{t}^{m}$, where $a$ and $b$ are the coefficients we want to obtain, and discarding explosive paths for output and inflation leads 
to

$$
\begin{gathered}
a=-\frac{1-\beta \rho^{m}}{\left(1-\rho^{m}\right)\left(1-\beta \rho^{m}\right)+\Omega\left(\nu-\rho^{m}\right)}<0 \\
b=-\frac{1}{\left(1-\rho^{m}\right)\left(1-\beta \rho^{m}\right) \Omega^{-1}+\left(\nu-\rho^{m}\right)}<0
\end{gathered}
$$

where both coefficients imply that a positive monetary shock always reduces inflation and output in the canonical New-Keynesian model.

Figure 3.1 plots coefficients $a$ and $b$ for different values of $\nu$ and $\Omega$, under the calibration of Rupert and Šustek $(2019)^{7}$. As expected, flexible prices make output elasticity goes to zero at the same time that inflation elasticity is maximum. Moreover, a more active monetary policy reduces both elasticities.

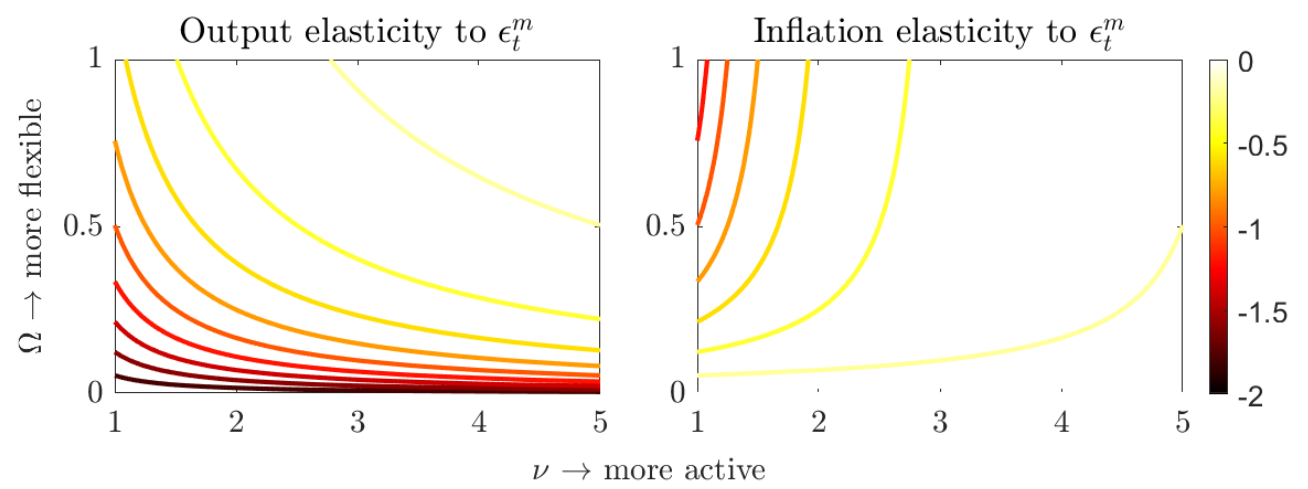

Note: Darker colors imply higher (absolute) elasticity values. Calibration: $\beta=0.99, \nu=1.5$, and $\rho^{m}=0.5$.

Figure 3.1: Output and inflation elasticity to a monetary shock

The real interest rate as deviation from its steady-state value can be obtained from the Fisher identity, $\hat{R}_{t}=\hat{i}_{t}-\mathbb{E}_{t} \pi_{t+1}$. Substituting our solution, we have

$$
\hat{R}_{t}=\underbrace{(1-\underbrace{\frac{1}{1+\frac{1-\rho^{m}}{\nu-\rho^{m}} \frac{1-\beta \rho^{m}}{\Omega}}}_{\in[0,1]})}_{\geq 0} \xi_{t}^{m}
$$

which implies that the real interest rate always increases/decreases right after a positive/negative monetary shock, consistent with the presence of a real interest rate transmission channel of monetary policy.

${ }^{7}$ The following calibration includes parameters that will be incorporated later to the model in this paper: $\beta=0.99, \eta=1, \varepsilon=0.83, \theta=0.7, \nu=1.5, \rho^{m}=0.5, \alpha=0.3, \delta=$ 0.025 . 
Chapter 3. On the Mechanics of New-Keynesian Models:

Smoothing the Capital Controversy Out

\subsection{2}

\section{Endogenous capital and interest-rate smoothing}

Rupert and Šustek (2019) argue that the real interest rate channel of monetary transmission in canonical New-Keynesian models is only observational, not structural, for, after introducing endogenous capital, a positive monetary shock can shift the real interest rate in any direction depending on the persistence of the shock, while the output gap becomes negative and inflation falls regardless of that persistence. This should raise concerns on the correct identification of VARs with sign restrictions, for example. We show, now, that adopting interest-rate-smoothing in the Taylor Rule - a prevalent feature of actual monetary policy practice as well as of middle-scale New-Keynesian models, such as Smets and Wouters (2003) and Smets and Wouters (2007) can deliver impulse-response functions with the sign consistent with the real interest rate channel in the empirically-relevant parameter range. This finding largely minimizes the identification problem from an empirical perspective.

We build on their model. Rupert and Šustek (2019) assume that there is an economy-wide rental market of capital, so that at every period capital can be rented by the firms. In that sense, capital is not firm-specific. ${ }^{8}$ Moreover, they assume that whenever households change their stock of capital there is a quadratic adjustment cost, $-\frac{\kappa}{2}\left(k_{t+1}-k_{t}\right)^{2}$, where $k_{t}$ is the stock of capital inherited from the previous period, and $\kappa \geq 0$ is a parameter that governs the size of the adjustment cost in terms of foregone real income.

Resuming from the canonical model of section 3.3.1, there is a new Euler equation for the capital asset (3-19), where $\delta \in(0,1)$ is a depreciation rate, and $q_{t}$ is the price of capital in terms of current consumption, Tobin's q, such that $q_{t} \equiv 1+\kappa\left(k_{t+1}-k_{t}\right)$. The production function (3-5) is replaced by (3-20), which incorporates capital and labor in a proportion consistent with constant returns to scale, where $\alpha$ is the Cobb-Douglas coefficient of capital. Equation (3-21) is the condition for the optimal mix of capital and labor in production, which comes from the $\mathrm{CPO}$ of the firm. The marginal cost (3-6) is updated to include the rent on capital (3-22). The resources constraint (3-9) must account, now, for the investment flow so markets can clear (3-23). Finally, we substitute the previous Taylor rule (3-8), also adopted by Rupert and Šustek (2019), for one with interest-rate-smoothing (3-24), whose persistence is governed by $\rho^{i} \in[0,1)$.

${ }^{8}$ Altig et al. (2011) estimate a New-Keynesian DSGE model for the U.S. and find that this modeling choice for introducing endogenous capital results in firms enduring long spells before readjusting prices on average, up to 9 quarters. They show that firm-specific capital can turn that spell more aligned with empirical evidence from micro data, say, once a year. 


$$
\left.\begin{array}{r}
\frac{1}{c_{t}}=\beta \mathbb{E}_{t}\left(\frac{1}{c_{t+1}}\left(\frac{r_{t+1}-\delta}{q_{t}}+\frac{q_{t+1}}{q_{t}}\right)\right) \\
y_{t}=k_{t}^{\alpha} l_{t}^{1-\alpha} \\
\frac{w_{t}}{r_{t}}=\frac{1-\alpha}{\alpha}\left(\frac{k_{t}}{l_{t}}\right) \\
\mathrm{mc}_{t}=\left(\frac{r_{t}}{\alpha}\right)^{\alpha}\left(\frac{w_{t}}{1-\alpha}\right)^{1-\alpha} \\
y_{t}=c_{t}+k_{t+1}-(1-\delta) k_{t}+\frac{\kappa}{2}\left(k_{t+1}-k_{t}\right)^{2} \\
i_{t}=\rho^{i} i_{t-1}+\left(1-\rho^{i}\right)\left(i+\nu \pi_{t}\right)+\xi_{t}^{m}
\end{array}\right\}
$$

After substituting equation (3-21) into (3-22) by eliminating $r_{t}$, and substituting equation (3-4) into (3-20) so as to eliminate $l_{t}$, the model is log-linearized around the non-stochastic steady state $(\bar{\pi}=0, \bar{y}=1)$. For any variable $X$, $\hat{X} \equiv \frac{X_{t}-\bar{X}}{\bar{X}}$, with exception of $\hat{i}_{t} \equiv i_{t}-\bar{i}$ and $\hat{r}_{t} \equiv r_{t}-\bar{r}$. After that, it is possible to eliminate $\hat{r}_{t}, \mathrm{mc}_{t}, \hat{w}_{t}, i_{t}$ and $\hat{l}_{t}$, in order to obtain the following reduced system with only 4 equations.

$$
\left.\begin{array}{r}
-\hat{c}=-\mathbb{E}_{t} \hat{c}_{t+1}+\rho^{i} \hat{i}_{t-1}+\left(1-\rho^{i}\right) \nu \pi_{t}-\mathbb{E}_{t} \pi_{t+1}+\xi_{t}^{m} \\
-\hat{c}=-\mathbb{E}_{t} \hat{c}_{t+1}+\mathbb{E}_{t} \hat{g}_{t+1}+r \mathbb{E}_{t}\left(\hat{c}_{t+1}+\frac{1+\eta}{1-\alpha} \hat{y}_{t+1}-\frac{1+\alpha \eta}{1-\alpha} \hat{k}_{t+1}\right) \\
\pi_{t}=\Psi\left(\frac{\eta+\alpha}{1-\alpha} \hat{y}_{t}-\alpha \frac{1+\eta}{1-\alpha} \hat{k}_{t}+\hat{c}_{t}\right)+\beta \mathbb{E}_{t} \pi_{t+1} \\
\hat{y}_{t}=\frac{\bar{c}}{\bar{y}} \hat{c}_{t}+\frac{\bar{k}}{\bar{y}} \hat{k}_{t+1}-(1-\delta) \frac{\bar{k}}{\bar{y}} \hat{k}_{t}
\end{array}\right\}
$$

where $\Psi \equiv \chi \frac{(1-\theta)(1-\theta \beta)}{\theta}$, such that when prices are flexible, $\Psi \rightarrow \infty$. Moreover, $G_{t+1} \equiv \frac{q_{t+1}}{q_{t}}$ is the capital gain, so $\hat{g}_{t}=\hat{q}_{t}-\hat{q}_{t-1}=\bar{\kappa}\left(\hat{k}_{t+1}-\hat{k}_{t}\right)-\bar{\kappa}\left(\hat{k}_{t}-\hat{k}_{t-1}\right)$, where $\bar{\kappa}=\kappa \bar{k}$.

To check whether the negative response of real interest rates to a positive monetary shock remains as an identification problem, we sweep the combinations of parameter values for $\rho^{m} \in[0: 0.1: 0.9]$ and $\rho^{i} \in[0: 0.1: 0.9]$. As we could not find in Rupert and Šustek (2019) the $\bar{k}$ used by the authors, we tested different values until find one that approximately matches their impulse response functions: $\bar{k}=5.5$, or 1.375 times the annual output. ${ }^{9}$ Table 3.1 displays the sign of the reaction of the real interest rate right after the shock for all combinations under $\bar{K}=5.5 \bar{Y}, \delta=0.025$, and $\kappa=0.0$. Tables 3.2 and 3.3 increase $\kappa$ to 0.1 and 0.5 , respectively. As one can see, under the hypothesis of no adjustment costs, $\rho^{i}$ must be at least 0.9 to guarantee a positive response ${ }^{9}$ In Rupert and Šustek (2016), the authors set $\bar{k}=7.0938$. Brault and Khan (2019) use $\bar{k}=8.4568$. 
under all values of $\rho^{m}$. However, a small adjustment cost is already enough to largely increase the parameter range consistent with a real interest rate channel of monetary policy.

\begin{tabular}{lcccccccccc}
\hline \hline & $\rho^{i}=0$ & $\rho^{i}=0.1$ & $\rho^{i}=0.2$ & $\rho^{i}=0.3$ & $\rho^{i}=0.4$ & $\rho^{i}=0.5$ & $\rho^{i}=0.6$ & $\rho^{i}=0.7$ & $\rho^{i}=0.8$ & $\rho^{i}=0.9$ \\
\hline$\rho^{m}=0$ & + & + & + & + & + & + & + & + & + & + \\
$\rho^{m}=0.1$ & - & - & - & - & + & + & + & + & + & + \\
$\rho^{m}=0.2$ & - & - & - & - & - & - & - & + & + & + \\
$\rho^{m}=0.3$ & - & - & - & - & - & - & - & - & + & + \\
$\rho^{m}=0.4$ & - & - & - & - & - & - & - & - & - & + \\
$\rho^{m}=0.5$ & - & - & - & - & - & - & - & - & - & + \\
$\rho^{m}=0.6$ & - & - & - & - & - & - & - & - & - & + \\
$\rho^{m}=0.7$ & - & - & - & - & - & - & - & - & - & + \\
$\rho^{m}=0.8$ & - & - & - & - & - & - & - & - & - & + \\
$\rho^{m}=0.9$ & - & - & - & - & - & - & - & - & + & + \\
\hline \hline
\end{tabular}

Note: + indicates that the real interest rate increases right after a positive monetary shock; - indicates that it decreases; empty cells indicate that the Blanchard and Kahn conditions are not satisfied.

Table 3.1: Parameter sweep with $\frac{\bar{K}}{\bar{Y}}=5.5, \delta=0.025$, and $\kappa=0.0$

\begin{tabular}{lccccccccccc}
\hline \hline & $\rho^{i}=0$ & $\rho^{i}=0.1$ & $\rho^{i}=0.2$ & $\rho^{i}=0.3$ & $\rho^{i}=0.4$ & $\rho^{i}=0.5$ & $\rho^{i}=0.6$ & $\rho^{i}=0.7$ & $\rho^{i}=0.8$ & $\rho^{i}=0.9$ \\
\hline$\rho^{m}=0$ & + & + & + & + & + & + & + & + & + & + \\
$\rho^{m}=0.1$ & + & + & + & + & + & + & + & + & + & + \\
$\rho^{m}=0.2$ & + & + & + & + & + & + & + & + & + & + \\
$\rho^{m}=0.3$ & + & + & + & + & + & + & + & + & + & + \\
$\rho^{m}=0.4$ & + & + & + & + & + & + & + & + & + & + \\
$\rho^{m}=0.5$ & + & + & + & + & + & + & + & + & + & + \\
$\rho^{m}=0.6$ & - & - & + & + & + & + & + & + & + & + \\
$\rho^{m}=0.7$ & - & - & - & + & + & + & + & + & + & + \\
$\rho^{m}=0.8$ & - & - & - & + & + & + & + & + & + & + \\
$\rho^{m}=0.9$ & - & - & - & + & + & + & + & + & + & + \\
\hline \hline
\end{tabular}

Note: + indicates that the real interest rate increases right after a positive monetary shock; - indicates that it decreases; empty cells indicate that the Blanchard and Kahn conditions are not satisfied.

Table 3.2: Parameter sweep with $\frac{\bar{K}}{\bar{Y}}=5.5, \delta=0.025$, and $\kappa=0.1$ 
Chapter 3. On the Mechanics of New-Keynesian Models:

Smoothing the Capital Controversy Out

\begin{tabular}{lccccccccccc}
\hline \hline & $\rho^{i}=0$ & $\rho^{i}=0.1$ & $\rho^{i}=0.2$ & $\rho^{i}=0.3$ & $\rho^{i}=0.4$ & $\rho^{i}=0.5$ & $\rho^{i}=0.6$ & $\rho^{i}=0.7$ & $\rho^{i}=0.8$ & $\rho^{i}=0.9$ \\
\hline$\rho^{m}=0$ & + & + & + & + & + & + & + & + & + & + \\
$\rho^{m}=0.1$ & + & + & + & + & + & + & + & + & + & + \\
$\rho^{m}=0.2$ & + & + & + & + & + & + & + & + & + & + \\
$\rho^{m}=0.3$ & + & + & + & + & + & + & + & + & + & + \\
$\rho^{m}=0.4$ & + & + & + & + & + & + & + & + & + & + \\
$\rho^{m}=0.5$ & + & + & + & + & + & + & + & + & + & + \\
$\rho^{m}=0.6$ & + & + & + & + & + & + & + & + & + & + \\
$\rho^{m}=0.7$ & + & + & + & + & + & + & + & + & + & + \\
$\rho^{m}=0.8$ & + & + & + & + & + & + & + & + & + & + \\
$\rho^{m}=0.9$ & - & + & + & + & + & + & + & + & + & + \\
\hline \hline
\end{tabular}

Note: + indicates that the real interest rate increases right after a positive monetary shock; - indicates that it decreases; empty cells indicate that the Blanchard and Kahn conditions are not satisfied.

Table 3.3: Parameter sweep with $\frac{\bar{K}}{\bar{Y}}=5.5, \delta=0.025$, and $\kappa=0.5$

Thus, how restricting is the switching behavior of the real interest rate to a positive monetary shock for the estimation of VARs and DSGEs? We have seen that in the presence of interest-rate-smoothing, an empirically validated (Coibion and Gorodnichenko, 2012), theoretically desirable (i.e. Woodford (2003b), Sack and Wieland (2000)), and prevalent feature of middle-scale DSGE models (i.e. Smets and Wouters (2003) estimates $\rho^{i}=0.956$ for the Euro Area; Smets and Wouters (2007) estimates $\rho^{i}=0.75-0.84$ for the United States), a plausibly small adjustment cost is enough to reestablish the sign consistency with the real interest rate channel. Under no adjustment cost at all, $\rho^{i}>0.9$ would be enough.

\subsection{3}

\section{The mechanics}

Now, we make explicit the solution for the real interest rate by the method of undetermined coefficients, and compare it to the exposition of Rupert and Šustek (2019). We assume $\hat{c}_{t}=a_{0} \hat{k}_{t}+a_{1} \xi_{t}^{m}+a_{2} \hat{i}_{t-1} ; \hat{k}_{t+1}=$ $f_{0} \hat{k}_{t}+f_{1} \xi_{t}^{m}+f_{2} \hat{i}_{t-1} ; \pi_{t}=b_{0} \hat{k}_{t}+b_{1} \xi_{t}^{m}+b_{2} \hat{i}_{t-1} ;$ and $\hat{y}_{t}=d_{0} \hat{k}_{t}+d_{1} \xi_{t}^{m}+d_{2} \hat{i}_{t-1}$. The set of coefficients to be determined is $\left\{a_{0}, a_{1}, a_{2}, b_{0}, b_{1}, b_{2}, d_{0}, d_{1}, d_{2}, f_{0}\right.$, $\left.f_{1}, f_{2}\right\}$.

With the log-linearized Fisher relation, $\hat{R}_{t}=\hat{i}_{t}-\mathbb{E}_{t} \pi_{t+1}$, and the Euler equation (3-25) we can write:

$$
\begin{aligned}
& \hat{R}_{t}=\mathbb{E}_{t} \hat{c}_{t+1}-\hat{c}_{t} \\
& =\underbrace{\left(a_{0} f_{0}-a_{0}+a_{2}\left(1-\rho^{i}\right) \nu b_{0}\right) \hat{k}_{t}+\left(a_{0} f_{2}-a_{2}+a_{2} \rho^{i}+a_{2}\left(1-\rho^{i}\right) \nu b_{2}\right) \hat{i}_{t-1}}_{=0 \text { at the shock }}
\end{aligned}
$$




$$
+(\underbrace{\rho^{m} a_{1}-a_{1}+a_{2}\left(1-\rho^{i}\right) \nu b_{1}+a_{2}}_{\text {indirect effect of capital }} \underbrace{+a_{0} f_{1}}_{\text {direct effect of capital }}) \xi_{t}^{m}
$$

where $\hat{R}$ is the log-deviation of the gross real interest rate. Unfortunately, the system does not seem to have a reduction that allows the direct interpretation of the sign of the coefficients. Instead, analysis must be done heuristically and numerically. ${ }^{10}$ When we remove interest-rate-smoothing, that is, when $\rho^{i}=0$, $a_{2}=0, f_{2}=0, b_{2}=0$, and $d_{2}=0$, the model is the same as the one portrayed in Rupert and Šustek (2019).

Under the benchmark calibration, with no adjustment costs and no interest-rate smoothing, the direct effect of capital to the real interest rate from a monetary shock is negative for all possible values of $\rho^{m}$, while the indirect effect is mostly positive. The indirect effect is larger than the direct one only at the lowest range of $\rho^{m}$, what can be seen in Figure 3.2. In Figure 3.3, we show that raising $\kappa$ to 0.1 increases both components of the total effect, amplifying the range consistent with the real interest rate channel. In Figure 3.4 , we introduce interest-rate smoothing, by setting $\rho^{i}=0.5$, with no capital adjustment costs. In that case, the total effect curve becomes flatter near the zero axis. Raising the adjustment cost to $\kappa=0.1$, as in Figure 3.5, is enough to bring the total effect curve above zero for all possible values of $\rho^{m}$.

${ }^{10}$ The system is non-linear in the coefficients, what means that multiple solutions may exist. Therefore, we impose the following restrictions to single out a solution: $a_{0}>0, d_{0}>0$, $a_{2} \leq 0, b_{2} \leq 0$, and $d_{2} \leq 0$. By that, we expect consumption to increase with the inherited stock of capital, as well as to decrease with the lagged nominal interest rate. Additionally, we expect output and inflation to also decrease with the lagged nominal interest rate. These signs are validated by the policy functions obtained from first-order perturbation in Dynare (Adjemian et al., 2011). 


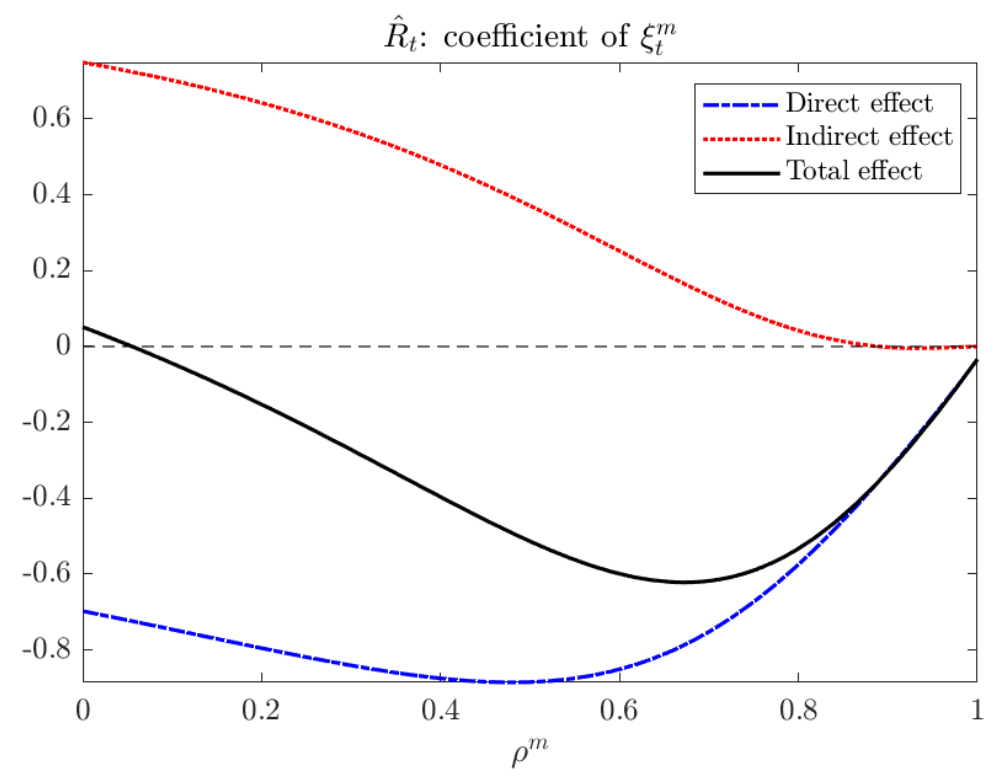

Figure 3.2: Decomposition of the effect of capital to $\hat{R}_{t}$ from a monetary shock when $\frac{\bar{K}}{\bar{Y}}=5.5, \rho^{i}=0$, and $\kappa=0$

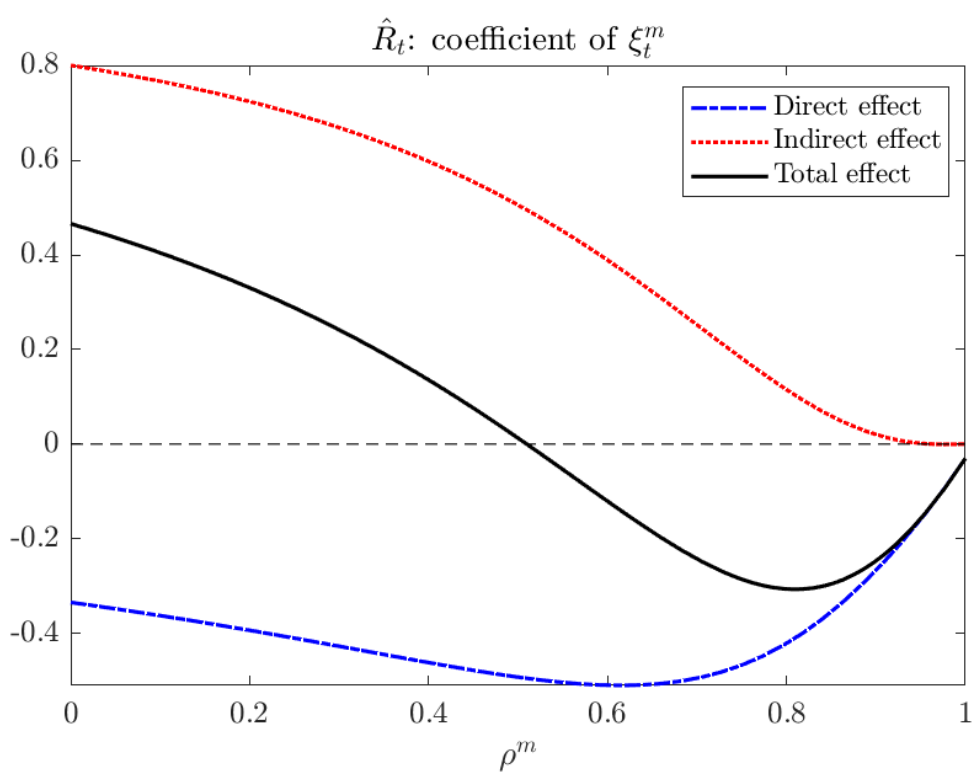

Figure 3.3: Decomposition of the effect of capital to $\hat{R}_{t}$ from a monetary shock when $\frac{\bar{K}}{\bar{Y}}=5.5, \rho^{i}=0$, and $\kappa=0.1$ 


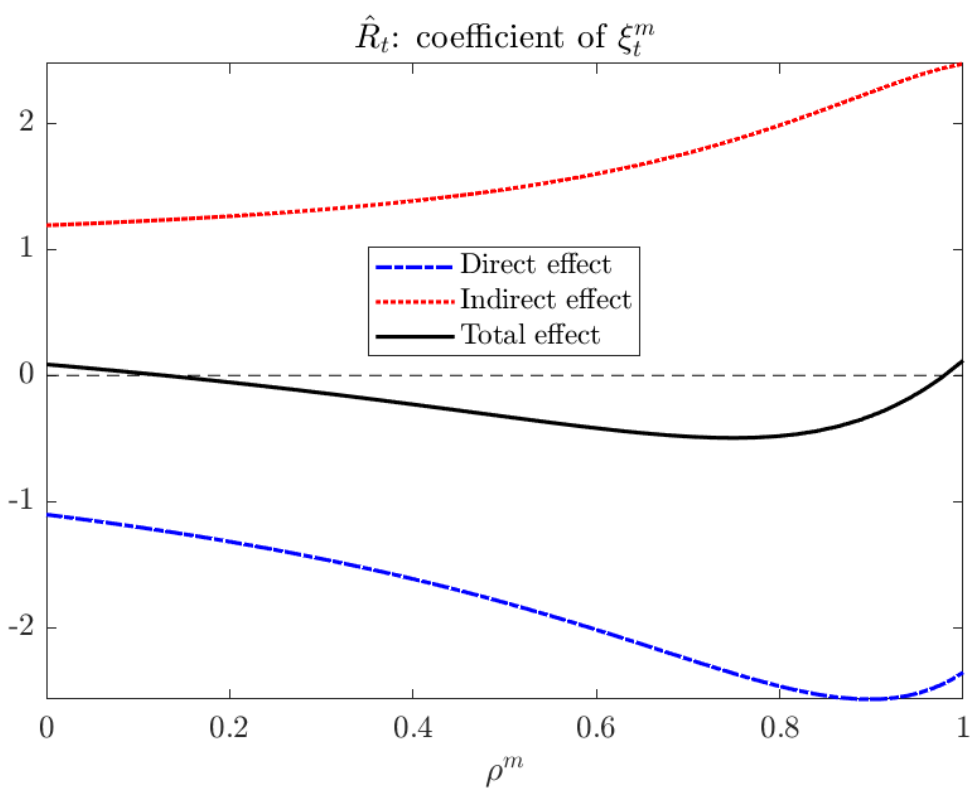

Figure 3.4: Decomposition of the effect of capital to $\hat{R}_{t}$ from a monetary shock when $\frac{\bar{K}}{\bar{Y}}=5.5, \rho^{i}=0.5$, and $\kappa=0$

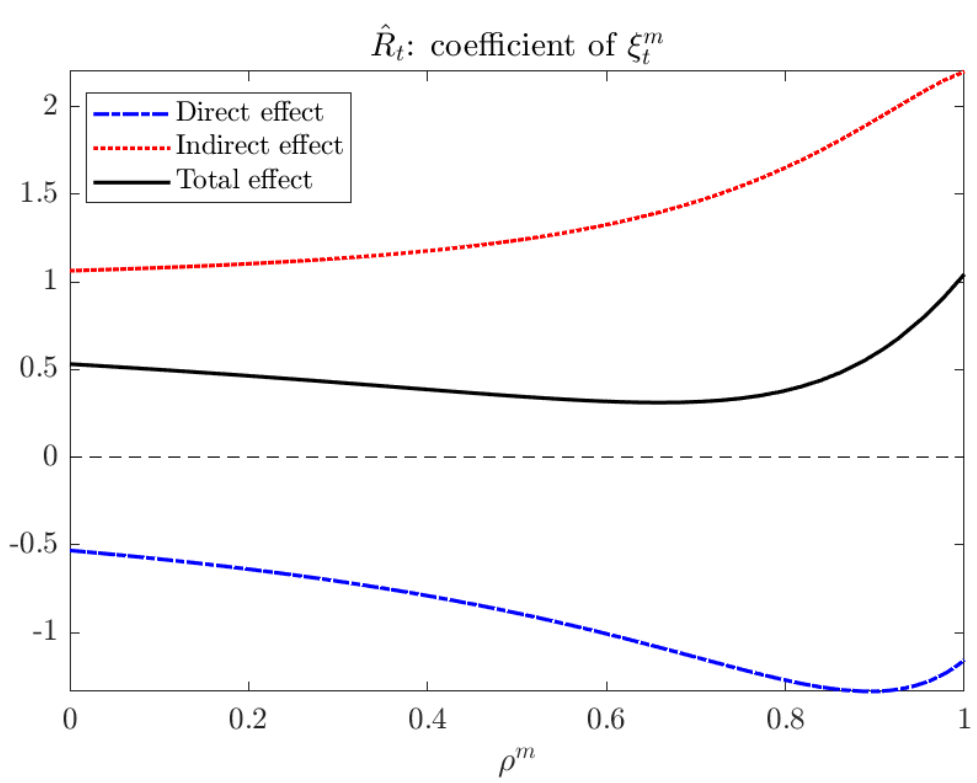

Figure 3.5: Decomposition of the effect of capital to $\hat{R}_{t}$ from a monetary shock when $\frac{\bar{K}}{\bar{Y}}=5.5, \rho^{i}=0.5$, and $\kappa=0.1$

\subsection{4}

\section{Impulse response functions}

Next, we plot the impulse response functions of the New-Keynesian model augmented with endogenous capital, adjustment costs, and interest rate smoothing. We calibrate the standard-deviation of the monetary shock to 1 p.p.. Graphs display percentage deviations from steady-state values, except interest rates which are measured in p.p. deviations from steady-state 
values. As expected, in all figures, output, consumption, and inflation respond negatively at the event of a contractionary shock. The capital stock also reduces, but with a lag, due to our timing convention. The nominal interest rate, by its turn, may react positively or negatively, as the last response sign is a consequence of inflation expectations, and inflation itself, reducing by a large amount due to the persistence of the monetary shock, an already documented pattern (Galí (2015) and Woodford (2003a)).

\subsubsection{1}

\section{The identification problem}

Figures 3.6 and 3.7 display the effect of a positive one-standard-deviation monetary shock to the model variables under different specifications for $\rho^{m}$ without adjustment costs and without smoothing. This is, basically, the identification problem revealed by Rupert and Šustek (2019), as the real interest rate goes up right after the shock in the first figure, but it goes down in the second one.
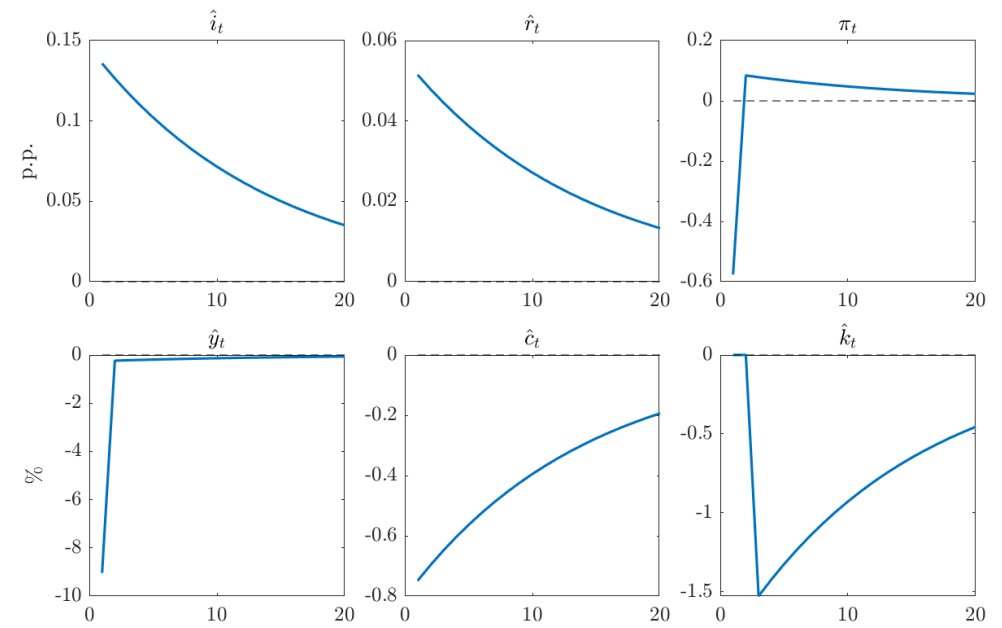

Figure 3.6: Impulse response function to a 1-standard-deviation monetary shock under $\rho^{m}=0, \rho^{i}=0, \frac{\bar{K}}{\bar{Y}}=5.5$, and $\kappa=0$ 

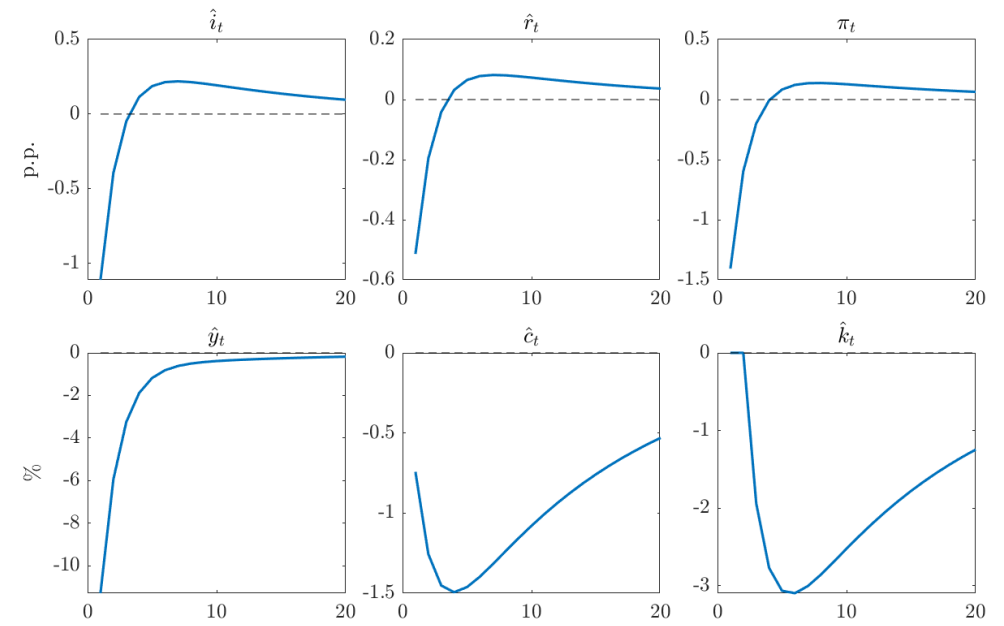

Figure 3.7: Impulse response function to a 1-standard-deviation monetary shock under $\rho^{m}=.50, \rho^{i}=0, \frac{\bar{K}}{\bar{Y}}=5.5$, and $\kappa=0$

\subsubsection{2}

\section{Fixing with high interest-rate smoothing}

Figures 3.8 and 3.9 show that a high level of interest-rate smoothing $\left(\rho^{i}=0.9\right)$ is able to reestablish the observational consistency with the real interest rate channel of monetary policy transmission. Despite that, in this case without capital adjustment costs, output overreacts becoming unrealistic.
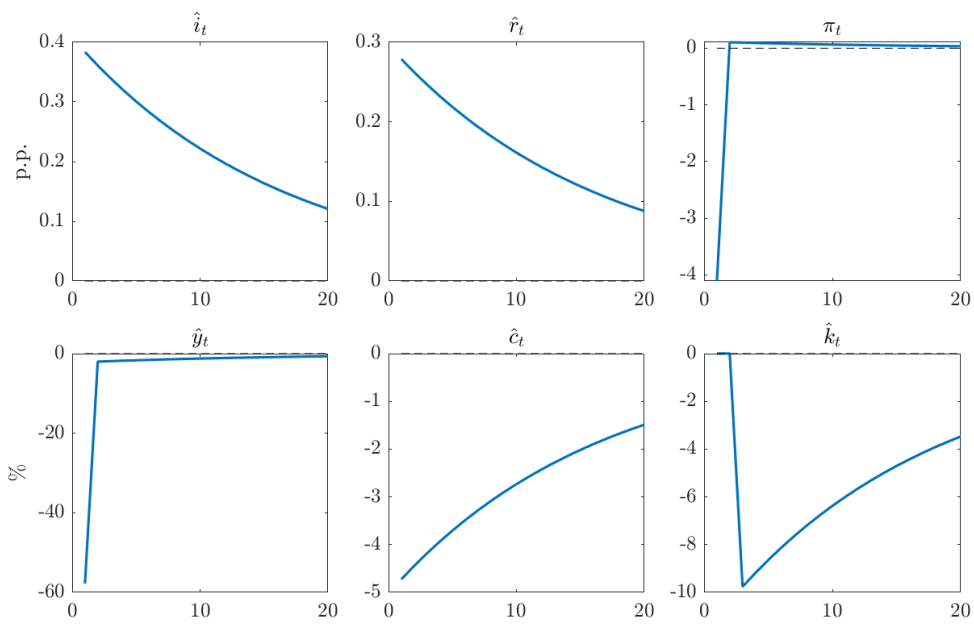

Figure 3.8: Impulse response function to a 1-standard-deviation monetary shock under $\rho^{m}=0, \rho^{i}=0.9, \frac{\bar{K}}{\bar{Y}}=5.5$, and $\kappa=0$ 

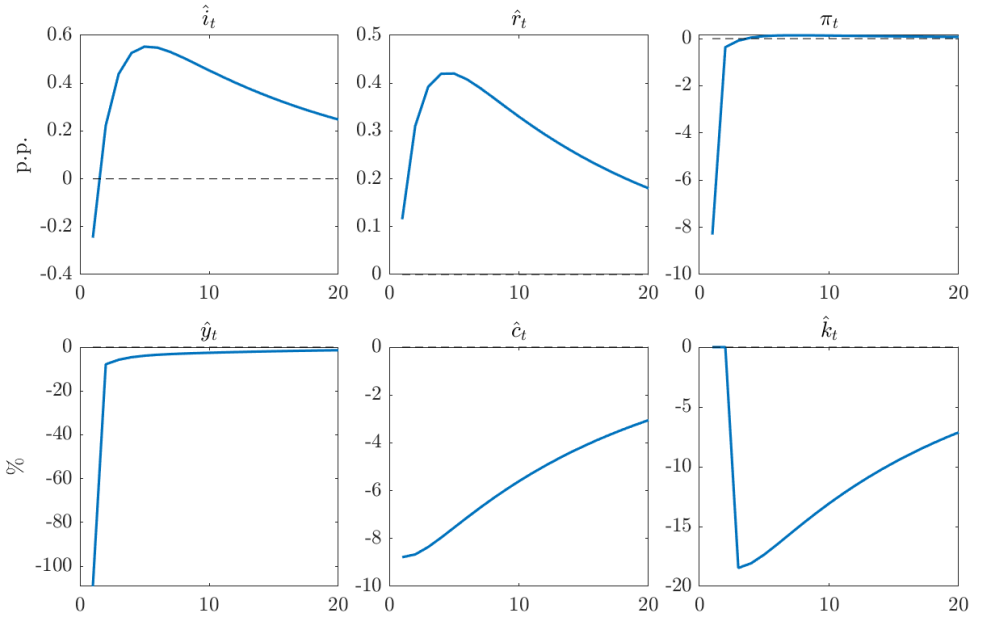

Figure 3.9: Impulse response function to a 1-standard-deviation monetary shock under $\rho^{m}=.50, \rho^{i}=0.9, \frac{\bar{K}}{\bar{Y}}=5.5$, and $\kappa=0$

\subsubsection{3}

\section{Fixing with low interest-rate smoothing and small adjustment cost}

Figures 3.10 and 3.11 show that the solution for the identification problem can also be obtained by combining a low level of smoothing with a small adjustment cost. The latter prevents output from overreacting right after the shock.
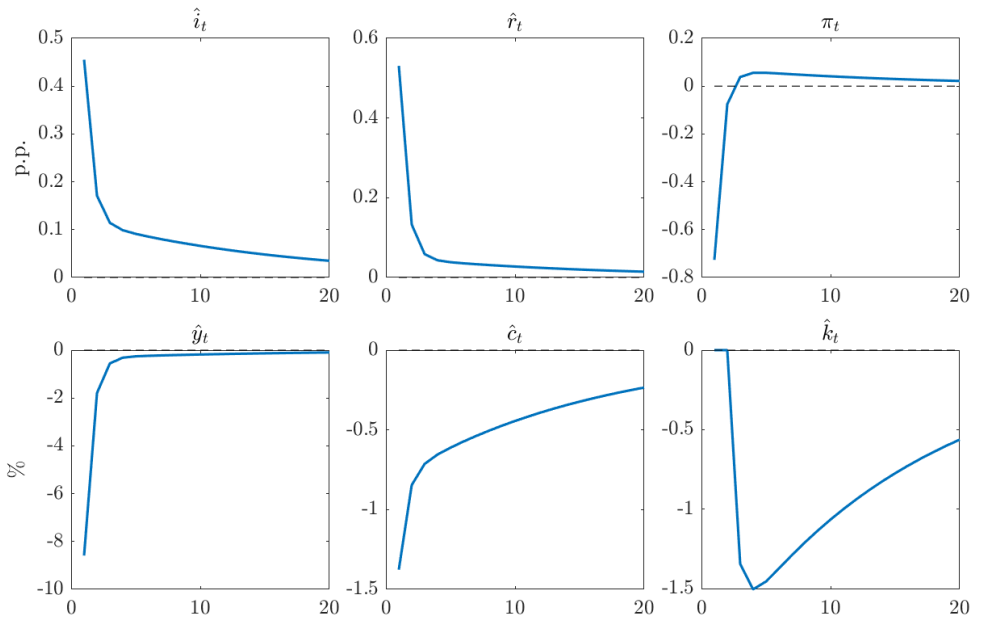

Figure 3.10: Impulse response function to a 1-standard-deviation monetary shock under $\rho^{m}=0, \rho^{i}=0.5, \frac{\bar{K}}{\bar{Y}}=5.5$, and $\kappa=0.1$ 

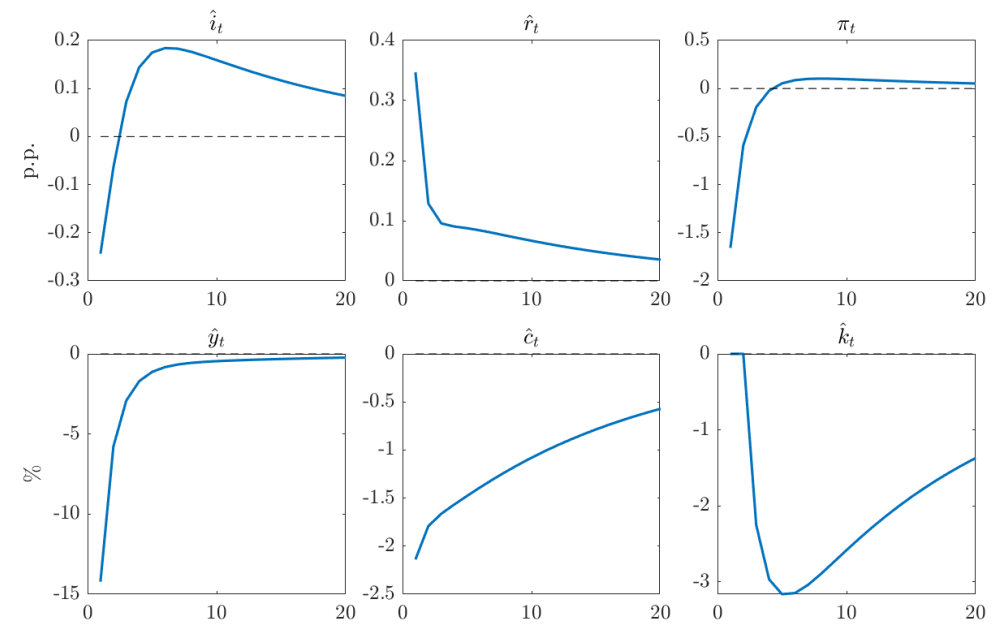

Figure 3.11: Impulse response function to a 1-standard-deviation monetary shock under $\rho^{m}=.50, \rho^{i}=0.5, \frac{\bar{K}}{\bar{Y}}=5.5$, and $\kappa=0.1$

\section{4}

\section{Conclusion}

This paper showed that the identification problem of canonical NewKeynesian models augmented with endogenous capital, revealed by Rupert and Šustek (2019), can be circumvented by the inclusion of empirically-validated interest-rate smoothing in the Taylor rule, a feature as prevalent in middlescale New-Keynesian models as capital itself. The sign of the real interest rate right after a positive monetary shock is positive under realistic parameters, reestablishing the observational consistency of the real interest rate channel of monetary policy transmission. 


\section{Bibliography}

Adjemian, Stéphane, Houtan Bastani, Michel Juillard, Fréderic Karamé, Junior Maih, Ferhat Mihoubi, Willi Mutschler, George Perendia, Johannes Pfeifer, Marco Ratto, and Sébastien Villemot. 2011. "Dynare: Reference Manual Version 4." CEPREMAP Dynare Working Papers 1.

Aguiar, Mark, Manuel Amador, Emmanuel Farhi, and Gita Gopinath. 2014. "Sovereign debt booms in monetary unions." American Economic Review, 104(5): 101-06.

Aiyagari, S Rao. 1994. "Uninsured idiosyncratic risk and aggregate saving." The Quarterly Journal of Economics, 109(3): 659-684.

Altig, David, Lawrence J Christiano, Martin Eichenbaum, and Jesper Linde. 2011. "Firm-specific capital, nominal rigidities and the business cycle." Review of Economic dynamics, 14(2): 225-247.

Arellano, Cristina. 2008. "Default risk and income fluctuations in emerging economies." American Economic Review, 98(3): 690-712.

Arellano, Cristina, Gabriel Mihalache, Yan Bai, et al. 2018. "Inflation Targeting with Sovereign Default Risk." Society for Economic Dynamics.

Arellano, Cristina, Yan Bai, and Gabriel P Mihalache. 2020. "Monetary policy and sovereign risk in emerging economies (NK-Default)." National Bureau of Economic Research.

Arena, Marco, and Julio E Revilla. 2009. Pro-cyclical fiscal policy in Brazil: evidence from the states. The World Bank.

Bacha, Edmar. 2010. "Além da Tríade: Há como reduzir os juros?" Texto para Discussão, IEPE/CdG 17.

Barro, Robert J. 1990. "Government spending in a simple model of endogeneous growth." Journal of political economy, 98(5, Part 2): S103-S125.

Barthélemy, Jean, and Magali Marx. 2017. "Solving endogenous regime switching models." Journal of Economic Dynamics and Control, 77: 1-25. 
Battistini, Niccolò, Giovanni Callegari, and Luca Zavalloni. 2019. "Dynamic fiscal limits and monetary-fiscal policy interactions."

Baxter, Marianne, and Robert G King. 1999. "Measuring business cycles: approximate band-pass filters for economic time series." Review of economics and statistics, 81(4): 575-593.

BCB. 2017. "Structural interest rates and monetary policy in Brazil." Banco Central do Brasil-Inflation Report, Q3.

Beers, David, and Patrisha de Leon-Manlagnit. 2019. "The BoC-BoE sovereign default database: what's new in 2019?"

Bevilaqua, Afonso S, and Eduardo Loyo. 2005. "Brazil's stress test of inflation targeting." BIS papers, 23: 98-108.

Bewley, Truman. 1986. "Stationary monetary equilibrium with a continuum of independently fluctuating consumers." Contributions to mathematical economics in honor of Gérard Debreu, 79.

Bi, Huixin. 2012. "Sovereign default risk premia, fiscal limits, and fiscal policy." European Economic Review, 56(3): 389-410.

Bi, Huixin. 2017. "Fiscal Sustainability: A Cross-Country Analysis." Economic Review (Kansas City), 102(4): 5-36.

Bi, Huixin, and Nora Traum. 2012. "Estimating sovereign default risk." American Economic Review, 102(3): 161-66.

Bi, Huixin, and Nora Traum. 2014. "Estimating fiscal limits: The case of greece." Journal of applied Econometrics, 29(7): 1053-1072.

Bi, Huixin, Eric M Leeper, and Campbell Leith. 2018. "Sovereign default and monetary policy tradeoffs." International Journal of Central Banking, 14(3): 289-324.

Bi, Huixin, Wenyi Shen, and Shu-Chun Susan Yang. 2020. "Fiscal Implications of Interest Rate Normalization in the United States." Federal Reserve Bank of Kansas City Working Paper, , (20-12).

Bi, Huixin, Wenyi Shen, and Shu-Chun S Yang. 2016. "Fiscal limits in developing countries: A DSGE Approach." Journal of Macroeconomics, 49: 119130.

Binning, Andrew, and Junior Maih. 2017. "Modelling Occasionally Binding Constraints Using Regime-Switching." 
Blanchard, Olivier. 2004. "Fiscal dominance and inflation targeting: lessons from Brazil." National Bureau of Economic Research.

Blanchard, Olivier, and Jordi Galí. 2007. "Real wage rigidities and the New Keynesian model." Journal of money, credit and banking, 39: 35-65.

Bonam, Dennis, and Jasper Lukkezen. 2019. "Fiscal and monetary policy coordination, macroeconomic stability, and sovereign risk premia." Journal of Money, Credit and Banking, 51(2-3): 581-616.

Brault, Joshua, and Hashmat Khan. 2019. "The Real Interest Rate Channel is Structural in Contemporary New-Keynesian Models." Carleton University, Department of Economics.

Carrillo, Julio, Patrick Fève, and Julien Matheron. 2018. "Monetary policy inertia or persistent shocks: a DSGE analysis." Eighth issue (March 2007) of the International Journal of Central Banking.

Carvalho, Carlos, Fernanda Nechio, and Tiago Tristao. 2019. "Taylor Rule Estimation by OLS." Federal Reserve Bank of San Francisco.

Chang, Yoosoon, Junior Maih, and Fei Tan. 2019. "Origins of monetary policy shifts: A new approach to regime switching in dsge models."

Christiano, Lawrence J, and Terry J Fitzgerald. 2003. "The band pass filter." international economic review, 44(2): 435-465.

Clarida, Richard, Jordi Gali, and Mark Gertler. 1999. "The science of monetary policy: a new Keynesian perspective." Journal of economic literature, 37(4): 1661-1707.

Cochrane, John H. 1998. "A frictionless view of US inflation." NBER macroeconomics annual, 13: 323-384.

Cochrane, John H. 2009. Asset pricing: Revised edition. Princeton university press.

Coibion, Olivier, and Yuriy Gorodnichenko. 2012. "Why are target interest rate changes so persistent?" American Economic Journal: Macroeconomics, 4(4): 126-62.

Coleman, Wilbur John. 1991. "Equilibrium in a production economy with an income tax." Econometrica: Journal of the Econometric Society, 1091-1104. 
Costa, Oswaldo Luiz Valle, Marcelo Dutra Fragoso, and Ricardo Paulino Marques. 2006. Discrete-time Markov jump linear systems. Springer Science \& Business Media.

Davig, Troy, and Eric M Leeper. 2007. "Generalizing the Taylor principle." American Economic Review, 97(3): 607-635.

Davig, Troy, Eric M Leeper, and Todd B Walker. 2010. ““'Unfunded liabilities" and uncertain fiscal financing." Journal of Monetary Economics, 57(5): 600-619.

Davig, Troy, Eric M Leeper, and Todd B Walker. 2011. "Inflation and the fiscal limit." European Economic Review, 55(1): 31-47.

Davig, Troy, Eric M Leeper, Richard H Clarida, and Jesper Lindé. 2006. "Endogenous monetary policy regime change [with comments]." Vol. 2006, 345-391, The University of Chicago Press Chicago, IL.

de Carvalho, Carlos Viana, and André D Vilela. 2015. "What If Brazil Hadn't Floated the Real in 1999?" Brazilian Review of Econometrics, 35(2): 265-308.

De Castro, Marcos R, Solange N Gouvea, Andre Minella, Rafael Santos, and Nelson F Souza-Sobrinho. 2015. "SAMBA: Stochastic analytical model with a bayesian approach." Brazilian Review of Econometrics, 35(2): 103-170.

De Paoli, Bianca, and Pawel Zabczyk. 2013. "Cyclical risk aversion, precautionary saving, and monetary policy." Journal of Money, Credit and Banking, 45(1): 1-36.

D'Erasmo, Pablo, and Enrique G Mendoza. 2016. "Distributional incentives in an equilibrium model of domestic sovereign default." Journal of the European Economic Association, 14(1): 7-44.

Duffie, Darrell, and Kenneth J Singleton. 1999. "Modeling term structures of defaultable bonds." The review of financial studies, 12(4): 687-720.

Du, Wenxin, and Jesse Schreger. 2016. "Local currency sovereign risk." The Journal of Finance, 71(3): 1027-1070.

Eaton, Jonathan, and Mark Gersovitz. 1981. "Debt with potential repudiation: Theoretical and empirical analysis." The Review of Economic Studies, 48(2): 289-309. 
Edge, Rochelle M, Michael T Kiley, and Jean-Philippe Laforte. 2008. "Natural rate measures in an estimated DSGE model of the US economy." Journal of Economic Dynamics and control, 32(8): 2512-2535.

Edwards, Sebastian. 1986. "The pricing of bonds and bank loans in international markets: An empirical analysis of developing countries' foreign borrowing." European Economic Review, 30(3): 565-589.

Feenstra, Robert C, Robert Inklaar, and Marcel P Timmer. 2015. "The next generation of the Penn World Table." American economic review, 105(10): 3150-82.

Ferreira, Alex Luiz, and Miguel A León-Ledesma. 2007. "Does the real interest parity hypothesis hold? Evidence for developed and emerging markets." Journal of International Money and Finance, 26(3): 364-382.

Fève, Patrick, and Jean-Guillaume Sahuc. 2017. "In search of the transmission mechanism of fiscal policy in the Euro area." Journal of Applied Econometrics, 32(3): 704-718.

Fraga, Arminio, Ilan Goldfajn, and Andre Minella. 2003. "Inflation targeting in emerging market economies." NBER macroeconomics annual, 18: 365400.

Franco, Gustavo HB. 2017. A moeda e a lei: Uma história monetária brasileira, 1933-2013. Editora Schwarcz-Companhia das Letras.

Friedman, M. 1970. "The counter-revolution in monetary theory, Institute of Econonic Affairs for the Wincott Foundation." Occasional Paper, 33: 8.

Galí, Jordi. 2015. Monetary policy, inflation, and the business cycle: an introduction to the new Keynesian framework and its applications. . $2^{\text {nd }}$ ed., Princeton, USA:Princeton University Press.

Gali, Jordi, and Tommaso Monacelli. 2005. "Monetary policy and exchange rate volatility in a small open economy." The Review of Economic Studies, 72(3): 707-734.

Galli, Carlo. 2020. "Inflation, Default Risk and Nominal Debt." UCL manuscript.

Gavin, Michael, and Roberto Perotti. 1997. "Fiscal policy in latin america." NBER macroeconomics annual, 12: 11-61.

Gelman, Andrew, Donald B Rubin, et al. 1992. "Inference from iterative simulation using multiple sequences." Statistical science, 7(4): 457-472. 
Greenwood, Jeremy, Zvi Hercowitz, and Gregory W Huffman. 1988. "Investment, capacity utilization, and the real business cycle." The American Economic Review, 402-417.

Herbst, Edward P, and Frank Schorfheide. 2015. Bayesian estimation of DSGE models. Princeton University Press.

Hills, Timothy S, Taisuke Nakata, and Sebastian Schmidt. 2019. "Effective lower bound risk." European Economic Review, 120: 103321.

Hodrick, Robert J, and Edward C Prescott. 1997. "Postwar US business cycles: an empirical investigation." Journal of Money, credit, and Banking, 1-16.

Ireland, Peter N. 2010. "Monetary transmission mechanism." In Monetary economics. 216-223. Springer.

Justiniano, Alejandro, and Bruce Preston. 2010. "Monetary policy and uncertainty in an empirical small open-economy model." Journal of Applied Econometrics, 25(1): 93-128.

Keen, Benjamin, and Yongsheng Wang. 2007. "What is a realistic value for price adjustment costs in New Keynesian models?" Applied Economics Letters, 14(11): 789-793.

Kimball, Miles. 1995. "The Quantitative Analytics of the Basic Neomonetarist Model." Journal of Money, Credit and Banking, 27(4): 1241-77.

Kim, Jinill, Sunghyun Kim, Ernst Schaumburg, and Christopher A Sims. 2008. "Calculating and using second-order accurate solutions of discrete time dynamic equilibrium models." Journal of Economic Dynamics and Control, 32(11): 3397-3414.

Kocherlakota, Narayana. 2015. "Public Debt and the Long-Run Neutral Real Interest Rate."

Kulish, Mariano. 2007. "Should monetary policy use long-term rates?" The BE Journal of Macroeconomics, 7(1).

Laubach, Thomas, and John C Williams. 2003. "Measuring the natural rate of interest." Review of Economics and Statistics, 85(4): 1063-1070.

Leeper, Eric M. 1991. "Equilibria under 'active'and 'passive'monetary and fiscal policies." Journal of Monetary Economics, 27(1): 129-147.

Leeper, Eric M, and Tao Zha. 2003. "Modest policy interventions." Journal of Monetary Economics, 50(8): 1673-1700. 
Lowenkron, Alexandre, and Márcio Garcia. 2005. "Cousin Risks: The Extent and the Causes of Positive Correlation between Country and Currency Risks." Texto para discussão, 507.

Loyo, Eduardo. 1999. "Tight money paradox on the loose: a fiscalist hyperinflation." manuscript, Harvard University.

Lucas Jr, Robert, et al. 1976. "Econometric policy evaluation: A critique." Vol. 1, 19-46, Elsevier.

Maih, Junior. 2015. "Efficient perturbation methods for solving regimeswitching DSGE models."

Maršál, Aleš, Lorant Kaszab, and Roman Horvath. 2017. "Government Spending and the Term Structure of Interest Rates in a DSGE Model." Research Department, National Bank of Slovakia.

Miller, Max, James D Paron, and Jessica A Wachter. 2020. "Sovereign default and the decline in interest rates." Available at SSRN.

Mishkin, Frederic S. 1984. "Are real interest rates equal across countries? An empirical investigation of international parity conditions." The Journal of Finance, 39(5): 1345-1357.

Önal, Recep, and Gazi Erçel. 1999. "Letter of Intent of the government of Turkey."

Neiss, Katharine S, and Edward Nelson. 2003. "The real-interest-rate gap as an inflation indicator." Macroeconomic dynamics, 7(2): 239-262.

Orphanides, Athanasios, and John C Williams. 2002. "Robust monetary policy rules with unknown natural rates." Brookings Papers on Economic Activity, 2002(2): 63-145.

Orphanides, Athanasios, and John C Williams. 2008. "Learning, expectations formation, and the pitfalls of optimal control monetary policy." Journal of Monetary Economics, 55: S80-S96.

Pallara, Kevin, and Jean-Paul Renne. 2019. "Fiscal Limits and Sovereign Credit Spreads." Available at SSRN 3475425.

Pastine, Ivan. 2002. "Speculation and the decision to abandon a fixed exchange rate regime." Journal of International Economics, 57(1): 197-229.

Pastore, Affonso Celso. 1991. "A reforma monetária do Plano Collor." Revista Brasileira de Economia, 45: 157-174. 
Rachel, Lukasz, and Thomas Smith. 2015. "Secular drivers of the global real interest rate." Staff Working Paper No. 571, Bank of England.

Ramirez, Francisco A, and Allan Wright. 2017. "What are the fiscal limits for the developing economies of Central America and the Caribbean?" IDB Working Paper Series.

Reinhart, Carmen, Kenneth Rogoff, and Miguel Savastano. 2003. "Debt intolerance." Brookings Papers on Economic Activity, 1: 1-74.

Reinhart, Carmen M, and Kenneth S Rogoff. 2009. This Time Is Different: Eight Centuries of Financial Folly. Princeton University Press.

Reis, Ricardo. 2018. "Discussion of "Sovereign Default and Monetary Policy Tradeoffs"." International Journal of Central Banking.

Rotemberg, Julio J. 1982. "Sticky prices in the United States." Journal of Political Economy, 90(6): 1187-1211.

Rupert, Peter, and Roman Šustek. 2016. "On the mechanics of NewKeynesian models." School of Economics and Finance at Queen Mary University of London Working Paper, 784.

Rupert, Peter, and Roman Šustek. 2019. "On the mechanics of NewKeynesian models." Journal of Monetary Economics, 102: 53-69.

Sack, Brian, and Volker Wieland. 2000. "Interest-rate smoothing and optimal monetary policy: a review of recent empirical evidence." Journal of Economics and Business, 52(1-2): 205-228.

Sargent, Thomas, and N Wallace. 1981. "Some Unpleasant Monetarist Arithmetic." Federal Reserve Bank of Minneapolis Quarterly Review, 5(3): 1-17.

Schabert, Andreas. 2010. "Monetary policy under a fiscal theory of sovereign default." Journal of Economic Theory, 145(2): 860-868.

Schabert, Andreas, and Sweder JG Van Wijnbergen. 2014. "Sovereign default and the stability of inflation-targeting regimes." IMF Economic Review, 62(2): 261-287.

Schmelzing, Paul. 2020. "Staff Working Paper No. 845 Eight centuries of global real interest rates, RG, and the 'suprasecular'decline, 1311-2018."

Sims, Christopher A. 1994. "A simple model for study of the determination of the price level and the interaction of monetary and fiscal policy." Economic theory, 4(3): 381-399. 
Smets, Frank, and Rafael Wouters. 2003. "An estimated dynamic stochastic general equilibrium model of the Euro Area." Journal of the European Economic Association, 1(5): 1123-1175.

Smets, Frank, and Rafael Wouters. 2007. "Shocks and frictions in US business cycles: A Bayesian DSGE approach." American economic review, 97(3): 586-606.

Sturzenegger, Federico, and Jeromin Zettelmeyer. 2008. "Haircuts: estimating investor losses in sovereign debt restructurings, 1998-2005." Journal of international Money and Finance, 27(5): 780-805.

Sturzenegger, Federico, and Rogério LF Werneck. 2006. "Fiscal federalism and procyclical spending: The cases of Argentina and Brazil." Económica, 52.

Tauchen, George. 1986. "Finite state markov-chain approximations to univariate and vector autoregressions." Economics letters, 20(2): 177-181.

Taylor, John B. 1993. "Discretion versus policy rules in practice." Vol. 39, 195214, Elsevier.

Taylor, John B, and John C Williams. 2010. "Simple and robust rules for monetary policy." In Handbook of monetary economics. Vol. 3, 829-859. Elsevier.

Uribe, Martin. 2006. "A fiscal theory of sovereign risk." Journal of Monetary Economics, 53(8): 1857-1875.

Wicksell, Knut. 1898. Interest and Prices: A Study of the Causes Regulating the Value of Money. Originally published as Geldzins und Güterpreise in 1898. Translated to English in 1936 for the Royal Economic Society. Republished by Read Books Ltd. in 2013.

Woodford, Michael. 1994. "Monetary policy and price level determinacy in a cash-in-advance economy." Economic theory, 4(3): 345-380.

Woodford, Michael. 1995. "Price-level determinacy without control of a monetary aggregate." Vol. 43, 1-46, Elsevier.

Woodford, Michael. 2001. "The Taylor rule and optimal monetary policy." American Economic Review, 91(2): 232-237.

Woodford, Michael. 2003a. Interest and Prices: Foundations of a Theory of Monetary Policy. . $1^{\text {st }}$ ed., Princeton, USA:Princeton University Press. 
Woodford, Michael. 2003b. "Optimal interest-rate smoothing." The Review of Economic Studies, 70(4): 861-886.

Woodford, Michael. 2011. Interest and prices: Foundations of a theory of monetary policy. Princeton, USA:Princeton University Press. 


\section{Appendix: Chapter 1}

\section{A.1 \\ Estimation of the real neutral rate using univariate filters}

Estimation is conducted with quarterly country data from the IMF-IFS as follows. All countries are sorted in descending order by forecasted nominal Q42020 GDP measured in USD as of 27/01/2020. Countries are classified using the IMF-WEO definition of emerging and advanced economies. The largest 20 advanced and the largest 20 emerging economies are selected from the dataset. The real ex-ante interest rate for each country is calculated according to a linearized Fisher equation, that is, subtracting a series of nominal interest rate by a series of inflation expectation, both with the same time horizon. For the nominal interest rate (NR), we chose the annualized rate on national Treasury Bills (local-currency 1-year-maturity federal government bonds). For the inflation expectation, we estimated $\mathrm{AR}(\mathrm{p})$ models for each country's quarterly CPI inflation series with p ranging from 0 to 4 lags. Then, for each country, we selected the model with the lowest BIC information criterion. Since not all selected countries had enough observations of the aforementioned time series available, some of the initially selected countries had to be removed from the sample. Having defined each country's inflation forecast model, we built a series of 1-year-ahead inflation forecast for each country. A summary of the data sample is available in Table A.1.

After calculating all country-specific ex-ante real rate series, we applied three statistical filters on them: $\operatorname{HP}(\lambda=1600)$, Baxter-King $(\min =6, \max =32$, order $=12)$, and Christiano-Fitzgerald $(\min =6, \max =32) .{ }^{1}$ We calculated the median of these filters and their range as shown in Figures A.1 (Advanced Economies) and A.2 (Emerging Economies). Finally, we obtained with the country-specific medians three statistics for each country group: the group median, the arithmetic group mean, and the country-weighted group mean using the aforementioned GDP values (Figure 1.1).

${ }^{1}$ The original reference of each filter is, in order, Hodrick and Prescott (1997), Baxter and King (1999), and Christiano and Fitzgerald (2003). 


\begin{tabular}{|c|c|c|c|c|c|c|}
\hline & Name & Status & NR Start & NR End & CPI Start & CPI End \\
\hline US & United States of America & Advanced & $1950 \mathrm{Q} 1$ & 2020Q1 & $1955 \mathrm{Q} 2$ & $2020 \mathrm{Q} 1$ \\
\hline GB & United Kingdom & Advanced & $1964 \mathrm{Q} 1$ & $2016 \mathrm{Q} 3$ & $1955 \mathrm{Q} 2$ & $2020 \mathrm{Q} 1$ \\
\hline IT & Italy & Advanced & $1977 \mathrm{Q} 1$ & $2020 \mathrm{Q} 1$ & $1955 \mathrm{Q} 2$ & $2020 \mathrm{Q} 1$ \\
\hline CA & Canada & Advanced & $1950 \mathrm{Q} 1$ & $2017 \mathrm{Q} 2$ & $1949 \mathrm{Q} 2$ & $2020 \mathrm{Q} 1$ \\
\hline ES & Spain & Advanced & $1987 \mathrm{Q} 3$ & $2020 \mathrm{Q} 1$ & $1954 \mathrm{Q} 2$ & $2020 \mathrm{Q} 1$ \\
\hline SE & Sweden & Advanced & $1960 \mathrm{Q} 1$ & $2017 \mathrm{Q} 2$ & $1955 \mathrm{Q} 2$ & $2020 \mathrm{Q} 1$ \\
\hline BE & Belgium & Advanced & $1957 \mathrm{Q} 1$ & $2017 \mathrm{Q} 4$ & $1955 \mathrm{Q} 2$ & $2020 \mathrm{Q} 1$ \\
\hline IL & Israel & Advanced & $1995 \mathrm{Q} 1$ & $2020 \mathrm{Q} 1$ & $1952 \mathrm{Q} 2$ & $2020 \mathrm{Q} 1$ \\
\hline HK & Hong Kong & Advanced & $1992 \mathrm{Q} 4$ & $2018 \mathrm{Q} 4$ & $1981 \mathrm{Q} 1$ & $2020 \mathrm{Q} 1$ \\
\hline BR & Brazil & Emerging & $1995 \mathrm{Q} 1$ & $2020 \mathrm{Q} 1$ & $1980 \mathrm{Q} 1$ & $2020 \mathrm{Q} 1$ \\
\hline MX & Mexico & Emerging & $1978 \mathrm{Q} 1$ & $2020 \mathrm{Q} 1$ & $1957 \mathrm{Q} 2$ & $2020 \mathrm{Q} 1$ \\
\hline SA & Saudi Arabia & Emerging & $2009 \mathrm{Q} 2$ & $2018 \mathrm{Q} 1$ & $1980 \mathrm{Q} 2$ & $2020 \mathrm{Q} 1$ \\
\hline PL & Poland & Emerging & $1992 \mathrm{Q} 1$ & $2017 \mathrm{Q} 1$ & $1988 \mathrm{Q} 2$ & $2020 \mathrm{Q} 1$ \\
\hline TH & Thailand & Emerging & $2001 \mathrm{Q} 1$ & $2020 \mathrm{Q} 1$ & $1965 \mathrm{Q} 2$ & $2020 \mathrm{Q} 1$ \\
\hline ZA & South Africa & Emerging & $1957 \mathrm{Q} 1$ & $2020 \mathrm{Q} 1$ & $1957 \mathrm{Q} 2$ & $2020 \mathrm{Q} 1$ \\
\hline PH & Philippines & Emerging & $1976 \mathrm{Q} 1$ & $2019 \mathrm{Q} 4$ & $1957 \mathrm{Q} 2$ & $2020 \mathrm{Q} 1$ \\
\hline BD & Bangladesh & Emerging & $2006 \mathrm{Q} 3$ & $2020 \mathrm{Q} 1$ & $1993 \mathrm{Q} 4$ & $2020 \mathrm{Q} 1$ \\
\hline EG & Egypt & Emerging & $1997 \mathrm{Q} 1$ & $2020 \mathrm{Q} 1$ & $1957 \mathrm{Q} 2$ & $2019 \mathrm{Q} 4$ \\
\hline
\end{tabular}

Table A.1: Filters: Summary of the data sample
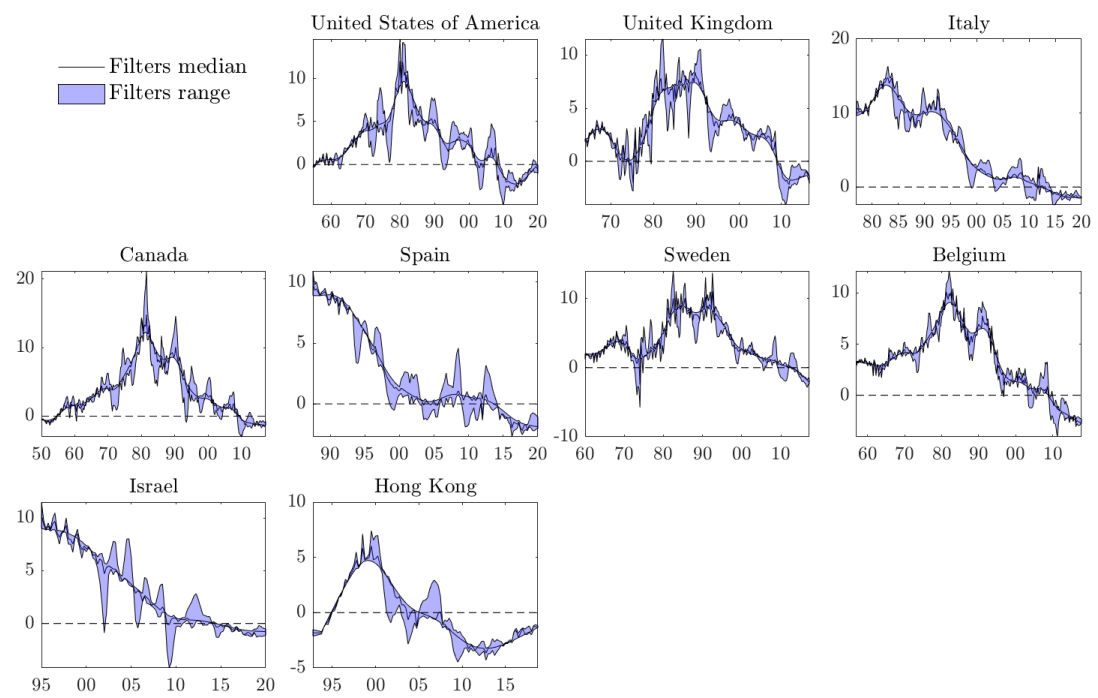

Figure A.1: Advanced Economies: Real neutral rates (\% per annum) estimated by univariate filters 

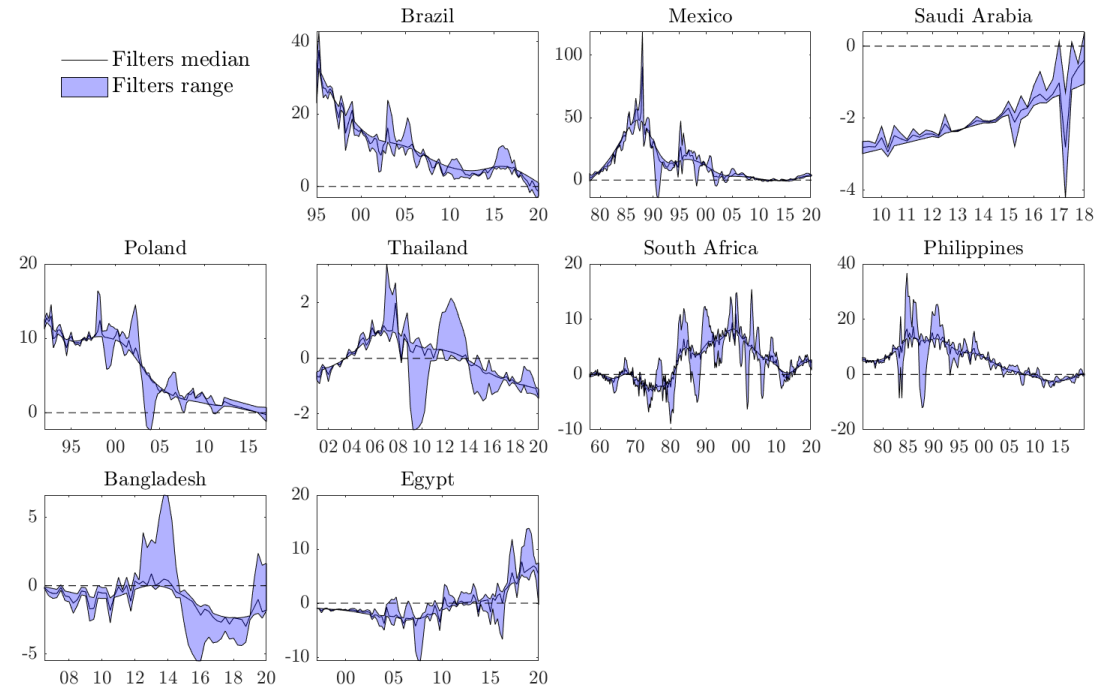

Figure A.2: Emerging Economies: Real neutral rates (\% per annum) estimated by univariate filters 


\section{A. 2 Model derivation under a price-level targeting rule}

The same model we derived in Section 1.4 under Assumption 1.6 of an inflation-targeting (or Taylor) rule can easily be derived under a price-level targeting (or Wicksellian) rule. We start from assumptions (1.1) to (1.5), and expose the Fisher equation in its log-linear form:

$$
p_{t}=\mathbb{E}_{t} p_{t+1}+r_{t}^{n}-i_{t}
$$

where, exactly as before, $\mathbb{E}_{t}$ is the rational expectations operator conditional on all information available at the end of time $t, p_{t}$ is the log of the price level at period $t, r_{t}^{n}$ is the equilibrium real rate of interest (and the natural one) at period $t$, while $i_{t}$ is the short-term nominal interest rate at period $t$. We can interpret this equation as an equilibrium condition instead of as an identity for the same reasons exposed for the inflation-targeting derivation. In other words, at every instant $t$, the price level that clears the goods market (and equates saving and investment) is the one given by equation (A-1).

\section{A.2.1}

\section{Neo-Wicksellian model with price-level targeting}

Now, assume the central bank sets $i_{t}$, the money rate in Wicksell's language, as arguably envisioned by the latter ${ }^{2}$, such that $p_{t}$ and $i_{t}$ should move in the same direction and targeted inflation is zero.

Assumption A.1 (Wicksellian risk-free policy rule) the central bank sets the nominal interest rate of a risk-free asset, $i_{t}$, through a Wicksellian rule of the type $i_{t}=\bar{\iota}_{t}+\phi\left(p_{t}-\bar{p}\right)$, where $\left\{\bar{\iota}_{j}\right\}_{j=t}^{\infty}$ is an exogenous process for a time-varying intercept determined independently of the evolution of prices which may or may not be correlated with $\left\{r_{j}^{n}\right\}_{j=t}^{\infty} ; \bar{p}$ is the log of the price level target; and $\phi>0$.

Without loss of generality, hereafter we set $\bar{P}=1$, where $\bar{P}$ is the price-level target. Inserting Assumption A.1 into the Fisher relation (A-1) to eliminate $i_{t}$, we obtain the law of movement of the equilibrium price level:

$$
p_{t}=\alpha \mathbb{E}_{t} p_{t+1}+\alpha\left(r_{t}^{n}-\bar{\iota}_{t}\right)
$$

where $\alpha \equiv \frac{1}{1+\phi}$ is a coefficient that satisfies $0<\alpha<1$. If the process $\left\{r_{t}^{n}, \bar{l}_{t}\right\}$ is bounded then $p_{t}$ is unique and bounded ${ }^{3}$, obtained by iterating forward equation (A-2), which gives us

${ }^{2}$ This is Woodford's interpretation of Wicksell's work, since the latter did not mathematically specify such a rule, even more its log-linear approximation.

${ }^{3} \mathrm{~A}$ proof is available in Woodford (2003a)'s Appendix A.4. 


$$
p_{t}=\sum_{j=0}^{\infty} \alpha^{j+1} \mathbb{E}_{t}\left(r_{t+j}^{n}-\bar{\iota}_{t+j}\right)
$$

As a consequence, the equilibrium price level will fluctuate in a bounded interval around its long-run average value:

$$
\bar{p} \equiv \frac{\overline{r^{n}}-\bar{\iota}}{\phi}
$$

where $\bar{p}, \overline{r^{n}}$ and $\bar{\iota}$ are the long-run average of the log price level, of the natural interest rate and of the time-varying intercept, respectively.

The behavior of Woodford (2003a)'s simple model is summarized in Figure A.3 $(\phi=0.1)$ and Figure A.4 $(\phi=0.2)$, in which all panels are plotted assuming an economy starting from the steady state at period $t=0$, whose only shocks are the ones specified in each panel, and that $\bar{\iota}_{t}=\overline{r^{n}}$ at all periods unless otherwise stated. The panels can be synthesized as follows:
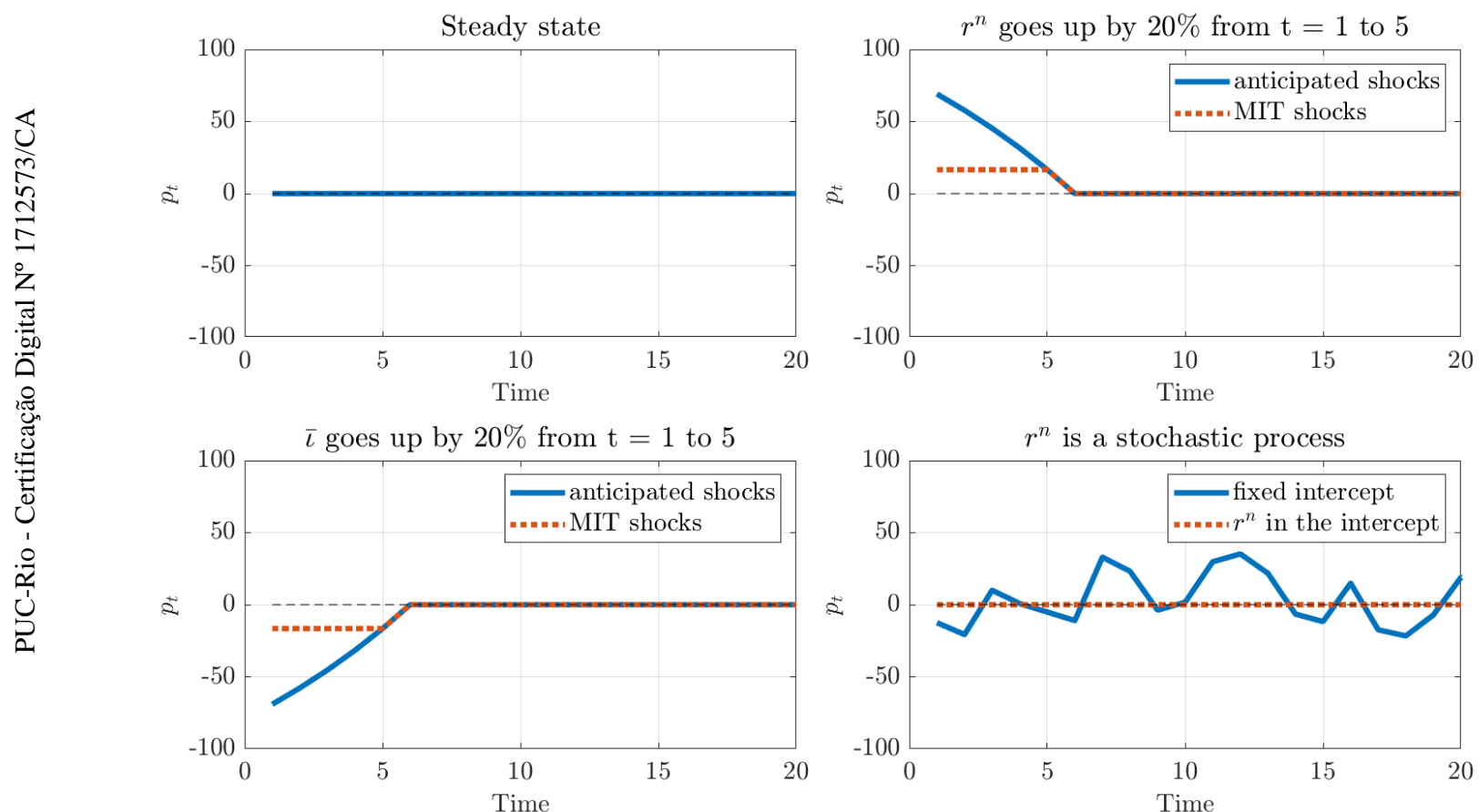

Figure A.3: The price level under neo-Wicksellian monetary theory $(\phi=0.1)$ 

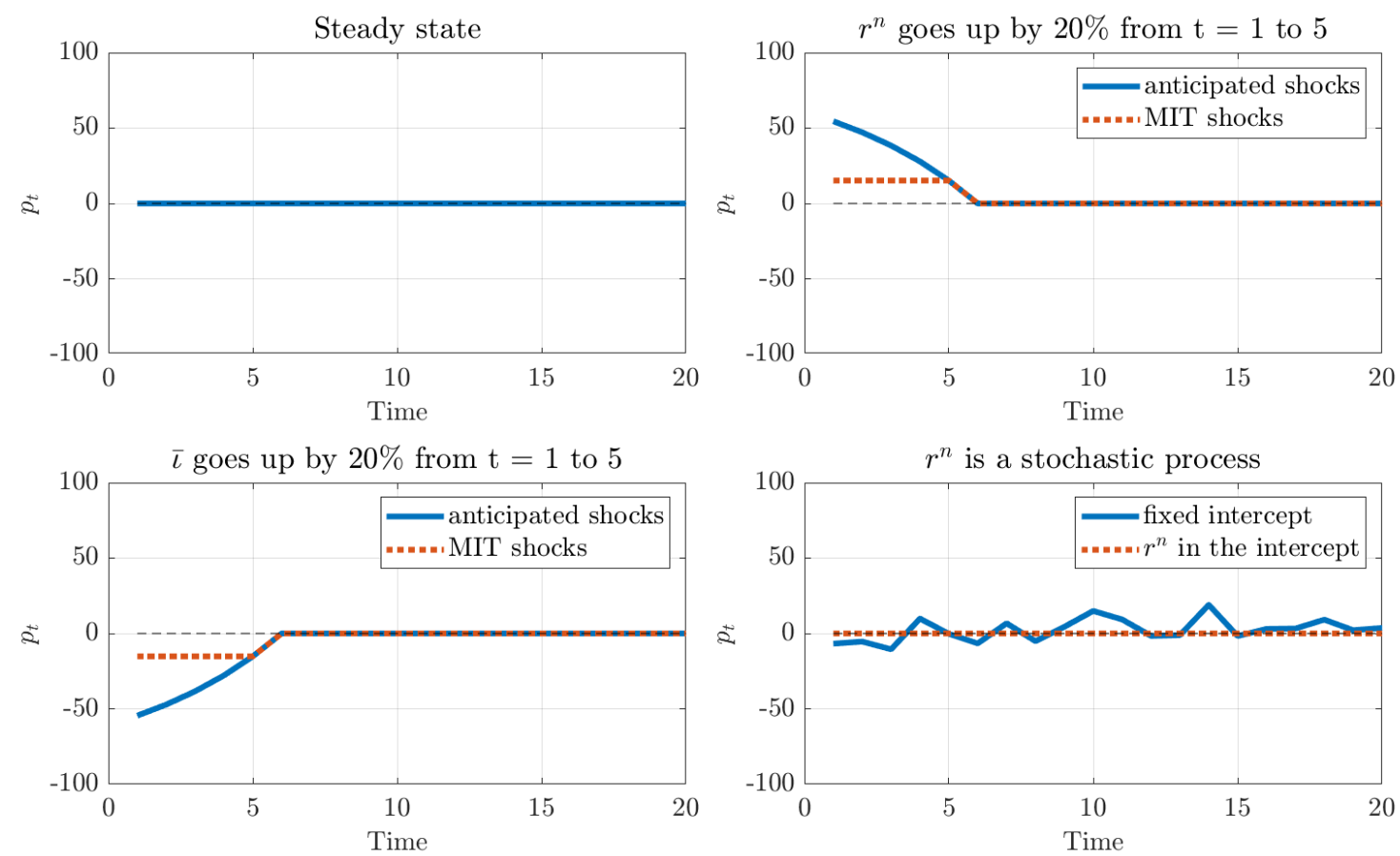

Figure A.4: The price level under neo-Wicksellian monetary theory $(\phi=0.2)$

- There is no distinction in this model between the equilibrium price level and the price level since prices are flexible. If $\bar{\iota}_{t}=r_{t}^{n} \forall t$, then the price level never leaves its steady-state value (top-left panel and red line of bottom-right panel of Figure A.3);

- An expected increase (decrease) in the equilibrium real rate at any time from $t=1$ to $t=\infty$ will increase (decrease) equilibrium prices today (top-right panel of Figure A.3). If the sequence of shocks is anticipated at period $t=1$ (blue line), the increase (decrease) of the price level is larger than if shocks are individually seen as MIT shocks ${ }^{4}$ (red line);

- An expected tightening (loosening) of the policy rule, represented in the model by a raise (reduction) of the rule's intercept, at any time from $t=1$ to $t=\infty$ will decrease (increase) equilibrium prices today (bottomleft panel of Figure A.3). Here rational expectations play a role again, since if the sequence of shocks is anticipated by the agents (blue line), the reduction (increase) of the price level is more intense than if they consider shocks to be individually MIT shocks (red line);

- $r_{t}^{n}$ is a sufficient statistic for how real factors affect $p_{t}$ in the model as any additional information about real variables does not expand the information set. By closely tracking the natural interest rate, monetary policy is able to stabilize prices (red line in bottom-right panel of Figure

${ }^{4} \mathrm{An}$ MIT shock is an unexpected shock, usually inflicted at the deterministic steady-state equilibrium, that once it happens it is not expected to happen again by the agents. 
A.3) when $\left\{r_{t}^{n}\right\}$ follows a stochastic process. Any intercept that differs from the natural interest rate will fail to stabilize at all periods the level of prices, where the specific combination of a stationary $\left\{r_{t}^{n}\right\}$ with an intercept fixed at the steady-state value of $r_{t}^{n}$ results in the price level fluctuating around the target (blue line);

- The higher (lower) the reaction coefficient $\phi$ of the policy rule, the more reduced (augmented) is the intensity of deviations from the price-level target. One can see this by comparing the panels of Figure A.3, whose $\phi=0.1$, with the respective panels of Figure A.4, whose $\phi=0.2$.

\section{A.2.2}

\section{Monetary policy with risk in the policy asset under price-level targeting}

We, now, redefine the Wicksellian policy rule so as to incorporate the fact that the policy asset is risky.

Assumption A.2 (Wicksellian risky policy rule) the central bank sets the nominal interest rate of a risky asset, $i_{t}$, through a Wicksellian rule of the type $i_{t}=\bar{\iota}_{t}+\phi\left(p_{t}-\bar{p}\right)$, where $\left\{\bar{\iota}_{j}\right\}_{j=t}^{\infty}$ is an exogenous process for a timevarying intercept determined independently of the evolution of prices which may or may not be correlated with $\left\{r_{j}^{n}\right\}_{j=t}^{\infty} ; \bar{p}$ is the log of the price level target; and $\phi>0$.

Taking assumptions (1.1) to (1.5), (1.7) to (1.8), and (A.2) as valid, the expected net return of the policy asset in line with Definition 1.1 is ${ }^{5}$

$$
\mathbb{E}_{t} i_{t+1}^{\text {Risky }}=\left(1-\mathbb{E}_{t} \mathcal{D}_{t+1} \delta_{t+1}\right) i_{t}-\mathbb{E}_{t} \mathcal{D}_{t+1} \delta_{t+1}
$$

Next, relying on Assumption 1.7 of no arbitrage opportunities, nominal returns must equalize in expectations

$$
i_{t}^{R F}=\mathbb{E}_{t} i_{t+1}^{\text {Risky }}
$$

where, as before, $i_{t}^{R F}$ is the risk-free net nominal interest rate.

Substituting the policy rule of Assumption A.2 into the policy asset expected return (1-9) and then through the no-arbitrage condition (1-10) into the Fisher equation (A-1), we obtain the equilibrium price level in the risky policy asset economy

$$
\begin{array}{r}
p_{t}=\sum_{j=0}^{\infty} \Upsilon_{t, j+1} \mathbb{E}_{t}\left(r_{t+j}^{n}-\left(1-\mathbb{E}_{t} \mathcal{D}_{t+j+1} \delta_{t+j+1}\right) \bar{\iota}_{t+j}+\mathbb{E}_{t} \mathcal{D}_{t+j+1} \delta_{t+j+1}\right) \\
\Upsilon_{t, j+1} \equiv \prod_{k=1}^{j+1}\left(\frac{1}{1+\left(1-\mathbb{E}_{t} \mathcal{D}_{t+k} \delta_{t+k}\right) \phi}\right) \quad \forall j \geq 0, \forall t
\end{array}
$$

${ }^{5}$ Equations (1-9) and (1-10) are reproduced here for the help of the reader. 
For $p_{t}$ to exist and be unique, the process $\left\{r_{t}^{n}, \mathcal{D}_{t}, \delta_{t}, \bar{\iota}_{t}\right\}$ must be bounded and more assumptions must be made about $\left\{\mathcal{D}_{t}\right\},\left\{\delta_{t}\right\}$, and $\phi$. Imposing further that $\phi>0$, like in the canonical case, and that for all $t$ there is at least one infinite sequence $k_{n} \subset[1, \infty)$ such that $0 \leq \mathbb{E}_{t} \mathcal{D}_{t+k} \delta_{t+k}<1$ in that sequence is sufficient for assuring determinacy since we have already assumed that the object $\left\{\mathcal{D}_{t}\right\}$ represents a probability and $\left\{\delta_{t}\right\}$ a fraction, which implies that $0 \leq\left\{\mathcal{D}_{t} \delta_{t}\right\} \leq 1$ for all $t$. These conditions assure for all $t$ that $0<\frac{1}{1+\left(1-\mathbb{E}_{t} \mathcal{D}_{t+k} \delta_{t+k}\right) \phi}<1$ for at least one infinite sequence $k_{n} \subset[1, \infty)$. Overall, determinacy is guaranteed under rather mild restrictions. For one, when full (not partial) default is expected at the next period with certainty at all periods, the policy-asset market simply collapses. In that extreme case, $\mathbb{E}_{t} \mathcal{D}_{t+k} \delta_{t+k}=1$ for all $t$ and all $k$, such that we have an explosive process. For two, assuming that all sequences of $k_{n} \subset[1, \infty)$ such that $0 \leq \mathbb{E}_{t} \mathcal{D}_{t+k} \delta_{t+k}<1$ are finite imposes that after a certain $k=\tilde{k}$ the risky policy asset becomes strictly a full confiscation ad eternum by the government, what is quite unrealistic. For three, such sufficient requirements for determinacy still allow for full default to be expected for certain at any amount of periods into the future. Finally, note that under the implicit assumption that $\phi$ is time-invariant these are not only sufficient but also necessary conditions. Allowing $\phi$ to vary in time would allow for equilibrium determinacy even with $\phi<0$ at some periods.

Next, we give a formal proof of determinacy conditions for the price-level targeting case. A proof for when the central bank adopts inflation targeting is available in Proposition 1.1.

\section{Proposition A.1 (Price level determinacy under price-level targeting)} $A$ bounded process $\left\{r_{t}^{n}, \mathcal{D}_{t}, \delta_{t}, \bar{\iota}_{t}\right\}$, a monetary policy rule such as the one proposed in Assumption A.2 with $\phi>0$, the fact that $\mathcal{D}_{t}$ is a process that represents a probability and $\delta_{t}$ is a process that represents a fraction, and the condition that for all $t$ there is at least one infinite sequence $k_{n} \subset[1, \infty)$ such that $0 \leq \mathbb{E}_{t} \mathcal{D}_{t+k} \delta_{t+k}<1$ in that sequence are necessary and sufficient conditions so that the price level equilibrium exists and is unique.

Proof. Available in Appendix A.3.

Now, we prove which intercept for the Wicksellian rule is able to stabilize the price level at all times. The equivalent proof for a central bank that targets inflation is developed in Proposition 1.2.

\section{Proposition A.2 (Optimal intercept under price-level targeting)}

Monetary policy can stabilize prices through operations with the risky asset if it can track the sequence of natural interest rates $\left\{r_{t+j}^{n}\right\}_{j=0}^{\infty}$, the sequence of 
one-period-ahead policy-asset default probabilities $\left\{\mathcal{D}_{t+j+1}\right\}_{j=0}^{\infty}$, the sequence of one-period-ahead expected haircuts $\left\{\delta_{t+j+1}\right\}_{j=0}^{\infty}$, and it credibly adopts at period $t$ a Wickellian rule with the sequence of time-varying intercepts $\left\{\bar{\iota}_{t+j}\right\}_{j=0}^{\infty} \equiv\left\{\frac{r_{t+j}^{n}+\mathbb{E}_{t} \mathcal{D}_{t+j+1} \delta_{t+j+1}}{1-\mathbb{E}_{t} \mathcal{D}_{t+j+1} \delta_{t+j+1}}\right\}_{j=0}^{\infty}$.

Proof. Available in Appendix A.3.

From the equilibrium price level equation (A-5) and Figures A.5 $(\phi=0.1)$ and A.6 $(\phi=0.2)$, one can see that default expectations affect prices in four ways:

- First, it directly changes the level of prices: $\Upsilon_{j+1}>\alpha^{j+1} \quad \forall j \geq 0$, the higher the default probability, the higher the price level (top-left panel of Figure A.5).

- Second, it reduces the power of monetary policy w.r.t. prices (middleright panel of Figure A.5):

$\frac{\left(1-\mathbb{E}_{t} \mathcal{D}_{t+j+1} \delta_{t+j+1}\right)}{\Pi_{k=1}^{j+1}\left[1+\left(1-\mathbb{E}_{t} \mathcal{D}_{t+k} \delta_{t+k}\right) \phi\right]} \bar{l}_{t+j}<\frac{1}{\Pi_{k=1}^{j+1}[1+\phi]} \bar{l}_{t+j} \quad \forall \mathbb{E}_{t} \mathcal{D}_{t+1} \delta_{t+1}>0$. Simulations of the model for different correlations between $r_{t}^{n}$ and $\mathbb{E}_{t} \mathcal{D}_{t+1}$ show that the power reduction in monetary policy is robust even when considered the whole time-sequence of expected default probabilities. One way of seeing the inflationary bias that policy-asset risk introduces is to compare the multiplier of $r_{t+j}^{n}, \Upsilon_{t, j+1}$, with the multiplier of $\bar{\iota}_{t+j}$, $\Upsilon_{t, j+1}\left(1-\mathbb{E}_{t} \mathcal{D}_{t+j+1} \delta_{t+j+1}\right)$, and note that the first one is larger for any positive $\mathbb{E}_{t} \mathcal{D}_{t+j+1} \delta_{t+j+1}$.

- Third, the expected haircut term amplifies the reduction of power of monetary policy, as the higher $\mathbb{E}_{t} \mathcal{D}_{t+j+1} \delta_{t+j+1}$ the higher is the price level in equilibrium (bottom-left panel at Figure A.5). Nevertheless, its effect is numerically dominated in reasonable calibrations, where $\left(1-\mathbb{E}_{t} \mathcal{D}_{t+j+1} \delta_{t+j+1}\right) \gg \mathbb{E}_{t} \mathcal{D}_{t+j+1} \delta_{t+j+1}$.

- Fourth, monetary policy is no longer able to stabilize prices at all periods by just tracking $\left\{r_{t}^{n}\right\}$; it has to track a function of the natural interest rate, the default probability, and the haircut (Proposition A.2). Despite that, note that even though tracking $\left\{r_{t}^{n}\right\}$ does not fully stabilize prices, it does reduce the volatility of prices under the assumption of independence between $\left\{r_{t}^{n}\right\}$ and $\left\{\mathcal{D}_{t}\right\}$ (bottom-right panel of Figure A.5).

- Finally, by comparing the panels of Figure A.5) $(\phi=0.08)$ with their equivalents in Figure A.6 $(\phi=0.15)$, one can see the consequence of increasing $\phi$. Considering only the trajectory of the price level, the effects of conducting monetary policy with defaultable bonds can be consistently attenuated with a more hawkish stance. 

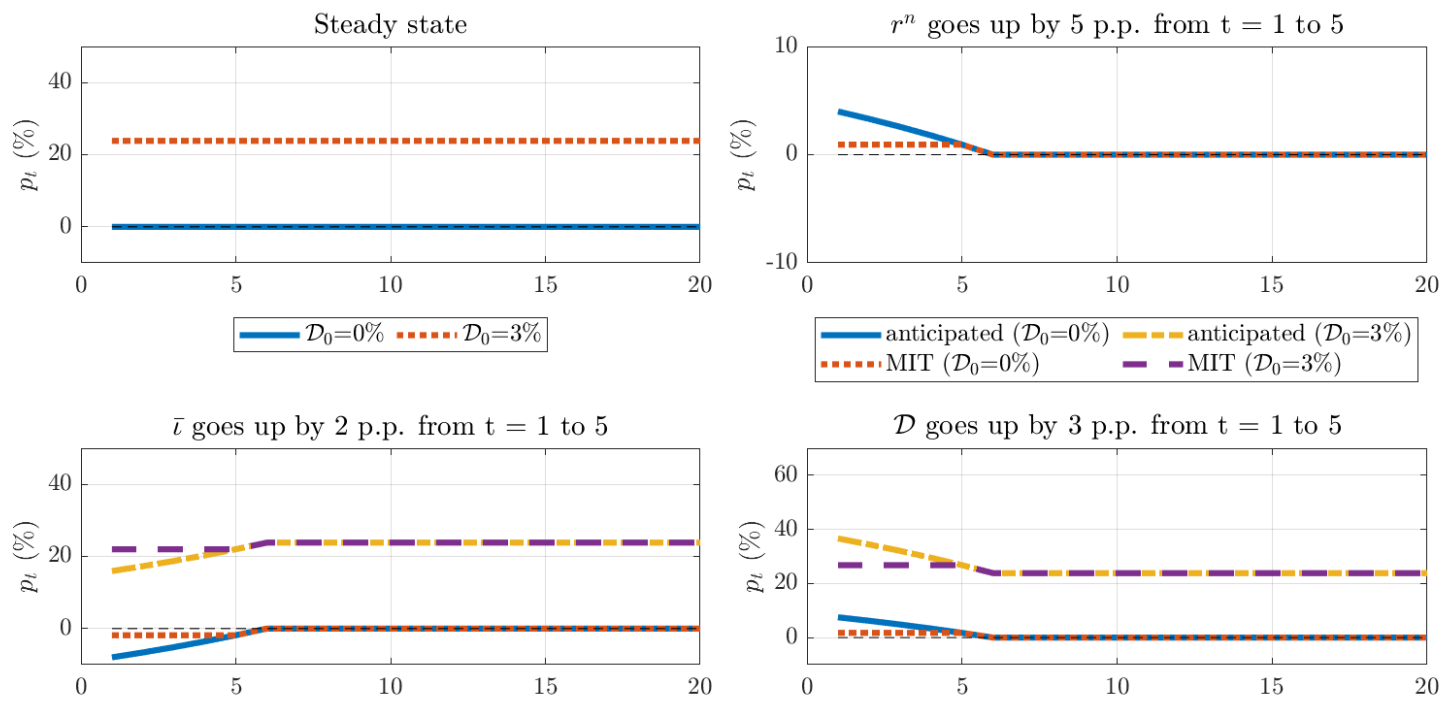

anticipated $\left(\mathcal{D}_{0}=0 \%\right)--=\operatorname{anticipated}\left(\mathcal{D}_{0}=3 \%\right)$

anticipated $\left(\mathcal{D}_{0}=0 \%\right)--=\operatorname{anticipated}\left(\mathcal{D}_{0}=3 \%\right)$ \#MMT $\left(\mathcal{D}_{0}=0 \%\right) \quad-\quad-\operatorname{MIT}\left(\mathcal{D}_{0}=3 \%\right)$ $\ldots$ MIT $\left(\mathcal{D}_{0}=0 \%\right) \quad-\quad-\operatorname{MIT}\left(\mathcal{D}_{0}=3 \%\right)$

$\delta$ goes up by 20 p.p. from $\mathrm{t}=1$ to 5
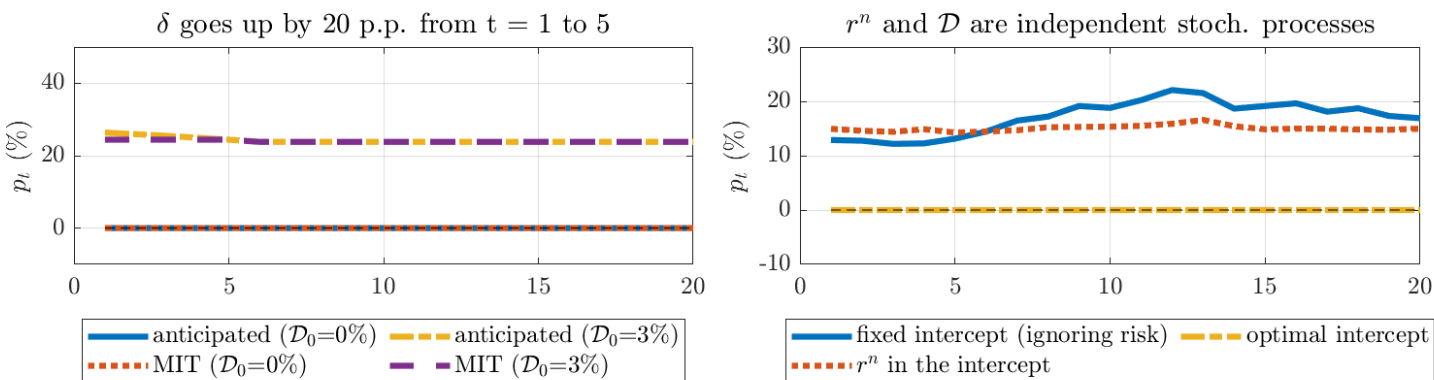

Figure A.5: The price level under neo-Wicksellian monetary theory augmented with policy-asset risk $(\phi=0.08)$ 

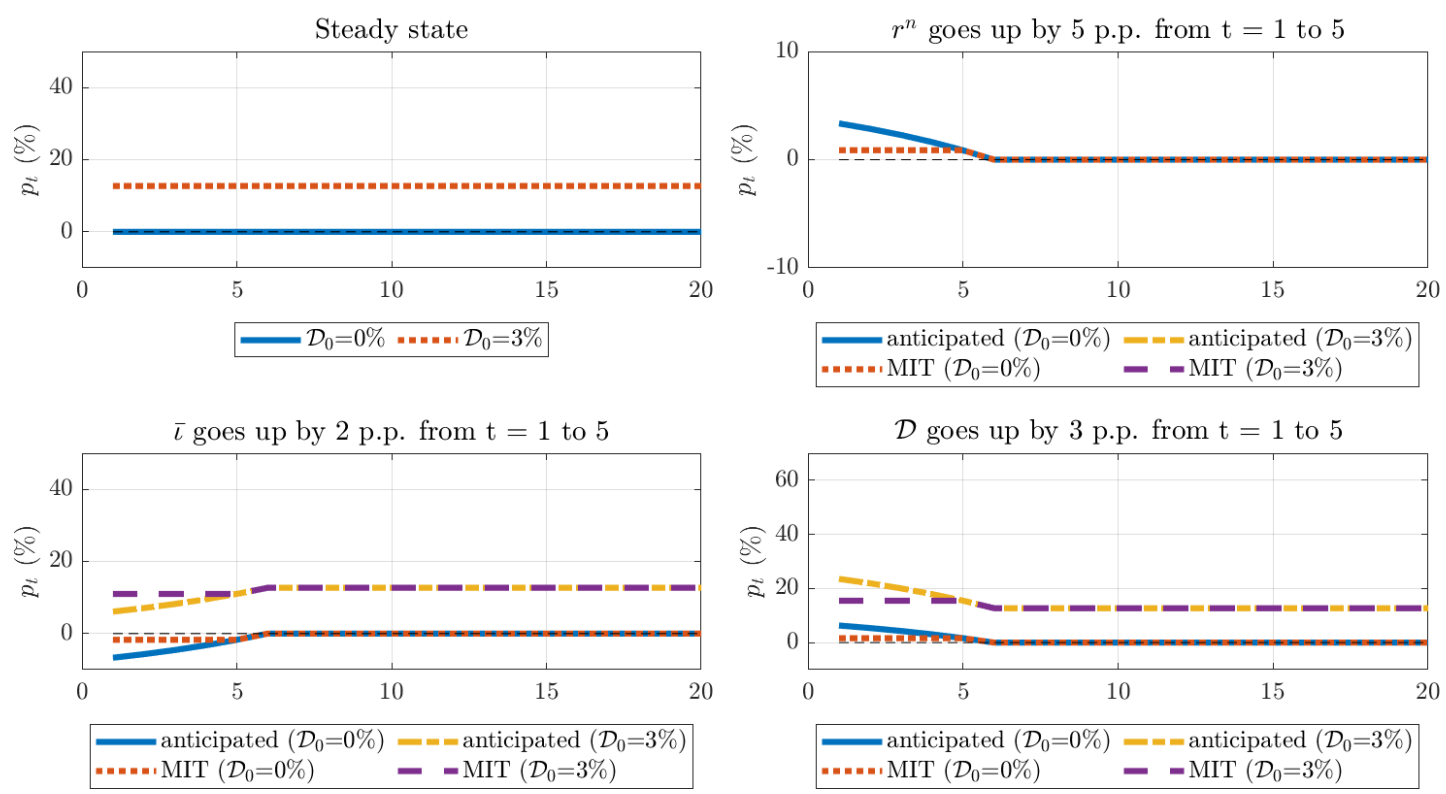

- anticipated $\left(\mathcal{D}_{0}=0 \%\right)-=-\operatorname{anticipated}\left(\mathcal{D}_{0}=3 \%\right)$
MIT $\left(\mathcal{D}_{0}=0 \%\right)$

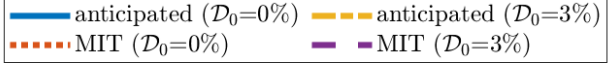
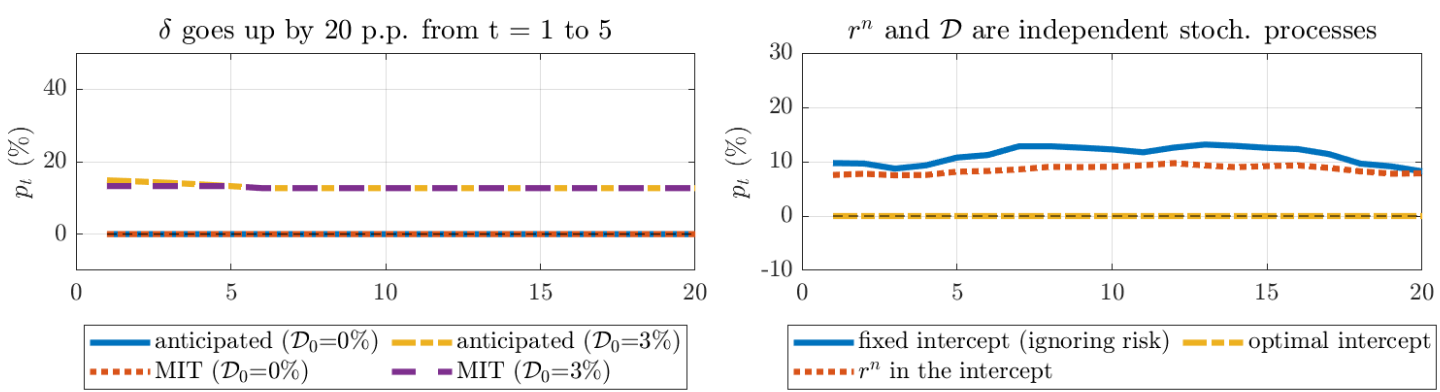

Figure A.6: The price level under neo-Wicksellian monetary theory augmented with policy-asset risk $(\phi=0.15)$

\section{A.2.3}

\section{The high-price-level bias}

The high-price-level bias inherent to conducting monetary policy with risky assets partially disconnects the unconditional mean of the price level from the central bank's target. We show this, next, by recovering the recursive formulation of (A-5) and taking the unconditional mean of both sides of that equation. Up to first order, these are the results.

$$
\begin{array}{r}
\mathbb{E} p=\Upsilon\left(\mathbb{E} r^{n}-(1-\mathbb{E} \mathcal{D} \delta) \mathbb{E} \bar{\iota}+\mathbb{E} \mathcal{D} \delta+\mathbb{E} p\right) \quad \text { where } \Upsilon \equiv\left(\frac{1}{1+(1-\mathbb{E} \mathcal{D} \delta) \phi}\right) \\
\mathbb{E} p=\frac{\Upsilon}{1-\Upsilon}\left(\mathbb{E} r^{n}-(1-\mathbb{E} \mathcal{D} \delta) \mathbb{E} \bar{\iota}+\mathbb{E} \mathcal{D} \delta\right) \\
\mathbb{E} p=\frac{1}{(1-\mathbb{E} \mathcal{D} \delta) \phi}\left(\mathbb{E} r^{n}-(1-\mathbb{E} \mathcal{D} \delta) \mathbb{E} \bar{\iota}+\mathbb{E} \mathcal{D} \delta\right)
\end{array}
$$

To make explicit the bias, we assume that the intercept of the policy rule 
is the same of the canonical model, that is $\mathbb{E} \bar{\iota}=\mathbb{E} r^{n}$, and we obtain

$$
\mathbb{E} p=\underbrace{\frac{\mathbb{E} \mathcal{D} \delta}{(1-\mathbb{E} \mathcal{D} \delta) \phi}\left(1+\mathbb{E} r^{n}\right)}_{\text {price-level bias }}
$$

which will collapse to the price level target $(\bar{p}=0)$ only when $\mathbb{E} \mathcal{D} \delta=0$, that is, only when the policy asset is non-defaultable, which brings us back to the canonical case. As long as $r^{n}>-1$, the price-level bias is positive for any positive default probability lower than 1 . Trivially, if the unconditional mean is full confiscation $(\mathbb{E} \mathcal{D} \delta=1)$, then prices are not determined. Finally, note that the bias reduces with the size of $\phi$, suggesting that more active monetary policy can mitigate it. The bias also increases with the default probability and reduces with the recovery rate.

So, how large is the price-level bias? Under the near-optimal intercept rule $\left(\mathbb{E} \bar{\iota}=\mathbb{E} r^{n}\right)$, Tables $\mathrm{A} .2$ and $\mathrm{A} .3$ calculate that variable in percentage points for some combinations of $\mathbb{E} \mathcal{D} \delta$ and $\phi$, arbitrarily assuming $\mathbb{E} r^{n}=4 \%$, for $\delta=0.05$ and $\delta=0.6$, respectively. For policy rules with low values of $\phi$, the bias is not negligible at all, while for rules with relatively high values of $\phi$ it is mostly attenuated.

Table A.2: Price-level bias (p.p.) with $\delta=0.05$

\begin{tabular}{l|ccccc}
\hline \hline & $\phi=0.2$ & $\phi=0.5$ & $\phi=1.0$ & $\phi=1.5$ & $\phi=2.0$ \\
\hline $\mathcal{D}=0.0 \%$ & 0.0 & 0.0 & 0.0 & 0.0 & 0.0 \\
$\mathcal{D}=2.5 \%$ & 0.7 & 0.3 & 0.1 & 0.1 & 0.1 \\
$\mathcal{D}=5.0 \%$ & 1.3 & 0.5 & 0.3 & 0.2 & 0.1 \\
$\mathcal{D}=7.5 \%$ & 2.0 & 0.8 & 0.4 & 0.3 & 0.2 \\
$\mathcal{D}=10.0 \%$ & 2.6 & 1.1 & 0.5 & 0.3 & 0.3 \\
\hline \hline
\end{tabular}

Table A.3: Price-level bias (p.p.) with $\delta=0.60$

\begin{tabular}{l|ccccc}
\hline \hline & $\phi=0.2$ & $\phi=0.5$ & $\phi=1.0$ & $\phi=1.5$ & $\phi=2.0$ \\
\hline $\mathcal{D}=0.0 \%$ & 0.0 & 0.0 & 0.0 & 0.0 & 0.0 \\
$\mathcal{D}=2.5 \%$ & 7.9 & 3.2 & 1.6 & 1.1 & 0.8 \\
$\mathcal{D}=5.0 \%$ & 16.1 & 6.4 & 3.2 & 2.1 & 1.6 \\
$\mathcal{D}=7.5 \%$ & 24.5 & 9.8 & 4.9 & 3.3 & 2.5 \\
$\mathcal{D}=10.0 \%$ & 33.2 & 13.3 & 6.6 & 4.4 & 3.3 \\
\hline \hline
\end{tabular}




\section{A.3 \\ Propositions and proofs}

Here, we provide the proofs for some of the propositions in this paper. We keep their original numbering.

\section{Proposition A.3 (Inflation determinacy under inflation targeting)}

$A$ bounded process $\left\{r_{t}^{n}, \mathcal{D}_{t}, \delta_{t}, \bar{l}_{t}\right\}$, a monetary policy rule such as the one proposed in Assumption 1.9 with $\phi^{\pi}>\frac{1}{1-\mathbb{E}_{t} \mathcal{D}_{t+1} \delta_{t+1}}$ for all $t$, the fact that $\mathcal{D}_{t}$ is a process that represents a probability and $\delta_{t}$ is a process that represents a fraction, and the condition that for all t there is at least one infinite sequence $k_{n} \subset[1, \infty)$ such that $0 \leq \mathbb{E}_{t} \mathcal{D}_{t+k} \delta_{t+k}<1$ in that sequence are necessary and sufficient conditions so that equilibrium inflation exists and it is unique.

Proof. We start by proving that conditions are sufficient. $0<\frac{1}{\left(1-\mathbb{E}_{t} \mathcal{D}_{t+k} \delta_{t+k}\right) \phi^{\pi}}<$ 1 for all $t$ and at least one infinite sequence $k_{n} \subset[1, \infty)$. This leads to $\Upsilon_{t, j+1}^{\pi} \leq 1$ and $\Upsilon_{t, j+1}^{\pi} \leq \Upsilon_{t, j}^{\pi}$ for all $t$ and all $j$. Moreover, $\lim _{j \rightarrow \infty} \Upsilon_{t, j+1}^{\pi}=0$ for all $t$. Since $\left\{r_{t}^{n}, \mathcal{D}_{t}, \delta_{t}, \bar{t}_{t}\right\}$ is a bounded process,

$\Gamma_{t+j}=\mathbb{E}_{t}\left(r_{t+j}^{n}-\left(1-\mathbb{E}_{t} \mathcal{D}_{t+j+1} \delta_{t+j+1}\right) \bar{\iota}_{t+j}+\mathbb{E}_{t} \mathcal{D}_{t+j+1} \delta_{t+j+1}\right)$ is also a bounded process. The sum of Equation 1-11 can be seen as the product of two bounded processes, $\Upsilon_{t+j+1}^{\pi}$ and $\Gamma_{t+j}$, which therefore will also be a bounded process. Let now a number $M>0$ be such that $\left|\Gamma_{n}\right| \leq M$. Let $\left\{\Upsilon_{n}^{\pi}\right\}$ be such that $\Upsilon_{n}^{\pi} \rightarrow 0$. Given $\epsilon>0$, for the positive number $\frac{\epsilon}{M}$, there exists some $N$ such that $\left|\Upsilon_{n}^{\pi}\right|<\frac{\epsilon}{M}$ for all $n \geq N$, so $\left|\Upsilon_{n}^{\pi} \Gamma_{n}\right| \leq M\left|\Upsilon_{n}^{\pi}\right|<M \cdot \frac{\epsilon}{M}=\epsilon$ for all such an $n$, this shows that $\Upsilon_{n}^{\pi} \Gamma_{n} \rightarrow 0$. This assures that equilibrium inflation exists and is unique, and therefore it is determined.

Now, we prove the proposed conditions are also necessary by contradiction. If $\phi^{\pi}=\frac{1}{1-\mathbb{E}_{t} \mathcal{D}_{t+1} \delta_{t+1}}$ for all $t$ then $\Upsilon_{t, j+1}^{\pi}=1$ for all $t$ and all $j$. Since $\Gamma_{n} \rightarrow \mathbb{E}\left(\Gamma_{n}\right)=\bar{L}$ where $\bar{L}$ is a finite number, the convergence of the sum will only happen in case $\mathbb{E}\left(\Gamma_{n}\right)=0$, as if the latter expectation is positive or negative then $\pi_{t}$ (and $p_{t}$ ) diverge to $\infty$ or $-\infty$, respectively, constituting an unstable equilibrium. If $\phi^{\pi}<\frac{1}{1-\mathbb{E}_{t} \mathcal{D}_{t+1} \delta_{t+1}}$ for all $t$, then $\Upsilon_{t, j+1}^{\pi}>1$ in at least one infinite sequence $j_{n} \subset[1, \infty)$, and then $\Upsilon_{n}^{\pi} \rightarrow \infty$, while $\Gamma_{n} \rightarrow \mathbb{E}\left(\Gamma_{n}\right)=\bar{L}$. Their product will diverge. Thus, $\phi^{\pi}>\frac{1}{1-\mathbb{E}_{t} \mathcal{D}_{t+1} \delta_{t+1}}$ for all $t$ is a necessary condition. If there is no infinite sequence in which $k_{n} \subset[1, \infty)$ such that $0 \leq \mathbb{E}_{t} \mathcal{D}_{t+k} \delta_{t+k}<1$ in that sequence then there may be only finite sequences of that kind, none of them converging to zero, and there is still an infinite sequence in which $k_{n} \subset[1, \infty)$ such that $0 \leq \mathbb{E}_{t} \mathcal{D}_{t+k} \delta_{t+k}=1$. The sum diverges. This assures that the proposed conditions are not only sufficient but also necessary. 


\section{Proposition A.4 (Optimal intercept under inflation targeting)}

Monetary policy is able to stabilize inflation through operations with the risky asset if it can track the sequence of natural interest rates $\left\{r_{t+j}^{n}\right\}_{j=0}^{\infty}$, the sequence of one-period-ahead policy-default probabilities $\left\{\mathcal{D}_{t+j+1}\right\}_{j=0}^{\infty}$, the sequence of one-period-ahead expected haircuts $\left\{\delta_{t+j+1}\right\}_{j=0}^{\infty}$, and it credibly adopts at period $t$ a Taylor rule with the sequence of time-varying intercepts $\left\{\bar{\iota}_{t+j}\right\}_{j=0}^{\infty} \equiv\left\{\frac{r_{t+j}^{n}+\mathbb{E}_{t} \mathcal{D}_{t+j+1} \delta_{t+j+1}}{1-\mathbb{E}_{t} \mathcal{D}_{t+j+1} \delta_{t+j+1}}\right\}_{j=0}^{\infty}$.

Proof. Substituting $\bar{\iota}_{t+j}=\frac{r_{t+j}^{n}+\mathbb{E}_{t} \mathcal{D}_{t+j+1} \delta_{t+j+1}}{1-\mathbb{E}_{t} \mathcal{D}_{t+j+1} \delta_{t+j+1}}$ into the equilibrium inflation for the risky economy (1-11), all terms of the respective summation collapse to zero.

\section{Proposition A.5 (Price level determinacy under price-level targeting)}

$A$ bounded process $\left\{r_{t}^{n}, \mathcal{D}_{t}, \delta_{t}, \bar{\iota}_{t}\right\}$, a monetary policy rule such as the one proposed in Assumption A.2 with $\phi>0$, the fact that $\mathcal{D}_{t}$ is a process that represents a probability and $\delta_{t}$ is a process that represents a fraction, and the condition that for all $t$ there is at least one infinite sequence $k_{n} \subset[1, \infty)$ such that $0 \leq \mathbb{E}_{t} \mathcal{D}_{t+k} \delta_{t+k}<1$ in that sequence are necessary and sufficient conditions so that the price level equilibrium exists and is unique.

Proof. We start by proving that conditions are sufficient. $0<$ $\frac{1}{1+\left(1-\mathbb{E}_{t} \mathcal{D}_{t+k} \delta_{t+k}\right) \phi}<1$ for all $t$ and at least one infinite sequence $k_{n} \subset[1, \infty)$. This leads to $\Upsilon_{t, j+1} \leq 1$ and $\Upsilon_{t, j+1} \leq \Upsilon_{t, j}$ for all $t$ and all $j$. Moreover, $\lim _{j \rightarrow \infty} \Upsilon_{t, j+1}=0$ for all $t$. Since $\left\{r_{t}^{n}, \mathcal{D}_{t}, \delta_{t}, \bar{\iota}_{t}\right\}$ is a bounded process, $\Gamma_{t+j}=\mathbb{E}_{t}\left(r_{t+j}^{n}-\left(1-\mathbb{E}_{t} \mathcal{D}_{t+j+1} \delta_{t+j+1}\right) \bar{\iota}_{t+j}+\mathbb{E}_{t} \mathcal{D}_{t+j+1} \delta_{t+j+1}\right)$ is also a bounded process. The sum of Equation A-5 can be seen as the product of two bounded processes, $\Upsilon_{t+j+1}$ and $\Gamma_{t+j}$, which therefore will also be a bounded process. Let now a number $M>0$ be such that $\left|\Gamma_{n}\right| \leq M$. Let $\left\{\Upsilon_{n}\right\}$ be such that $\Upsilon_{n} \rightarrow 0$. Given $\epsilon>0$, for the positive number $\frac{\epsilon}{M}$, there exists some $N$ such that $\left|\Upsilon_{n}\right|<\frac{\epsilon}{M}$ for all $n \geq N$, so $\left|\Upsilon_{n} \Gamma_{n}\right| \leq M\left|\Upsilon_{n}\right|<M \cdot \frac{\epsilon}{M}=\epsilon$ for all such an $n$, what shows that $\Upsilon_{n} \Gamma_{n} \rightarrow 0$. This assures that the price level equilibrium exists and is unique, and therefore it is determined.

Now, we prove the proposed conditions are also necessary by contradiction. If $\phi=0$ then $\Upsilon_{t, j+1}=1$ for all $t$ and all $j$. Since $\Gamma_{n} \rightarrow \mathbb{E}\left(\Gamma_{n}\right)=\bar{L}$ where $\bar{L}$ is a finite number, the convergence of the sum will only happen in case $\mathbb{E}\left(\Gamma_{n}\right)=0$, as if the latter expectation is positive or negative then $p_{t}$ diverges to $\infty$ or $-\infty$, respectively, constituting an unstable equilibrium. If $\phi<0$, then $\Upsilon_{t, j+1}>1$ in at least one infinite sequence $j_{n} \subset[1, \infty)$, and then $\Upsilon_{n} \rightarrow \infty$, while $\Gamma_{n} \rightarrow \mathbb{E}\left(\Gamma_{n}\right)=\bar{L}$. Their product will diverge. Thus, $\phi>0$ is a necessary condition. If there is no infinite sequence in which $k_{n} \subset[1, \infty)$ 
such that $0 \leq \mathbb{E}_{t} \mathcal{D}_{t+k} \delta_{t+k}<1$ in that sequence then there may be only finite sequences of that kind, none of them converging to zero, and there is still an infinite sequence in which $k_{n} \subset[1, \infty)$ such that $0 \leq \mathbb{E}_{t} \mathcal{D}_{t+k} \delta_{t+k}=1$. The sum diverges. This assures that the proposed conditions are not only sufficient but also necessary.

\section{Proposition A.6 (Optimal intercept under price-level targeting)}

Monetary policy can stabilize prices through operations with the risky asset if it can track the sequence of natural interest rates $\left\{r_{t+j}^{n}\right\}_{j=0}^{\infty}$, the sequence of one-period-ahead policy-asset default probabilities $\left\{\mathcal{D}_{t+j+1}\right\}_{j=0}^{\infty}$, the sequence of one-period-ahead expected haircuts $\left\{\delta_{t+j+1}\right\}_{j=0}^{\infty}$, and it credibly adopts at period $t$ a Wickellian rule with the sequence of time-varying intercepts $\left\{\bar{\iota}_{t+j}\right\}_{j=0}^{\infty} \equiv\left\{\frac{r_{t+j}^{n}+\mathbb{E}_{t} \mathcal{D}_{t+j+1} \delta_{t+j+1}}{1-\mathbb{E}_{t} \mathcal{D}_{t+j+1} \delta_{t+j+1}}\right\}_{j=0}^{\infty}$.

Proof. Substituting $\bar{\iota}_{t+j}=\frac{r_{t+j}^{n}+\mathbb{E}_{t} \mathcal{D}_{t+j+1} \delta_{t+j+1}}{1-\mathbb{E}_{t} \mathcal{D}_{t+j+1} \delta_{t+j+1}}$ into the equilibrium price level for the risky economy (A-5), all terms of the respective summation collapse to zero. 


\section{A. 4 \\ A default-risky cashless economy}

We derive a simple adaptation of the canonical cashless flexible-price model of Woodford (2003a, ch. 2, sec. 1) to show that it can underpin the partial equilibrium default-risky cashless model developed in this paper. We keep the same notation whenever possible.

There is a cashless economy with a goods market, a financial market, infinitely-lived households, a government, and a central bank. Time is discrete. Both markets are completely frictionless, that is, they are perfectly competitive, prices adjust continuously to clear them, and state-contingent securities of any kind can be traded. The goods market exchanges a single good whose endowment at every period is exogenous. All prices are quoted in terms of a single monetary unit of account defined in terms of a claim to a certain quantity of a one-period liability issued exclusively by the central bank, which can also issue other one-period liabilities that promise to pay additional units of that same liability at the next period - this allows the central bank to control both the nominal interest yield and the quantity of these liabilities. The government issues every period one-period nominal bonds and imposes lump-sum nominal taxes, which can be negative, to the households. Government is tricky, though. There are random times in which it fails to repay its bonds. Worse than that, it also controls the central bank, and when it fails to repay its bonds the central bank fails to repay its liabilities. As usual, arbitrage relations describe the conditions under which any agent is willing to hold any liability at any time. As there are no impediments to arbitrage, these conditions are always satisfied in equilibrium, so there is a well-defined exchange rate at any time between units of government bonds, goods, and central bank's liabilities.

A representative household summarizes a continuum of identical households who maximizes

$$
\mathbb{E}_{0}\left\{\sum_{t=0}^{\infty} \beta^{t} u\left(C_{t} ; \xi_{t}\right)\right\}
$$

where $\mathbb{E}_{0}$ is the rational expectation operator conditional upon the state of the economy at period $0 ; \beta$ is a subjective discount factor, $u($.$) is a one-period$ utility function, $C_{t}$ represents consumption, and $\xi_{t}$ is an exogenous stochastic disturbance to $u($.$) . We restrict u($.$) to be concave and strictly increasing in$ $C_{t}$. Under complete markets, a household's flow budget constraint is expressed by

$$
M_{t}+B_{t} \leq W_{t}+P_{t} Y_{t}-T_{t}-P_{t} C_{t}
$$

where $M_{t}$ is end-of-period balances of the central bank's asset; $B_{t}$ is the end-ofperiod nominal value of the portfolio of assets not issued by the central bank; $W_{t}$ is the beginning-of-period financial wealth; $Y_{t}$ is the exogenous endowment 
of the good; $P_{t}$ is its price; and $T_{t}$ is the net nominal tax collection by the government. Financial wealth evolves according to

$$
W_{t+1}=\left(1+i_{t+1}^{\text {Risky }}\right) M_{t}+A_{t+1}
$$

such that $i_{t+1}^{\text {Risky }}$ is the net nominal interest rate actually paid on the central bank's asset held at the end of period $t$; and $A_{t+1}$ is the value of the portfolio of assets not issued by the central bank held at the end of period $t$ after the realization of the state of the economy at period $t+1$. It is helpful to revisit the derived relation (1-9) for $\mathbb{E}_{t} i_{t+1}^{\text {Risky }}$ and the arbitrage condition (1-10). Note that the timing of $i_{t+1}^{\text {Risky }}$ is defined as that as it is only known with certainty at period $t+1$.

The assumption of no arbitrage opportunities implies the existence of a unique stochastic discount factor, $Q_{t, t+1}$, which prices at the end of period $t$ any asset maturing at period $t+1$, say $B_{t}$,

$$
B_{t}=\mathbb{E}_{t}\left[Q_{t, t+1} A_{t+1}\right]
$$

whose net interest rate, $i_{t}^{A}$ can be written as

$$
1=\mathbb{E}_{t}\left[Q_{t, t+1}\left(1+i_{t}^{A}\right)\right]
$$

like any other return, such as

$$
1=\mathbb{E}_{t}\left[Q_{t, t+1}\left(1+i_{t+1}^{\text {Risky }}\right)\right]
$$

The conditional expectation of the stochastic discount factor is also the inverse of the gross rate at the end of period $t, 1+i_{t}^{R F}$, of an asset that pays with certainty 1 unit of the monetary unit of account at period $t+1$

$$
\frac{1}{1+i_{t}^{R F}}=\mathbb{E}_{t}\left[Q_{t, t+1}\right]
$$

Equations (A-9), (A-10), and (A-11) completely describe the resources constraint. Using (A-10) and (A-11) to eliminate $B_{t}$ in (A-9), we can rewrite the flow budget constraint as

$$
P_{t} C_{t}+M_{t}\left(1-\mathbb{E}_{t}\left[Q_{t, t+1}\left(1+i_{t+1}^{\text {Risky }}\right)\right]\right)+\mathbb{E}_{t}\left[Q_{t, t+1} W_{t+1}\right] \leq W_{t}+\left[P_{t} Y_{t}-T_{t}\right]
$$

The household can choose any non-negative value for $C_{t}$ and $M_{t}$ as long as they are jointly consistent with (A-15) given her expected state-contingent wealth at the beginning of next period, $W_{t+1}$. Note that if we imposed the assumption of risk-neutrality to the households or, still, if we assumed that the risky component of $i_{t+1}^{\text {Risky }}$ is completely exogenous, then we could rewrite $(\mathrm{A}-15)$ as 


$$
P_{t} C_{t}+\Delta_{t} M_{t}+\mathbb{E}_{t}\left[Q_{t, t+1} W_{t+1}\right] \leq W_{t}+\left[P_{t} Y_{t}-T_{t}\right]
$$

where $\Delta_{t} \equiv \frac{i_{t}^{R F}-\mathbb{E}_{t} i_{t+1}^{\text {Risky }}}{1+i_{t}^{R F}}$, which represents the opportunity cost of holding wealth in risky-monetary form if the risk-free asset exists.

We proceed further by imposing two restrictions. First, a limit on borrowing to avoid Ponzi schemes at all times (and all states of nature),

$$
\sum_{T=t}^{\infty} \mathbb{E}_{t}\left[Q_{t, T}\left(P_{T} Y_{T}-T_{T}\right)\right]<\infty
$$

where $Q_{t, T} \equiv \prod_{s=t+1}^{T} Q_{s-1, s}$. Second, we formalize the no arbitrage assumption. If the risk-free asset does exits, then at all times it must be true that

$$
\mathbb{E}_{t}\left[Q_{t, t+1}\left(1+i_{t}^{R F}\right)\right] \geq \mathbb{E}_{t}\left[Q_{t, t+1}\left(1+i_{t}^{A}\right)\right] \geq \mathbb{E}_{t}\left[Q_{t, t+1}\left(1+i_{t+1}^{\text {Risky }}\right)\right]
$$

so the household cannot borrow without limits at the risk-free rate to finance unlimited consumption and still pay back its loan at the next period. A proof that the infinite sequence of flow budget constraints, (A-15) or (A-16), are equivalent to a single intertemporal budget constraint is obtainable by following the same steps of the one available in Woodford (2003a, ch. 2, Appendix, Proof of Proposition 2.1). The optimizing problem of the representative household consists in choosing $C_{t} \geq 0$ and $M_{t} \geq 0$ for all periods $t \geq 0$ satisfying the sequence of (A-15), or (A-16), given its initial wealth, $W_{0}$, in addition to both goods and assets expected prices to maximize (A-8) subject to (A-17) and (A18) at all periods. Finally, we impose the cashless limit, which in our economy requires that at all periods either $M_{t}=0$ or (A-18) holds with equality (in case the risk-free asset exists). Given the optimal path for the policy variables $\left(C_{t}\right.$ and $\left.M_{t}\right)$, the sequence of budget constraints delivers a path for $W_{t}$, which, by its turn, results in a path for $A_{t}$, with (A-10), and $B_{t}$, with (A-11). The first-order conditions of this optimization are

$$
\frac{u_{c}\left(C_{t} ; \xi_{t}\right)}{u_{c}\left(C_{t+1} ; \xi_{t+1}\right)}=\frac{\beta}{Q_{t, t+1}} \frac{P_{t}}{P_{t+1}}
$$

which must hold for all periods and states of nature, the sequence of flow budget constraints, (A-15) or (A-16), evaluated with equality, and the transversality condition

$$
\lim _{T \rightarrow \infty} \mathbb{E}_{t}\left[Q_{t, T} W_{T}\right]=0
$$

From (A-14), we have that the nominal risk-free rate will be given by

$$
1+i_{t}^{R F}=\beta^{-1}\left\{\mathbb{E}_{t}\left[\frac{u_{c}\left(C_{t+1} ; \xi_{t+1}\right)}{u_{c}\left(C_{t} ; \xi_{t}\right)} \frac{P_{t}}{P_{t+1}}\right]\right\}^{-1}
$$

We can establish, now, all the conditions for a rational expectations equilibrium in the model. In addition to the conditions previously stated for 
the representative household, markets must clear at all periods. Therefore, for all periods it must be that

$$
\begin{array}{r}
C_{t}=Y_{t} \\
M_{t}=M_{t}^{S} \\
A_{t+1}=A_{t+1}^{S}
\end{array}
$$

where $M_{t}^{S}$ is the supply of the central bank's asset; and $A_{t+1}^{S}$ is the aggregate value at the beginning of period $t+1$ of all assets not issued by the central bank at the end of period $t$. Had we not already limited bonds maturity to 1 period, $A_{t+1}^{S}$ could be defined more broadly as

$$
A_{t+1}^{S} \equiv \sum_{j=1}^{\infty} \mathbb{E}_{t+1}\left[Q_{t+1} B_{t, t+j}^{S}\right]
$$

where $B_{t, t+j}^{S}$ refers to the supply of nominal coupons to be paid at period $t+j$ from bonds outstanding at the end of period $t$.

Moving further, if $M_{t}^{S}>0$, then market-clearing will force (A-18) to be true with equality. We proceed by substituting (A-22) into (A-21) so to obtain the equilibrium condition for the nominal interest rate

$$
1+i_{t}^{R F}=\beta^{-1}\left\{\mathbb{E}_{t}\left[\frac{u_{c}\left(Y_{t+1} ; \xi_{t+1}\right)}{u_{c}\left(Y_{t} ; \xi_{t}\right)} \frac{P_{t}}{P_{t+1}}\right]\right\}^{-1}
$$

In case of a real risk-free asset, the equilibrium condition reduces to

$$
1+r_{t}^{R F}=\beta^{-1}\left\{\mathbb{E}_{t}\left[\frac{u_{c}\left(Y_{t+1} ; \xi_{t+1}\right)}{u_{c}\left(Y_{t} ; \xi_{t}\right)}\right]\right\}^{-1}
$$

Finally, the transversality condition (A-20) in equilibrium can be written in terms of the end-of-period value of total liabilities, $D_{t} \equiv M_{t}^{S}+B_{t}^{S}$, as

$$
\lim _{T \rightarrow \infty} \beta^{T} \mathbb{E}_{t}\left[u_{c}\left(Y_{T} ; \xi_{T}\right) \frac{D_{T}}{P_{T}}\right]=0
$$

and the Ponzi scheme restriction can be described as

$$
\beta^{T} \sum_{T=t}^{\infty} \mathbb{E}_{t}\left[u_{c}\left(Y_{T} ; \xi_{T}\right) Y_{T}\right]<\infty
$$

We proceed further by characterizing policy in this economy. The monetary policy is conducted with a (linearized) Taylor risky policy rule as proposed by Assumption 1.9. The policy-asset default probability, $\left\{\mathcal{D}_{t}\right\}$, is exogenous as in Assumption 1.8, and we also assume exogeneity for the haircut $\left\{\delta_{t}\right\}$ but imposing that $0 \leq \delta_{t} \leq 1 \forall t$, so the return in case of default must be lower or equal to the policy rate in case of repayment at all times. The no-arbitrage Assumption 1.7 further implies the relation (1-9) between the conditional ex- 
pected value of the risky rate, $\mathbb{E}_{t} i_{t+1}^{\text {Risky }}$, and the realized value in each possible future state of nature (default or not default). The supply of central bank's assets, $M_{t}^{S}$, does not enter in the equilibrium conditions, for we simplify assuming it to also follow an exogenous path. Finally, we assume in this paper that fiscal policy is always kept passive. One simple way of characterizing such a policy is assuming a balanced-budget rule so that $\Delta D_{t}=0$ at all periods. This sets an exogenous path for $\left\{D_{t}\right\}$. We are ready to define the rational-expectations equilibrium of our model.

Definition A.1 A rational-expectations equilibrium of the default-risky cashless economy is a set of processes $\left\{P_{t}, i_{t+1}^{\text {Risky }}\right\}$ that satisfy the no-arbitrage condition (A-18) with equality, the Euler equation of the nominal risk-free asset (A-26), the transversality condition (A-28), and the monetary policy rule (Assumption 1.9) at all periods $t \geq 0$, given the exogenous processes $\left\{Y_{t}, \xi_{t}\right\}$, which satisfy the no-Ponzi scheme condition (A-29), $\left\{0 \leq \mathcal{D}_{t} \leq 1\right\},\left\{0 \leq \delta_{t} \leq 1\right\}$, and $\left\{M_{t}^{S}, D_{t}\right\}$. 


\section{A.5 Monetary policy targets the risky rate using safe assets}

In Bi, Leeper and Leith (2018), the authors pose the interest rate rule as targeting either a default-risk-free rate or a default-risky rate, which slightly adapted to our notation result in rules (A-30) and (A-31), respectively, where $\bar{\pi}$ is the fixed net inflation target, $\varphi$ is the response coefficient to inflation deviation from the target, $i_{t}^{R F}$ is the nominal net risk-free rate, and $i_{t+1}^{R}$ is the nominal net default-risky rate. They do not assume, though, that the central bank uses a risky asset to conduct monetary policy, instead they claim that through open market operations, with a presumably safe policy asset, the central bank can affect the risky asset interest rate due to arbitrage.

$$
\begin{aligned}
& \frac{1}{1+i_{t}^{R F}}=\frac{1}{1+\bar{\iota}_{t}}+\varphi\left(\frac{1}{1+\pi_{t}}-\frac{1}{1+\bar{\pi}}\right) \\
& \frac{1}{1+i_{t+1}^{R}}=\frac{1}{1+\bar{\iota}_{t}}+\varphi\left(\frac{1}{1+\pi_{t}}-\frac{1}{1+\bar{\pi}}\right)
\end{aligned}
$$

In their exposition of the interest rate mechanism, they shut down the nominal rigidity of their cashless New-Keynesian model, assuming then flexible prices, and replace the production function by a constant endowment specification. In this simplified economy, the Euler equation generates the following Fisher equations for each policy rule, respectively

$$
\begin{aligned}
& \frac{1}{1+i_{t}^{R F}}=\beta \mathbb{E}_{t}\left[\frac{1}{1+\pi_{t+1}}\right] \\
& \frac{1}{1+i_{t+1}^{R}}=\beta \mathbb{E}_{t}\left[\frac{1-\delta_{t+1}}{1+\pi_{t+1}}\right]
\end{aligned}
$$

where $\beta$ is the subjective discount factor, and $\delta_{t+1}$ is the stochastic fraction at which the government defaults at period $t+1$. In case of full repayment, $\delta_{t+1}=0$.

Next, they derive a law of movement for inflation when each rule is adopted by the monetary authority, respectively equations (A-34) and (A-35).

$$
\begin{aligned}
& \left(\frac{1}{1+\pi_{t}}-\frac{1}{1+\bar{\pi}}\right)=\frac{\beta}{\varphi} \mathbb{E}_{t}\left[\frac{1}{1+\pi_{t+1}}-\frac{1}{1+\bar{\pi}}\right] \\
& \left(\frac{1}{1+\pi_{t}}-\frac{1}{1+\bar{\pi}}\right)=\frac{\beta}{\varphi} \mathbb{E}_{t}\left[\frac{1-\delta_{t+1}}{1+\pi_{t+1}}-\frac{1}{1+\bar{\pi}}\right]
\end{aligned}
$$

As Reis (2018) points out, in this derivation, they make an implicit assumption that will bias their results. They assume that the intercept of both policy rules is fixed as well as it is the same and given by $\bar{\iota}_{t}=\frac{1+\bar{\pi}}{\beta}-1$. 
This intercept only makes sense, though, for when the central bank targets a risk-free rate. When the targeted rate is risky, the intercept should adjust to the risk premium embedded in the risky bond: $\bar{\iota}_{t}=\frac{1+\bar{\pi}}{\left(1-\delta_{t+1}\right) \beta}-1$. Afterward, the authors iterate forward the laws of movement of inflation, and obtain for the risk-free and the risky rate targets, respectively, equations (A-36) and (A-37).

$$
\begin{array}{r}
\frac{1}{1+\pi_{t}}=\frac{1}{1+\bar{\pi}} \\
\frac{1}{1+\pi_{t}}=\frac{1}{1+\bar{\pi}}\left(1-\frac{\beta}{\varphi}\right)\left[1+\sum_{j=1}^{\infty}\left(\frac{\beta}{\varphi}\right)^{j} \Pi_{k=1}^{j}\left(1-\delta_{t+k}\right)\right]
\end{array}
$$

To make the analysis more tractable, the authors impose to equation A-37 a constant default rate for all periods $\left(\delta_{t}=\delta\right)$, and obtain a biased expression for inflation (A-38).

$$
\left(1+\pi_{t}\right)=(1+\bar{\pi})\left(\frac{1-\frac{\beta(1-\delta)}{\varphi}}{1-\frac{\beta}{\varphi}}\right)
$$

Finally, Bi, Leeper and Leith (2018) rewrite the risky interest rate policy rule in terms of the risk-free rate.

$$
\frac{1}{1+i_{t}^{R F}}=\frac{1}{1+\bar{\iota}_{t}}+\frac{\varphi}{1-\delta}\left[\frac{1}{1+\pi_{t}}-\left(\frac{1}{1+\bar{\pi}}-\frac{\delta}{\varphi\left(1+\bar{\iota}_{t}\right)}\right)\right]
$$

From equations (A-36) and (A-39), we can summarize the main results of Bi, Leeper and Leith (2018) concerning monetary policy. First, if the central bank targets the risk-free rate using a risk-free instrument, the presence of government default risk does not prevent the central bank from hitting the inflation target. Second, default raises the effective gross inflation target from $1+\bar{\pi}$ to $\frac{1+\bar{\pi}}{1-\delta \frac{\beta}{\varphi}}$, so that the announced inflation target is unattainable $\left(1-\delta \frac{\beta}{\varphi}<1\right)$. One can find that result by substituting the intercept used by the authors into the right-hand side of equation A-39, and comparing the announced inflation target with the effective one. Third, the authors say that default makes monetary policy "more active" since the effective inflation feedback coefficient becomes higher: $\frac{\varphi}{1-\delta}>\varphi$.

Now, we correct the intercept of equation (A-37), as suggested by Reis (2018), for the case in which the central bank targets the risky interest rate.

$$
\left(\frac{1}{1+\pi_{t}}-\frac{1}{1+\bar{\pi}}\right)=\frac{\beta}{\varphi} \mathbb{E}_{t}\left(1-\delta_{t+1}\right)\left[\frac{1}{1+\pi_{t+1}}-\frac{1}{1+\bar{\pi}}\right]
$$

Iterating forward equation (A-40), and imposing a constant default rate 
$\left(\delta_{t}=\delta\right)$, we get

$$
\frac{1}{1+\pi_{t}}=\frac{1}{1+\bar{\pi}}
$$

just like when the central bank targets the risk-free rate (A-36), what invalidates Bi, Leeper and Leith (2018)'s second result. Thus, after adjusting the intercept in that paper, whether the central bank targets a risk-free or a risky rate, the announced inflation target and the effective one will be the same. Rewriting the policy rule that targets the risky interest rate in terms of the risk-free rate it becomes now

$$
\begin{aligned}
& \frac{1}{1+i_{t}^{R F}}=\frac{1}{(1-\delta)\left(1+\bar{\iota}_{t}\right)}+\frac{\varphi}{1-\delta}\left[\frac{1}{1+\pi_{t}}-\frac{1}{1+\bar{\pi}}\right] \\
& =\frac{\beta}{1+\bar{\pi}}+\frac{\varphi}{1-\delta}\left[\frac{1}{1+\pi_{t}}-\frac{1}{1+\bar{\pi}}\right]
\end{aligned}
$$

(after a log-approximation of interest rates)

$$
i_{t}^{R F} \approx r^{n}+\bar{\pi}+\frac{\varphi}{1-\delta}\left[\pi_{t}-\bar{\pi}\right]
$$

Equation (A-42) provides us the risk-free rule that would be equivalent to targeting the risky rate. As one can see from that equation, the effective intercept is now the gross nominal risk-free rate, $\left(\frac{1+\bar{\pi}}{\beta}=(1+\bar{\pi})\left(1+r^{n}\right)\right)$. Moreover, Bi, Leeper and Leith (2018)'s third result, that default makes monetary policy "more active", remains even after we have fixed the intercept, in apparent divergence with our finding that it makes it "less active". However, the difference lies in the fact that our policy asset is risky while theirs is still risk-free although specified in terms of a risky rate. A proper comparison between the inflation-reaction coefficients would be $\frac{\varphi}{1-\delta}$ against $\phi^{\pi}(1-\delta)$. Under our specification, default weakens the effective response of inflation to changes in the policy rate.

Naturally, fixing the intercept will also change the dynamics of $\mathrm{Bi}$, Leeper and Leith (2018)'s model, for we actually have a different rule now than the one proposed in that paper, more specifically, the positive link between default and inflation seems, at least, partially compromised. 


\section{A.6 \\ Monetary policy power}

In this appendix, we simulate monetary policy power under an inflationtargeting regime for 5 different correlation values $(-1.0,-0.5,0.0,0.5,1.0)$ between $r_{t}^{n}$ and $\mathbb{E}_{t} \mathcal{D}_{t+1}$ in Figures A.7, A.8, A.9, A.10, and A.11. We randomly draw 10,000 vectors of $r_{t}^{n}$ and $\mathbb{E}_{t} \mathcal{D}_{t+1}$ with 40 periods each from a multivariate normal distribution. We calibrate $\mathbb{E} r_{t}^{n}=0.04, \operatorname{Std}\left(r^{n}\right)=0.005$, and set the intercept of the policy rule to be equal to $\mathbb{E} r_{t}^{n}$ at all periods. Additionally, we calibrate $\mathbb{E} \mathcal{D}_{t+1}=0.10$ and $\operatorname{Std}\left(\mathcal{D}_{t+1}\right)=0.01$, while we suppose no recovery rate $\left(\delta_{t}=1 \forall t\right)$. We replace negative numbers drawn with their absolute values.

In the graphs, we plot only 100 vectors and 40 periods to avoid too much cluttering. In the first column of each figure, we plot the scatter plot of the vectors drawn. In the second column, we plot the difference of the multiplier $\Upsilon_{t, j+1}^{\pi}$, which multiplies the natural interest rate, in the default-risky scenario against in the risk-free one for each term period. In the third column, we compare the same scenarios, but from the perspective of the coefficient that multiplies the policy rule intercept. Finally, our results show that monetary policy power reduces no matter the correlation between $r_{t}^{n}$ and $\mathbb{E}_{t} \mathcal{D}_{t+1}$, what is easily observed in the graphs at the last column of each figure, as the sum of all terms from $t=1$ to $t=40$ aggregates to the total change of the inflation rate at $t=0$, which is largely positive for all values of $\phi^{\pi}$ simulated $(1.1,1.5$, 2.0). Note that increasing $\phi^{\pi}$ reduces the total change of the inflation rate generated by the presence of default in the policy asset. Although we do not display here, results are robust to price-level targeting. 

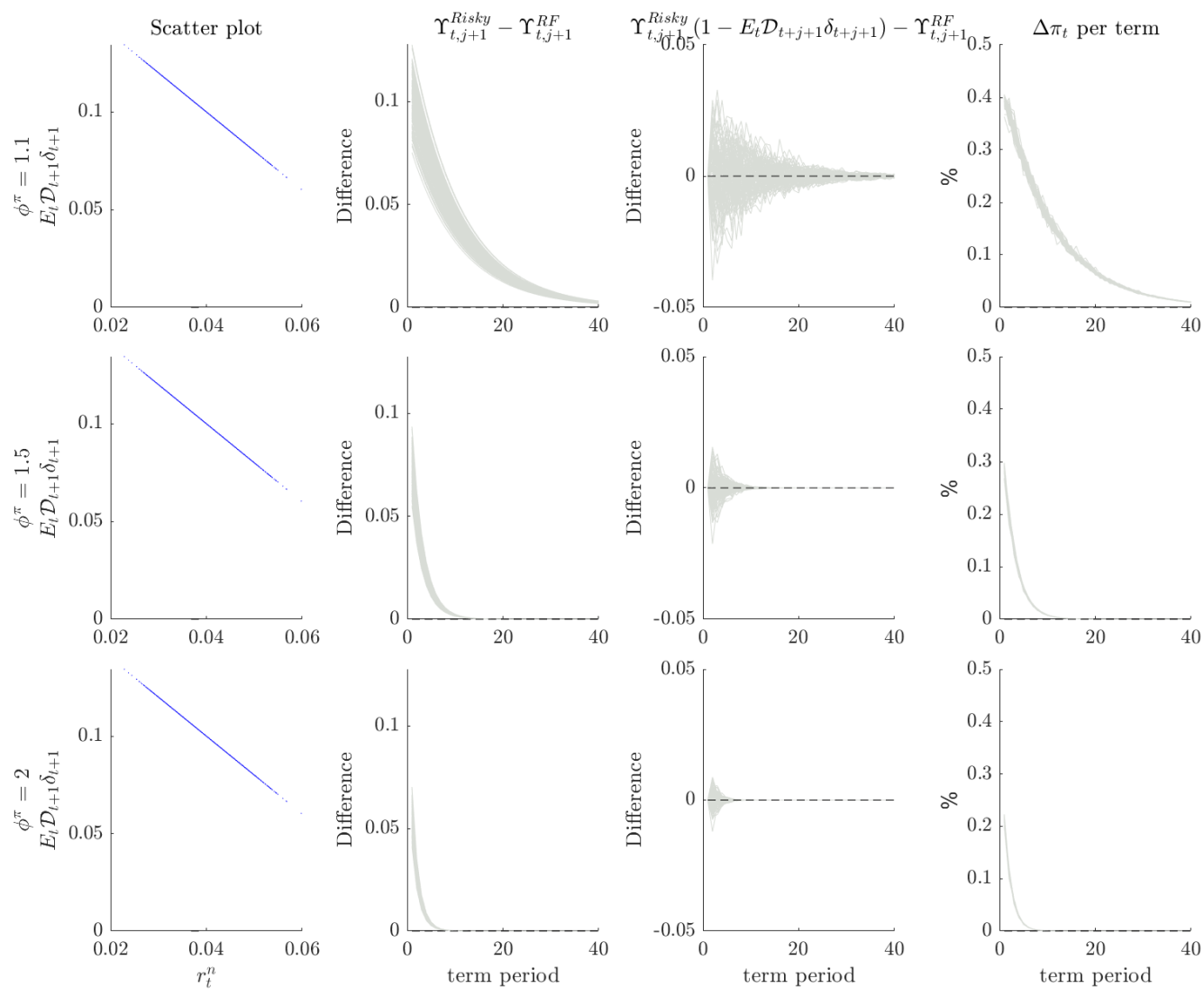

Figure A.7: Monetary policy power under inflation targeting: $\operatorname{Corr}\left(r_{t}^{n}, \mathbb{E}_{t} \mathcal{D}_{t+1}\right)=-1$ 

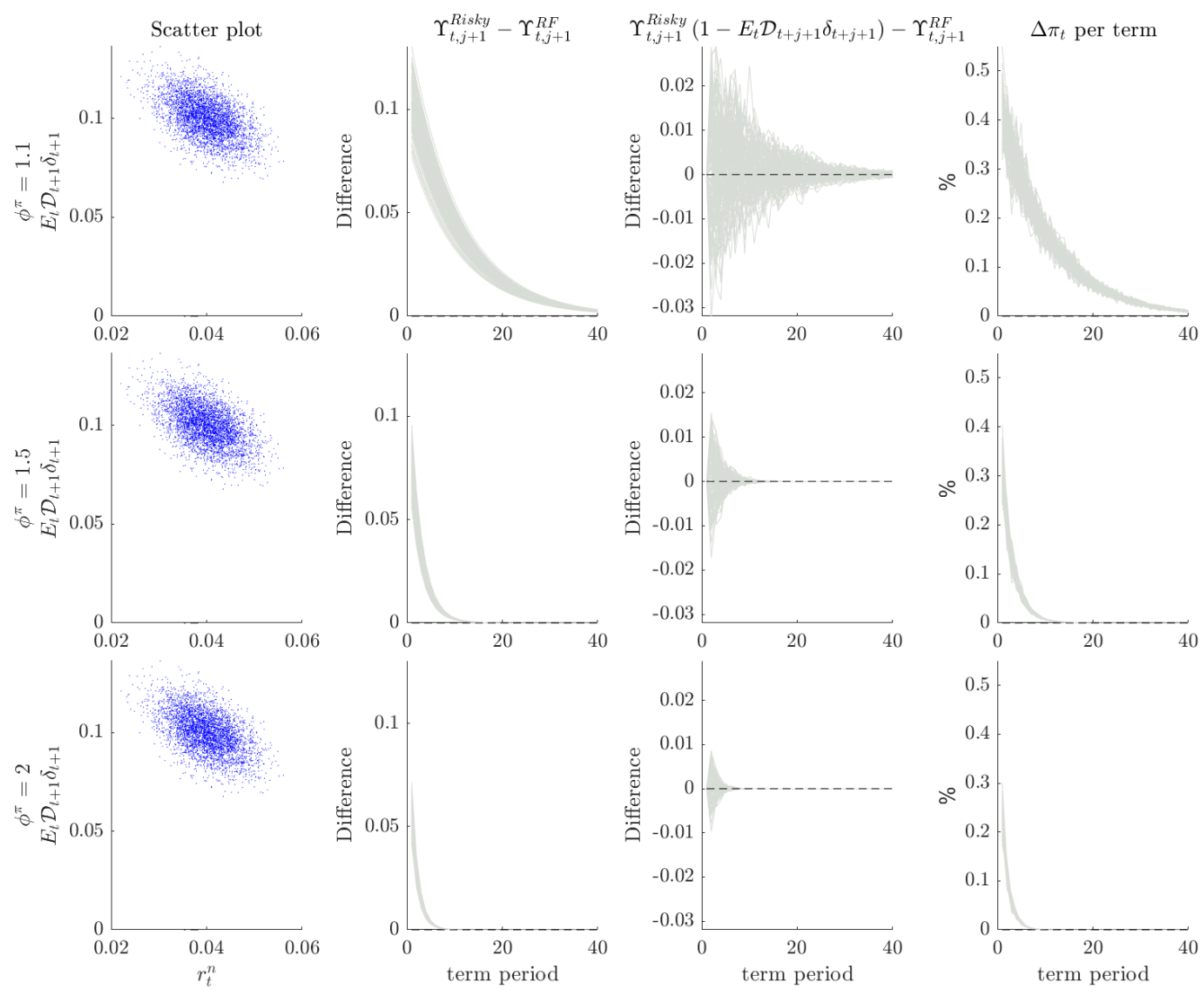

Figure A.8: Monetary policy power under inflation targeting: $\operatorname{Corr}\left(r_{t}^{n}, \mathbb{E}_{t} \mathcal{D}_{t+1}\right)=-0.5$ 

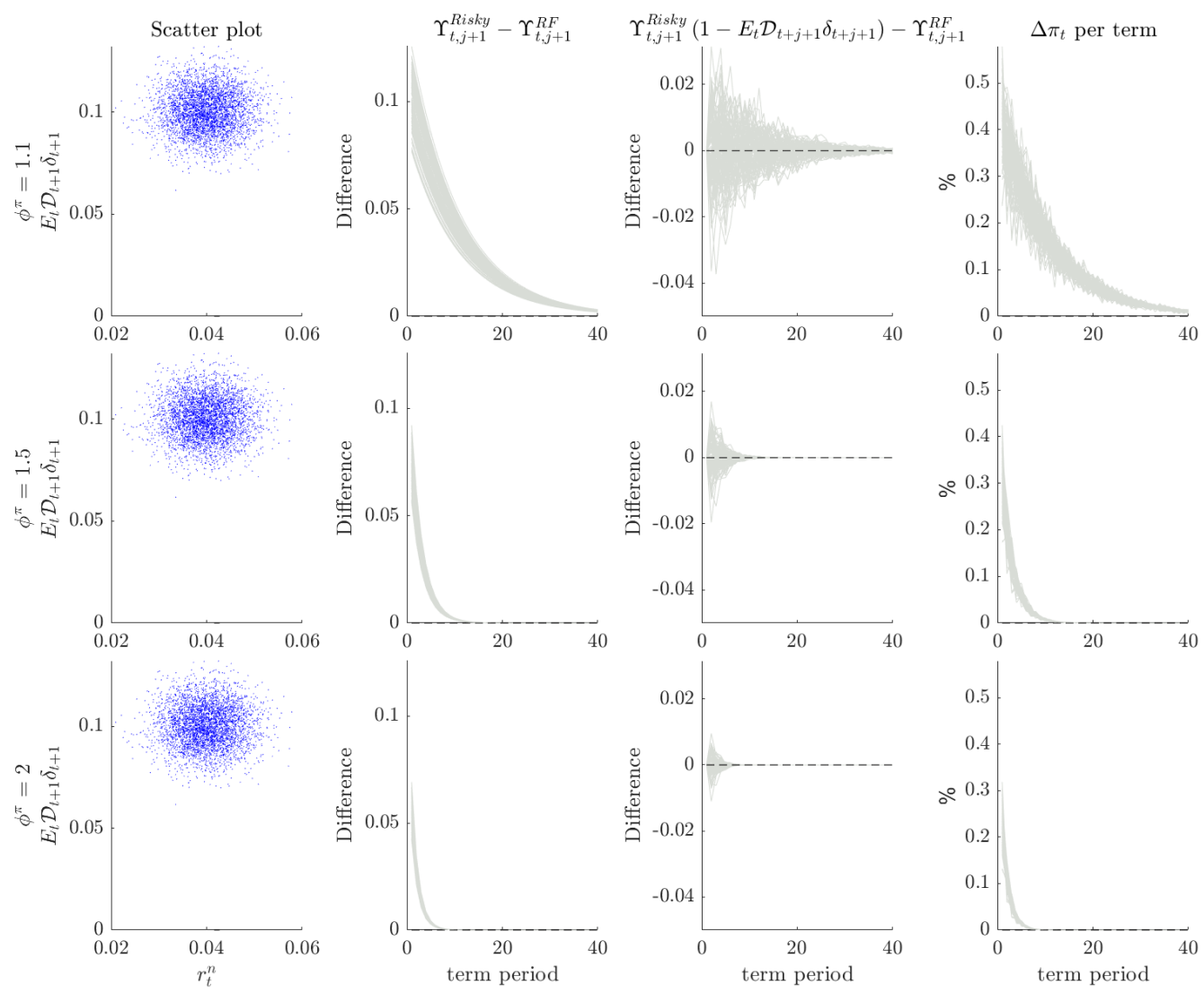

Figure A.9: Monetary policy power under inflation targeting: $\operatorname{Corr}\left(r_{t}^{n}, \mathbb{E}_{t} \mathcal{D}_{t+1}\right)=0$ 

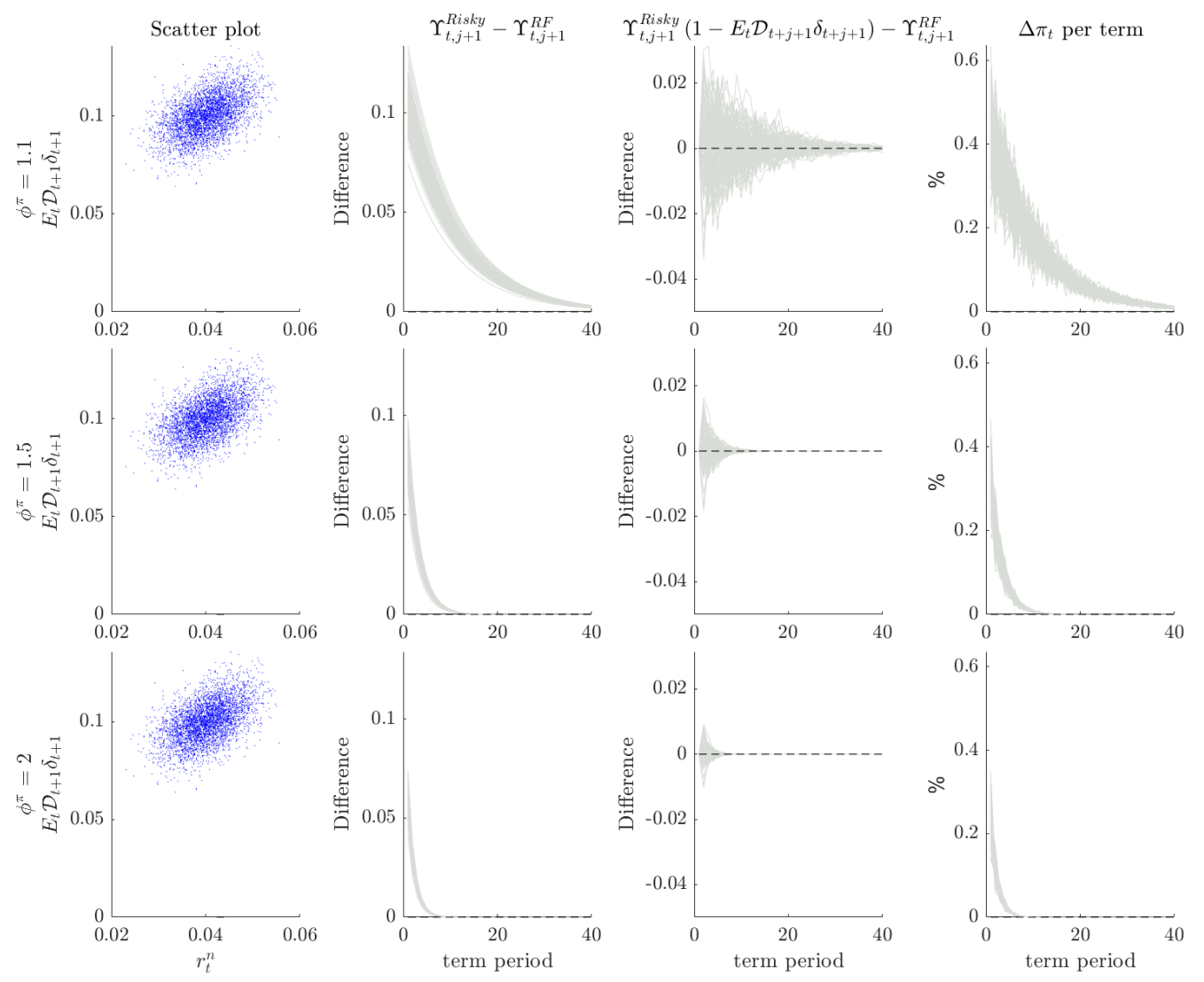

Figure A.10: Monetary policy power under inflation targeting: $\operatorname{Corr}\left(r_{t}^{n}, \mathbb{E}_{t} \mathcal{D}_{t+1}\right)=0.5$ 

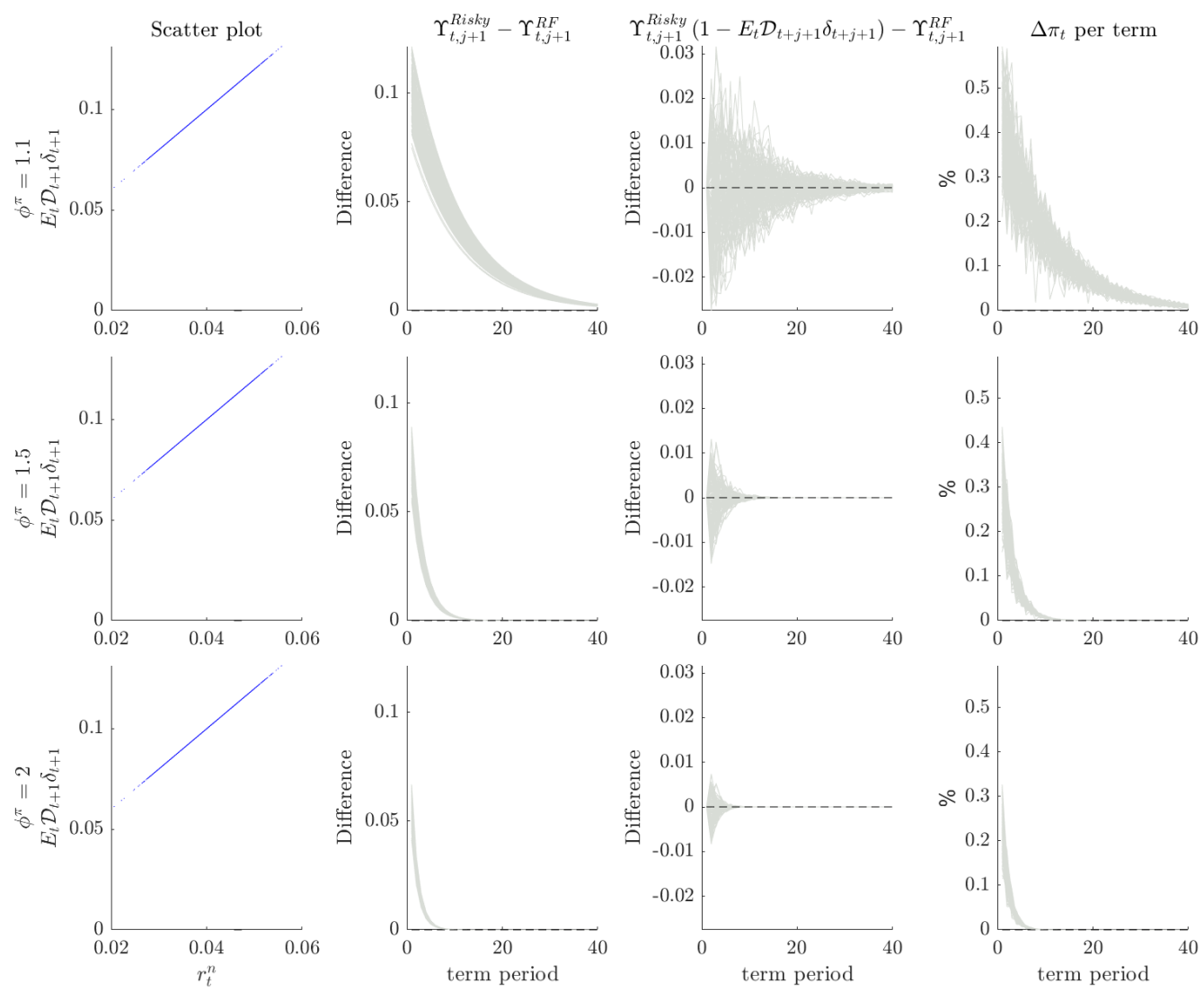

Figure A.11: Monetary policy power under inflation targeting: $\operatorname{Corr}\left(r_{t}^{n}, \mathbb{E}_{t} \mathcal{D}_{t+1}\right)=1$ 


\section{A.7}

\section{Testable implications of the model: correlations}

In this section, we plot the correlation between inflation (or the price level) and the policy-asset risk for the cases when each $r_{t}^{n}$ and $\mathbb{E}_{t} \mathcal{D}_{t+1}$ follows a normal $\mathrm{AR}(1)$ simulated process which is positively or negatively pairwise correlated, in complement to the uncorrelated case exposed in Figure 1.6.

\section{A.7.1}

\section{Inflation targeting}

Under inflation targeting, we pick correlations to be 1 (Figure A.12), 0.5 (Figure A.13), -0.5 (Figure A.14), and -1 (Figure A.15). As one can see, the fact that tracking $r_{t}^{n}$ induces positive correlation between inflation and default probability is unchanged by the correlation of the underlying processes for $r_{t}^{n}$ and $\mathbb{E}_{t} \mathcal{D}_{t+1}$. The same is true for the fact that raising $\phi^{\pi}$ (the hawkishness of monetary policy) also raises that very same correlation.
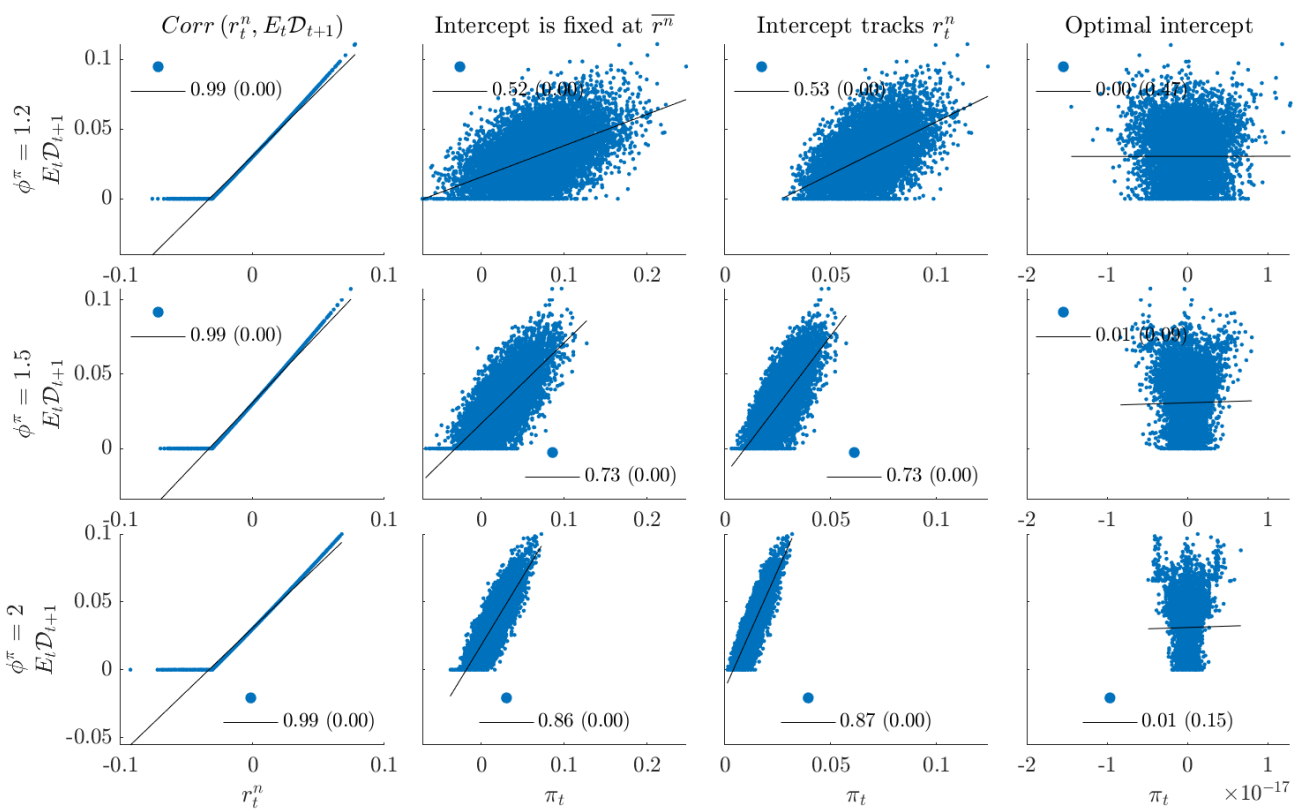

Note: p-values between parentheses.

Figure A.12: Correlation between the default probability and inflation under inflation targeting: $\operatorname{Corr}\left(r_{t}^{n}, \mathbb{E}_{t} \mathcal{D}_{t+1}\right)=1$ 


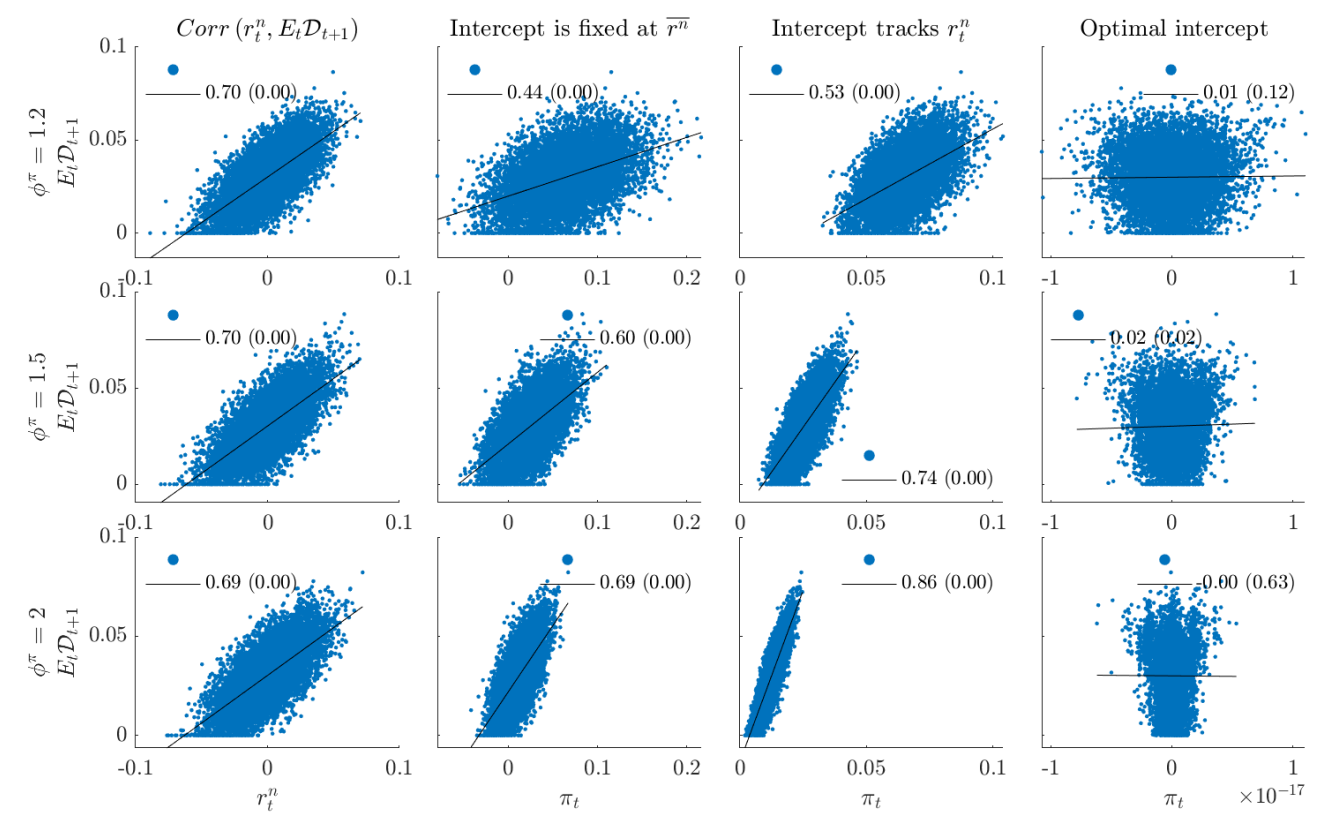

Note: p-values between parentheses.

Figure A.13: Correlation between the default probability and inflation under inflation targeting: $\operatorname{Corr}\left(r_{t}^{n}, \mathbb{E}_{t} \mathcal{D}_{t+1}\right)=0.5$
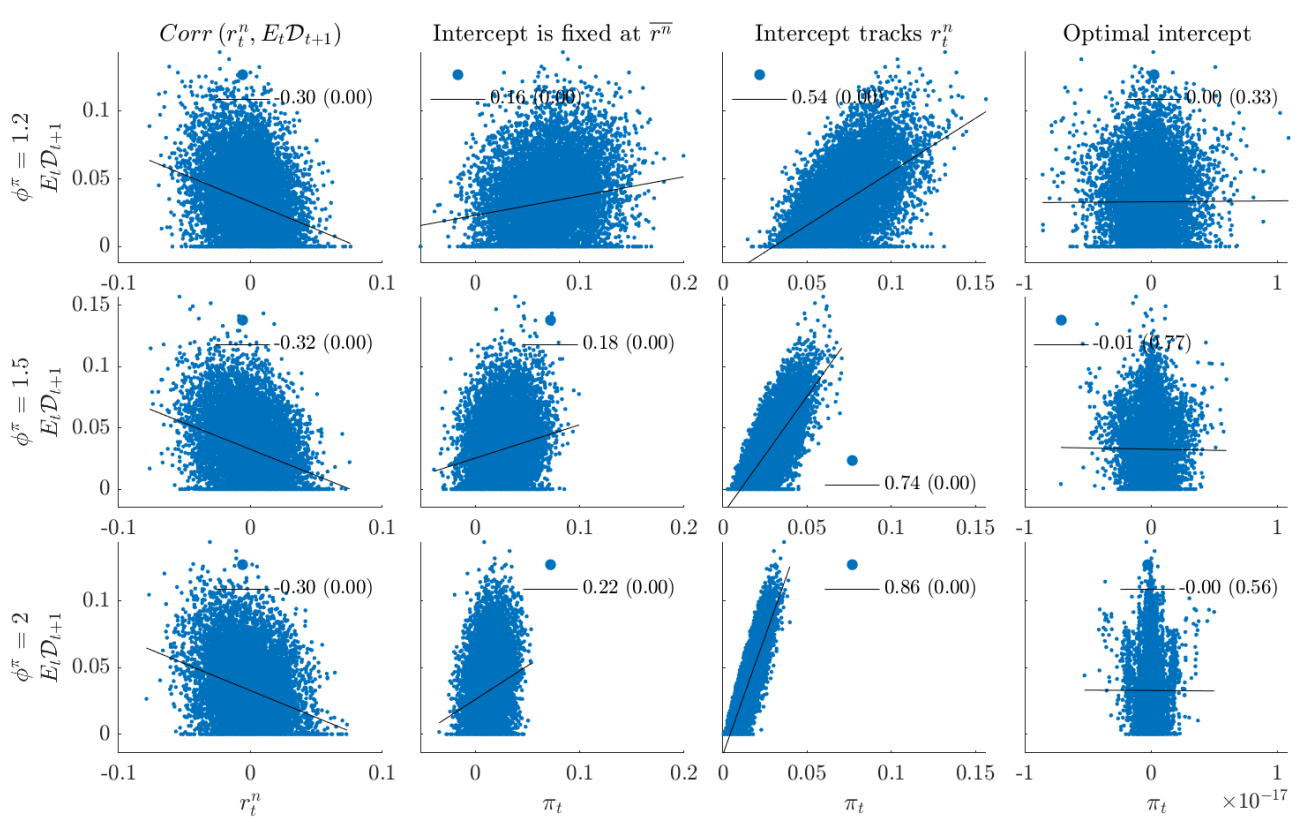

Note: p-values between parentheses.

Figure A.14: Correlation between the default probability and inflation under inflation targeting: $\operatorname{Corr}\left(r_{t}^{n}, \mathbb{E}_{t} \mathcal{D}_{t+1}\right)=-0.5$ 

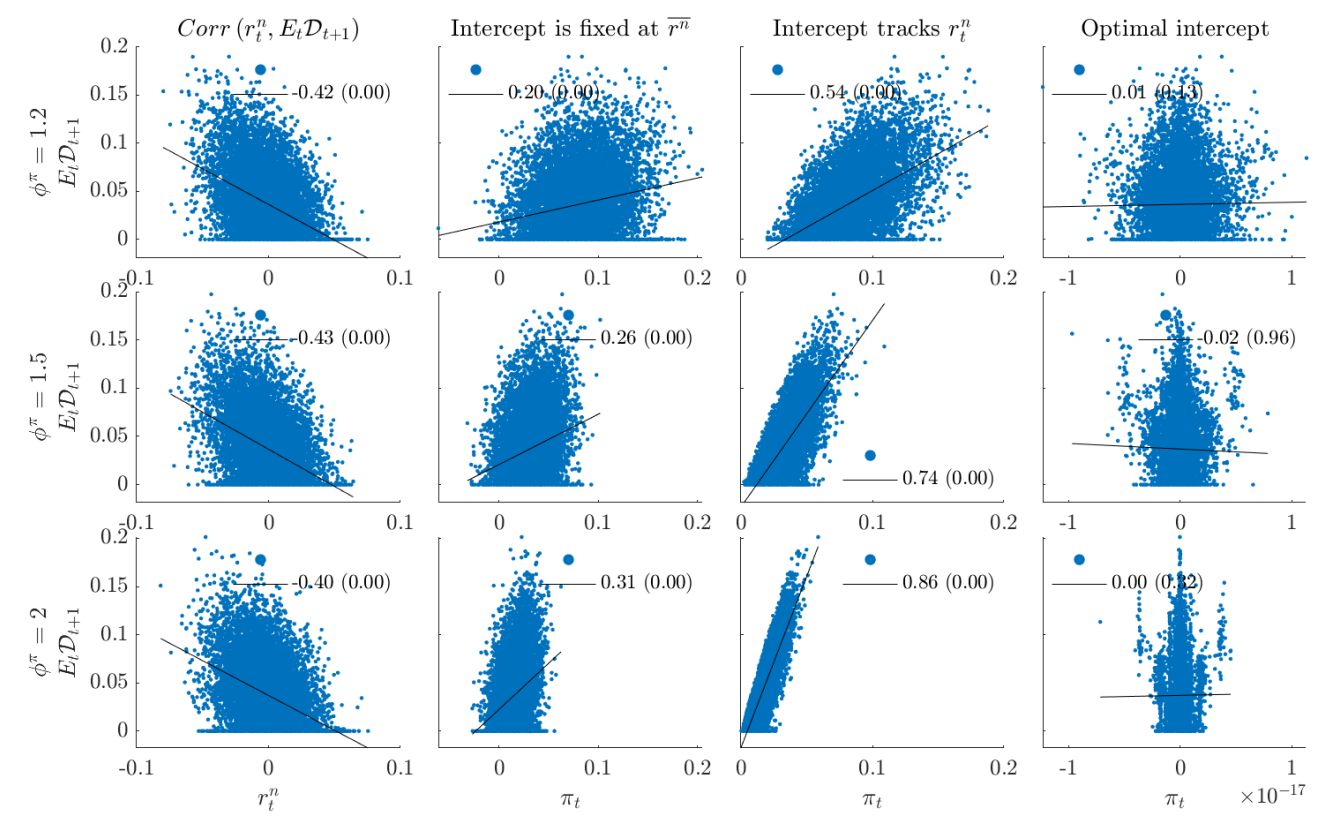

Note: p-values between parentheses.

Figure A.15: Correlation between the default probability and inflation under inflation targeting: $\operatorname{Corr}\left(r_{t}^{n}, \mathbb{E}_{t} \mathcal{D}_{t+1}\right)=-1$

\section{A.7.2 \\ Price-level targeting}

Under price-level targeting, we pick correlations to be 1 (Figure A.16), 0.5 (Figure A.17), 0.0 (Figure A.18), -0.5 (Figure A.19), and -1 (Figure A.20). As one can see, the fact that tracking $r_{t}^{n}$ induces positive correlation between the price level and default probability is unchanged by the correlation of the underlying processes for $r_{t}^{n}$ and $\mathbb{E}_{t} \mathcal{D}_{t+1}$. The same is true for the fact that raising $\phi$ (the hawkishness of monetary policy) also raises that very same correlation. 

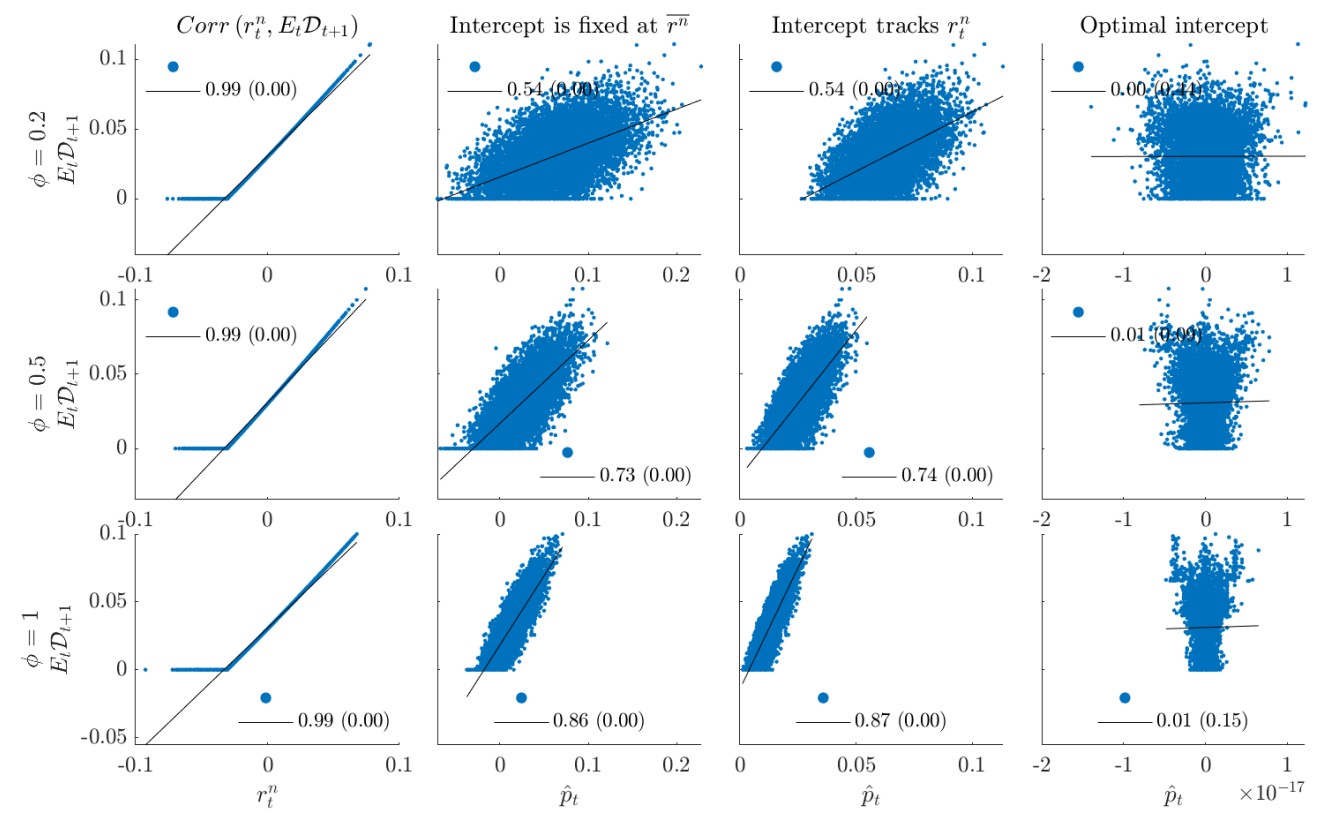

Note: p-values between parentheses.

Figure A.16: Correlation between the default probability and the price level under price level targeting: $\operatorname{Corr}\left(r_{t}^{n}, \mathbb{E}_{t} \mathcal{D}_{t+1}\right)=1$
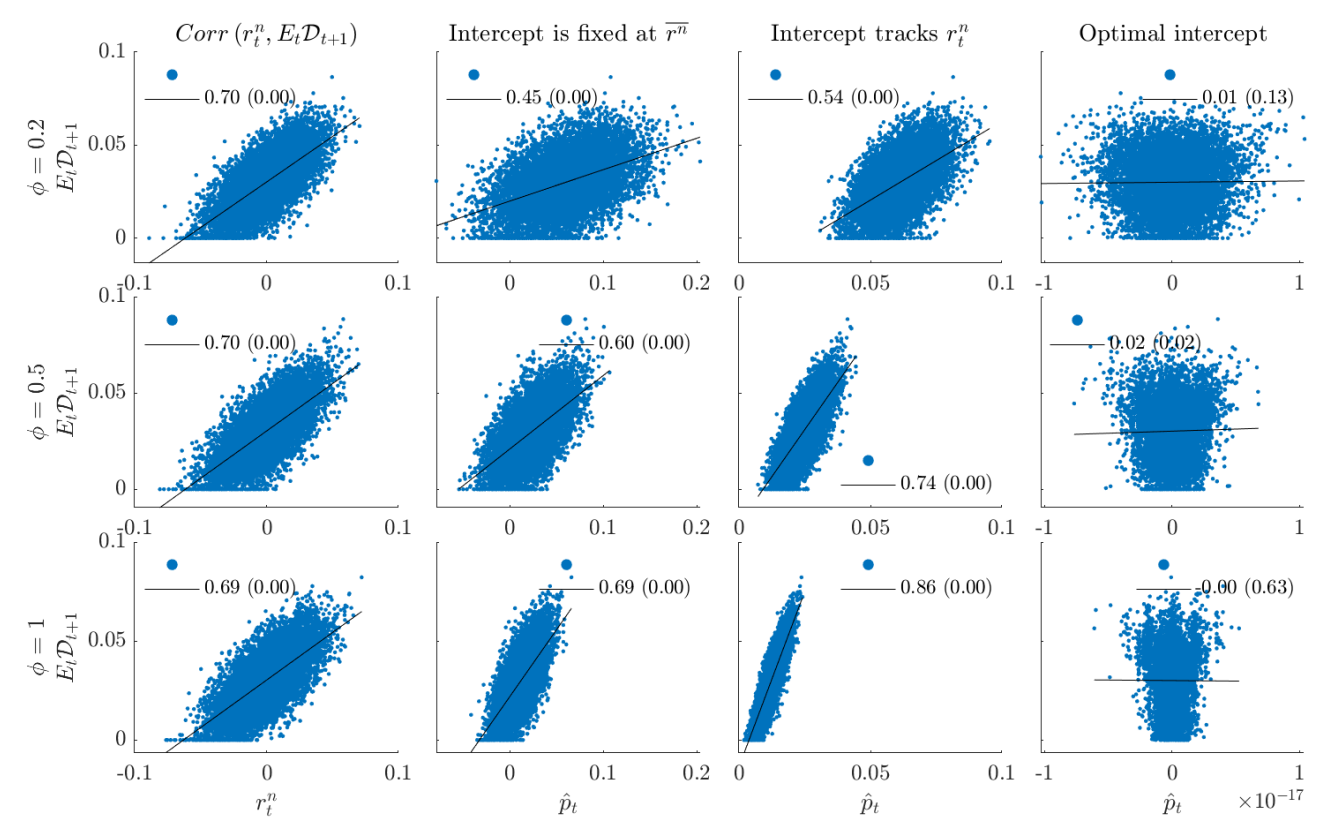

Note: p-values between parentheses.

Figure A.17: Correlation between the default probability and the price level under price level targeting: $\operatorname{Corr}\left(r_{t}^{n}, \mathbb{E}_{t} \mathcal{D}_{t+1}\right)=0.5$ 


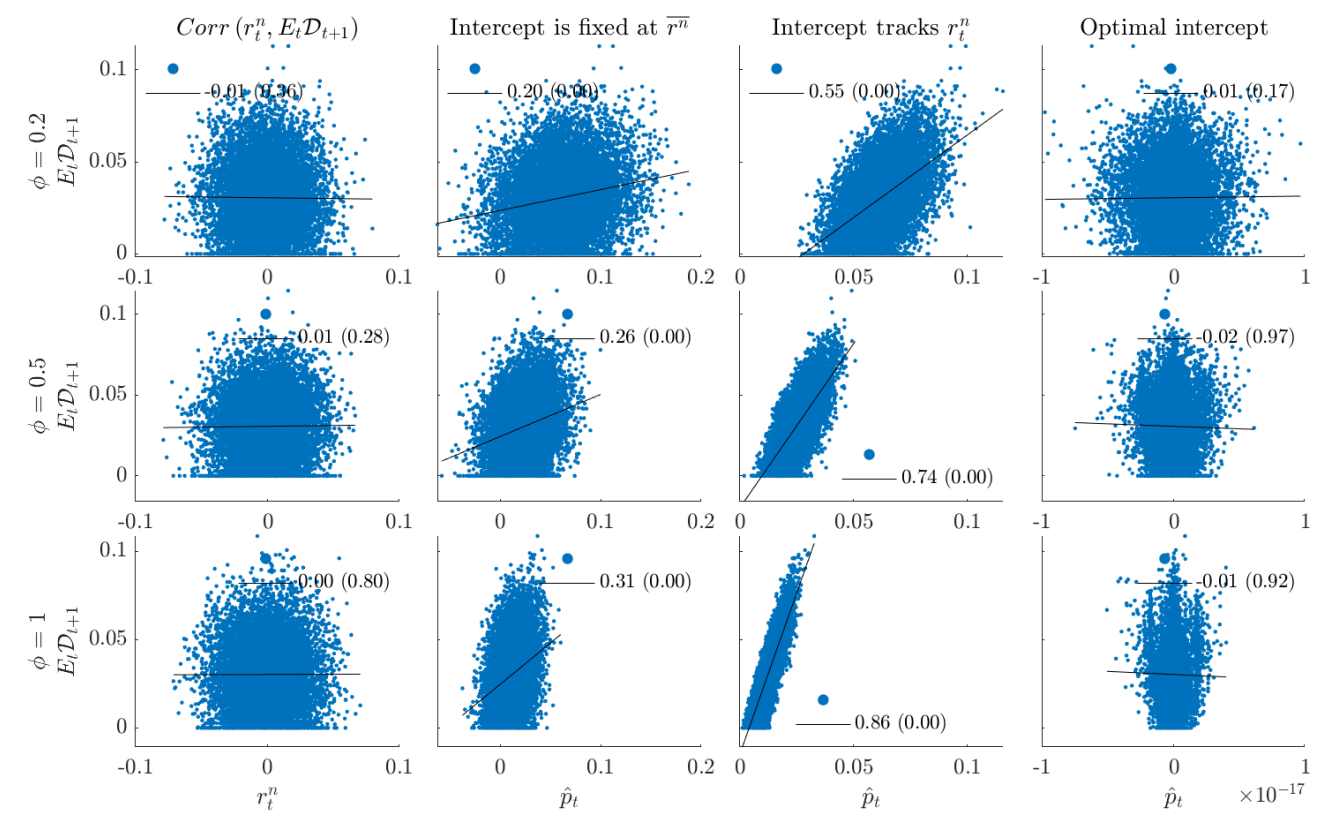

Note: p-values between parentheses.

Figure A.18: Correlation between the default probability and the price level under price level targeting: $\operatorname{Corr}\left(r_{t}^{n}, \mathbb{E}_{t} \mathcal{D}_{t+1}\right)=0$
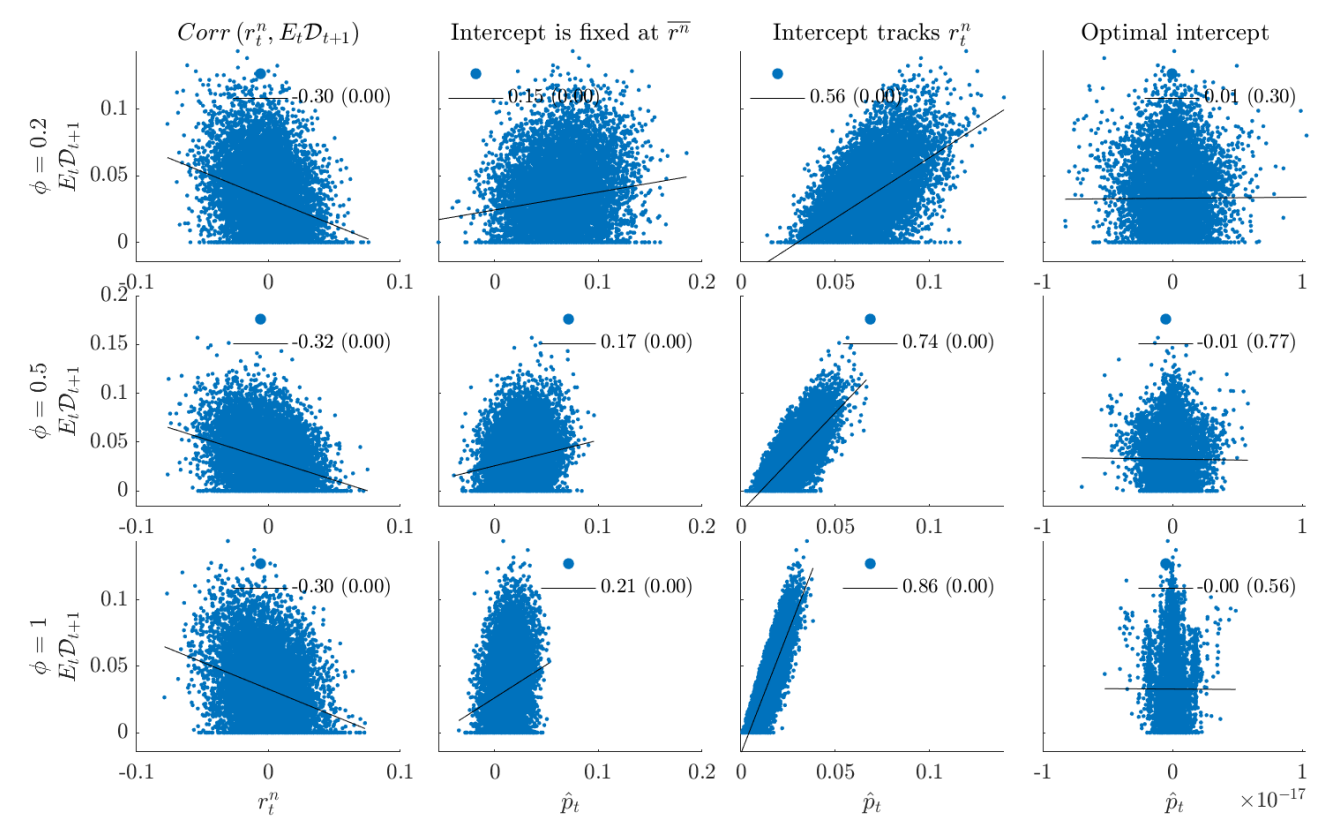

Note: p-values between parentheses.

Figure A.19: Correlation between the default probability and the price level under price level targeting: $\operatorname{Corr}\left(r_{t}^{n}, \mathbb{E}_{t} \mathcal{D}_{t+1}\right)=-0.5$ 


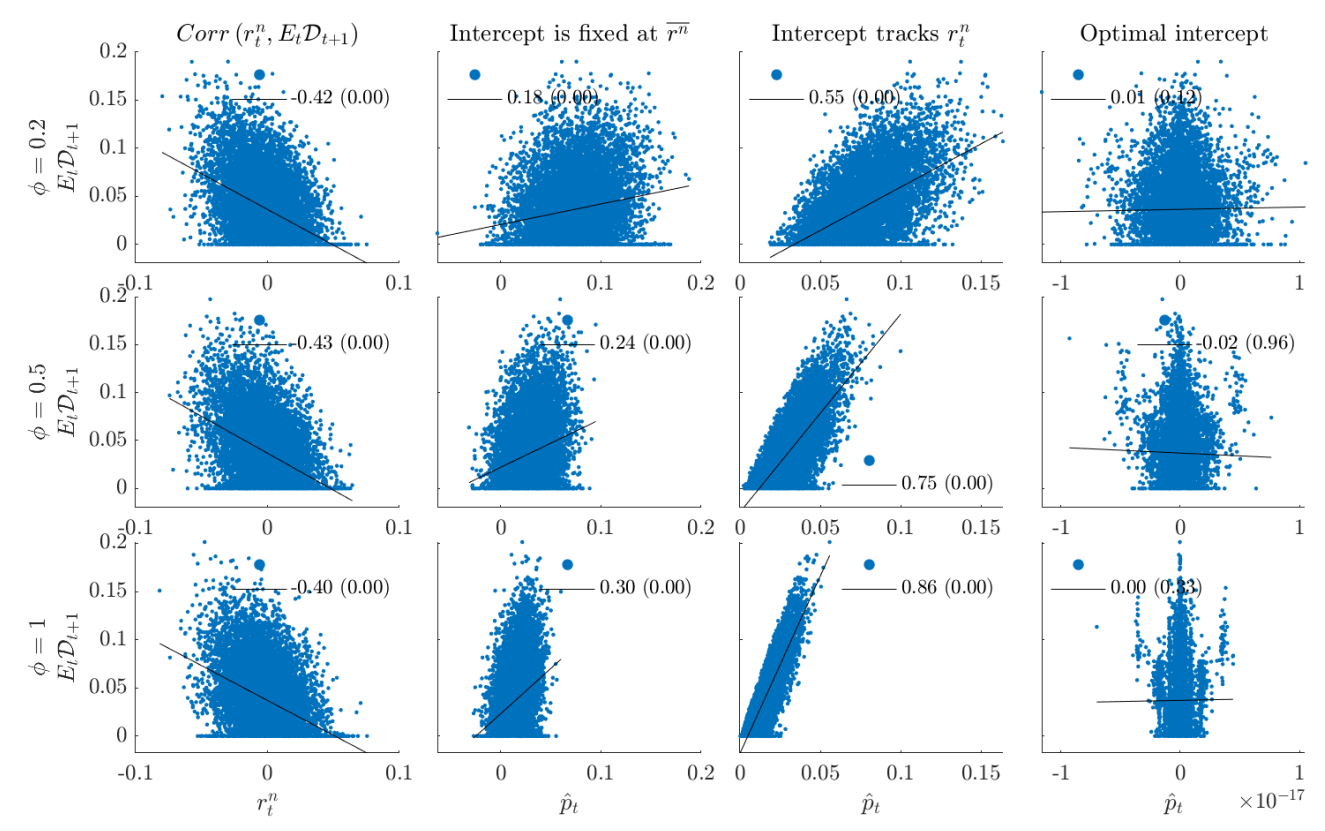

Note: p-values between parentheses.

Figure A.20: Correlation between the default probability and the price level under price level targeting: $\operatorname{Corr}\left(r_{t}^{n}, \mathbb{E}_{t} \mathcal{D}_{t+1}\right)=-1$

\section{A.7.3}

\section{Country-specific correlations}

Next, we show country-specific pairwise correlations between nominal interest rate, CPI inflation, and a measure of country-risk. For emerging economies, we use 5-year CDS in USD, while for advanced economies we use the 1-year nominal interest rate spread w.r.t. to 1-year nominal U.S. Treasuries.

Among emerging countries, the correlation between inflation and default risk is significant at least at the $10 \%$ level for seven of them (Brazil, Russian Federation, Poland, South Africa, the Philippines, Colombia, and Egypt); it is indistinguishable from zero for China, Mexico, Saudi Arabia, Turkey, and Malaysia; while it is significantly negative for none. Among advanced economies, Sweden presents positive regression coefficient significant at the $10 \%$ level; Hong Kong presents negative one significant at the $5 \%$ level; while the coefficient is indistinguishable from zero for the remaining countries in that group. 

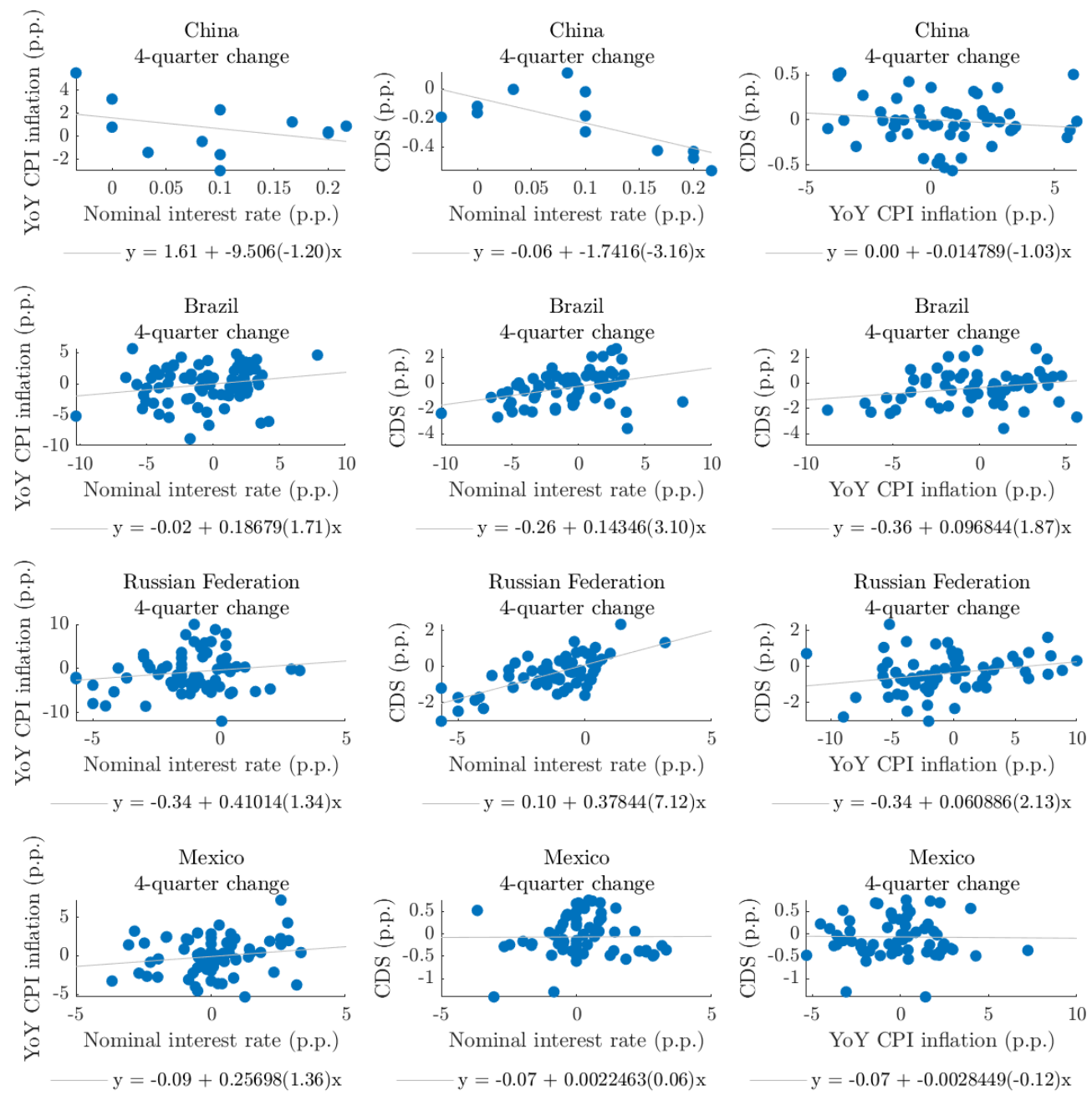

Note: t-statistics between parentheses; NaN means that there are not enough observations.

Figure A.21: Scatter plot of emerging economies: nominal interest rate, inflation, and default risk (Part 1) 

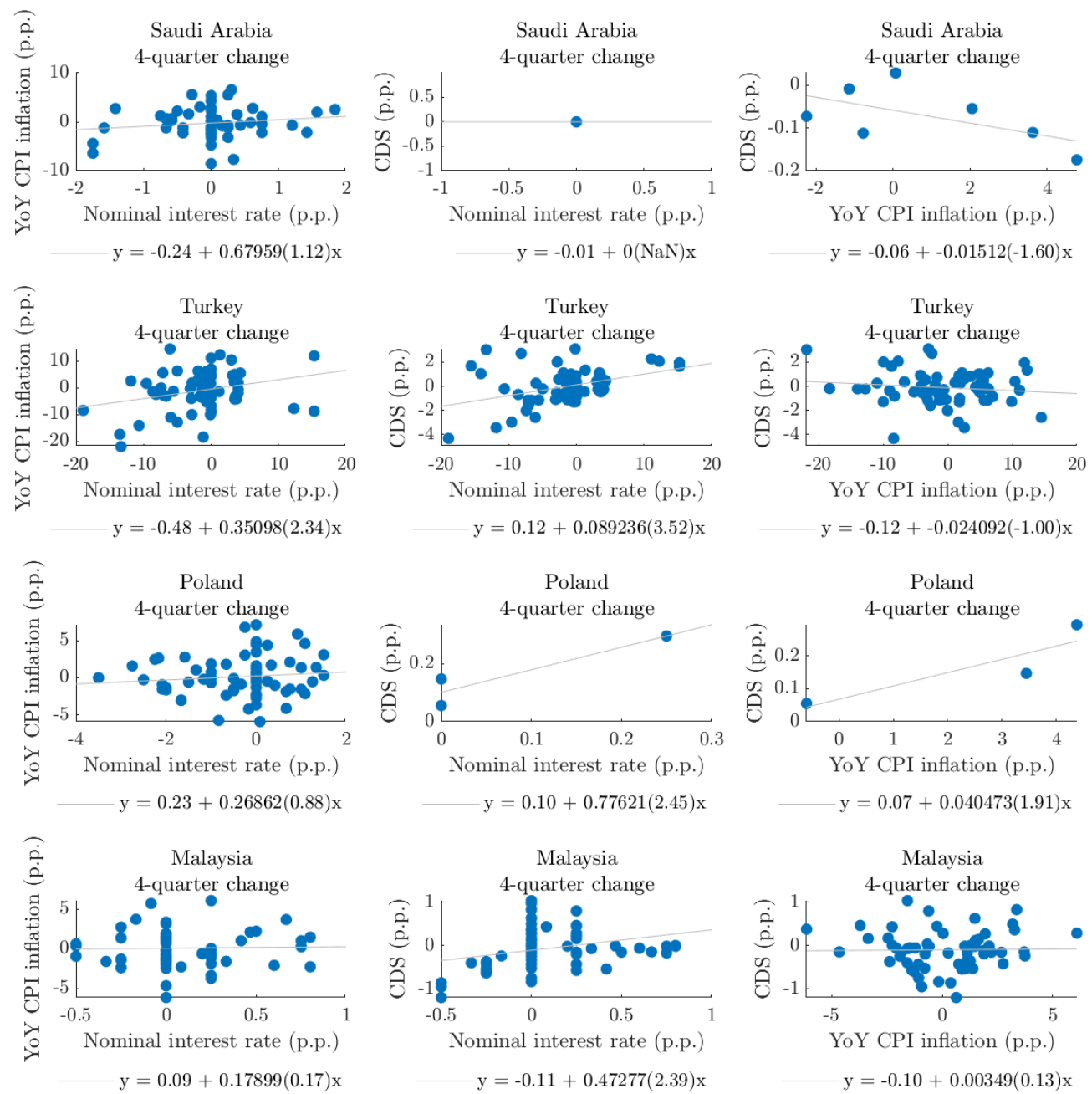

Note: t-statistics between parentheses; NaN means that there are not enough observations.

Figure A.22: Scatter plot of emerging economies: nominal interest rate, inflation, and default risk (Part 2) 

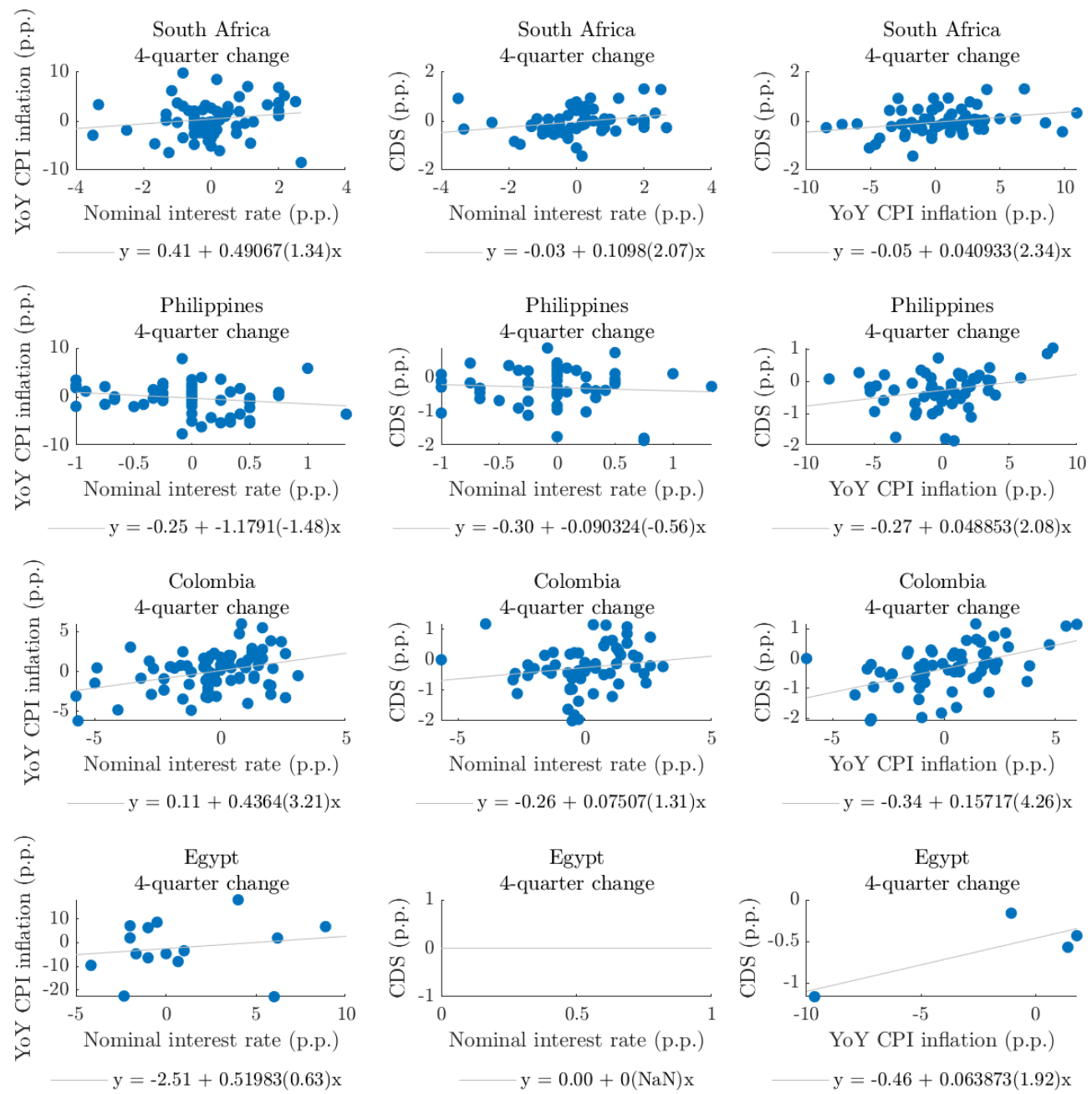

Note: t-statistics between parentheses; NaN means that there are not enough observations.

Figure A.23: Scatter plot of emerging economies: nominal interest rate, inflation, and default risk (Part 3) 

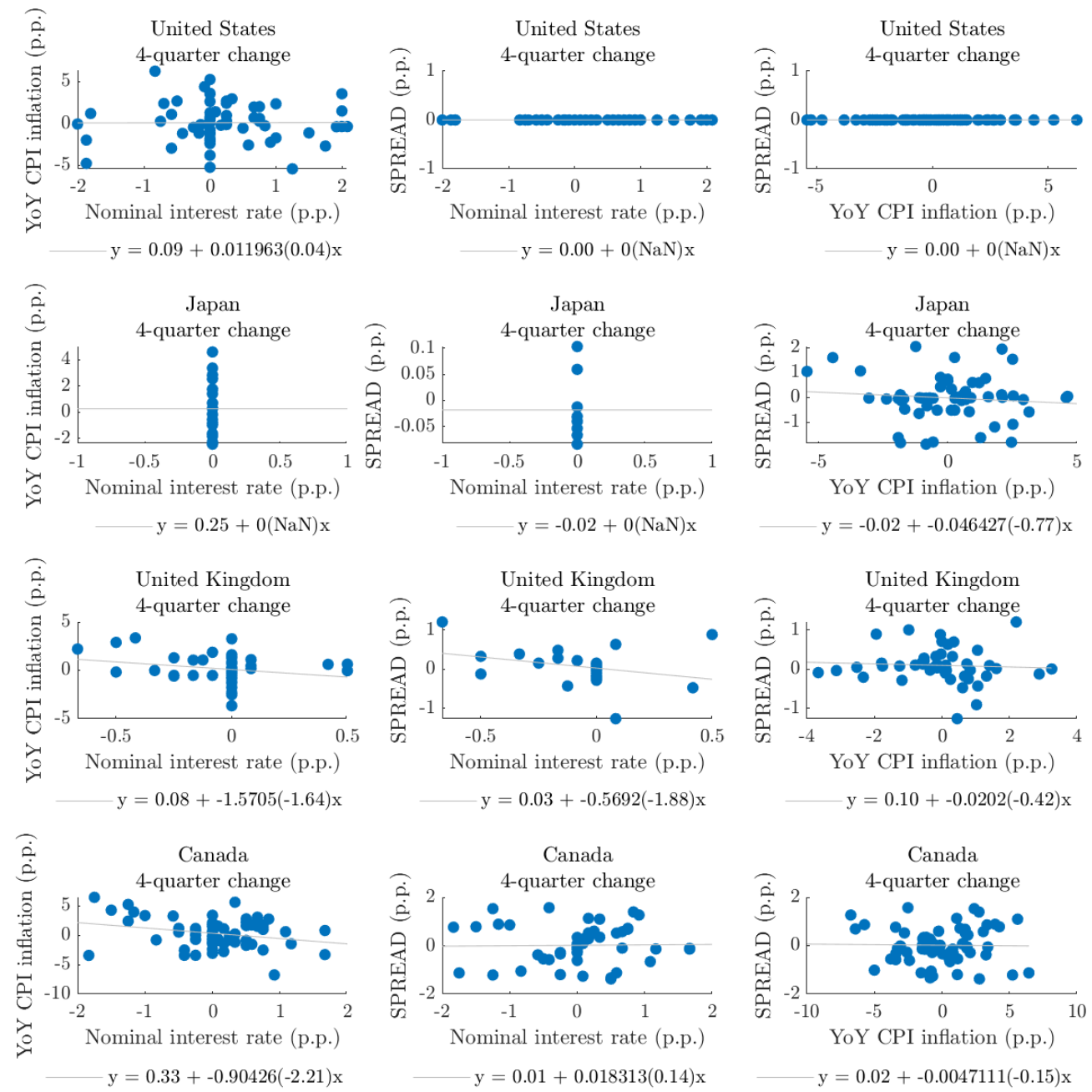

Note: t-statistics between parentheses; NaN means that there are not enough observations.

Figure A.24: Scatter plot of advanced economies: nominal interest rate, inflation, and default risk (Part 1) 

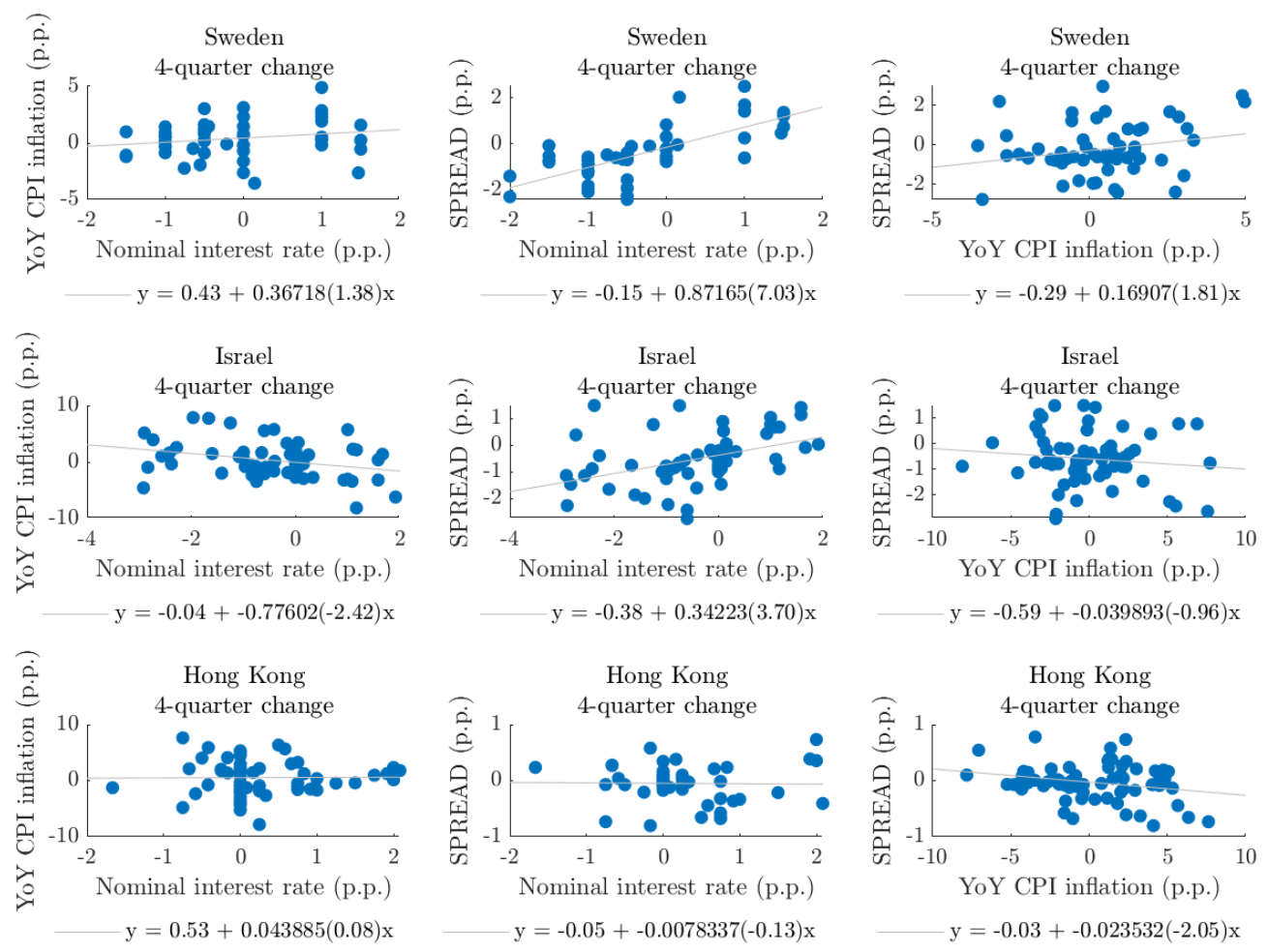

Note: t-statistics between parentheses; NaN means that there are not enough observations.

Figure A.25: Scatter plot of advanced economies: nominal interest rate, inflation, and default risk (Part 2)

\section{A.7.4}

\section{Alternative measures of risk}

Here, we reproduce aggregate and country-specific correlations using Du and Schreger (2016)'s 5-year local-currency credit spread (LCCS) as a measure of risk. The data range is the same: 2000Q1-2019Q4. In the list of emerging economies, we have 12 countries: Brazil, China, India, Indonesia, Malaysia, Mexico, Philippines, Poland, Russian Federation, South Africa, Thailand, and Turkey. In the list of advanced economies, we have 8 countries: Canada, Israel, Japan, Norway, Republic of Korea, Sweden, Switzerland, and United Kingdom. 

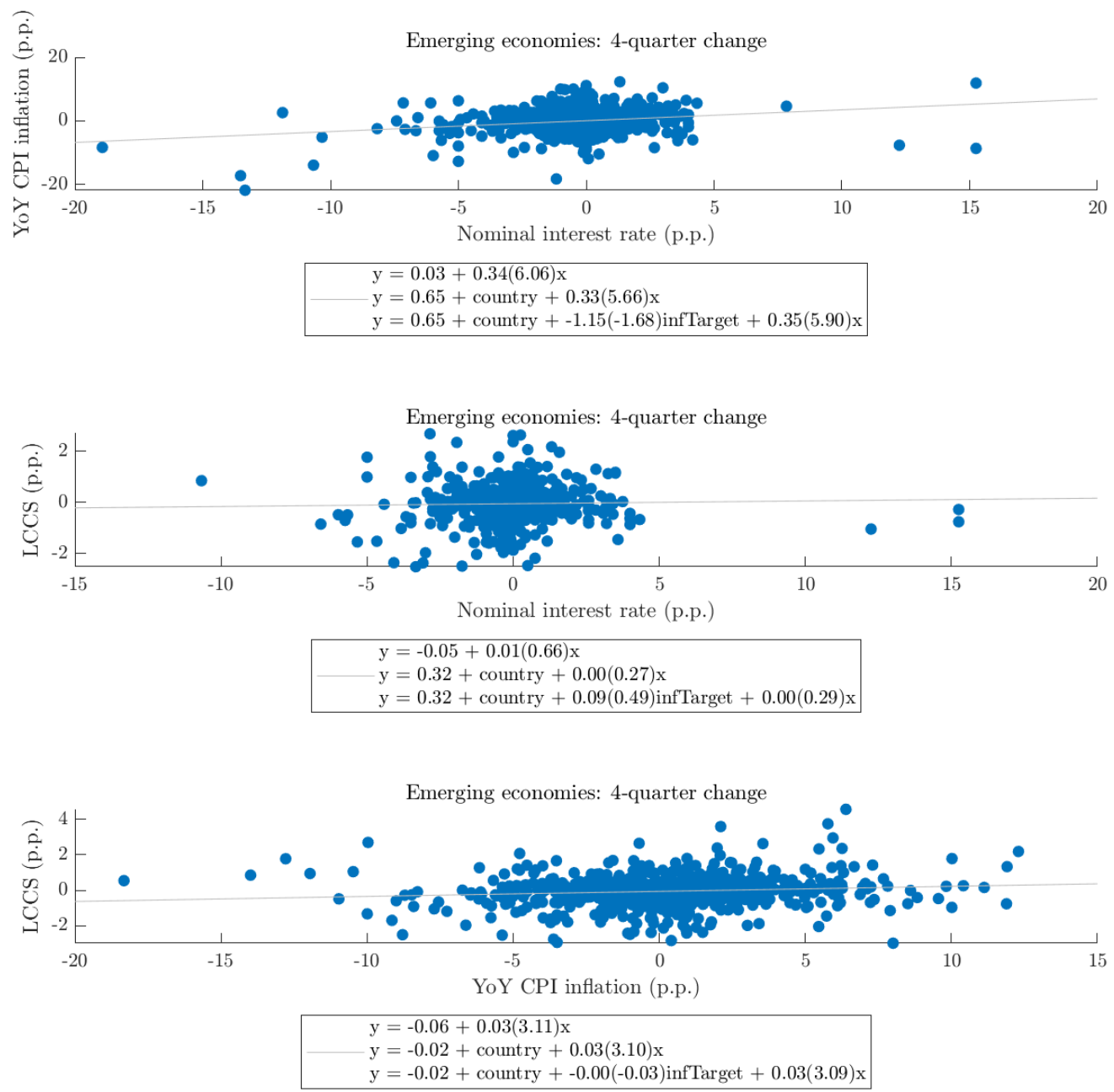

Note: between parentheses are t-statistics; "country" is a country-fixed effect; "infTarget" is a dummy that equals 1 when inflation targeting is adopted at the observation.

Figure A.26: Scatter plot of pooled emerging economies: nominal interest rate, inflation, and LCCS 

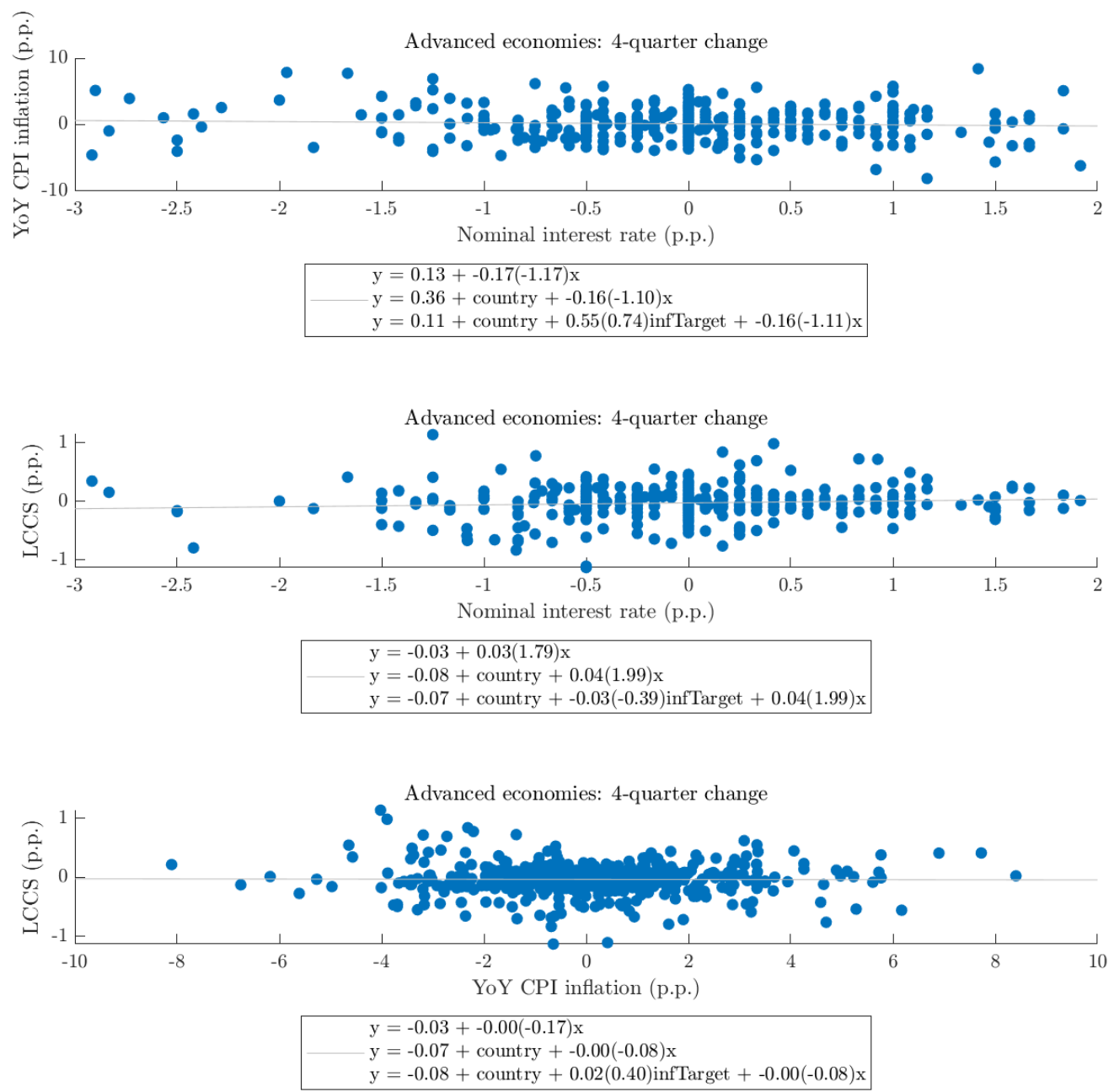

Note: between parentheses are t-statistics; "country" is a country-fixed effect; "infTarget" is a dummy that equals 1 when inflation targeting is adopted at the observation.

Figure A.27: Scatter plot of pooled advanced economies: nominal interest rate, inflation, and LCCS 

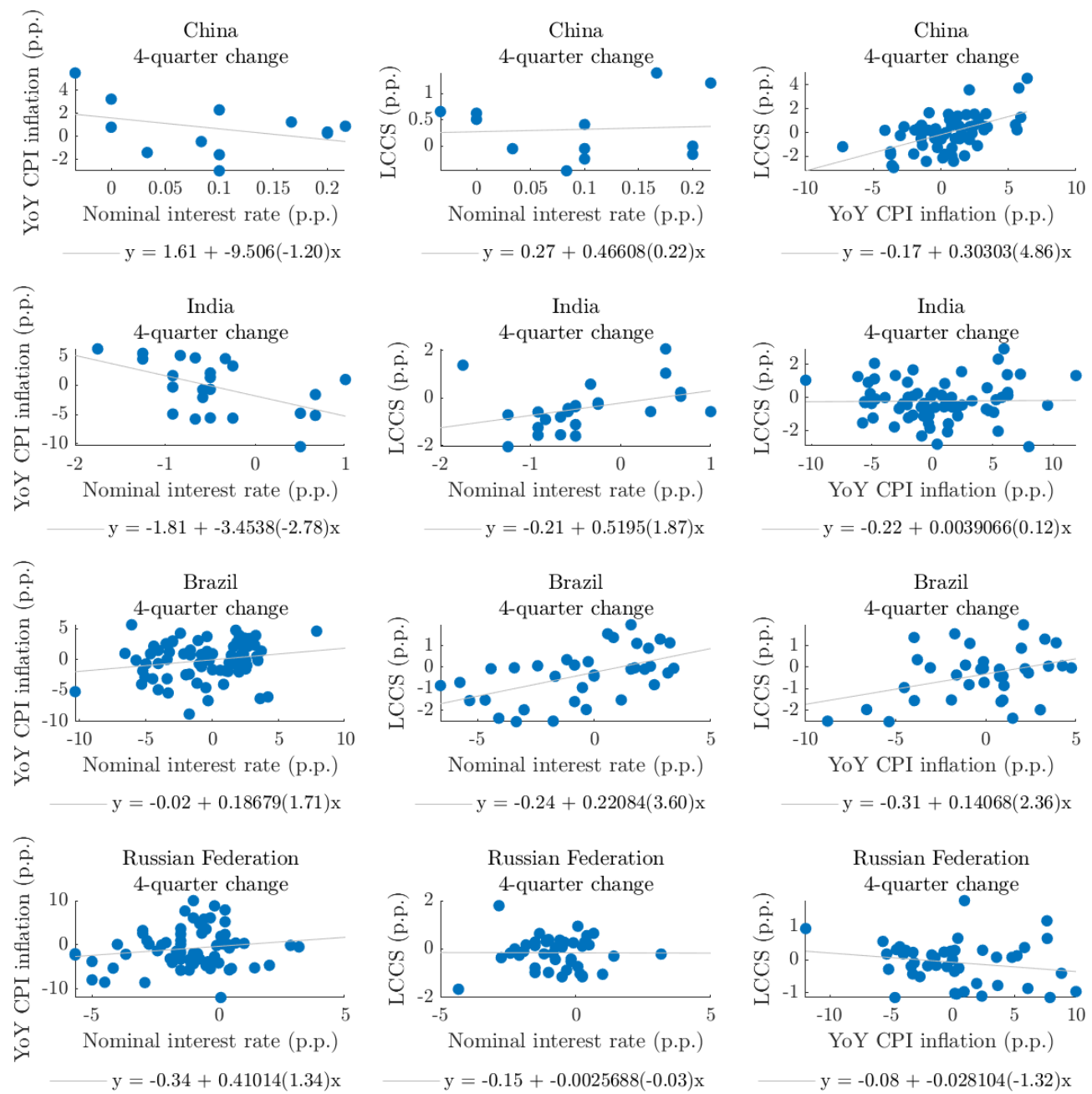

Note: t-statistics between parentheses; NaN means that there are not enough observations.

Figure A.28: Scatter plot of emerging economies: nominal interest rate, inflation, and LCCS (Part 1) 

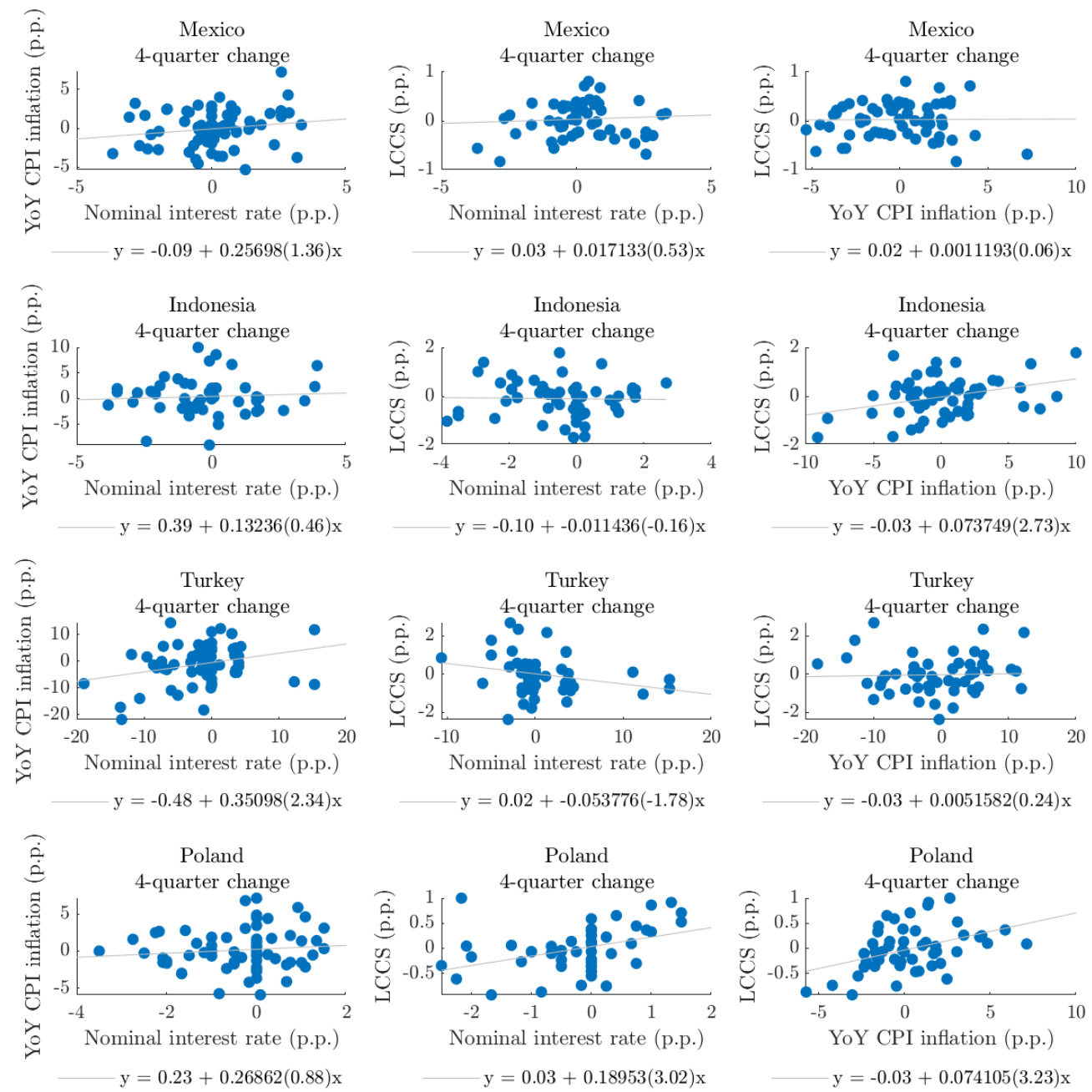

Note: t-statistics between parentheses; NaN means that there are not enough observations.

Figure A.29: Scatter plot of emerging economies: nominal interest rate, inflation, and LCCS (Part 2) 

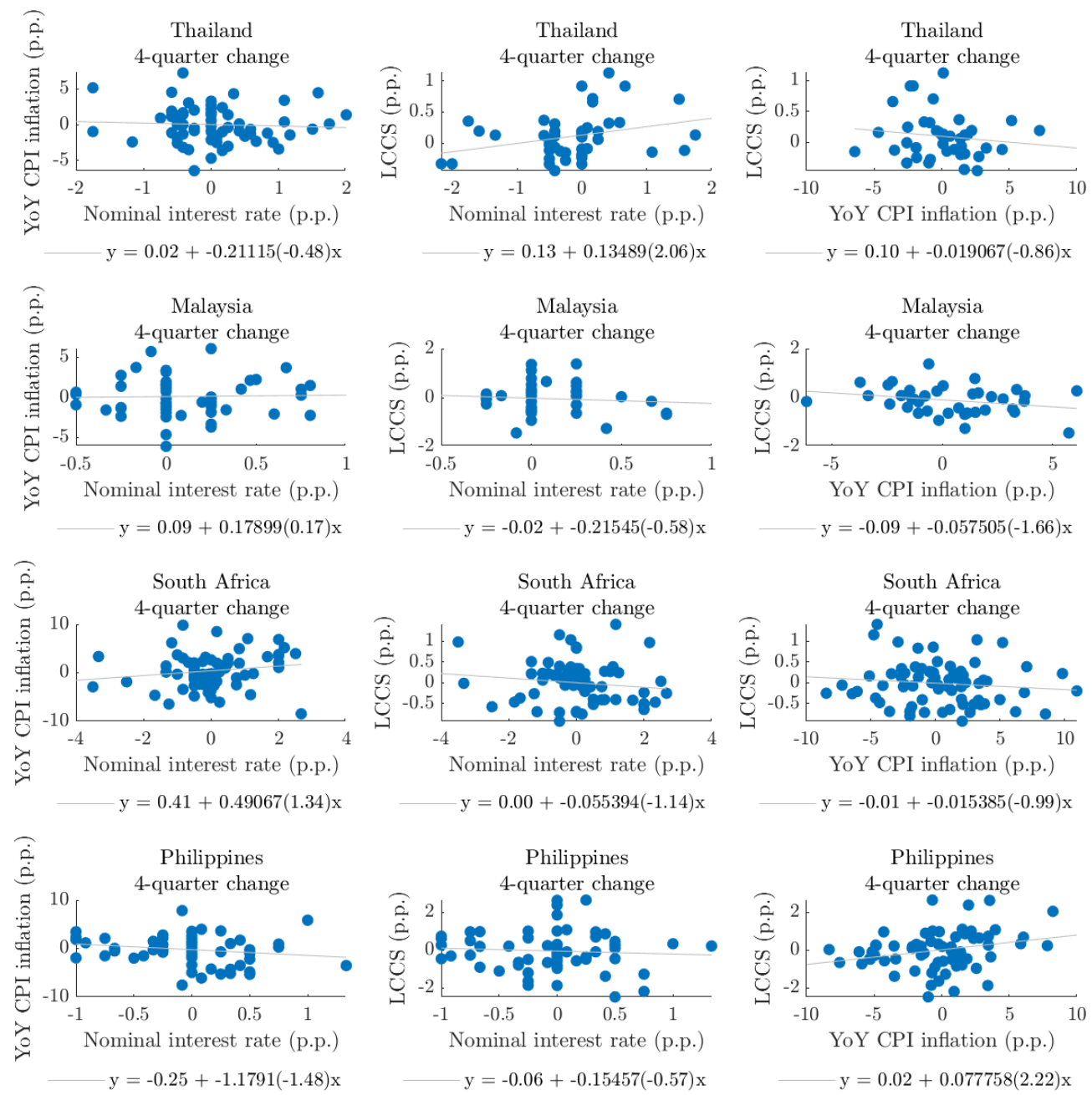

Note: t-statistics between parentheses; NaN means that there are not enough observations.

Figure A.30: Scatter plot of emerging economies: nominal interest rate, inflation, and LCCS (Part 3) 

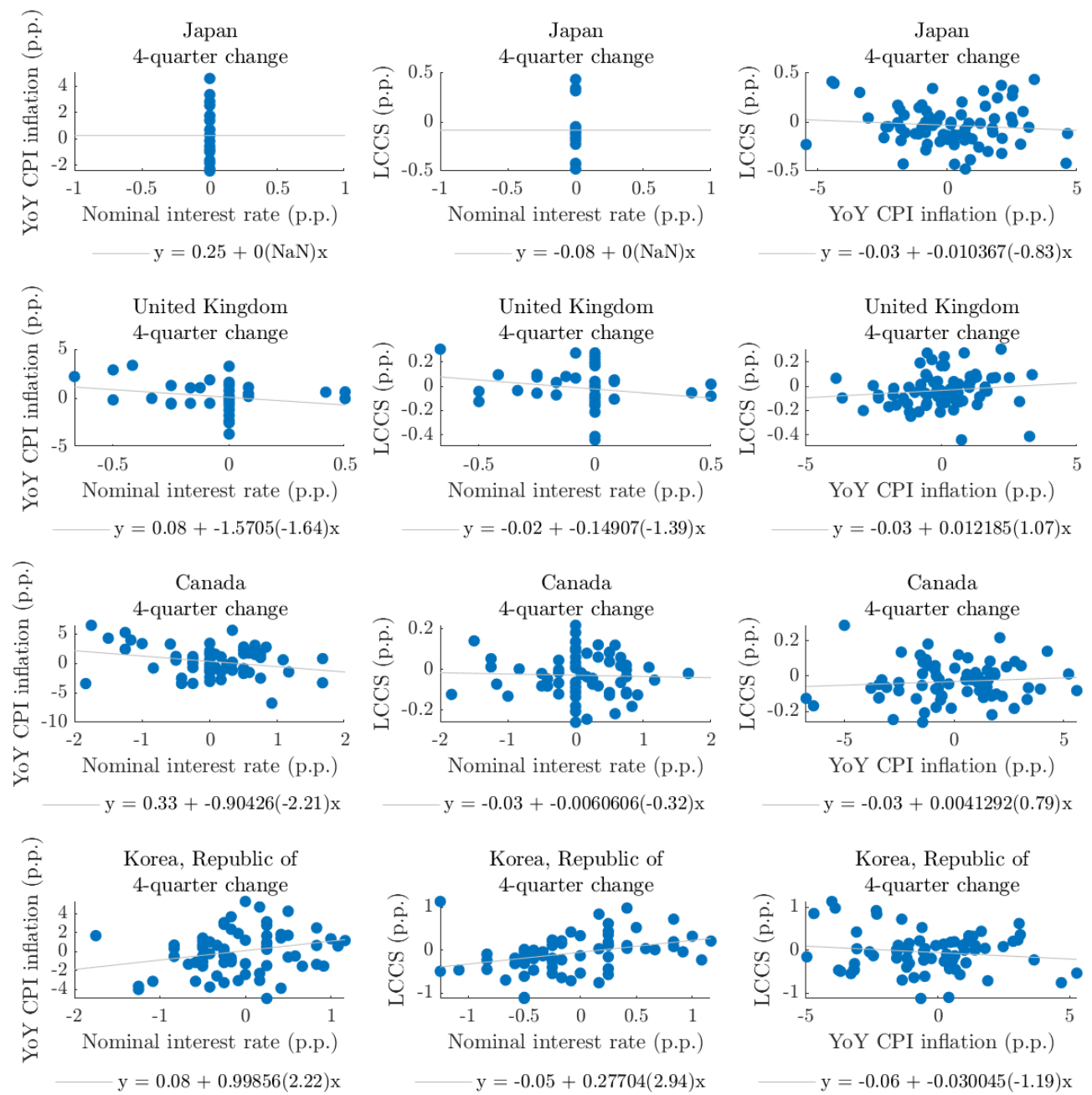

Note: t-statistics between parentheses; NaN means that there are not enough observations.

Figure A.31: Scatter plot of advanced economies: nominal interest rate, inflation, and LCCS (Part 1) 

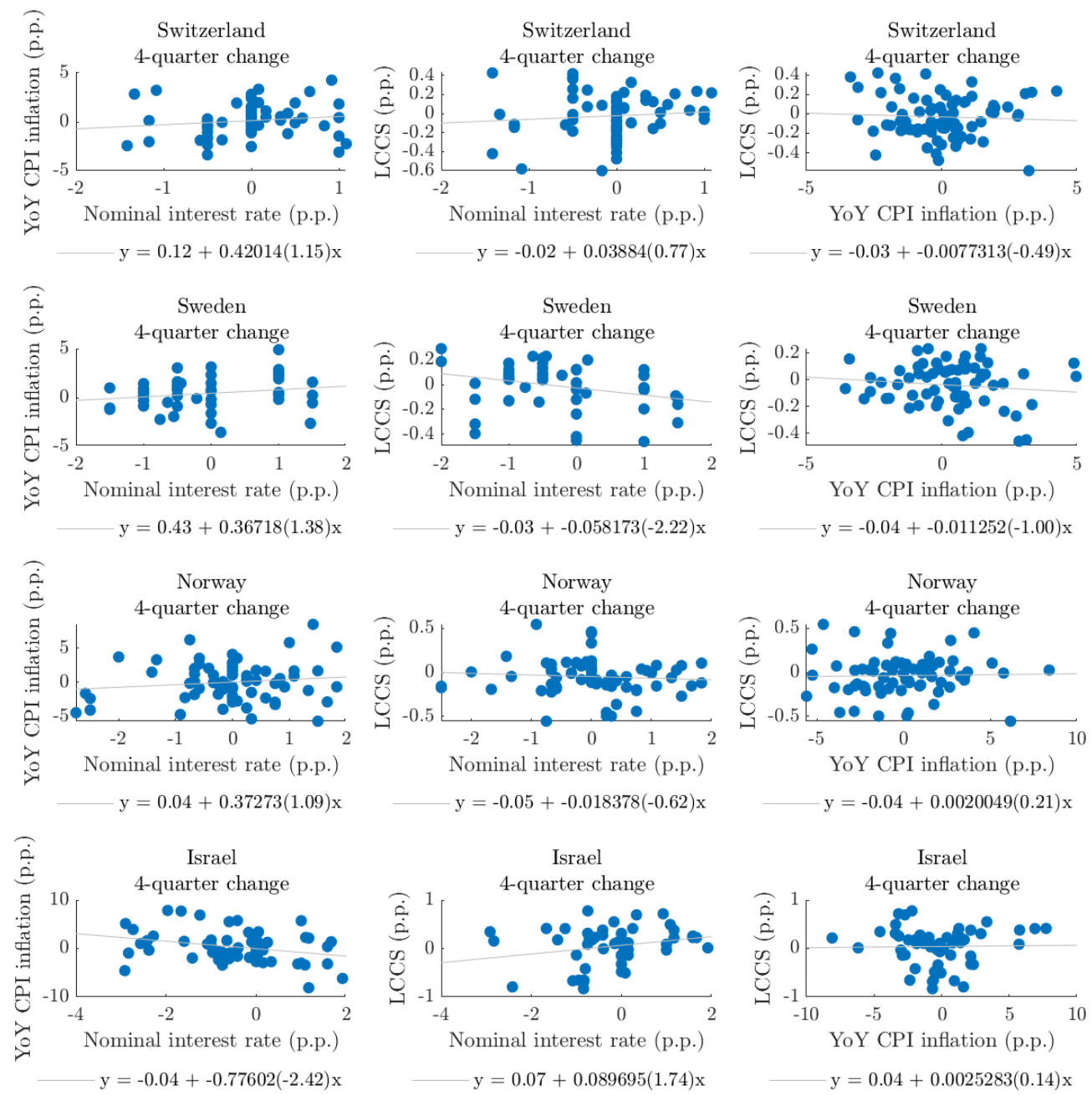

Note: t-statistics between parentheses; NaN means that there are not enough observations.

Figure A.32: Scatter plot of advanced economies: nominal interest rate, inflation, and LCCS (Part 2)

\section{A.7.5}

\section{CDS data source}

The Bloomberg tickers of the CDS time series are listed in Tables A.4, A.5, and A.6. Only emerging-economy CDS contracts were used in this paper as liquidity on advanced-economy contracts is very low. Not all listed countries qualified to the sample, though, due to the lack of enough data points. 
Table A.4: CDS data source: part 1

\begin{tabular}{|l|l|l|}
\hline Country & Ticker Description & Bloomberg Ticker \\
\hline Brazil & BRAZIL CDS USD SR 5Y D14 & CBRZ1U5 CBIN Curncy \\
\hline Colombia & COLOM CDS USD SR 5Y D14 & CCOL1U5 CBIN Curncy \\
\hline Argentina & ARGENT CDS USD SR 5Y D14 & CT350188 CBIN Curncy \\
\hline Mexico & MEX CDS USD SR 5Y D14 & CMEX1U5 CBIN Curncy \\
\hline Chile & CHILE CDS USD SR 5Y D14 & CCHIL1U5 CBIN Curncy \\
\hline Peru & PERU CDS USD SR 5Y D14 & CPERU1U5 CBIN Curncy \\
\hline Venezuela & VENZ CDS USD SR 5Y D14 & CVENZ1U5 CBIN Curncy \\
\hline Panama & PANAMA CDS USD SR 5Y D14 & CPAN1U5 CBIN Curncy \\
\hline Uruguay & URUGUA CDS USD SR 5Y D14 & CX352614 CMAI Curncy \\
\hline Costa Rica & COSTAR CDS USD SR 5Y D14 & CT409282 CMAI Curncy \\
\hline Guatemala & GUATEM CDS USD SR 5Y D14 & CX352582 CMAI Curncy \\
\hline El Salvador & ELSALV CDS USD SR 5Y D14 & CX352550 CMAI Curncy \\
\hline Turkey & TURKEY CDS USD SR 5Y D14 & CTURK1U5 CBIN Curncy \\
\hline South Africa & REPSOU CDS USD SR 5Y D14 & CSOAF1U5 CBIN Curncy \\
\hline Russia & RUSSIA CDS USD SR 5Y D14 & CRUSS1U5 CBIN Curncy \\
\hline Saudi Arabia & KSA CDS USD SR 5Y D14 & CT965307 CBIN Curncy \\
\hline Lebanon & LEBAN CDS USD SR 5Y D14 & CT358551 CMAI Curncy \\
\hline Hungary & HUNGARY CDS USD SR 5Y D14 & CHUN1U5 CMAI Curncy \\
\hline Poland & POLAND CDS USD SR 5Y D14 & CPOLD1U5 CMAI Curncy \\
\hline & & \\
\hline
\end{tabular}

Table A.5: CDS data source: part 2

\begin{tabular}{|l|l|l|}
\hline Country & Ticker Description & Bloomberg Ticker \\
\hline Egypt & EGYPT CDS USD SR 5Y D14 & CEGY1U5 CMAI Curncy \\
\hline Ukraine & UKRAIN CDS USD SR 5Y D14 & CUKR1U5 CMAI Curncy \\
\hline Abu Dhabi & ABUDHAB CDS USD SR 5Y D14 & CX855707 CMAI Curncy \\
\hline Romania & ROMANI CDS USD SR 5Y D14 & CROA1U5 CMAI Curncy \\
\hline Oman & OMAN CDS USD SR 5Y D14 & CT991547 CMAI Curncy \\
\hline Bulgaria & BGARIA CDS USD SR 5Y D14 & CBULG1U5 CMAI Curncy \\
\hline Kazakhstan & KAZAKS CDS USD SR 5Y D14 & CKAZ1U5 CMAI Curncy \\
\hline Nigeria & NIGERIA CDS USD SR 5Y D14 & CT393726 CMAI Curncy \\
\hline Tunisia & BTUN CDS USD SR 5Y D14 & CTUN1U5 CMAI Curncy \\
\hline Morocco & MOROC CDS USD SR 5Y D14 & CY002690 CMAI Curncy \\
\hline Serbia & SERBIA CDS USD SR 5Y D14 & CT355197 CMAI Curncy \\
\hline Algeria & ZZALGR CDS USD SR 5Y D14 & CT393750 CMAI Curncy \\
\hline Angola & ANGOL CDS USD SR 5Y D14 & CY341739 CMAI Curncy \\
\hline Iraq & IRAQ CDS USD SR 5Y D14 & CT394067 CMAI Curncy \\
\hline
\end{tabular}


Table A.6: CDS data source: part 3

\begin{tabular}{|l|l|l|}
\hline Country & Ticker Description & Bloomberg Ticker \\
\hline Kenya & KENYA CDS USD SR 5Y D14 & CY341643 CMAI Curncy \\
\hline Cyprus & CYPRUS CDS USD SR 5Y D14 & CT412021 CMAI Curncy \\
\hline Senegal & SENEGAL CDS USD SR 5Y D14 & CY342027 CMAI Curncy \\
\hline Rwanda & RWAND CDS USD SR 5Y D14 & CY341931 CMAI Curncy \\
\hline Cameroon & REPUBLICOFCAMEROON CDS USD SR & CY341835 CMAI Curncy \\
\hline Japan & JGB CDS USD SR 5Y D14 & CJGB1U5 CMAI Curncy \\
\hline Australia & AUSTLA CDS USD SR 5Y D14 & CT855561 CBIN Curncy \\
\hline New Zealand & NZ CDS USD SR 5Y D14 & CT778495 CMAI Curncy \\
\hline South Korea & KOREA CDS USD SR 5Y D14 & CKREA1U5 CMAI Curncy \\
\hline Indonesia & INDON CDS USD SR 5Y D14 & CINO1U5 CMAI Curncy \\
\hline China & CHINAGOV CDS USD SR 5Y D14 & CCHIN1U5 CBIN Curncy \\
\hline India & INDIA CDS USD SR 5Y D14 & CIGB1U5 CMAI Curncy \\
\hline Malaysia & MALAYS CDS USD SR 5Y D14 & CMLAY1U5 CBIN Curncy \\
\hline Philippines & PHILIP CDS USD SR 5Y D14 & CPHIL1U5 CBIN Curncy \\
\hline Thailand & THAI CDS USD SR 5Y D14 & CTHAI1U5 CMAI Curncy \\
\hline Vietnam & VIETNM CDS USD SR 5Y D14 & CX355151 CMAI Curncy \\
\hline Hong Kong & HONGK CDS USD SR 5Y D14 & CHKS1U5 CMAI Curncy \\
\hline Pakistan & PKSTAN CDS USD SR 5Y D14 & CPKT1U5 CMAI Curncy \\
\hline & & \\
\hline
\end{tabular}




\section{B}

\section{Appendix: Chapter 2}

\section{B.1}

\section{Steady state of the model}

In this section, we derive regime-specific non-stochastic steady states for this paper's model. Note that we define variables with an overline as the steadystate values of respective variables, and hereafter we make thorough use of our calibration in Table 2.3.

We start by defining two indicator functions that will promote the switching behavior across the four regime-specific steady states.

$$
\begin{array}{r}
\mathbb{1}_{\tau_{t}>\tau_{t}^{\max } \in\{0,1\}} \\
\mathbb{1}_{B_{t-1}>\mathcal{B}_{t} \in\{0,1\}}
\end{array}
$$

The first indicator function will regulate the tax rate at the steady state. Equation 2-50 and Table 2.3 give us the values for $\bar{\tau}_{\tau_{t}=\tau_{t}^{\max }}$ and $\bar{\tau}_{\tau_{t}<\tau_{t}^{\max }}$, respectively, so we obtain $\overline{\tau^{\max }}$ and $\bar{\tau}$ :

$$
\begin{array}{r}
\overline{\tau^{\max }}=\frac{\chi}{1+\chi}=\bar{\tau}_{\tau_{t}=\tau_{t}^{\max }} \\
\bar{\tau}=\left(1-\mathbb{1}_{\tau_{t}>\tau_{t}^{\max } \in\{0,1\}}\right) \bar{\tau}_{\tau_{t}<\tau_{t}^{\max }}+\mathbb{1}_{\tau_{t}>\tau_{t}^{\max } \in\{0,1\}} \bar{\tau}_{\tau_{t}=\tau_{t}^{\max }}
\end{array}
$$

The second indicator function will regulate the value of $\bar{\delta}$ :

$$
\bar{\delta}=\mathbb{1}_{B_{t-1}>\mathcal{B}_{t} \in\{0,1\}} \bar{\delta}_{\delta_{t}>0}
$$

We proceed, then, by stabilizing the endogenous variables that are affected by the shocks in a first pass. From our calibration, we opt to normalize $\bar{Y}=1$ at the no-binding regime, what allows us to calibrate $\bar{A}$ as a function of $\eta$ and $\theta$ :

$$
\bar{Y}=\left(\frac{(\theta-1)}{\theta} \frac{(1-\bar{\tau})}{\eta}\right)^{\frac{1}{\chi}}(\overline{K A})^{1+\frac{1}{\chi}} \Rightarrow \bar{A}=\frac{1}{\bar{K}}\left(\frac{\bar{Y}}{\left(\frac{(\theta-1)}{\theta} \frac{(1-\bar{\tau})}{\eta}\right)^{\frac{1}{\chi}}}\right)^{\left(\frac{1}{1+\frac{1}{\chi}}\right)} \Rightarrow \bar{A}=\frac{1}{\bar{K}}\left(\frac{1}{\left(\frac{(\theta-1)}{\theta} \frac{(1}{1}\right.}\right.
$$


To finally pin down $\bar{A}$ and $\eta$, we simultaneously solve a system with equations (B-6) and (B-7), imposing that $\bar{N}=1 / 3$.

$$
\bar{N}=\frac{1}{3}=\left(\frac{(\theta-1)}{\theta} \frac{(1-\bar{\tau})}{\eta} \overline{K A}\right)^{\frac{1}{\chi}}
$$

Then we obtain, in order:

$$
\begin{array}{r}
\bar{W}=\overline{K A} \\
\bar{C}=\bar{Y}-\bar{G}=1-\bar{G} \\
\overline{C^{N R}}=\left(\frac{(\theta-1)}{\theta} \frac{1}{\eta}\right)^{\frac{1}{\chi}}((1-\bar{\tau}) \overline{K A})^{1+\frac{1}{\chi}}+\bar{Z} \\
\overline{C^{R}}=\frac{1}{1-\gamma^{N R}}\left(1-\bar{G}-\gamma^{N R} \overline{C^{N R}}\right) \\
\overline{U_{c}}=\left(\overline{C^{R}}+\alpha_{G} \bar{G}-\eta \frac{\bar{N}^{1+\chi}}{1+\chi}\right)^{-\sigma} \\
\bar{T}=\bar{\tau}\left(\frac{(\theta-1)}{\theta} \frac{(1-\bar{\tau})}{\eta}\right)^{\frac{1}{\chi}}(\overline{K A})^{1+\frac{1}{\chi}}
\end{array}
$$

Given the inflation target, $\bar{\Pi}$, and $\overline{\mathcal{M}}$ we can define the steady-state expressions for our model's interest rates.

$$
\begin{array}{r}
\overline{r^{R F}}=\overline{r^{n}}=-1+\frac{1}{\beta} \\
\bar{i}=-1+\bar{\Pi} \frac{1}{\beta}
\end{array}
$$

Next, we obtain the steady-state intercept of each policy rule by adding or subtracting the steady-state risk premium, $\bar{\Phi}=\left(\bar{r}-\overline{r^{n}}\right)$, when necessary. ${ }^{1}$ The nominal policy interest rate will depend on the policy rule as follows:

If central bank operated a risk-free asset and targeted a risk-free rate:

$$
\begin{array}{r}
\bar{r}=-1+\frac{1}{\beta} \\
\bar{\iota}=\bar{r} \\
\bar{i}=(1+\bar{r}) \bar{\Pi}-1
\end{array}
$$

${ }^{1}$ One way of interpreting this modeling device is that the central bank employs the stabilizing intercept on average, but the way that it deals with fluctuations on expected default risk is what affects differently each policy rule. 
If central bank operates a risky asset and ignores risk:

$$
\begin{array}{r}
\bar{r}=-1+\frac{1}{\beta(1-\bar{\delta})} \\
\bar{\iota}=\overline{r^{n}}+\left(\bar{r}-\overline{r^{n}}\right)=\bar{r} \\
\bar{i}=(1+\bar{r}) \bar{\Pi}-1
\end{array}
$$

If central bank operates a risky asset and adjusts by default risk:

$$
\begin{array}{r}
\bar{r}=-1+\frac{1}{\beta(1-\bar{\delta})} \\
\bar{\iota}=\bar{r} \\
\bar{i}=(1+\bar{r}) \bar{\Pi}-1
\end{array}
$$

With our calibration for $\bar{G}$ from Table 2.3, we can find the actual repaid debt, $\overline{B^{d}}$, the fiscal limit, $\overline{\mathcal{B}}$, and the policy default probability, $\overline{\mathcal{D}}$, all evaluated at the steady state as a function of $\bar{B}$ :

$$
\begin{array}{r}
\overline{B^{d}}=(1-\bar{\delta}) \bar{B} \\
\overline{\mathcal{B}}=\mathcal{B}(\bar{A}, \bar{G}) \\
\overline{\mathcal{D}}=\operatorname{Pr}(\bar{B}>\overline{\mathcal{B}})=\frac{1}{1+\exp \left(\gamma_{0}+\gamma_{b}(\bar{B}-\overline{\mathcal{B}})\right)}
\end{array}
$$

With our calibration for $\bar{B}$ from Table 2.3 , we can certainly find the steady-state value of previous variables that we left as a function of $\bar{B}$. However, due to different levels of distortionary taxation and default risk, each regime would have its own steady-state debt level. We fix this by simultaneously solving the equation for the intercept of the policy rule at the steady state, in addition to (B-27), and (B-28)

$$
\bar{B}=\frac{((1+\bar{\iota}) \bar{\Pi})\left(\bar{G}+\bar{Z}+\overline{T_{L S}}-\bar{T}\right)}{(1-(1+\bar{\iota})(1-\delta))}
$$

where we introduce a regime-specific fixed lump-sum tax, $\overline{T_{L S}}$, to impose stationarity on the debt trajectory.

In the calculation of fiscal limits, variables are evaluated assuming the tax rate constraint is binding while the default constraint is not. To obtain the steady-state values in that regime just remake previous steps accordingly. 


\section{B.2}

\section{Log-linearized model}

In the third step of the solution algorithm, the model is approximated in first order around each regime-specific steady state for the regime-switching method. Here, we present the log-linearized equations used in that approximation. Note that for any variable $X_{t}, \widetilde{x}_{t} \equiv \log \left(X_{t}\right)-\log (\bar{X}) \approx \frac{X_{t}-\bar{X}}{\bar{X}}$. To simplify notation, though, we define $\widetilde{w}_{t} \equiv \log \left(\frac{W_{t}}{P_{t}}\right)-\log \left(\frac{\bar{W}}{\bar{P}}\right)$, and, for variables denoted with greek letters, we do not replace them by their respective lower case versions. Moreover, we define $\widetilde{R}_{t}^{i} \equiv \log \left(1+i_{t}\right)-\log (1+\bar{i})$, ${\widetilde{R^{\iota}}}_{t} \equiv \log \left(1+\bar{\iota}_{t}\right)-\log (1+\overline{\bar{\iota}}), \widetilde{R^{R F}}{ }_{t} \equiv \log \left(1+r_{t}^{R F}\right)-\log \left(1+\overline{r^{R F}}\right)$, and $\widetilde{\Phi}_{t} \equiv \log \left(1-\delta_{t}\right)-\log (1-\bar{\delta})$. Finally, we define an auxiliary constant, the steady-state fiscal deficit, given by $\Upsilon \equiv(1-\bar{\delta}) \frac{\bar{B}}{\overline{\bar{\Pi}}}+\bar{G}+\bar{Z}-\bar{T}$. Beware that $\bar{\delta}$ is regime-specific.

\section{B.2.1}

\section{Equations}

We start by listing the exogenous processes.

$$
\begin{array}{r}
\widetilde{a}_{t}=\rho_{A} \widetilde{a}_{t-1}+\sigma_{A} \varepsilon_{t}^{A}-\mathbb{1}_{B_{t-1}>\mathcal{B}_{t}} \delta^{\mathrm{TFP}} \\
\widetilde{g}_{t}=\rho_{G G} \widetilde{g}_{t-1}+\rho_{G Y} \widetilde{y}_{t-1}+\sigma_{G} \varepsilon_{t}^{G} \\
\widetilde{\mathcal{M}}_{t}=\rho_{\mathcal{M}} \widetilde{\mathcal{M}}_{t-1}+\sigma_{\mathcal{M}} \varepsilon_{t}^{\mathcal{M}} \\
\widetilde{\beta}_{t}=\rho_{\beta} \widetilde{\beta}_{t-1}+\sigma_{\beta} \varepsilon_{t}^{\beta}
\end{array}
$$

Now, we list the endogenous equations for any given monetary policy rule.

$$
\begin{array}{r}
\widetilde{\mathrm{mc}}_{t}=\widetilde{w}_{t}-\widetilde{a}_{t}-\gamma^{G \Psi} \widetilde{g}_{t} \\
(\mathrm{~B}-33) \\
\widetilde{w}_{t}=\frac{\bar{\tau}}{1-\bar{\tau}} \widetilde{\tau}_{t}+\chi \widetilde{n}_{t} \\
(\mathrm{~B}-34) \\
\widetilde{y}_{t}=\widetilde{a}_{t}+\gamma_{G \Psi} \widetilde{g}_{t}+\widetilde{n}_{t} \\
(\mathrm{~B}-35) \\
\widetilde{\Pi}_{t}=\frac{\theta}{\phi^{C}} \widetilde{\mathrm{mc}}_{t}+\beta \mathbb{E}_{t} \widetilde{\Pi}_{t+1} \\
(\mathrm{~B}-36) \\
\widetilde{y}_{t}=\frac{\bar{C}}{\bar{Y}} \widetilde{c}_{t}+\frac{\overline{\bar{G}}}{\bar{Y}} \widetilde{g}_{t}
\end{array}
$$




$$
\begin{array}{r}
\widetilde{m}_{t, t+1}=-\widetilde{R}_{t}^{R F} \\
(\widetilde{B}-38) \\
\widetilde{R^{R F}} t=\frac{\overline{C^{R}}}{\Upsilon}\left(\mathbb{E}_{t} \widetilde{c}_{t+1}-\widetilde{c^{R}}{ }_{t}\right)+\alpha_{G} \frac{\bar{G}}{\Upsilon}\left(\mathbb{E}_{t} \widetilde{g}_{t+1}-\widetilde{g}_{t}\right)-\eta \frac{\bar{N}^{\chi+1}}{\Upsilon}\left(\mathbb{E}_{t} \widetilde{n}_{t+1}-\widetilde{n}_{t}\right)
\end{array}
$$

$$
\widetilde{R^{G o v}}{ }_{t}=\widetilde{R^{R F}}{ }_{t}+\mathbb{E}_{t} \widetilde{\Pi}_{t+1}+\mathbb{E}_{t} \widetilde{\Phi}_{t+1}
$$

$$
\widetilde{R}_{t}^{i}=\phi^{i} \widetilde{R}_{t-1}^{i}+\left(1-\phi^{i}\right) \widetilde{R}_{t}^{\bar{\imath}}+\left(1-\phi^{i}\right) \phi^{\pi} \widetilde{\Pi}_{t}+\left(1-\phi^{i}\right) \phi^{y} \widetilde{y}_{t}+\mathcal{M}_{t}
$$

$$
\widetilde{b}_{t}=\widetilde{R}_{t}{ }_{t}+\frac{(1-\bar{\delta}) \bar{B}}{\Upsilon \bar{\Pi}}\left(\left(1-\delta_{t}\right) \widetilde{b}_{t-1}-\widetilde{\Pi}_{t}\right)+\frac{\bar{G}}{\Upsilon} \widetilde{g}_{t}+\frac{\bar{Z}}{\Upsilon} \widetilde{z}_{t}+\frac{\bar{T}}{\Upsilon} \widetilde{t}_{t}
$$

$$
\delta_{t}=\mathbb{1}_{B_{t-1}>\mathcal{B}_{t}} \bar{\delta}
$$

$$
\widetilde{\tau}_{t}=\mathbb{1}_{\mathbb{E}_{t} \tau_{t+1}>\tau^{\max }} \tau^{\max }+\left(1-\mathbb{1}_{\mathbb{E}_{t} \tau_{t+1}>\tau^{\max }}\right)\left[\rho_{\tau} \widetilde{\tau}_{t-1}+\gamma_{\tau}\left(\widetilde{b}_{t-1}-\widetilde{y}_{t-1}\right)\right]
$$

$$
\widetilde{t}_{t}=\widetilde{\tau}_{t}+\widetilde{y}_{t}
$$

$$
\widetilde{z}_{t}=0
$$

$$
\begin{aligned}
& \frac{\overline{C^{N R}}}{\overline{C^{N R}}-\bar{Z}} \widetilde{c}^{N R} t=\frac{\overline{C^{N R}}}{\overline{C^{N R}}-\bar{Z}} \widetilde{z}_{t}-\frac{\bar{\tau}}{1-\bar{\tau}} \widetilde{\tau}_{t}+\widetilde{w}_{t}+\widetilde{n}_{t} \\
& \widetilde{c}_{t}=\left(1-\gamma^{N R}\right) \frac{\overline{C^{R}}}{\bar{C}} \widetilde{c}_{t}+\gamma^{N R} \frac{\overline{C^{N R}}}{\bar{C}} \widetilde{c}^{N R}{ }_{t}
\end{aligned}
$$

The intercepts of the four monetary policy rules are approximated, in order, as follows. Note that $\overline{\bar{\imath}}$ varies, as it is specific to each rule.

$$
\text { Rule 1: } \quad{\widetilde{R^{\bar{\tau}}}}_{t}=\frac{\overline{r^{R F}}}{\overline{\bar{\iota}}} \widetilde{R^{R F}}{ }_{t}
$$

Rule 2: $\quad \widetilde{R^{\bar{\iota}}}{ }_{t}=\frac{\overline{r^{R F}}}{\overline{\bar{\iota}}} \widetilde{R^{R F}}{ }_{t}+\frac{\bar{\Phi}}{\overline{\bar{\iota}}} \mathbb{E}_{t} \widetilde{\Phi}_{t+1}$

$$
\text { Rule 3: } \quad{\widetilde{R^{\bar{\iota}}}}_{t}=\frac{\overline{r^{R F}}}{\overline{\bar{\iota}}} \widetilde{R^{R F}}{ }_{t}
$$

$$
\text { Rule 4: } \quad \widetilde{R}_{t}^{\bar{\imath}}=\frac{\overline{r^{R F}}}{\overline{\bar{\iota}}} \widetilde{R^{R F}}{ }_{t}+\frac{\bar{\Phi}}{\overline{\bar{\iota}}} \mathbb{E}_{t} \widetilde{\Phi}_{t+1}
$$

As the policy asset may be defaultable or not depending on the policy 
rule, the relation between $\widetilde{R^{i}}$ and $\widetilde{R^{G o v}}{ }_{t}$ also depends on the policy rule.

$$
\begin{aligned}
& \text { Rules 1, } 2 \text { and } 4: \quad \widetilde{R}^{i}=\widetilde{R^{\text {Gov }}}{ }_{t} \\
& \text { Rule 3: } \quad \widetilde{R}_{t}^{i}=\widetilde{R^{R F}}{ }_{t}+\mathbb{E}_{t} \widetilde{\Pi}_{t+1}
\end{aligned}
$$

Finally, we express the default premium, $\widetilde{\Phi}_{t+1}$, as a linear function of the probability of reaching the fiscal limit, which, by its turn, is expressed as a linear function of the state variables that go into the fiscal limits computation and $\widetilde{b}_{t}$, where $\beta_{\mu a}, \beta_{\mu g}, \beta_{\sigma a}, \beta_{\sigma g}, \beta_{p 0}, \beta_{p b}, \beta_{p a}$, and $\beta_{p g}$ are parameters calibrated from the estimated fiscal limits. To simplify notation, we define an auxiliary constant $\Upsilon^{\mathrm{FL}} \equiv \frac{1}{1+e^{-\beta_{p 0}+\beta_{p b}\left(\bar{B}-\overline{\mu^{\mathrm{FL}}}\right)}}$.

$$
\begin{array}{r}
\widetilde{\Phi}_{t+1}=\widetilde{\delta} \widetilde{\operatorname{Pr}}\left(B_{t}>\mathcal{B}_{t+1}\right)_{t} \\
\widetilde{\mu^{\mathrm{FL}}}{ }_{t}=\beta_{\mu a} \widetilde{a}_{t}+\beta_{\mu g} \widetilde{g}_{t} \\
\widetilde{\sigma^{\mathrm{FL}}}{ }_{t}=\beta_{\sigma a} \widetilde{a}_{t}+\beta_{\sigma g} \widetilde{g}_{t} \\
\widetilde{\operatorname{Pr}}\left(B_{t}>\mathcal{B}_{t+1}\right)_{t}=-\Upsilon^{\mathrm{FL}}\left(\beta_{p b}\left(\widetilde{b}_{t}-\widetilde{\mu^{\mathrm{FL}}}{ }_{t}\right)+\beta_{p a} \widetilde{a}_{t}+\beta_{p g} \widetilde{g}_{t}\right)
\end{array}
$$




\section{B.3}

\section{Estimation of the single-regime model}

For calibrating the shock parameters of our model, we conduct a Bayesian estimation of its single-regime linearized version with only risk-free policy assets (non-linearities do not and are never expected to bind) and flexible prices. Hereafter, for any variable $X, X^{o b s}$ is its observed time series. The data sample covers the period between 1999Q3 and 2019Q4, encompassing 82 observation periods.

For $Y^{o b s}, C^{o b s}, G^{o b s}$, we use the log-difference of the quarterly deseasonalized real series calculated by the IBGE. For $\pi^{o b s}$, we turn the IPCA MoM\% series from the IBGE into an index, aggregate it quarterly, and then subtract the fourth root of each year's yearly gross inflation target subtracted by $1 .^{2}$ For $i^{\text {obs }}$, we aggregate the quarterly mean of both the daily Selic series (from the BCB) and the daily 3-month Swap Pre x DI series (from the B3). Then, we splice both series, using the latter whenever available. Once we have collected our 5 series, $\left(Y^{o b s}, C^{o b s}, G^{o b s}, \pi^{o b s}, i^{o b s}\right)$, we demean all of them by the sample mean.

Table B.1 displays the summary statistics of the sample, and Figure B.1 exhibits the series before demeaning. Moreover, (B-59) shows the measurement equations that are appended to the model, where, for any variable $X, X^{\text {det }}$ is the respective detrended series. We incorporate a measurement error of output, $\varepsilon_{t}^{m e, Y}$, to mitigate the misspecification problem of modeling an open-economy as a closed one. For estimation, we turn on the structural shocks $\varepsilon_{t}^{A}, \varepsilon^{\beta}, \varepsilon^{G}$, and $\varepsilon^{M}$.

$$
\left(\begin{array}{c}
Y_{t}^{\text {obs }} \\
C_{t}^{\text {obs }} \\
G_{t}^{\text {obs }} \\
\pi_{t}^{\text {obs }} \\
i_{t}^{\text {obs }}
\end{array}\right) \stackrel{\text { det }}{\longrightarrow}\left(\begin{array}{c}
Y_{t}^{\text {det }} \\
C_{t}^{\text {det }} \\
G_{t}^{\text {det }} \\
\pi_{t}^{\text {det }} \\
i_{t}^{\text {det }}
\end{array}\right)=\left(\begin{array}{c}
\log \left(Y_{t} / Y_{t-1}\right) \\
\log \left(C_{t} / C_{t-1}\right) \\
\log \left(G_{t} / G_{t-1}\right) \\
\pi_{t} \\
\left(1+i_{t}\right)^{4}-1
\end{array}\right)+\left(\begin{array}{c}
\varepsilon_{t}^{m e, Y} \\
0 \\
0 \\
0 \\
0
\end{array}\right)
$$

${ }^{2}$ Net inflation targets: in $1999,8 \%$; in $2000,6 \%$; in $2001,4 \%$; in $2002,3.5 \%$; in 2003, 4\%; in 2004, 5.5\%; from 2005 to 2018, 4.5\%; and in 2019, 4.25\%. For 2003 and 2004, the inflation targets originally announced were amended in the year before they should become effective, so we use the amended values. Source: https://www.bcb.gov.br/controleinflacao/historicometas 


\begin{tabular}{lccccc}
\hline \hline & $Y_{t}^{\text {obs }}$ & $C_{t}^{\text {obs }}$ & $G_{t}^{\text {obs }}$ & $\pi_{t}^{\text {obs }}$ & $i_{t}^{\text {obs }}$ \\
\hline Mean (\%) & 0.58 & 0.68 & 0.44 & 1.54 & 13.12 \\
Std. (\%) & 1.15 & 1.13 & 1.3 & 0.91 & 4.71 \\
AR(1) & 0.4 & 0.36 & -0.31 & 0.53 & 0.96 \\
Number of obs. & 82 & 82 & 82 & 82 & 82 \\
Start date & $1999 \mathrm{Q} 3$ & $1999 \mathrm{Q} 3$ & $1999 \mathrm{Q} 3$ & $1999 \mathrm{Q} 3$ & $1999 \mathrm{Q} 3$ \\
End date & $2019 \mathrm{Q} 4$ & $2019 \mathrm{Q} 4$ & $2019 \mathrm{Q} 4$ & $2019 \mathrm{Q} 4$ & $2019 \mathrm{Q} 4$ \\
\hline \hline
\end{tabular}

Table B.1: Summary of observables' statistics before demeaning
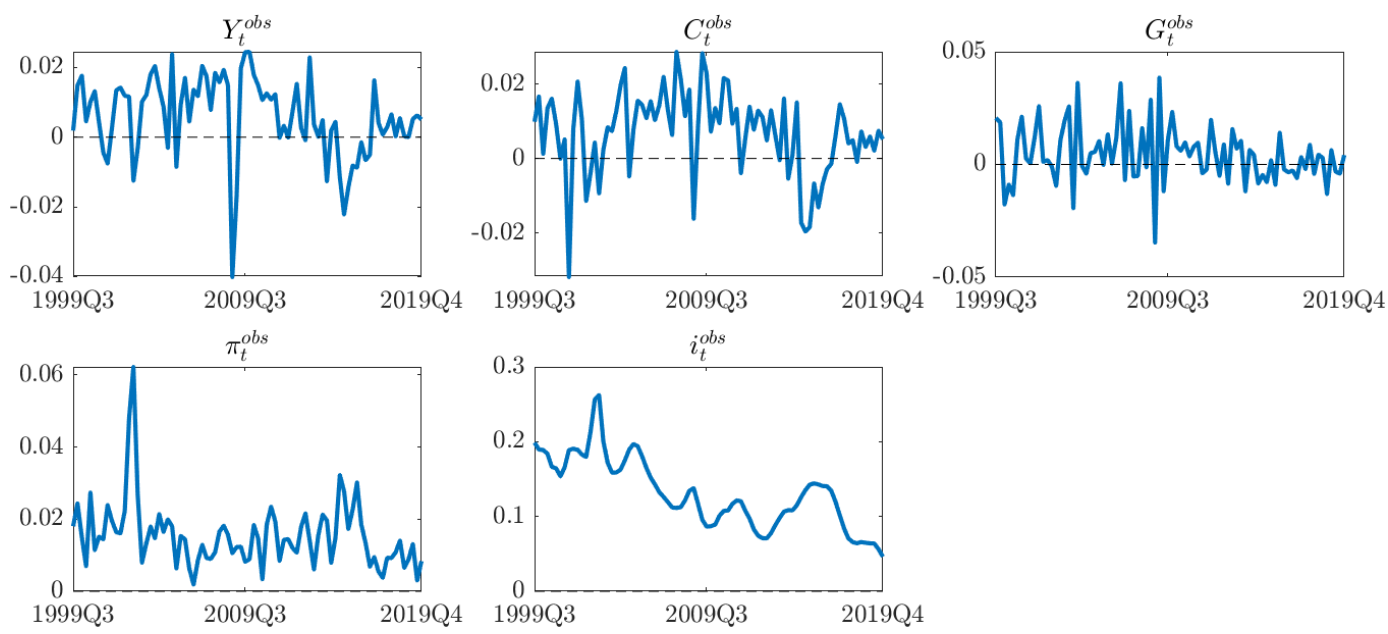

Figure B.1: Data before demeaning used for estimation

We pick for estimation 16 parameters associated with either the utility function, the spill-over of government expenses to total factor productivity, the monetary policy rule, the shock processes, or the measurement errors: $\sigma, \alpha_{G}, \gamma_{G \Psi}, \phi^{\pi}, \phi^{Y}, \phi^{i}, \rho^{A}, \rho^{\beta}, \rho^{G Y}, \rho^{G G}, \rho^{\mathcal{M}}, \sigma^{A}, \sigma^{\beta}, \sigma^{M}, \sigma^{G}, \sigma^{m e, Y}$. Consistent with recommendations in Herbst and Schorfheide (2015), we adopt beta distributions for parameters whose domain is exclusively $[0,1]$; inverse gamma distributions for the standard deviation of the shocks, and gamma distributions for other non-negative parameters; as well as normal distributions for the remaining ones. Each prior is identified by the tuple: distribution, lower bound, upper bound, and the fraction of that distribution contained between these bounds.

Before estimating the model, we linearize it, and only then we apply the Metropolis-Hastings algorithm to sample the posterior distribution of the parameters. We produce 8 Markov chains containing 200,000 draws each, where the first 20,000 draws of every chain have been dropped as burn-in. ${ }^{3}$

\footnotetext{
${ }^{3}$ The optimization algorithm is MATLAB's fmincon. All Markov chains have acceptance ratios near $35 \%$.
} 
In Table 2.4, we summarized the estimation specification for the priors and the characteristics of the posterior we obtained.

Figure B.2 plots the prior (blue full line) vs. the posterior (red dotted line) distribution of the estimated parameters, as well as the mode (green vertical line) and the mean (black vertical line) of each posterior distribution.

FigureB.3 plots the curvature at the mode of the posterior distribution of the estimated parameters vs. their respective priors. Blue-full lines are the priors, while red-dotted ones are the posteriors.

Figure B.4 shows the convergence of the estimated parameters according to the Potential Scale Reduction Factor (PSRF) of Gelman, Rubin et al. (1992). This metric makes a comparison of within-chain and between-chain variances, where a large deviation between them indicates non-convergence. A PSRF larger than 1 indicates that the between-chain variance is substantially greater than the within-chain variance, and, therefore, longer simulations would be needed. On the contrary, if a PSRF is close to 1 , then the chains are likely to have converged.

Figure B.5 exhibits the smoothed exogenous shocks after the estimation. Figure B.6 contrasts the observed against the smoothed series of the model obtained after estimation. Figure B.7 plots the variance decomposition of the observed variables into each exogenous shock contribution according to the estimated model. In each panel, the decomposition is carried on for the first 40 periods and for the long-run. 

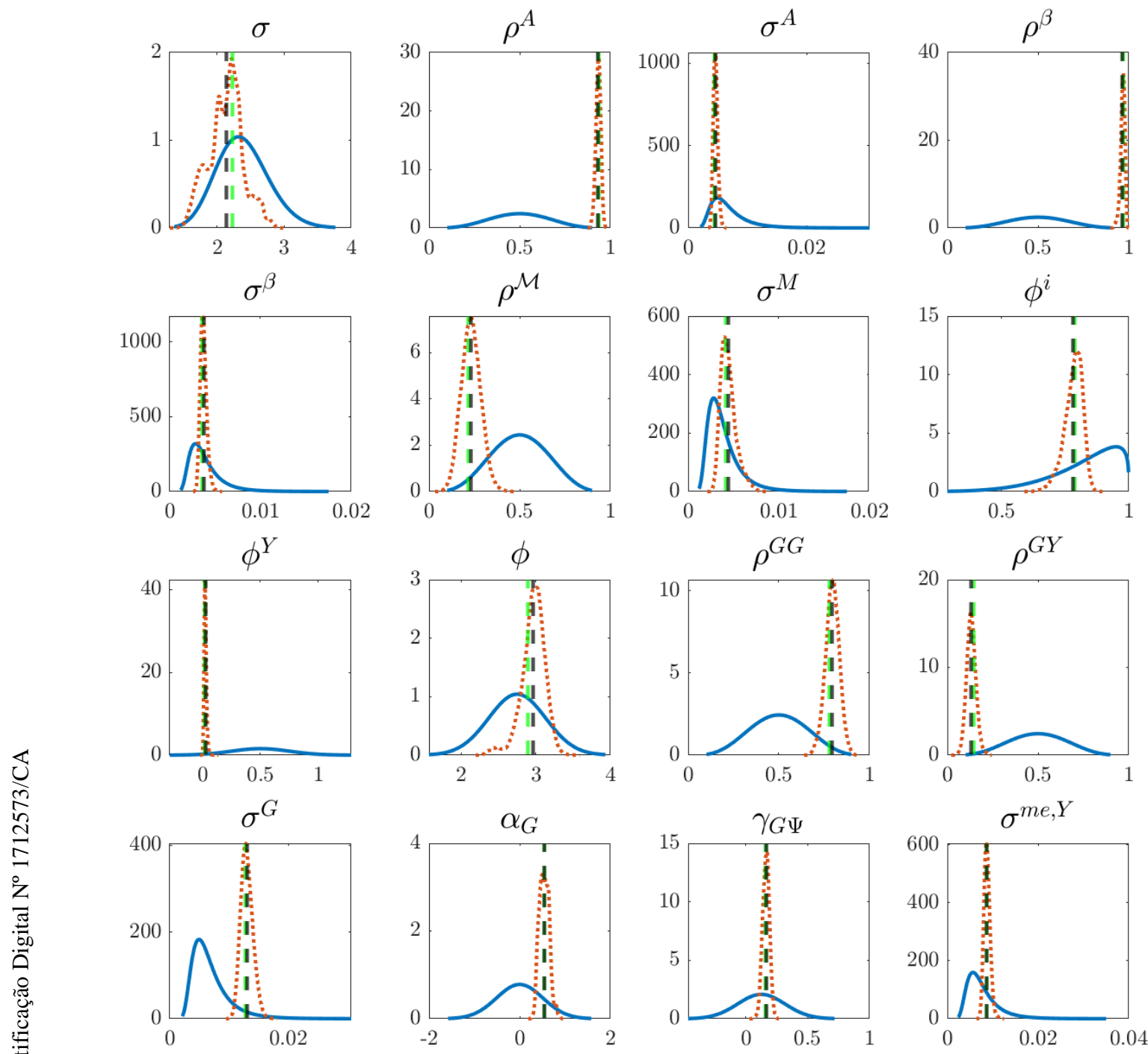

Figure B.2: Prior and posterior distributions of estimated parameters 

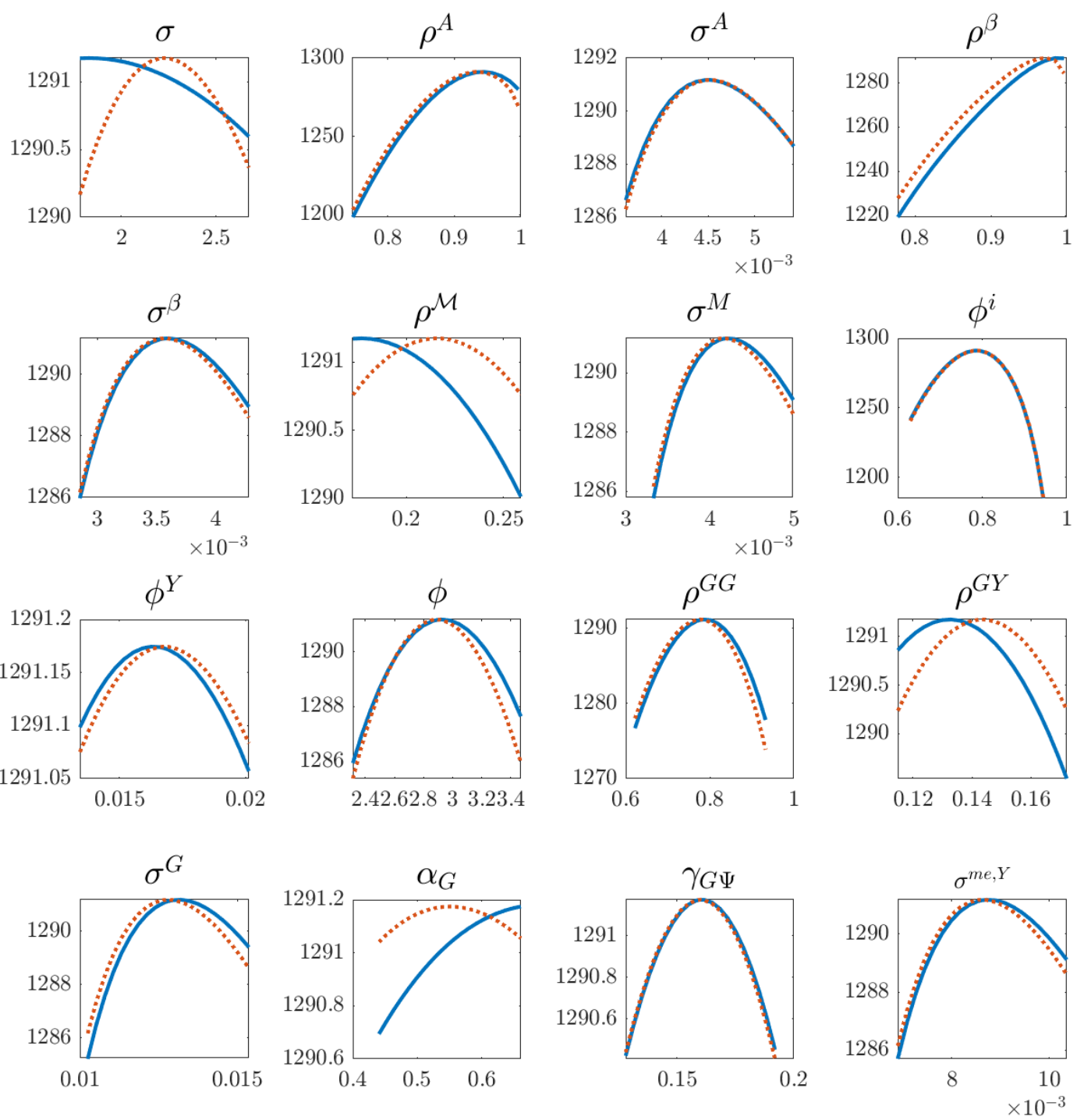

Figure B.3: Curvature at the mode of the posterior distribution of the estimated parameters 


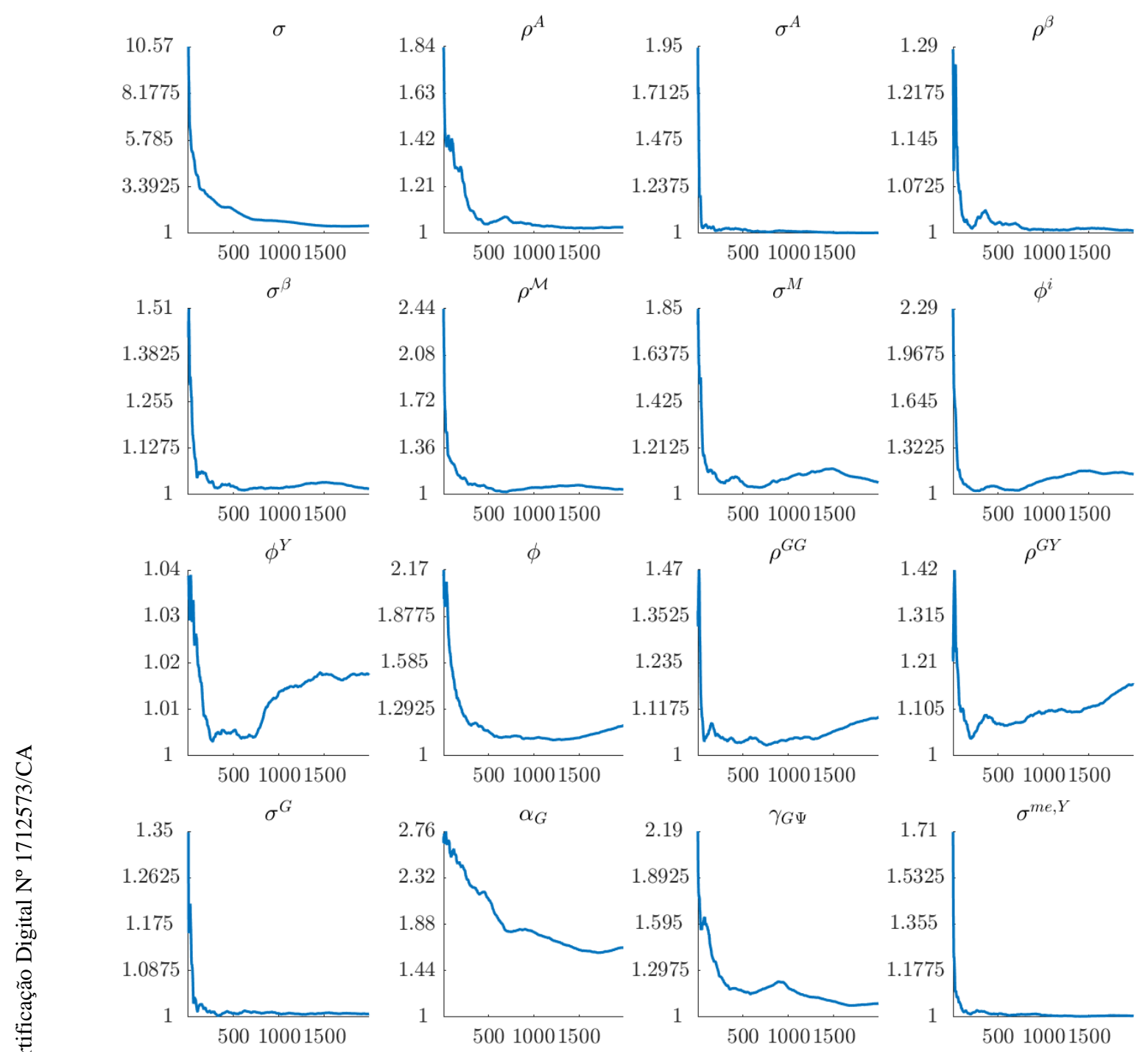

Figure B.4: PSRF of the estimated parameters
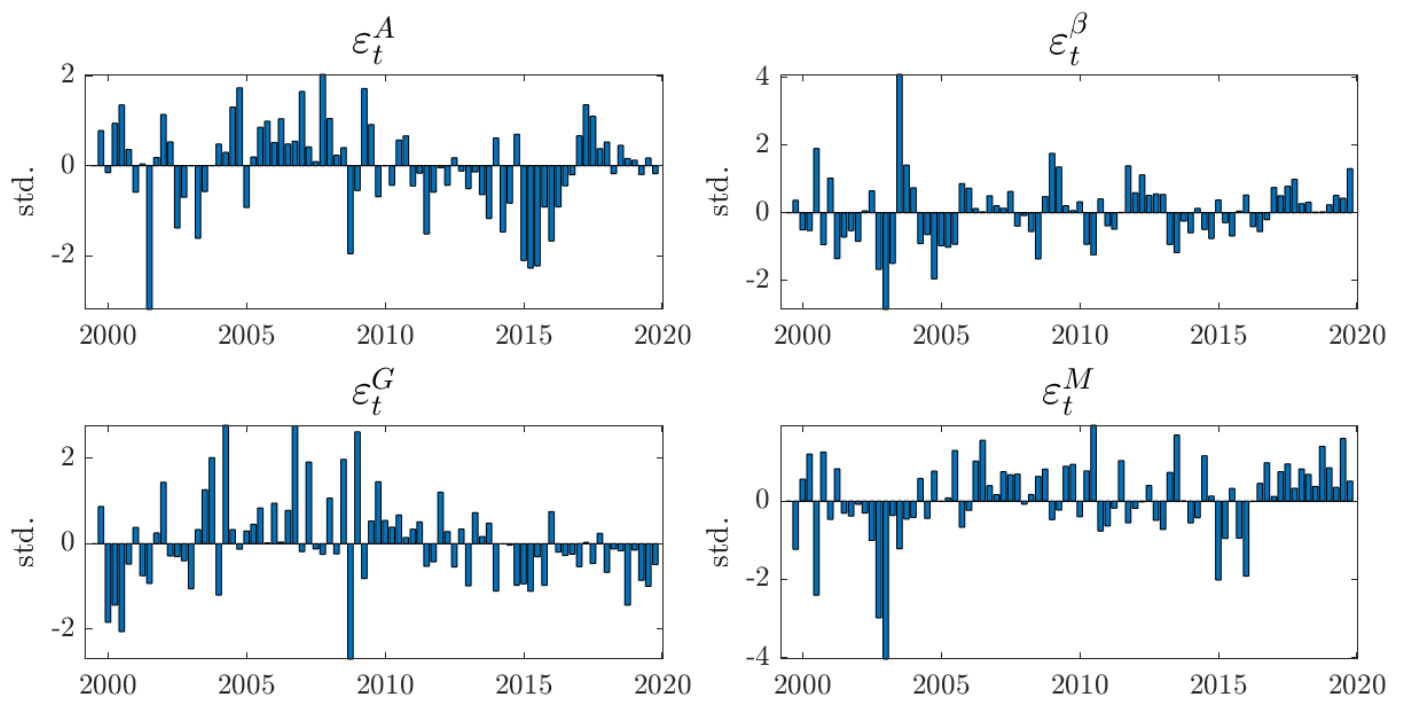

Figure B.5: Smoothed shocks from the estimated model 

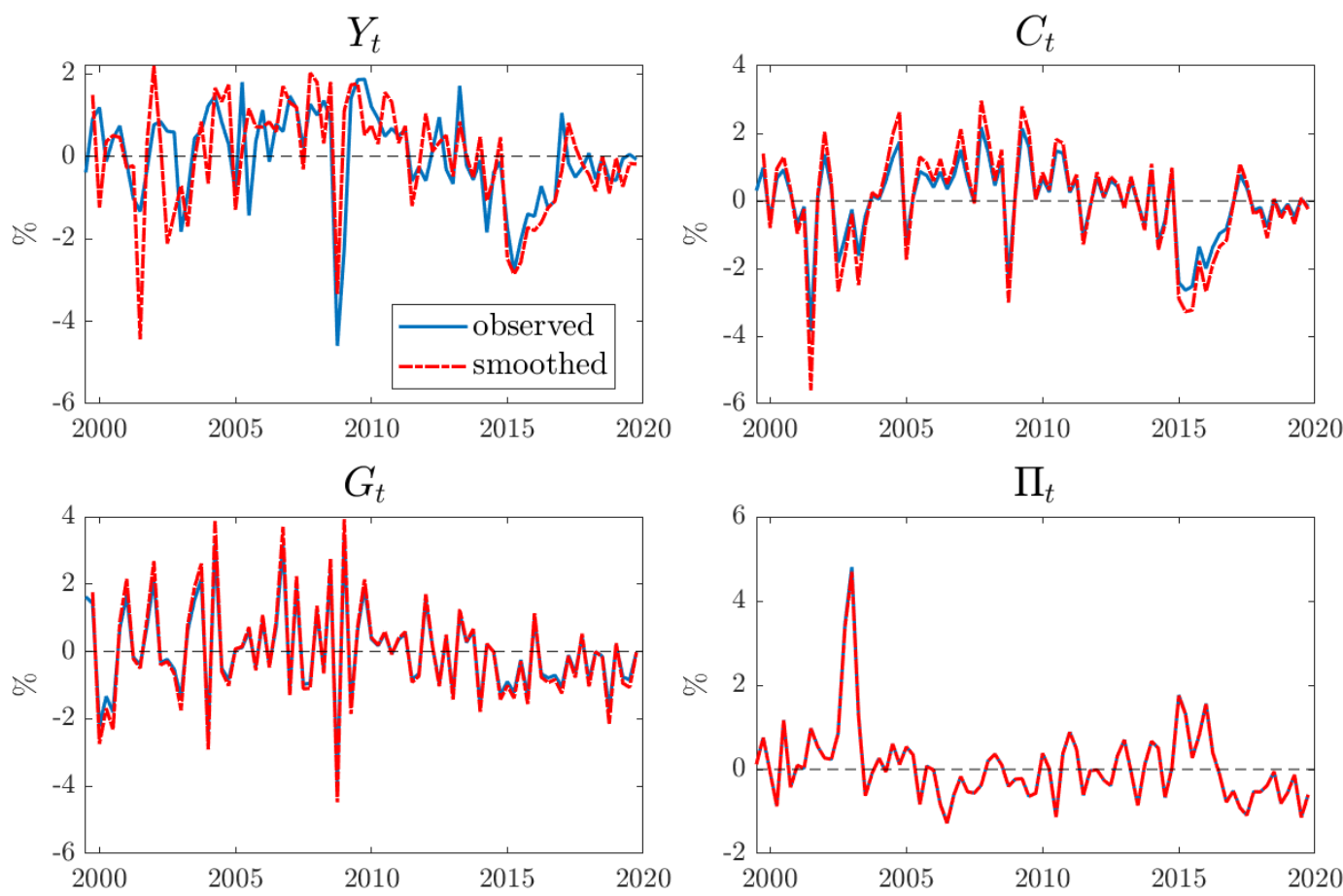

Uू

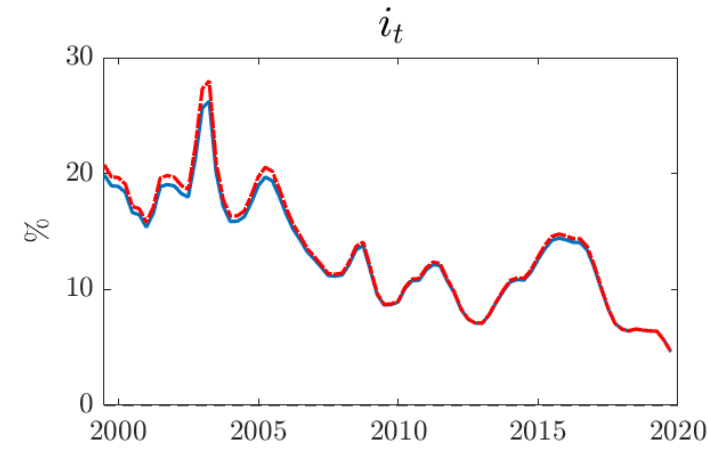

Figure B.6: Observed and smoothed variables after estimation 

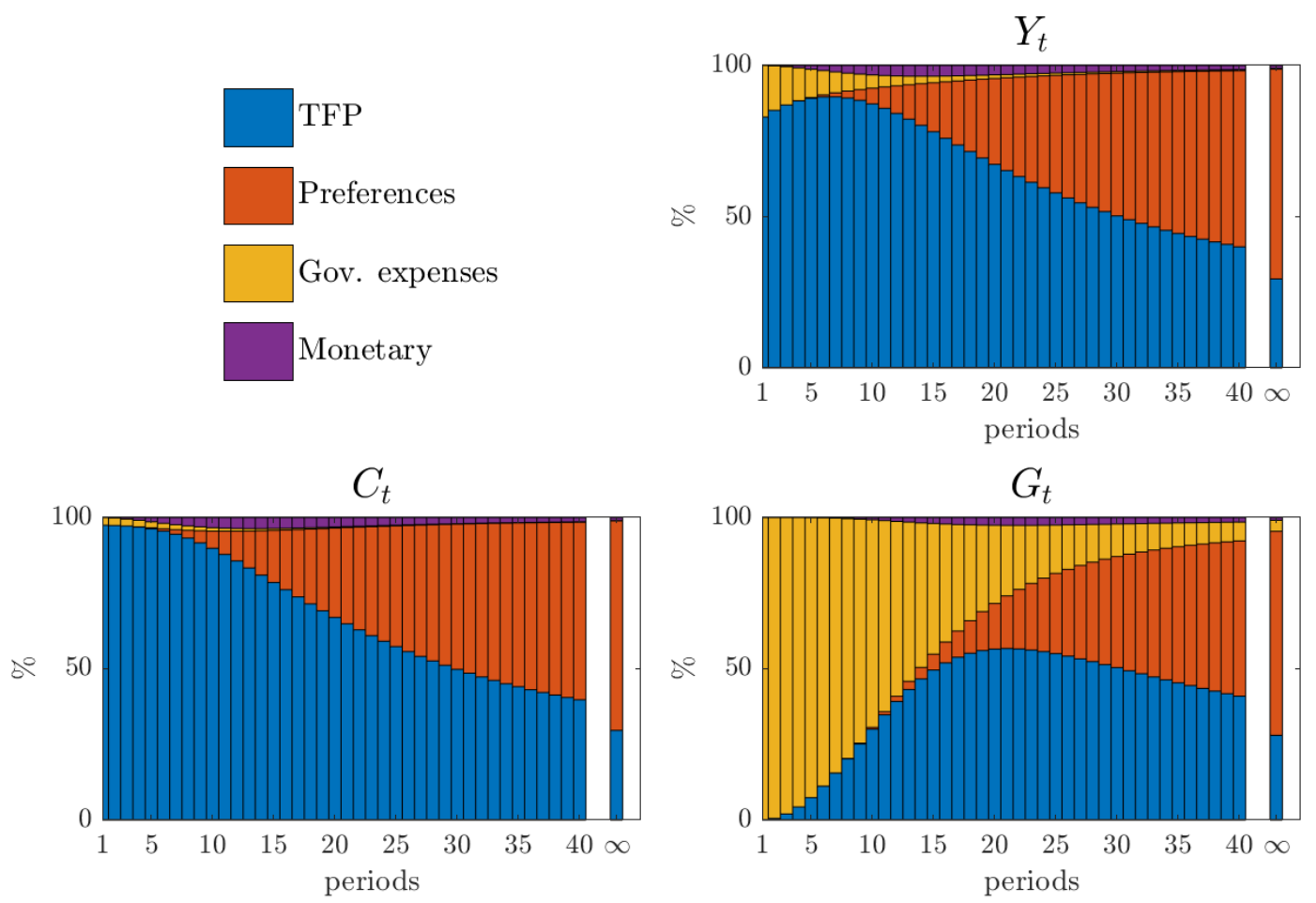

Uू.
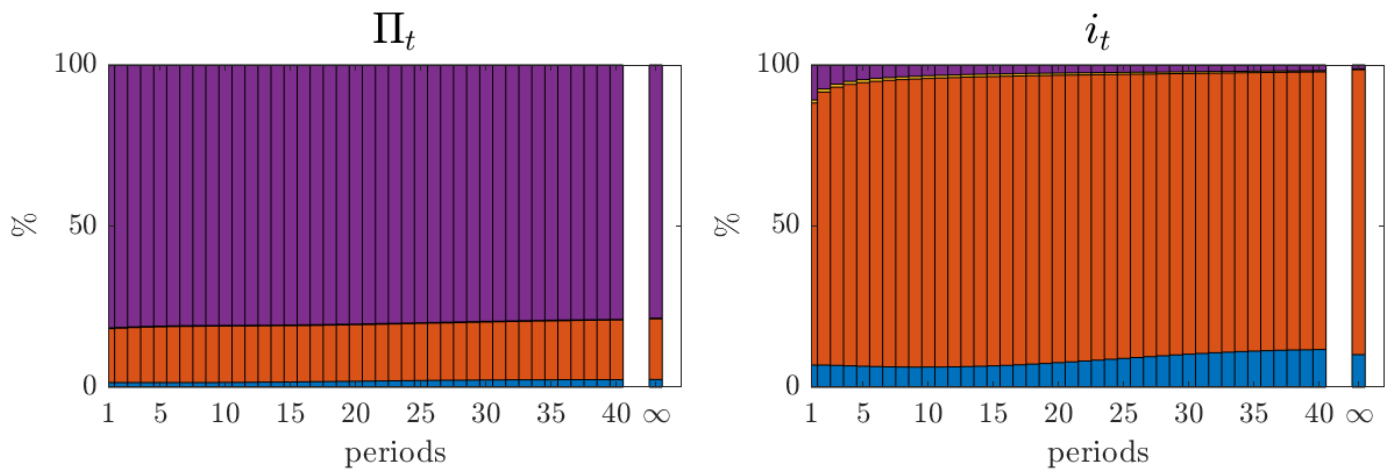

Figure B.7: Variance decomposition of the estimated model 


\section{B.4 Policy rules and stability}

We conduct a numerical exercise so as to obtain the parameter range in which a solution exists. This approach is warranted since the stability of regime-switching models with endogenous transition probabilities is still an open question in the literature. Barthélemy and Marx (2017) provide for conditions under which a unique bounded equilibrium exists in such models, guaranteeing local determinacy, but their approach is limited to the case of small shocks and smooth transition probabilities between regimes. The latter is violated in our model since the peak of the Laffer curve is an occasionally binding constraint whose transition probability is not modeled as a smooth function.

Our approach consists in numerically testing whether the solution algorithm is able to find any solution for different combinations of parameter values for $\phi^{\pi}$ and $\gamma_{\tau}$ under each policy rule. To highlight the importance of having risk in the policy asset, we test both the benchmark calibration and an alternative scenario in which the debt level is consistent with a $5 \%$ probability of sovereign default at the steady state. Additionally, to simplify the analysis, we turn off the interest rate smoothing and the reaction to output deviations from the steady state in the policy rules. We apply the Mean Squared Stability criterion of Costa, Fragoso and Marques (2006) to distinguish between what we call "stable" and "unstable" solutions. Although this is a method that only applies to regime-switching with constant transition probabilities, heuristically, we note that this may be helpful in mapping the parameter spaces in which finding a solution is dodgy and the likelihood that simulations diverge increases. ${ }^{4}$ Above all, one must remember that finding a solution here is no guarantee that it is unique. Therefore, we leave a rigorous definition of active/passive fiscal and monetary policy under endogenous regime-switching for future research. Hereafter, they will be only loosely located in the parameter space.

In constant parameter models, solution is stable as long as fiscal and monetary policy stances are mismatched à la Leeper (1991). ${ }^{5}$ Fiscal dominance

${ }^{4}$ We thank Junior Maih for sharing with us his considerations on the topic.

${ }^{5}$ As Leeper (1991) defines: "parameters associated with active behavior make policy unresponsive to current budgetary conditions and parameters connected with passive behavior force the authority to use its tax to balance the budget". "Tax" is understood here as inflation in the case of the monetary authority. With respect to this paper's model, contrary to what happens in Leeper (1991), fiscal disturbances may influence equilibrium prices and interest rates depending on the central bank's policy rule, but this happens through default risk, not in reason of the impossibility of stabilization of the debt level otherwise, since we limit our exploration to the combination of active monetary policy and passive fiscal policy. Besides, as default probability grows with the size of the debt, it also helps to rule out, at least some, explosive trajectories for the debt level. 
will operate in the third quadrant, while monetary one takes place in the first quadrant. No solution exists when both policies are active because independent variations in both violate the government's budget constraint. Multiple equilibria exist when both policies are passive, though. Figures B.8 and B.9 plot the two policy rules, ignoring the evolution of default risk and accounting for it, respectively, both under the benchmark calibration, $\overline{\mathcal{D}} \approx 0 \%$. Note that the parameter space of monetary dominance is amplified beyond the Taylor Principle and fiscal policy only needs to be slightly passive for the system to be solved. As steady-state default probability rises, stability conditions change dramatically. Figures B.10 and B.11 plot the same rules under $\overline{\mathcal{D}}=5 \%$. Violating the Taylor principle turns out more critical, while fiscal policy is demanded to react more strongly to deviations from the steady-state debt level, considerably shrinking the parameter space of stability. Overall, we can see in all figures that matching either active monetary policy with passive fiscal policy or passive monetary policy with active fiscal policy is a sufficient condition for the stability of the model under any of the presented rules.

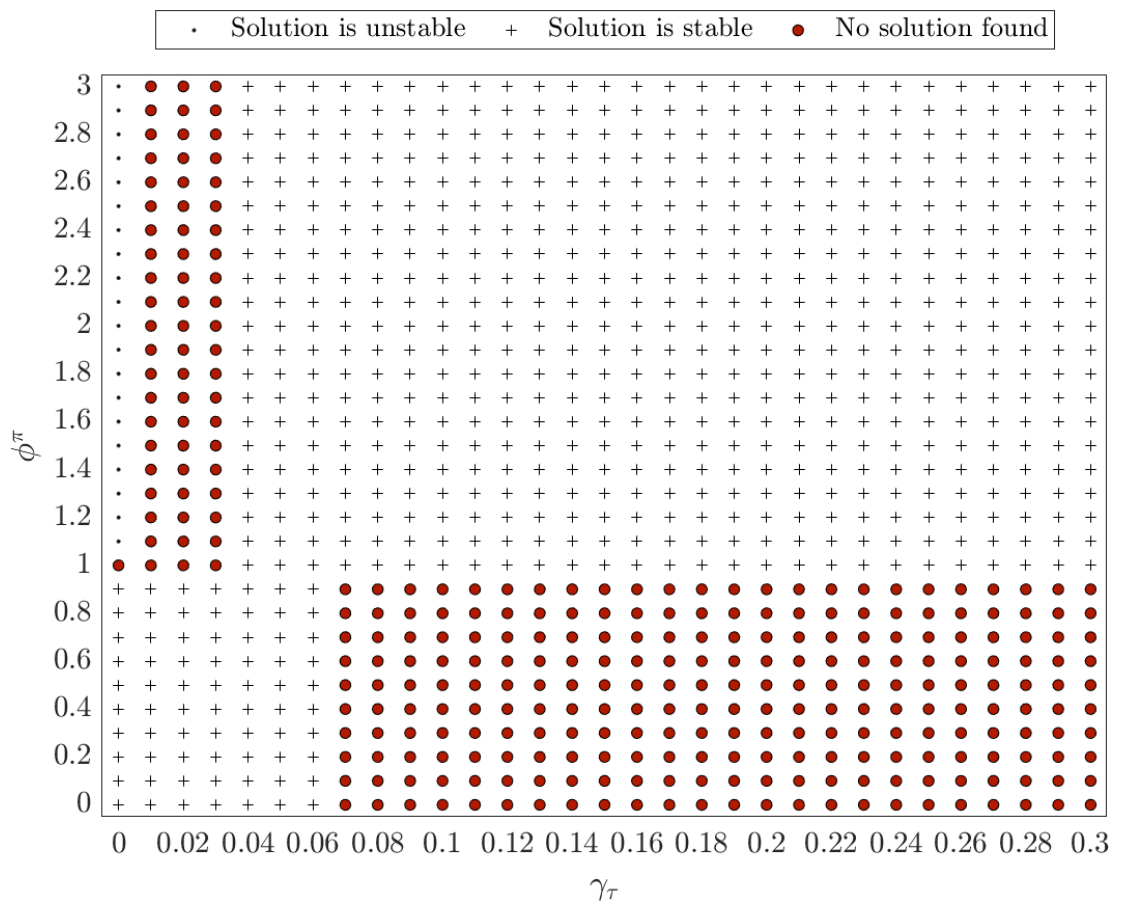

Note: In the lack of an adequate stability criterion for regime-switching models with endogenous transition probabilities, we rely on the Mean Squared Stability criterion of Costa, Fragoso and Marques (2006).

Figure B.8: Parameter stability: policy instrument is risky, but CB targets $r_{t}^{R F}$ under $\overline{\mathcal{D}}=0 \%$ 


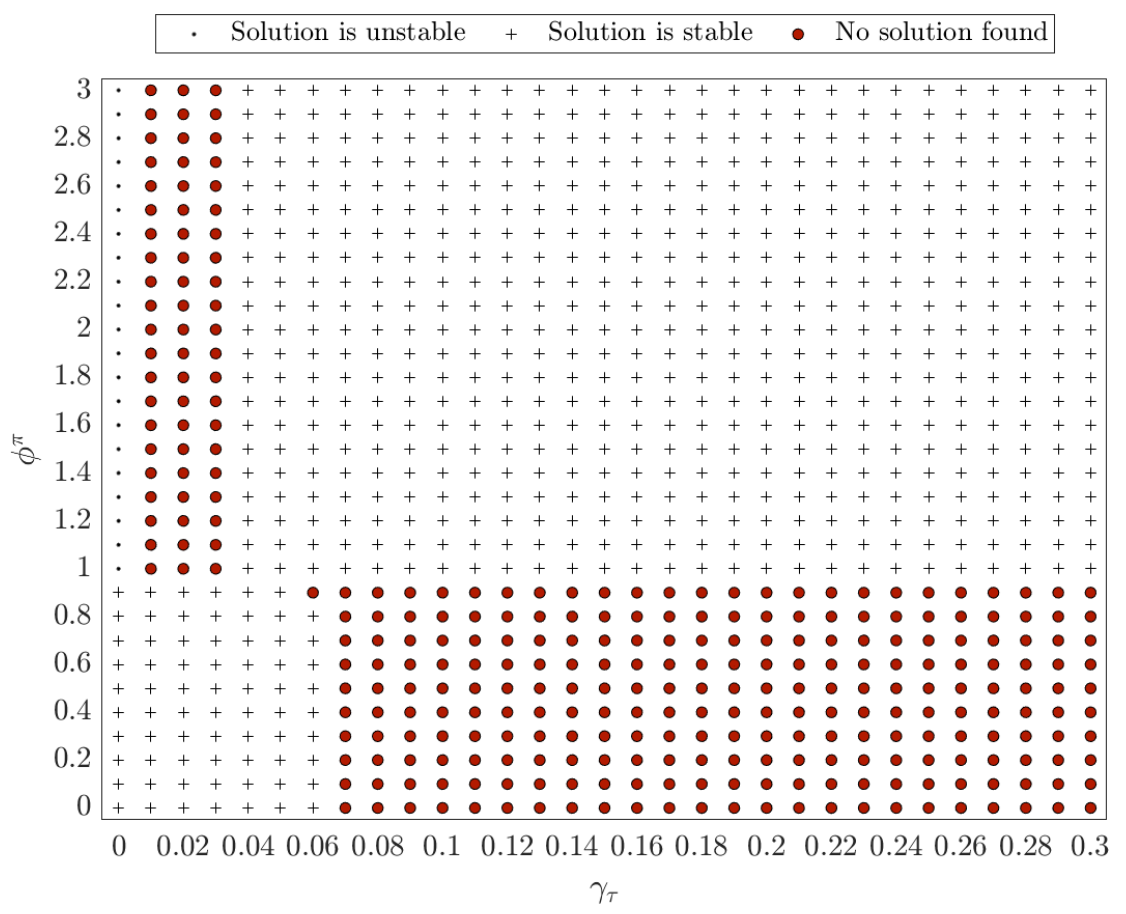

Note: In the lack of an adequate stability criterion for regime-switching models with endogenous transition probabilities, we rely on the Mean Squared Stability criterion of Costa, Fragoso and Marques (2006).

Figure B.9: Parameter stability: policy instrument is risky, and CB targets the risky rate under $\overline{\mathcal{D}}=0 \%$ 


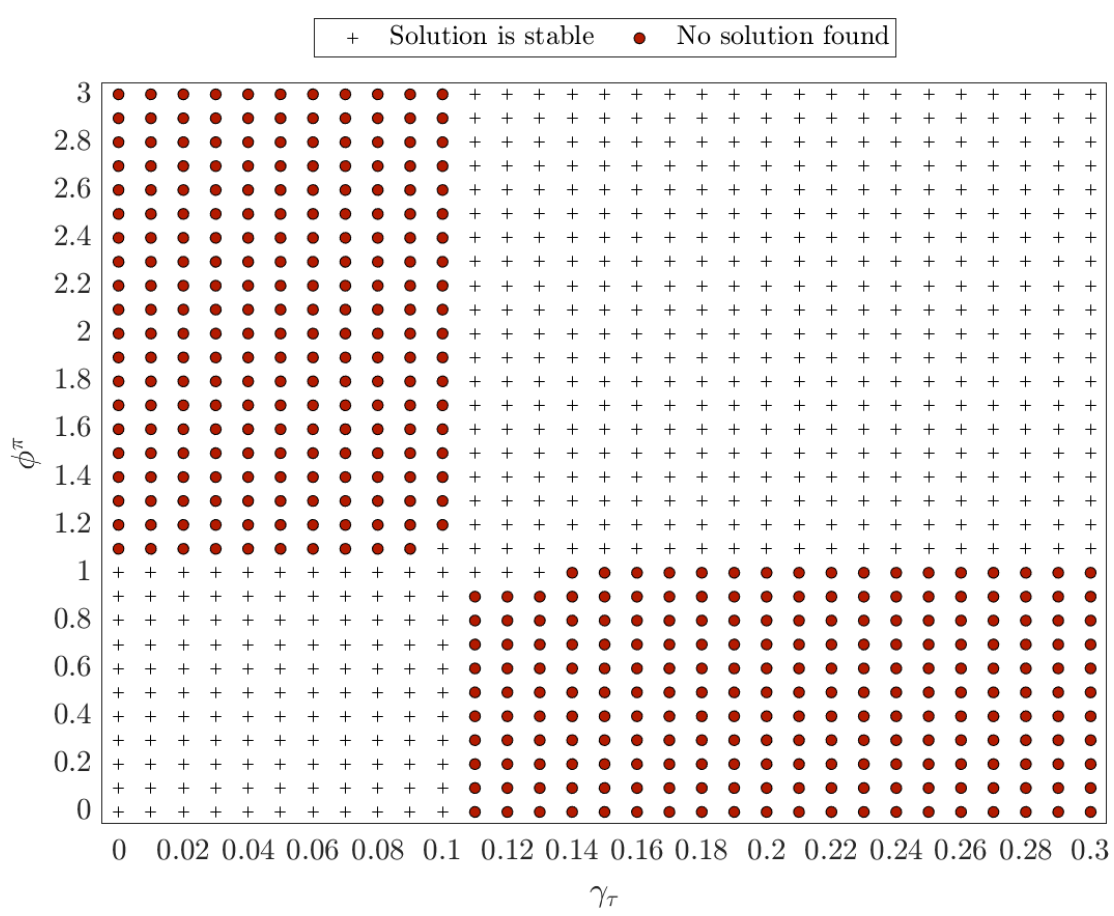

Note: In the lack of an adequate stability criterion for regime-switching models with endogenous transition probabilities, we rely on the Mean Squared Stability criterion of Costa, Fragoso and Marques (2006).

Figure B.10: Parameter stability: policy instrument is risky, but CB targets $r_{t}^{R F}$ under $\overline{\mathcal{D}}=5 \%$ 


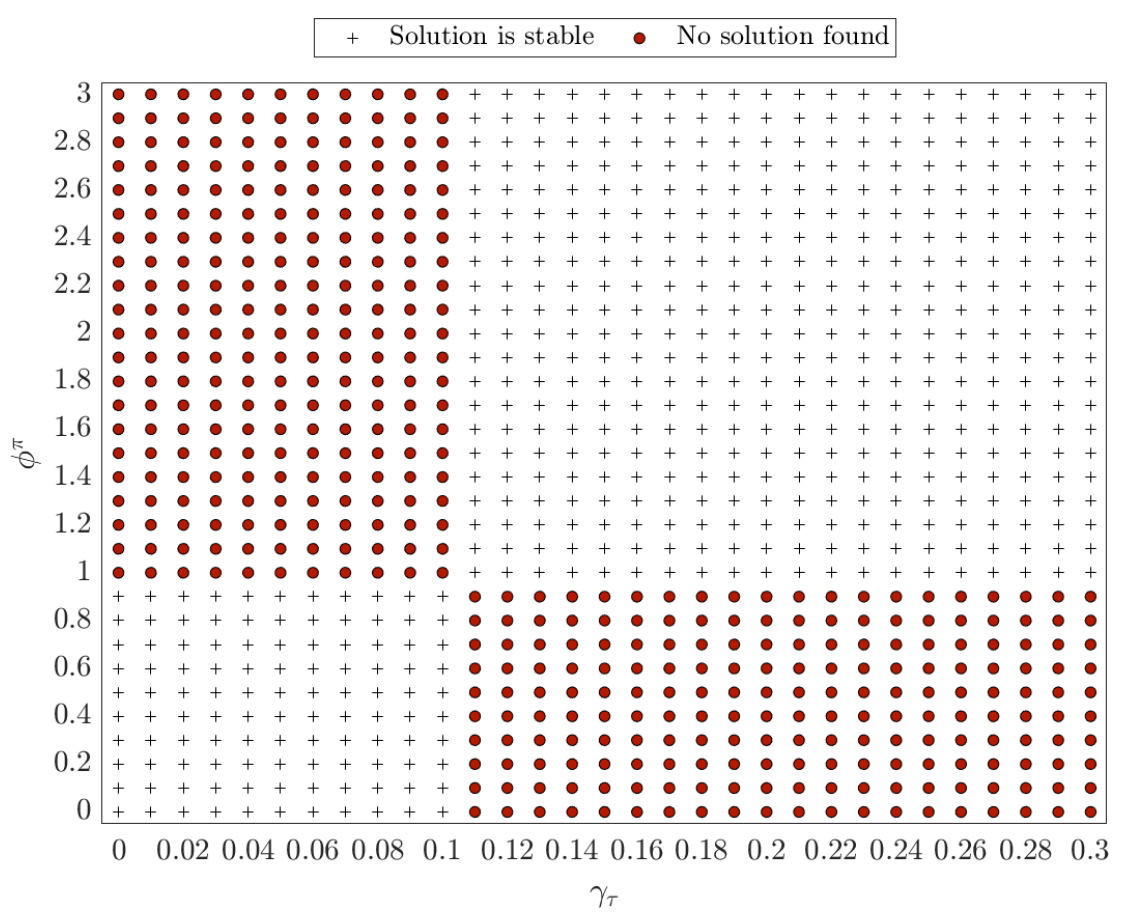

Note: In the lack of an adequate stability criterion for regime-switching models with endogenous transition probabilities, we rely on the Mean Squared Stability criterion of Costa, Fragoso and Marques (2006).

Figure B.11: Parameter stability: policy instrument is risky, and CB targets the risky rate under $\overline{\mathcal{D}}=5 \%$ 


\section{B.5 Impulse response functions}

How do the model variables react to the exogenous shocks? To answer that question, we plot in Figures B.12 and B.13 the regime-specific impulse response functions for the first two regimes of selected variables $\left(Y_{t}, C_{t}, N_{t}, \frac{B_{t}}{Y_{t}}, i_{t}, r_{t}, \Pi_{t}\right)$ to three different shocks $\left(\varepsilon^{A}, \varepsilon^{G}, \varepsilon^{\mathcal{M}}\right)$ under two different environments: (1) our calibrated $\bar{B}$, whose $\overline{\mathcal{D}}$ is low, at $\approx 0 \%$ (blue line); and a (2) hypothetical higher steady-state debt level whose default probability is at $1 \%$ (red-dotted line). Both environments assume the central bank adjusts the policy rule to default risk. In the figures, all variables start at their respective regime-specific non-stochastic steady-state values, and graphs display deviations from such values. To get a clearer response of monetary policy, we set $\phi^{Y}=0$ and $\phi^{i}=0$. Since, concerning the regime-specific steady state, crossing the fiscal limit only affects the haircut on the debt, which does not change fundamentally the dynamics of the model when there is no regimeswitching occurring, the same graphs for Regime 3 are similar to the ones in Regime 1, whereas the same graphs for Regime 4 are similar to the ones in Regime 2. Additionally, in Figures B.14 and B.15, we plot the regime-specific impulse response functions of, respectively, inflation and the policy rate in the first two regimes changing the policy rules. We omit here the effect on other variables because for them the difference between the rules is negligible near the regime-specific non-stochastic steady states, whereas inflation and the policy rate already exhibit the diverging dynamics enacted by each rule. The monetary shock is the main driver of inflation in our model, a result that is explained by our monetary rules that closely track the inflation target.

With the caveat that all happens in general equilibrium, we provide, now, a rationale for the dynamics observed in the model. Under a one-standarddeviation positive TFP shock, the marginal productivity of labor increases the labor demand at the same time that higher real wages increase the labor supply, in which output increases as a result of both. Since government expenditures react only by a little and with a lag, the increment of output becomes mostly consumption for the households, whereas the consumption of the Ricardian type increases by more. The expansion of activity leads to higher tax revenues for the government, which allows that sovereign debt is reduced, what, by its turn, leads to lower tax rates given the fiscal rule of the government, what explains the behavior of Ricardian consumers. The improvement of the government's fiscal position reduces the probability of default at the next period, what reduces the real return demanded by the households to hold government bonds. Turning to prices, the reduction of real interest rates, 
generated by the fact that households are able to smooth out consumption with lower rates after the shock, decreases expected inflation, what, by its turn, reduces current prices, to which the central bank endogenously reacts by reducing the nominal interest rate according to its monetary policy rule. By comparing the two policy rules in Regime 1, tracking $r_{t}^{R F}$ leads to convergence to the inflation target from below. These results reverse in Regime 2, as higher output in reason of higher productivity is accompanied of higher government expenditures while the tax rate remains constant in that regime. As expected, adjusting the intercept to default risk is able to stabilize prices at all periods, like in the canonical case. Comparing the two environments, we have that the real sector reacts more strongly and with more persistence to the shock in the riskier set-up in reason of the more benign debt trajectory.

Under a one-standard-deviation positive shock to government expenditures, despite the positive effect over output in the short-run through the positive spill-over to productivity, the higher demand from the government will slowly weaken the latter's fiscal position, as it will lead to both higher debt accumulation and higher expected default probability. Debt growth, by its turn, will raise the tax rate given the fiscal policy rule. Higher tax rates lower the supply of labor while the demand for labor weakens given the lower aggregate demand. With eventually a lower amount of labor in equilibrium, the output must fall. Since government expenditures are mostly exogenous, it also means that less output is left for private consumption, which falls by relatively more than output. Due to the fact that prices are sticky, all this process can coexist with inflation if the central bank tracks $r_{t}^{R F}$. Under flexible prices, the results reverse and are numerically even smaller. Adjusting the intercept to default risk remains the stabilizing option for inflation. The real interest rate falls at the time of the shock, then it goes up as it is dominated by the rising debt accumulation and its effect over the default probability. Tax revenue increases, though, helping the government to recover fiscal balance in the long-run.

Finally, a positive monetary shock (a shock to the intercept of the policy rule) depresses the economy, for it has a negative effect on inflation, making it more difficult for the debt to be repaid by the government. Forward-looking agents anticipate, as a consequence, that higher taxes will be enacted by the fiscal authority into the future, leading Ricardian consumers to smooth out consumption by cutting it in the present. Note that under Regime 2 , at the peak of the Laffer curve, the monetary shock also depresses $Y_{t}, C_{t}$ and $N_{t}$, but this is purely due to sticky prices and the real interest rate channel. Under flexible prices, monetary policy is only neutral at the peak of the Laffer curve (Regimes 2 and 4), as in the other regimes its effect over the debt 
trajectory transmits to the real economy through the fiscal rule. This happens because, even though the policy rate still influences the debt accumulation by the government, the latter does not affect the tax rate in that regime, breaking the link with the incentives of the households to supply labor and their expected income. Monetary policy becomes hawkish for both policy rules, so that disinflation shows up, requiring a negative endogenous reaction of nominal interest rates. When prices are flexible, the endogenous component dominates, resulting in the reduction of $i_{t}, r_{t}$ and $\Pi_{t}$. Due to disinflation, it is harder now to roll over the stock of debt, for its real value has jumped up, pushing default probability in the same direction.

In general, the presence of positive $\overline{\mathcal{D}}$ amplifies the effect of the shocks on the debt accumulation process, what, by its turn, makes it more persistent on the real economy. 

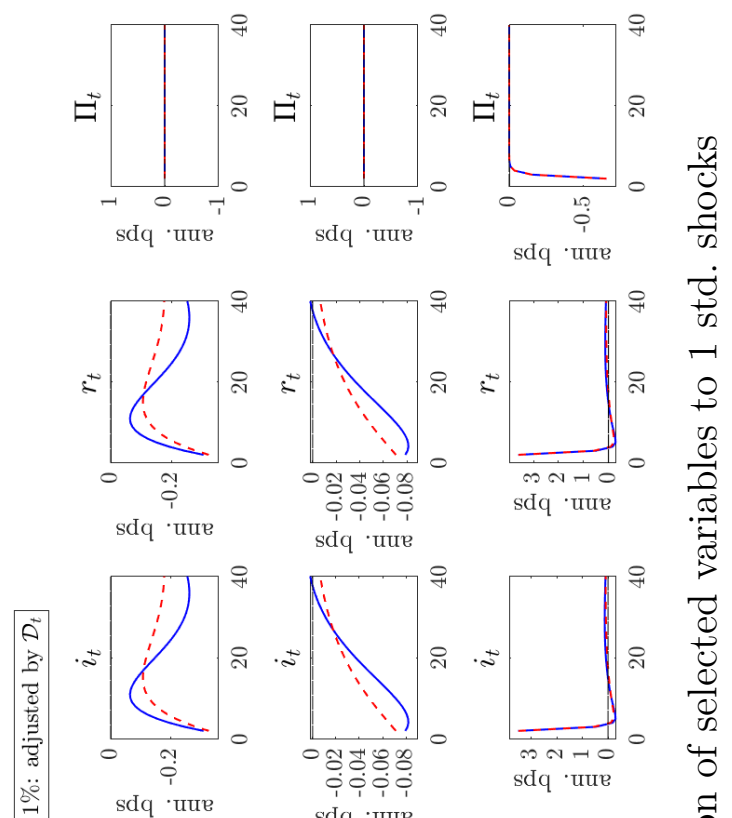

Uీ
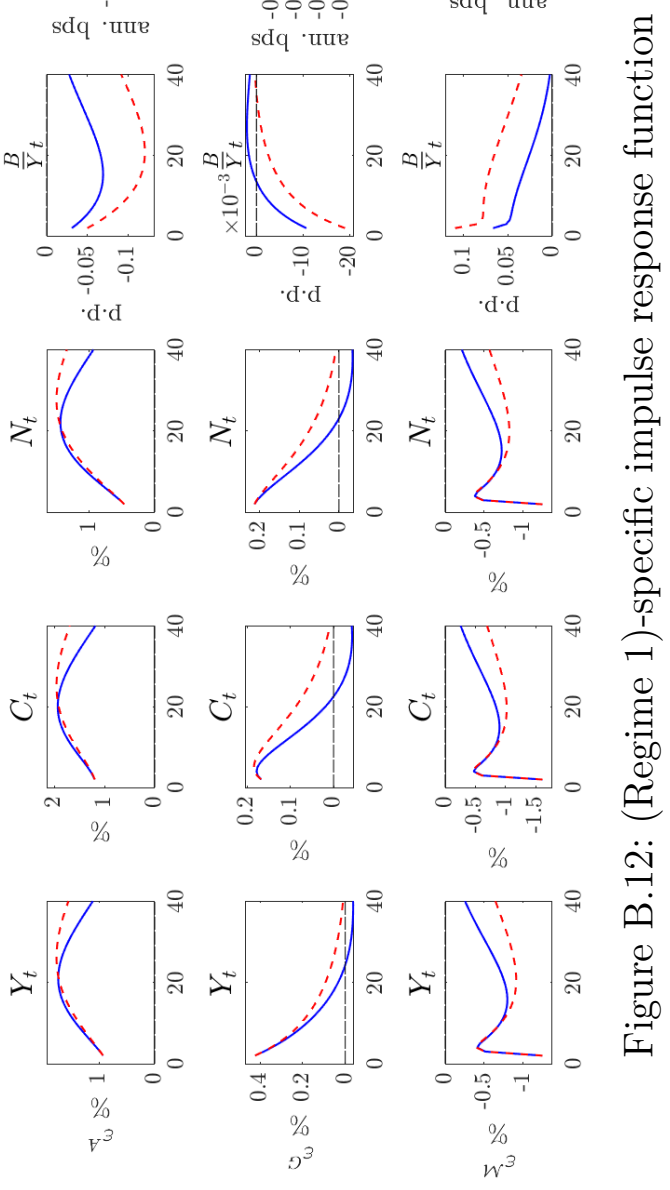

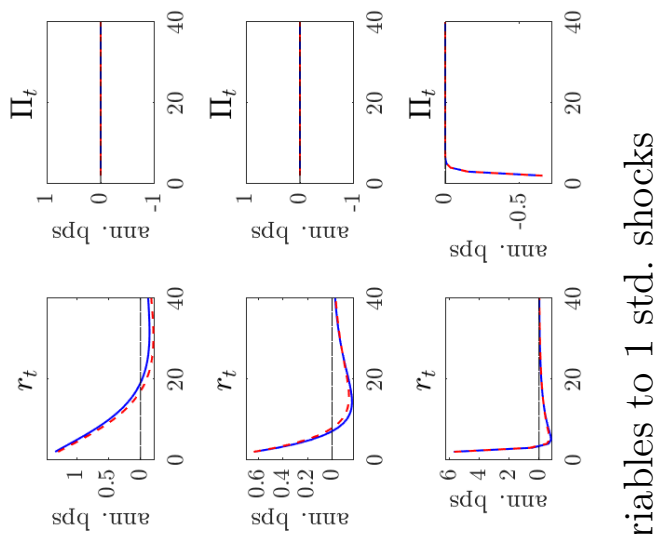

sdq 'uue sdq uue

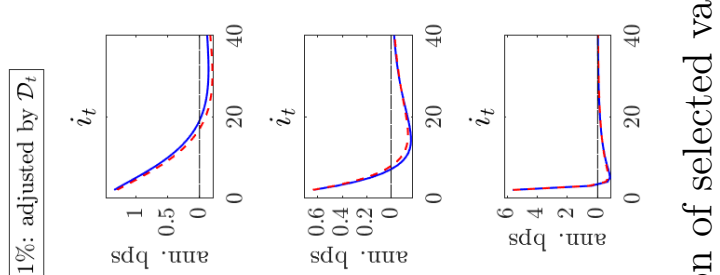

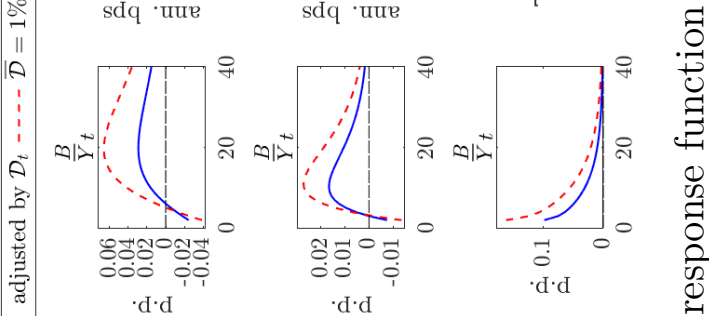
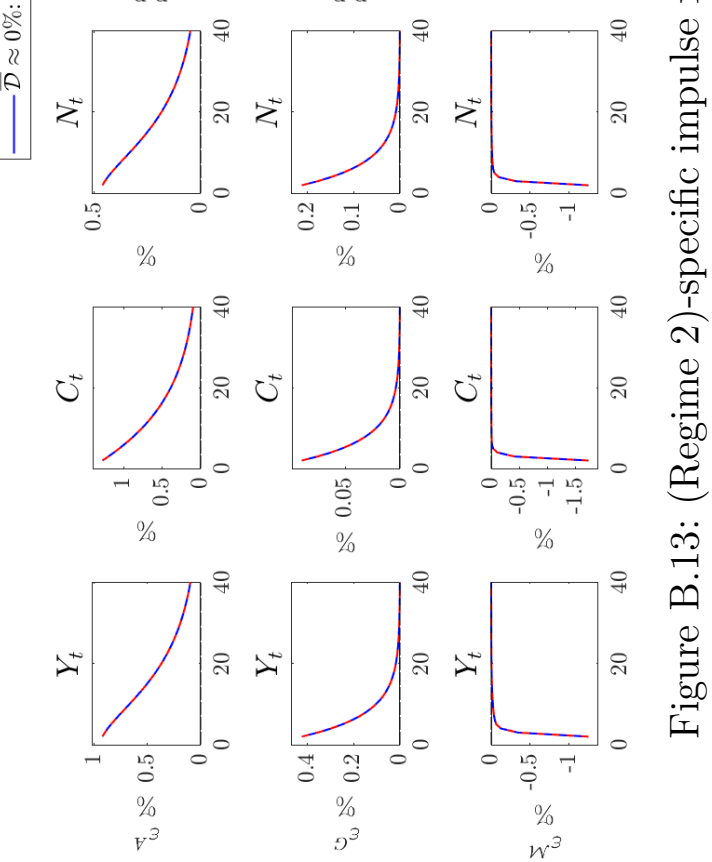

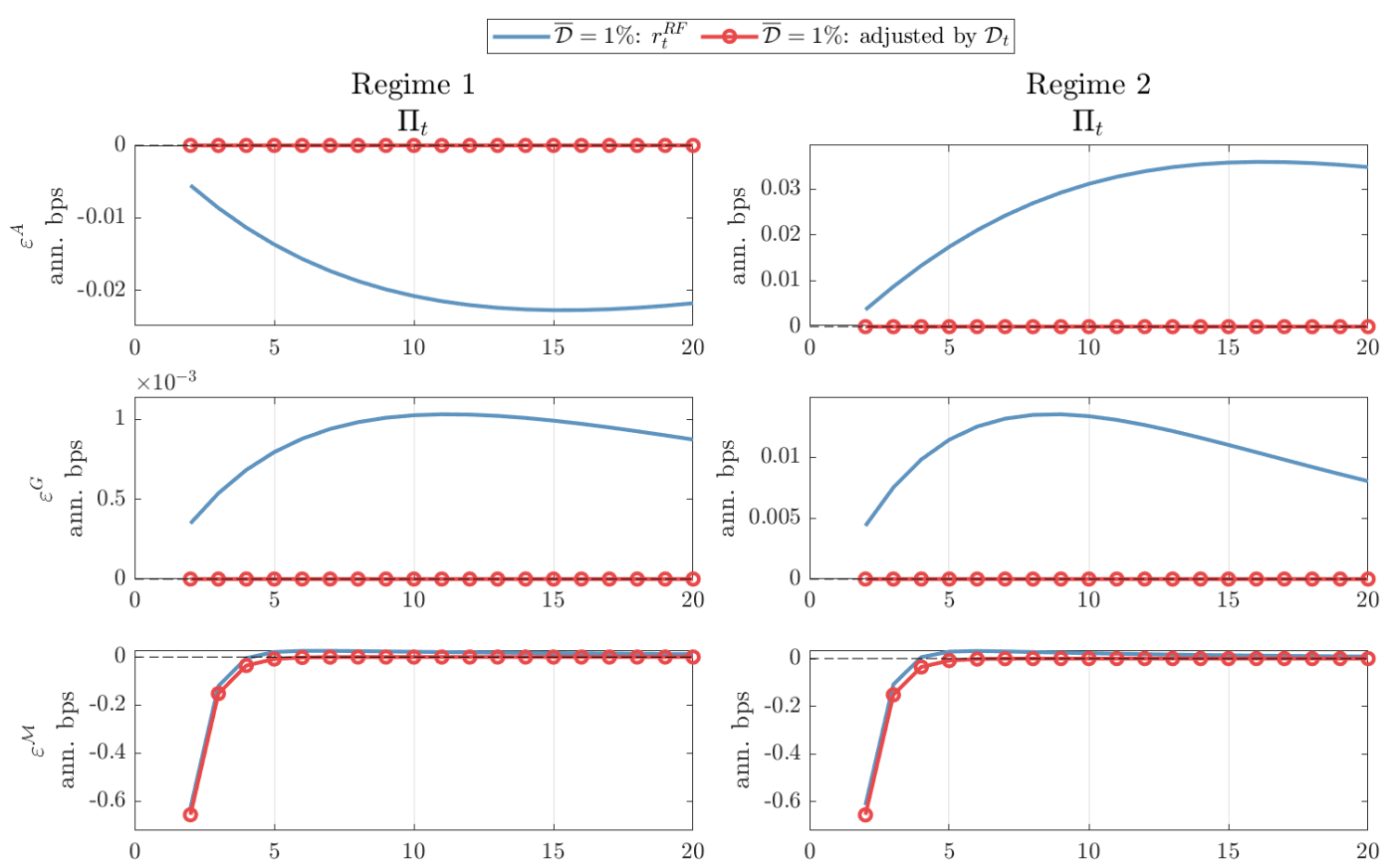

Figure B.14: Regime-specific impulse response functions of $\Pi_{t}$ to 1 std. shocks
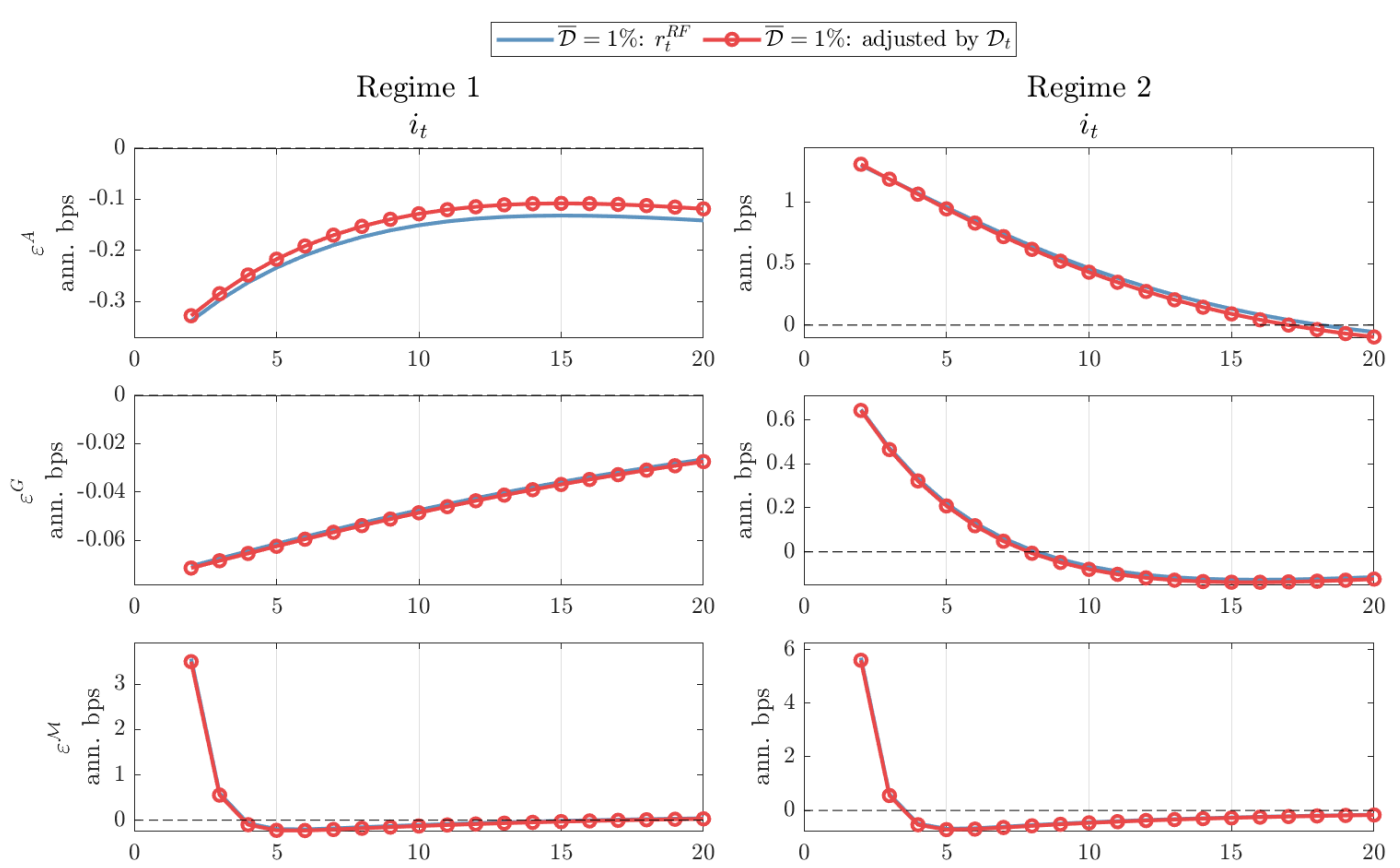

Figure B.15: Regime-specific impulse response functions of $i_{t}$ to 1 std. shocks 


\section{B.6 Welfare}

In our model, we have both Ricardian and non-Ricardian households, who will enjoy differently the benefits and downsides of inflating or defaulting the debt. On the one hand, higher inflation in the present means lower taxes in the future, what benefits both types of agents. On the other hand, inflation works as a wealth tax on the portfolio of Ricardian households. Moreover, when the government defaults on the debt, while it reduces the wealth of the Ricardian type by reducing the debt level, what, coeteris paribus, reduces the expected tax rates levied on both types of agents, it also enacts a negative TFP shock in the economy, which alone is enough to worsen the trajectory of the debt by reducing expected government revenues.

To compare welfare under different policy rules, we first turn off both smoothing and the dependency on the output gap and then we simulate the model resorting to 4 Markov chains with 330,000 periods each $(30,000$ excluded as burn-in $)^{6}$. We plot the result for the risk-adjusted rule in Figure B.16. The graphs for Rule 1 are omitted here because both rules exhibit the same pattern to the extent that they are not individually distinguishable by visual inspection. As our measure of welfare, we adopt the second-order Taylor expansion of the discounted sum of expected utility flows (2-2) around the nonstochastic steady state of each regime. Assuming that all individual households have the same weight in the welfare arithmetic, and recollecting that both types supply the same amount of labor at any period, while $\gamma^{N R}$ is the fraction of non-Ricardian households in the whole population, the welfare equations can be recursively written as in (B-60) and (B-61). They allow us to answer the question on which policy rule is best in the sense that it maximizes either type-specific or aggregate welfare.

$$
\begin{gathered}
U_{t}^{i}=\frac{\left(C_{t}^{i}+\alpha_{G} G_{t}-\eta \frac{N_{t}^{1+\chi}}{1+\chi}\right)^{1-\sigma}}{1-\sigma}+\beta \mathbb{E}_{t} U_{t+1}^{i} \quad i \in\{R, N R\} \\
U_{t}=\left(1-\gamma^{N R}\right) U_{t}^{R}+\gamma^{N R} U_{t}^{N R}
\end{gathered}
$$

${ }^{6}$ Although not originally meant for regime-switching models, we resort to the pruning method of Kim et al. (2008) to exclude explosive paths. 


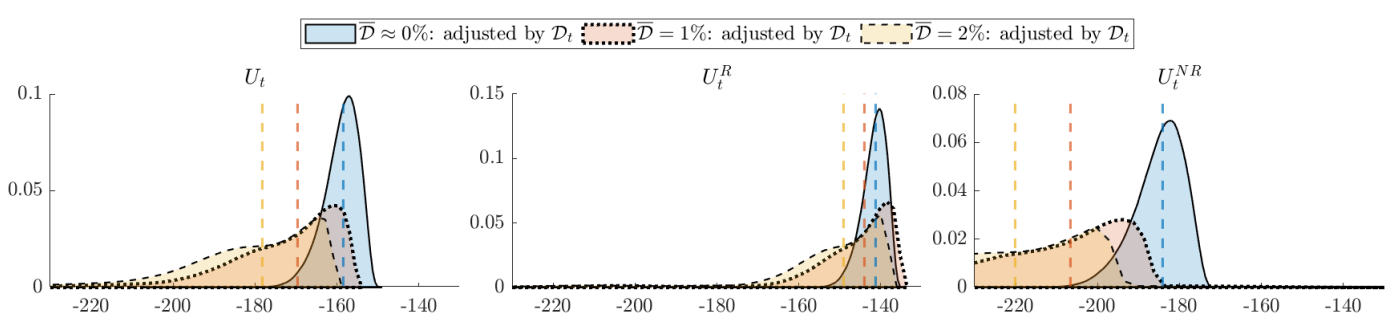

Note: Each vertical line is at the median of the distribution with the same color. Horizontal axis indicates the values of the variables, while the vertical axis indicates the frequency of each value. Density functions are estimated with the Epanechnikov kernel.

Figure B.16: Welfare comparison

Analyzing the results of the simulations, we find that the policy rule that adjusts the intercept to policy-default risk, despite reducing inflation and the policy rate in equilibrium, comes with a small welfare cost under our calibration and for up to low default probabilities. Figure B.17 shows that accommodating default risk may improve welfare for it keeps the debt level to some extent lower, what, by our fiscal rule, induces lower taxes in this economy. The result is the same no matter the household is Ricardian or not, what will be shown next and indicates alignment of interests between these two types of agents in the specification of the monetary policy rule.

Our finding that a central bank that avoids adjusting the intercept of the policy rule to the evolution of policy-default risk maximizes welfare is only valid under our calibration and in the subset of our tested rules. It is still possible that untested rules dominate our rule of choice in terms of welfare, or that different calibrations result in other policy recommendations. To investigate this, we conduct a sensitivity analysis of the policy parameters $\phi^{\pi} \in[1.00: 0.25: 3.00]$ and $\gamma_{\tau} \in[0.100: 0.025: 0.200]$, running for each combination of them 4 Markov chains with 33,000 periods each where we exclude the first 3,000 periods as burn-in. In the Tables B.2, B.3, and B.4, we list the aggregate welfare under monetary policy rules 1 and 2, varying these parameters, and with a debt level consistent with $\approx 0 \%, 2 \%$, and $5 \%$ steadystate default probability, respectively. In the Appendix B.7, we discriminate the welfare of the Ricardian household and of the non-Ricardian one in Tables B.5, B.6, B.7, B.8, B.9, and B.10.

This sensitivity analysis suggests that, at the benchmark calibration $\left(\phi^{\pi}\right.$ $=2.965$ and $\gamma_{\tau}=0.108$ ), the policy parameters are already consistent with the maximization of welfare under both monetary policy rules for all types of agents. With $\overline{\mathcal{D}}=1 \%$, the $\phi^{\pi}$ that maximizes welfare should be quite low, near 1.0, or around 3.0 under Rule 1, while it should be close to 3.0 under 
Rule 2. The non-linearity under Rule 1 reflects gains of the non-Ricardian agent in detriment of the Ricardian type as the latter seems to be negatively affected by the proximity with the indeterminacy region, which by itself would recommend keeping $\phi^{\pi}$ at the high level region. In this scenario, welfare would also increase with a somewhat more passive stance of fiscal policy, by rising $\gamma_{\tau}$ to the $0.150-0.175$ region, a result that shows up even with just a remarkably small default probability. Beyond that, welfare deteriorates. With $\overline{\mathcal{D}}=2 \%$, the same recommendations are warranted. Finally, with $\overline{\mathcal{D}}=5 \%$, the parameter combinations that maximize welfare narrow down to $\gamma_{\tau}=0.200$ under both rules, while $\phi^{\pi}=3.0$ is optimal under Rule 1 and $\phi^{\pi}=2.0$ under Rule 2 . For the first time, a clear preference for offsetting policy-default risk appears. ${ }^{7}$ Nonetheless, and most important, pushing the economy's steady state toward its fiscal limit, or stabilizing the debt near it, consistently deteriorates welfare across the board. The coincidence of moderate-to-high levels of inflation in addition to high real and nominal policy rates observed in some emerging economies may, in fact, reflect an unpleasant reality underneath.

These results raise concerns on non-obvious distributional effects of monetary policy and are found for optimal calibrations of monetary and fiscal policy parameters in a small subset of rules near the fiscal limit. Nonetheless, they contribute to the policy debate on whether the domestic debt level of a country matters. As long as the latter is perceived as risky, the model developed in this paper says it does, even if domestic debt is denominated only in domestic currency.

${ }^{7}$ Our tests showed that this specific preference for offsetting default risk instead of accommodating it seems to be sensitive to the relative frequency of the regimes. Inducing a relative higher prevalence of default events can make accommodating default risk preferable to offsetting it. 

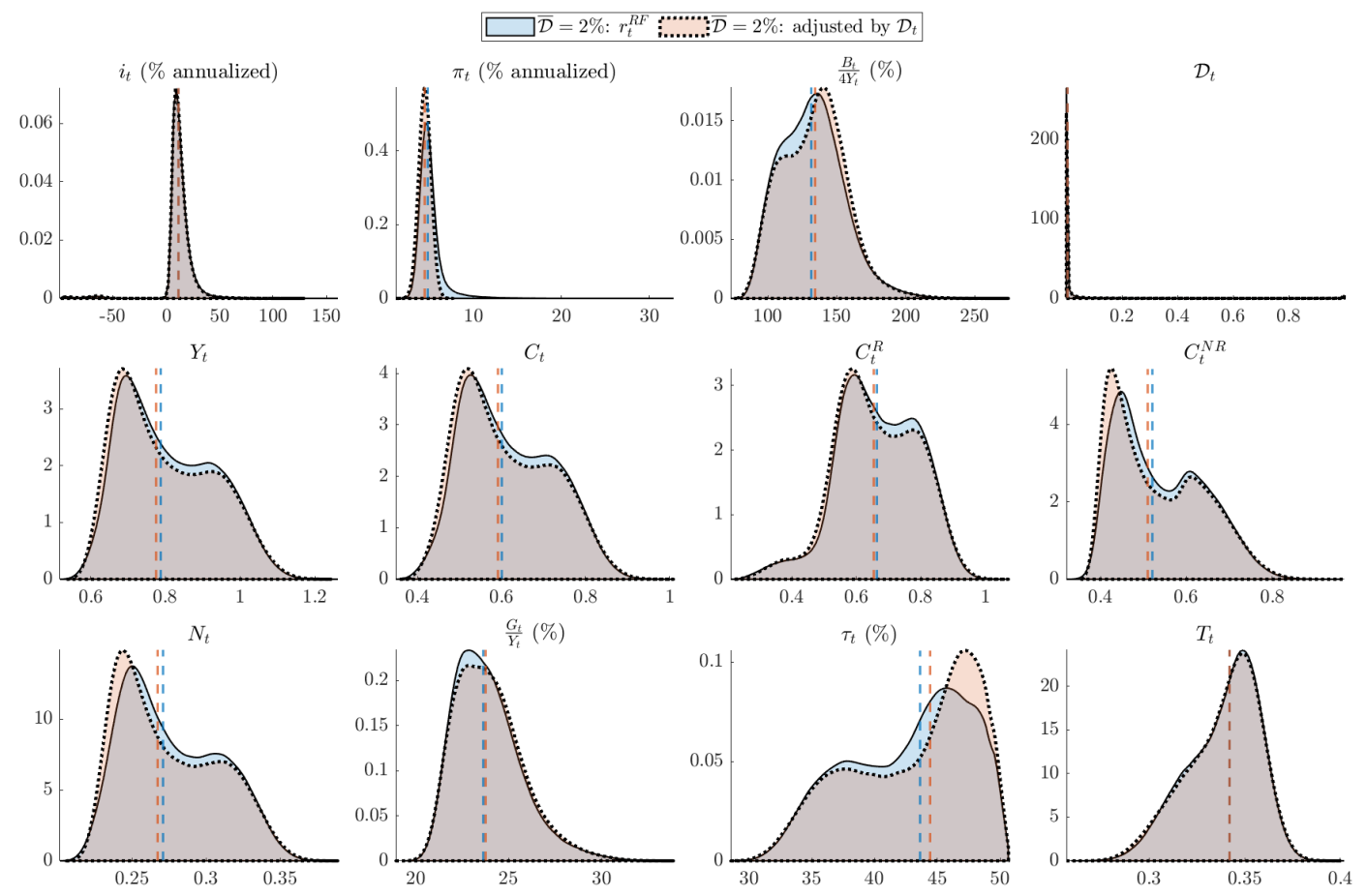

Note: Each vertical line is at the median of the distribution with the same color. Horizontal axis indicates the values of the variables, while the vertical axis indicates the frequency of each value. Density functions are estimated with the Epanechnikov kernel.

Figure B.17: Ergodic distribution of selected endogenous variables under different monetary policy rules near the fiscal limit ( $2^{\text {nd }}$ order approximation) 
Rule 1: Risky policy asset, but the CB ignores default-risk dynamics

\begin{tabular}{lrrrrr}
\hline \hline & $\gamma_{\tau}=0.100$ & $\gamma_{\tau}=0.125$ & $\gamma_{\tau}=0.150$ & $\gamma_{\tau}=0.175$ & $\gamma_{\tau}=0.200$ \\
\hline$\phi^{\pi}=1.00$ & $\infty$ & $\mathrm{NaN}$ & $-\infty$ & $\mathrm{NaN}$ & $-\infty$ \\
$\phi^{\pi}=1.25$ & -162 & -163 & -163 & -164 & -164 \\
$\phi^{\pi}=1.50$ & -161 & -161 & -162 & -162 & -162 \\
$\phi^{\pi}=1.75$ & -160 & -160 & -161 & -161 & -161 \\
$\phi^{\pi}=2.00$ & -160 & -160 & -160 & -161 & -161 \\
$\phi^{\pi}=2.25$ & -160 & -160 & -160 & -160 & -160 \\
$\phi^{\pi}=2.50$ & -159 & -160 & -160 & -160 & -160 \\
$\phi^{\pi}=2.75$ & -159 & -159 & -160 & -160 & -160 \\
$\phi^{\pi}=3.00$ & -159 & -159 & -159 & -160 & -160 \\
\hline \hline
\end{tabular}

Rule 2: Risky policy asset, and the CB perfectly tracks default-risk dynamics

\begin{tabular}{lrrrrr}
\hline & $\gamma_{\tau}=0.100$ & $\gamma_{\tau}=0.125$ & $\gamma_{\tau}=0.150$ & $\gamma_{\tau}=0.175$ & $\gamma_{\tau}=0.200$ \\
\hline$\phi^{\pi}=1.00$ & $\mathrm{NaN}$ & $\mathrm{NaN}$ & $\mathrm{NaN}$ & $\mathrm{NaN}$ & $\mathrm{NaN}$ \\
$\phi^{\pi}=1.25$ & -162 & -162 & -163 & -164 & -164 \\
$\phi^{\pi}=1.50$ & -161 & -161 & -162 & -162 & -162 \\
$\phi^{\pi}=1.75$ & -160 & -160 & -161 & -161 & -161 \\
$\phi^{\pi}=2.00$ & -160 & -160 & -160 & -161 & -161 \\
$\phi^{\pi}=2.25$ & -160 & -160 & -160 & -160 & -160 \\
$\phi^{\pi}=2.50$ & -159 & -160 & -160 & -160 & -160 \\
$\phi^{\pi}=2.75$ & -159 & -160 & -160 & -160 & -160 \\
$\phi^{\pi}=3.00$ & -159 & -159 & -159 & -160 & -160 \\
\hline \hline
\end{tabular}

Note: NaN means that no solution was found under that calibration. Shaded cells indicate the parameter values combinations that generate the highest welfare in the table.

Table B.2: Sensitivity analysis of aggregate welfare under $\overline{\mathcal{D}} \approx 0 \%$ 
Rule 1: Risky policy asset, but the CB ignores default-risk dynamics

\begin{tabular}{lrrrrr}
\hline \hline & $\gamma_{\tau}=0.100$ & $\gamma_{\tau}=0.125$ & $\gamma_{\tau}=0.150$ & $\gamma_{\tau}=0.175$ & $\gamma_{\tau}=0.200$ \\
\hline$\phi^{\pi}=1.00$ & -522 & -2241 & -398 & -547 & -876 \\
$\phi^{\pi}=1.25$ & -232 & -196 & -189 & -188 & -189 \\
$\phi^{\pi}=1.50$ & -219 & -189 & -183 & -182 & -183 \\
$\phi^{\pi}=1.75$ & -212 & -185 & -179 & -179 & -180 \\
$\phi^{\pi}=2.00$ & -206 & -182 & -177 & -176 & -177 \\
$\phi^{\pi}=2.25$ & -203 & -180 & -175 & -175 & -176 \\
$\phi^{\pi}=2.50$ & -202 & -178 & -174 & -174 & -175 \\
$\phi^{\pi}=2.75$ & -199 & -177 & -173 & -173 & -174 \\
$\phi^{\pi}=3.00$ & -198 & -176 & -172 & -172 & -173 \\
\hline \hline
\end{tabular}

Rule 2: Risky policy asset, and the CB perfectly tracks default-risk dynamics

\begin{tabular}{lrrrrr}
\hline \hline & $\gamma_{\tau}=0.100$ & $\gamma_{\tau}=0.125$ & $\gamma_{\tau}=0.150$ & $\gamma_{\tau}=0.175$ & $\gamma_{\tau}=0.200$ \\
\hline$\phi^{\pi}=1.00$ & $\mathrm{NaN}$ & $\mathrm{NaN}$ & $\mathrm{NaN}$ & $\mathrm{NaN}$ & $\mathrm{NaN}$ \\
$\phi^{\pi}=1.25$ & -234 & -198 & -189 & -188 & -190 \\
$\phi^{\pi}=1.50$ & -220 & -189 & -183 & -182 & -183 \\
$\phi^{\pi}=1.75$ & -213 & -185 & -179 & -179 & -180 \\
$\phi^{\pi}=2.00$ & -207 & -182 & -177 & -176 & -178 \\
$\phi^{\pi}=2.25$ & -204 & -180 & -175 & -175 & -176 \\
$\phi^{\pi}=2.50$ & -202 & -178 & -174 & -174 & -175 \\
$\phi^{\pi}=2.75$ & -200 & -177 & -173 & -173 & -174 \\
$\phi^{\pi}=3.00$ & -199 & -176 & -172 & -172 & -173 \\
\hline \hline
\end{tabular}

Note: NaN means that no solution was found under that calibration. Shaded cells indicate the parameter values combinations that generate the highest welfare in the table.

Table B.3: Sensitivity analysis of aggregate welfare under $\overline{\mathcal{D}}=2 \%$ 
Rule 1: Risky policy asset, but the CB ignores default-risk dynamics

\begin{tabular}{lrrrrr}
\hline \hline & $\gamma_{\tau}=0.100$ & $\gamma_{\tau}=0.125$ & $\gamma_{\tau}=0.150$ & $\gamma_{\tau}=0.175$ & $\gamma_{\tau}=0.200$ \\
\hline$\phi^{\pi}=1.00$ & 3718 & -5271 & $\mathrm{NaN}$ & $\mathrm{NaN}$ & $\mathrm{NaN}$ \\
$\phi^{\pi}=1.25$ & $\mathrm{NaN}$ & -2192 & -949 & -594 & -465 \\
$\phi^{\pi}=1.50$ & $\mathrm{NaN}$ & -2227 & -1000 & -627 & -479 \\
$\phi^{\pi}=1.75$ & $\mathrm{NaN}$ & -2206 & -1009 & -632 & -482 \\
$\phi^{\pi}=2.00$ & $\mathrm{NaN}$ & -2243 & -1005 & -634 & -473 \\
$\phi^{\pi}=2.25$ & $\mathrm{NaN}$ & -2012 & -1011 & -634 & -435 \\
$\phi^{\pi}=2.50$ & $\mathrm{NaN}$ & -1047 & -1007 & -616 & -401 \\
$\phi^{\pi}=2.75$ & $\mathrm{NaN}$ & -466 & -859 & -591 & -429 \\
$\phi^{\pi}=3.00$ & $\mathrm{NaN}$ & -780 & -775 & -549 & -303 \\
\hline \hline
\end{tabular}

Rule 2: Risky policy asset, and the CB perfectly tracks default-risk dynamics

\begin{tabular}{lrrrrr}
\hline & $\gamma_{\tau}=0.100$ & $\gamma_{\tau}=0.125$ & $\gamma_{\tau}=0.150$ & $\gamma_{\tau}=0.175$ & $\gamma_{\tau}=0.200$ \\
\hline$\phi^{\pi}=1.00$ & $\mathrm{NaN}$ & $\mathrm{NaN}$ & $\mathrm{NaN}$ & $\mathrm{NaN}$ & $\mathrm{NaN}$ \\
$\phi^{\pi}=1.25$ & $\mathrm{NaN}$ & -2475 & -1103 & -693 & -535 \\
$\phi^{\pi}=1.50$ & $\mathrm{NaN}$ & -2428 & -1081 & -683 & -458 \\
$\phi^{\pi}=1.75$ & $\mathrm{NaN}$ & -2268 & -1000 & -576 & -267 \\
$\phi^{\pi}=2.00$ & $\mathrm{NaN}$ & -2172 & -984 & -587 & -201 \\
$\phi^{\pi}=2.25$ & $\mathrm{NaN}$ & -1177 & -879 & -430 & -337 \\
$\phi^{\pi}=2.50$ & $\mathrm{NaN}$ & -1081 & -804 & -291 & -276 \\
$\phi^{\pi}=2.75$ & $\mathrm{NaN}$ & -614 & -596 & -300 & -255 \\
$\phi^{\pi}=3.00$ & $\mathrm{NaN}$ & -210 & -607 & -279 & -256 \\
\hline \hline
\end{tabular}

Note: NaN means that no solution was found under that calibration. Shaded cells indicate the parameter values combinations that generate the highest welfare in the table.

Table B.4: Sensitivity analysis of aggregate welfare under $\overline{\mathcal{D}}=5 \%$ 


\section{B.7 \\ Additional analyses}

\section{B.7.1}

Correlation between $\Pi_{t}$ and $\mathbb{E}_{t} \mathcal{D}_{t+1}$

In a companion paper, we find in a partial-equilibrium flexible-price monetary model that no matter the correlation between $r_{t}^{n}$ and $\mathbb{E}_{t} \mathcal{D}_{t+1}$, the correlation between $\Pi_{t}$ and $\mathbb{E}_{t} \mathcal{D}_{t+1}$ would be positive and grow with $\phi^{\pi}$ under either a fixed intercept rule or a rule that tracked $r_{t}^{n}$. In the specific case of a central bank that adjusts its rule to the default probability underlying its policy asset, however, the correlation would be eliminated. We repeat a similar exercise here, simulating the model for 4 Markov chains with 300,000 periods each, and measuring the correlation between inflation and expected default probability for different levels of steady-state default probability and several combinations of values for the policy parameters $\phi^{\pi}$ and $\gamma_{\tau}$. Note that the relevant range here will be the one that should, arguably, match active monetary policy with passive fiscal policy, that is, the upper-right quadrant of figures below. Empty squares in them represent parameter value combinations for which the model could not be solved, which happen to occur in the regions usually associated to indeterminacy in New-Keynesian models. To make clear the differences between the monetary policy rules, once again we simplify them by turning off the interest rate smoothing and the dependency on the output gap. Overall, we confirm that our companion paper results remain solid also under sticky prices.

Figure B.18 plots the studied correlation subject to each of the four monetary policy rules when varying the steady-state default probability from virtually $0 \%$ (benchmark calibration) up to 5\%. Ignoring default risk enacts a positive correlation that increases with the default probability. Adjusting the intercept to that risk or conducting monetary policy with risk-free assets, practically, eliminates the correlation. Reacting to defaut risk while operating risk-free assets, by its turn, entails a negative correlation that increases in size with the steady-state default risk.

Figure B.19 is built employing Rule 1, the central bank tracks $r_{t}^{R F}$, and varying the policy parameters $\phi^{\pi}$ and $\gamma_{\tau}$ under a debt level consistent with $5 \%$ default probability. As predicted by our partial equilibrium results, correlation is always positive, whenever a model solution is found (NA stands for no solution is available). This tells us that ignoring the evolution of risk in the underlying asset of monetary policy brings about a correlation of the same sign found in empirical data of emerging economies. In the literature, Schabert and 
Van Wijnbergen (2014) get a positive correlation in their model, because closeto-active fiscal policy in combination with active monetary policy jeopardizes macroeconomic stability. In our model, the explanation starts earlier, as a positive correlation is motivated by higher expected default rates of the policy asset being accommodated with lower policy rates (higher inflation).

Figure B.20 shows the results under Rule 2, the policy rule that adjusts for default risk. Since inflation is on the target at all periods except for monetary shocks, there is virtually no correlation, like what was predicted by our companion paper's partial equilibrium model. Remember that near zero, or very low correlation, is what is usually found in empirical data of advanced economies, a result that is perfectly consistent with that same rule in case the default probability is too small.

We, now, introduce two additional policy rules to show that this correlation may turn negative if monetary policy is operated with risk-free assets.

\section{Rule 3: Risk-free policy asset, and the CB perfectly tracks the real risk-free rate}

The policy asset is default-risk-free, and the CB wants to indirectly influence the rate of government bonds, which are default-risky, through arbitrage. This is the time-varying version of the canonical case.

$$
\bar{\iota}_{t}=r_{t}^{R F} \quad \text { and } \quad \mathbb{1}_{\text {Rule }}=1
$$

\section{Rule 4: Risk-free policy asset, but the CB targets a default-risky rate}

The policy asset is default-risk-free, but the CB operates as if its policy instrument shared the same default risk of government bonds. It knows, though, that the mean level of the default premium is not part of the real natural interest rate.

$$
\bar{\iota}_{t}=r_{t}^{R F}+\Phi_{t}-\bar{\Phi} \quad \text { and } \quad \mathbb{1}_{\text {Rule }}=0
$$

Figure B.21 shows that when the central bank operates with risk-free assets targeting the risk-free rate, Rule 3, the correlation between inflation and default risk is close to zero. Figure B.22, by its turn, plots the case in which the central bank targets a risky rate using risk-free assets, Rule 4. Correlation is, now, negative for all combinations in the upper-right quadrant as the negative impact of default risk on the trajectory of debt takes its toll from the trajectory of consumption (lower inflation). Such a negative correlation between inflation and default risk, despite at odds with real-world data, is also expected to be 
present in other models in the literature, like Bonam and Lukkezen (2019). In their model, debt-elastic sovereign interest rates under an augment of default risk crowd out consumption, alleviating pressure on inflation, and resulting in lower nominal interest rates.

Under Rule 1, increasing $\gamma_{\tau}$ brings the correlation between inflation and expected default risk closer to zero, that is, more reactive fiscal rules tend to attenuate such a correlation, approximating it of the optimal rule w.r.t inflation. It is important to note that other policy rules may enact different patterns of correlation. 

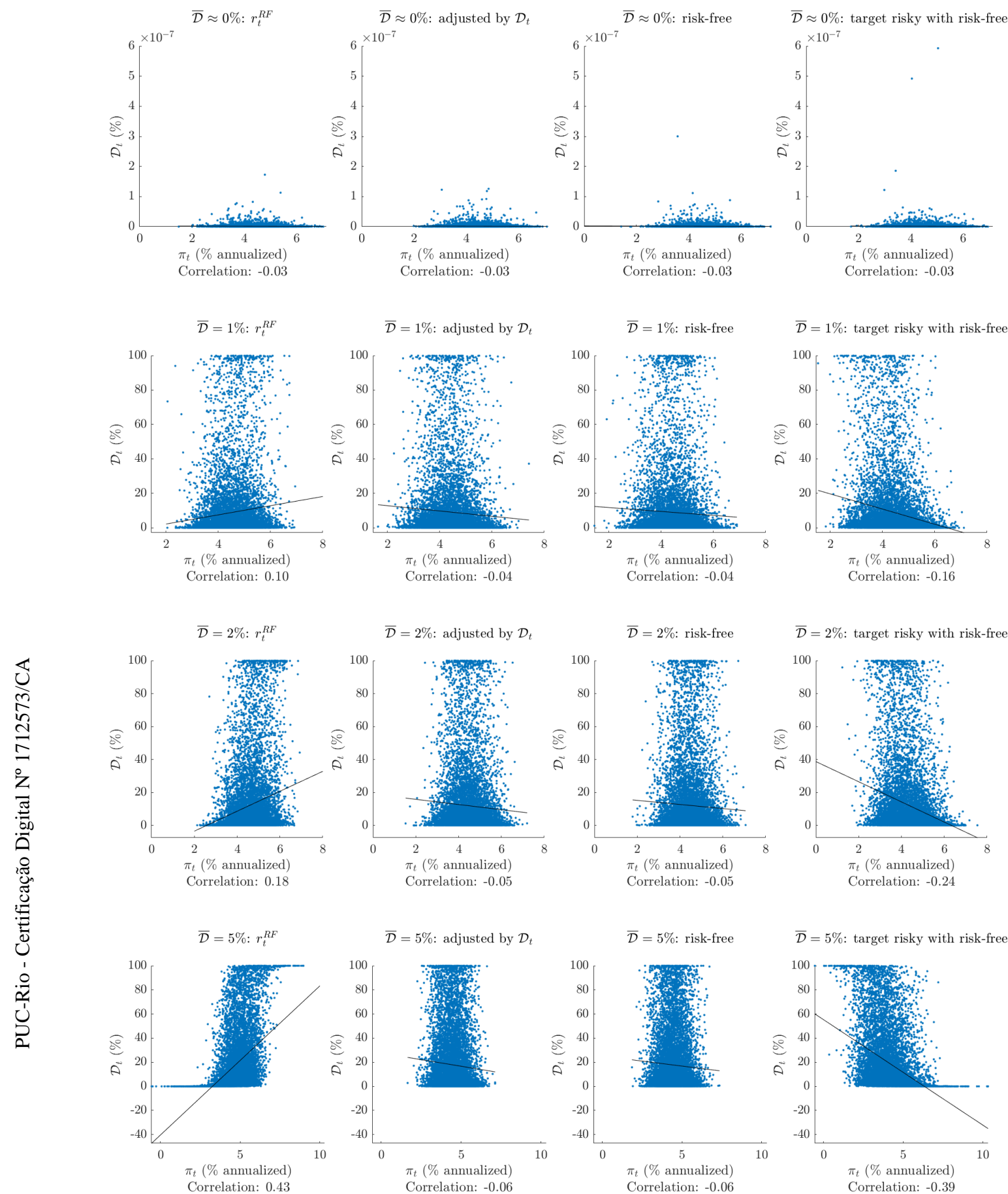

Figure B.18: Correlation between $\Pi_{t}$ and $\mathbb{E}_{t} \mathcal{D}_{t+1}$ under different $\overline{\mathcal{D}}$ and policy rules 


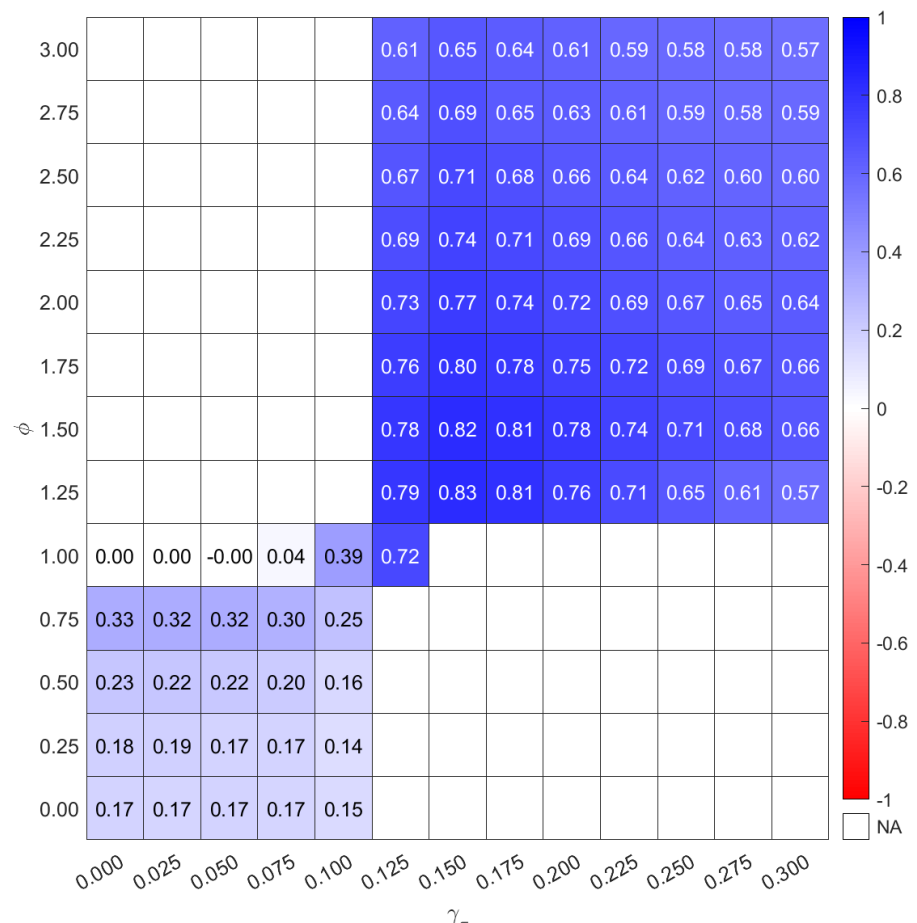

Figure B.19: Correlation between $\Pi_{t}$ and $\mathbb{E}_{t} \mathcal{D}_{t+1}$ under Rule 1 with $\overline{\mathcal{D}}=5 \%$

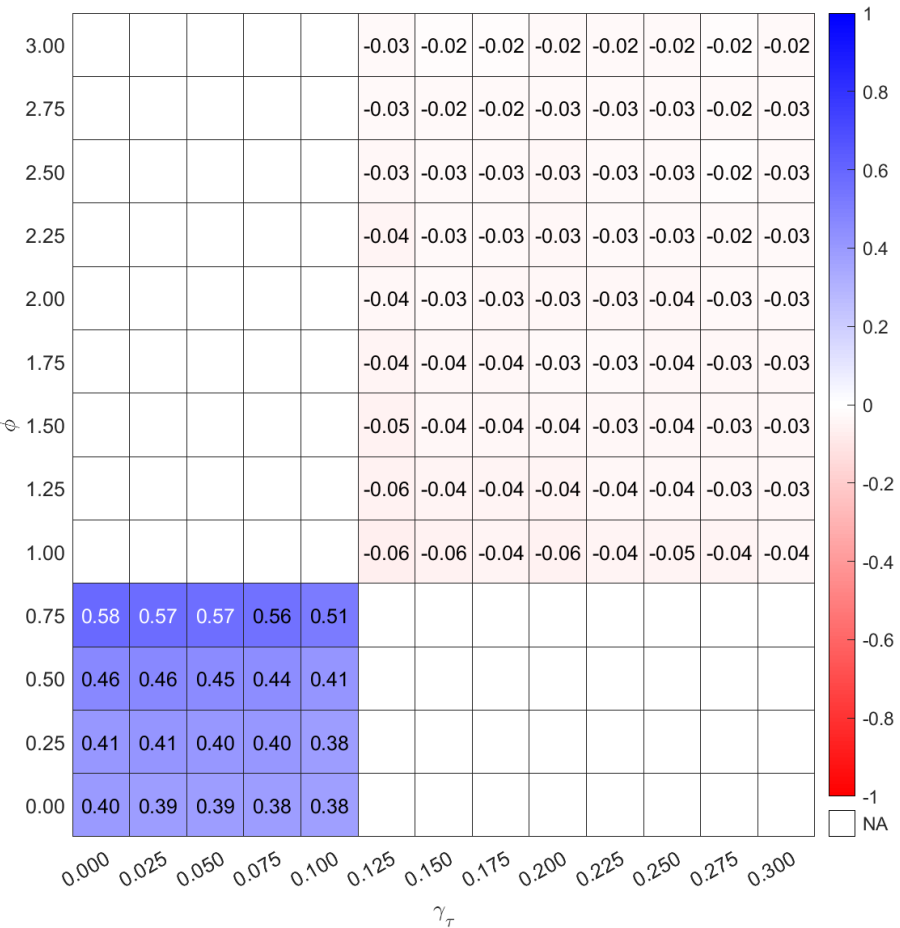

Figure B.20: Correlation between $\Pi_{t}$ and $\mathbb{E}_{t} \mathcal{D}_{t+1}$ under Rule 2 with $\overline{\mathcal{D}}=5 \%$ 


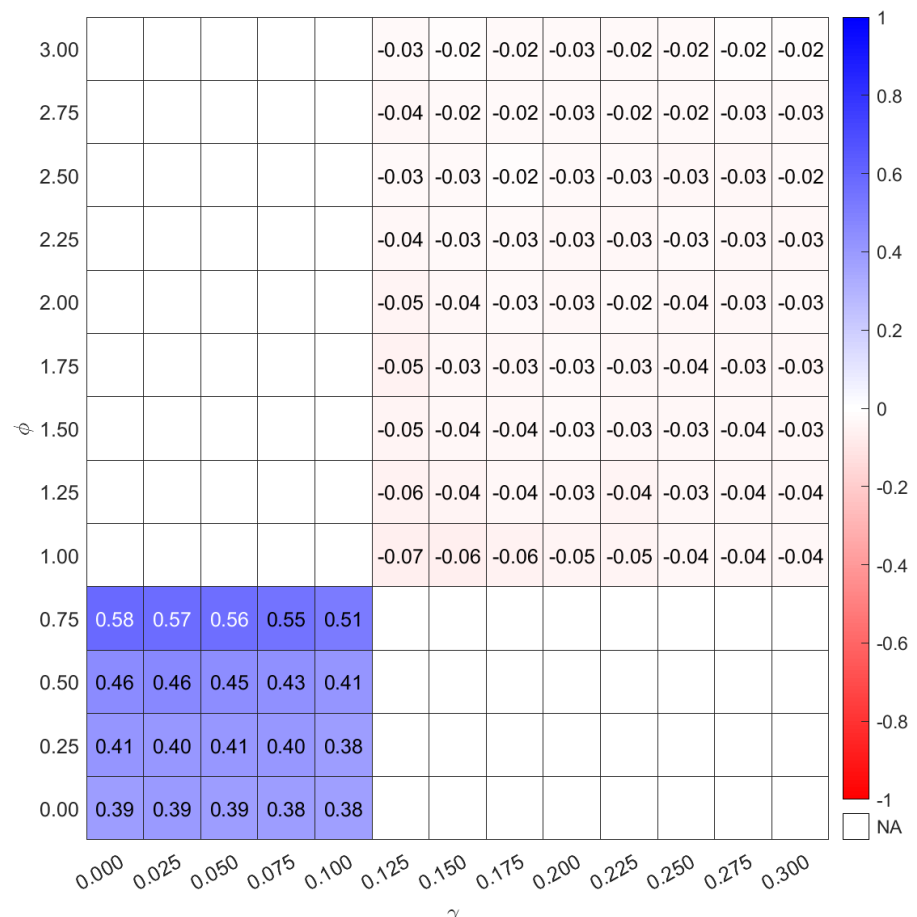

Figure B.21: Correlation between $\Pi_{t}$ and $\mathbb{E}_{t} \mathcal{D}_{t+1}$ under Rule 3 with $\overline{\mathcal{D}}=5 \%$

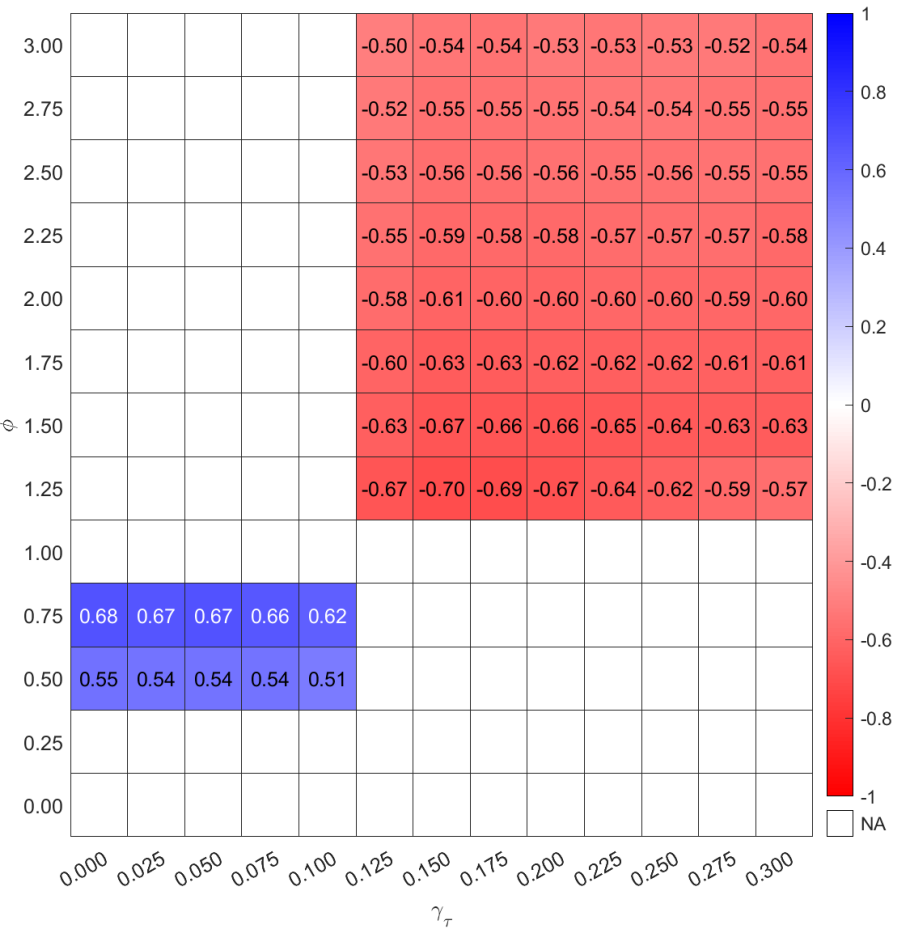

Figure B.22: Correlation between $\Pi_{t}$ and $\mathbb{E}_{t} \mathcal{D}_{t+1}$ under Rule 4 with $\overline{\mathcal{D}}=5 \%$

\section{B.7.2}

\section{Welfare of Ricardian and non-Ricardian households}




\section{B.7.2.1}

Sensitivity analysis under $\overline{\mathcal{D}} \approx 0 \%$

Rule 1: Risky policy asset, but the CB ignores default-risk dynamics

\begin{tabular}{lrrrrr}
\hline \hline & $\gamma_{\tau}=0.100$ & $\gamma_{\tau}=0.125$ & $\gamma_{\tau}=0.150$ & $\gamma_{\tau}=0.175$ & $\gamma_{\tau}=0.200$ \\
\hline$\phi^{\pi}=1.00$ & $\infty$ & $\mathrm{NaN}$ & $-\infty$ & $\mathrm{NaN}$ & $-\infty$ \\
$\phi^{\pi}=1.25$ & -144 & -145 & -145 & -146 & -146 \\
$\phi^{\pi}=1.50$ & -143 & -144 & -144 & -144 & -145 \\
$\phi^{\pi}=1.75$ & -143 & -143 & -143 & -143 & -144 \\
$\phi^{\pi}=2.00$ & -142 & -143 & -143 & -143 & -143 \\
$\phi^{\pi}=2.25$ & -142 & -142 & -143 & -143 & -143 \\
$\phi^{\pi}=2.50$ & -142 & -142 & -142 & -143 & -143 \\
$\phi^{\pi}=2.75$ & -142 & -142 & -142 & -142 & -143 \\
$\phi^{\pi}=3.00$ & -142 & -142 & -142 & -142 & -142 \\
\hline \hline
\end{tabular}

Rule 2: Risky policy asset, and the CB perfectly tracks default-risk dynamics

\begin{tabular}{lrrrrr}
\hline \hline & $\gamma_{\tau}=0.100$ & $\gamma_{\tau}=0.125$ & $\gamma_{\tau}=0.150$ & $\gamma_{\tau}=0.175$ & $\gamma_{\tau}=0.200$ \\
\hline$\phi^{\pi}=1.00$ & $\mathrm{NaN}$ & $\mathrm{NaN}$ & $\mathrm{NaN}$ & $\mathrm{NaN}$ & $\mathrm{NaN}$ \\
$\phi^{\pi}=1.25$ & -144 & -145 & -145 & -146 & -146 \\
$\phi^{\pi}=1.50$ & -143 & -144 & -144 & -144 & -145 \\
$\phi^{\pi}=1.75$ & -143 & -143 & -143 & -144 & -144 \\
$\phi^{\pi}=2.00$ & -142 & -143 & -143 & -143 & -143 \\
$\phi^{\pi}=2.25$ & -142 & -142 & -142 & -143 & -143 \\
$\phi^{\pi}=2.50$ & -142 & -142 & -142 & -143 & -143 \\
$\phi^{\pi}=2.75$ & -142 & -142 & -142 & -142 & -143 \\
$\phi^{\pi}=3.00$ & -142 & -142 & -142 & -142 & -142 \\
\hline \hline
\end{tabular}

Note: NaN means that no solution was found under that calibration. Shaded cells indicate the parameter values combinations that generate the highest welfare in the table.

Table B.5: Sensitivity analysis of Ricardian welfare under $\overline{\mathcal{D}} \approx 0 \%$ 
Rule 1: Risky policy asset, but the CB ignores default-risk dynamics

\begin{tabular}{lrrrrr}
\hline \hline & $\gamma_{\tau}=0.100$ & $\gamma_{\tau}=0.125$ & $\gamma_{\tau}=0.150$ & $\gamma_{\tau}=0.175$ & $\gamma_{\tau}=0.200$ \\
\hline$\phi^{\pi}=1.00$ & $\infty$ & $\mathrm{NaN}$ & $-\infty$ & $\mathrm{NaN}$ & $-\infty$ \\
$\phi^{\pi}=1.25$ & -189 & -189 & -190 & -190 & -191 \\
$\phi^{\pi}=1.50$ & -187 & -188 & -188 & -189 & -189 \\
$\phi^{\pi}=1.75$ & -186 & -187 & -187 & -187 & -188 \\
$\phi^{\pi}=2.00$ & -186 & -186 & -187 & -187 & -187 \\
$\phi^{\pi}=2.25$ & -186 & -186 & -186 & -186 & -187 \\
$\phi^{\pi}=2.50$ & -185 & -186 & -186 & -186 & -186 \\
$\phi^{\pi}=2.75$ & -185 & -186 & -186 & -186 & -186 \\
$\phi^{\pi}=3.00$ & -185 & -185 & -185 & -186 & -186 \\
\hline \hline
\end{tabular}

Rule 2: Risky policy asset, and the CB perfectly tracks default-risk dynamics

\begin{tabular}{lrrrrr}
\hline \hline & $\gamma_{\tau}=0.100$ & $\gamma_{\tau}=0.125$ & $\gamma_{\tau}=0.150$ & $\gamma_{\tau}=0.175$ & $\gamma_{\tau}=0.200$ \\
\hline$\phi^{\pi}=1.00$ & $\mathrm{NaN}$ & $\mathrm{NaN}$ & $\mathrm{NaN}$ & $\mathrm{NaN}$ & $\mathrm{NaN}$ \\
$\phi^{\pi}=1.25$ & -189 & -189 & -190 & -191 & -191 \\
$\phi^{\pi}=1.50$ & -187 & -188 & -188 & -188 & -189 \\
$\phi^{\pi}=1.75$ & -186 & -187 & -187 & -188 & -188 \\
$\phi^{\pi}=2.00$ & -186 & -186 & -187 & -187 & -187 \\
$\phi^{\pi}=2.25$ & -186 & -186 & -186 & -186 & -187 \\
$\phi^{\pi}=2.50$ & -185 & -186 & -186 & -186 & -186 \\
$\phi^{\pi}=2.75$ & -185 & -186 & -186 & -186 & -186 \\
$\phi^{\pi}=3.00$ & -185 & -185 & -185 & -186 & -186 \\
\hline \hline
\end{tabular}

Note: NaN means that no solution was found under that calibration. Shaded cells indicate the parameter values combinations that generate the highest welfare in the table.

Table B.6: Sensitivity analysis of Non-Ricardian welfare under $\overline{\mathcal{D}} \approx 0 \%$ 


\section{B.7.2.2}

Sensitivity analysis under $\overline{\mathcal{D}}=2 \%$

Rule 1: Risky policy asset, but the CB ignores default-risk dynamics

\begin{tabular}{lrrrrr}
\hline \hline & $\gamma_{\tau}=0.100$ & $\gamma_{\tau}=0.125$ & $\gamma_{\tau}=0.150$ & $\gamma_{\tau}=0.175$ & $\gamma_{\tau}=0.200$ \\
\hline$\phi^{\pi}=1.00$ & -722 & -1285 & -292 & -470 & -768 \\
$\phi^{\pi}=1.25$ & -186 & -164 & -159 & -159 & -160 \\
$\phi^{\pi}=1.50$ & -178 & -159 & -155 & -155 & -155 \\
$\phi^{\pi}=1.75$ & -173 & -156 & -153 & -152 & -153 \\
$\phi^{\pi}=2.00$ & -169 & -154 & -151 & -150 & -151 \\
$\phi^{\pi}=2.25$ & -167 & -153 & -150 & -149 & -150 \\
$\phi^{\pi}=2.50$ & -166 & -152 & -149 & -148 & -149 \\
$\phi^{\pi}=2.75$ & -165 & -151 & -148 & -148 & -148 \\
$\phi^{\pi}=3.00$ & -164 & -150 & -147 & -147 & -148 \\
\hline \hline
\end{tabular}

Rule 2: Risky policy asset, and the CB perfectly tracks default-risk dynamics

\begin{tabular}{lrrrrr}
\hline \hline & $\gamma_{\tau}=0.100$ & $\gamma_{\tau}=0.125$ & $\gamma_{\tau}=0.150$ & $\gamma_{\tau}=0.175$ & $\gamma_{\tau}=0.200$ \\
\hline$\phi^{\pi}=1.00$ & $\mathrm{NaN}$ & $\mathrm{NaN}$ & $\mathrm{NaN}$ & $\mathrm{NaN}$ & $\mathrm{NaN}$ \\
$\phi^{\pi}=1.25$ & -187 & -165 & -160 & -159 & -160 \\
$\phi^{\pi}=1.50$ & -178 & -159 & -155 & -155 & -155 \\
$\phi^{\pi}=1.75$ & -173 & -156 & -153 & -152 & -153 \\
$\phi^{\pi}=2.00$ & -170 & -154 & -151 & -150 & -151 \\
$\phi^{\pi}=2.25$ & -168 & -153 & -150 & -149 & -150 \\
$\phi^{\pi}=2.50$ & -166 & -152 & -149 & -148 & -149 \\
$\phi^{\pi}=2.75$ & -165 & -151 & -148 & -148 & -148 \\
$\phi^{\pi}=3.00$ & -164 & -150 & -147 & -147 & -148 \\
\hline \hline
\end{tabular}

Note: NaN means that no solution was found under that calibration. Shaded cells indicate the parameter values combinations that generate the highest welfare in the table.

Table B.7: Sensitivity analysis of Ricardian welfare under $\overline{\mathcal{D}}=2 \%$ 
Rule 1: Risky policy asset, but the CB ignores default-risk dynamics

\begin{tabular}{lrrrrr}
\hline \hline & $\gamma_{\tau}=0.100$ & $\gamma_{\tau}=0.125$ & $\gamma_{\tau}=0.150$ & $\gamma_{\tau}=0.175$ & $\gamma_{\tau}=0.200$ \\
\hline$\phi^{\pi}=1.00$ & -222 & -3675 & -556 & -663 & -1040 \\
$\phi^{\pi}=1.25$ & -301 & -245 & -232 & -230 & -232 \\
$\phi^{\pi}=1.50$ & -282 & -234 & -224 & -223 & -225 \\
$\phi^{\pi}=1.75$ & -271 & -228 & -219 & -218 & -220 \\
$\phi^{\pi}=2.00$ & -262 & -223 & -216 & -215 & -217 \\
$\phi^{\pi}=2.25$ & -258 & -220 & -214 & -213 & -215 \\
$\phi^{\pi}=2.50$ & -255 & -218 & -212 & -212 & -213 \\
$\phi^{\pi}=2.75$ & -252 & -216 & -210 & -210 & -212 \\
$\phi^{\pi}=3.00$ & -249 & -215 & -209 & -209 & -211 \\
\hline \hline
\end{tabular}

Rule 2: Risky policy asset, and the CB perfectly tracks default-risk dynamics

\begin{tabular}{lrrrrr}
\hline \hline & $\gamma_{\tau}=0.100$ & $\gamma_{\tau}=0.125$ & $\gamma_{\tau}=0.150$ & $\gamma_{\tau}=0.175$ & $\gamma_{\tau}=0.200$ \\
\hline$\phi^{\pi}=1.00$ & $\mathrm{NaN}$ & $\mathrm{NaN}$ & $\mathrm{NaN}$ & $\mathrm{NaN}$ & $\mathrm{NaN}$ \\
$\phi^{\pi}=1.25$ & -306 & -246 & -233 & -232 & -234 \\
$\phi^{\pi}=1.50$ & -284 & -234 & -224 & -223 & -225 \\
$\phi^{\pi}=1.75$ & -272 & -227 & -219 & -219 & -220 \\
$\phi^{\pi}=2.00$ & -263 & -223 & -216 & -215 & -217 \\
$\phi^{\pi}=2.25$ & -259 & -220 & -214 & -213 & -215 \\
$\phi^{\pi}=2.50$ & -255 & -218 & -212 & -211 & -213 \\
$\phi^{\pi}=2.75$ & -252 & -216 & -210 & -210 & -212 \\
$\phi^{\pi}=3.00$ & -251 & -215 & -209 & -209 & -211 \\
\hline \hline
\end{tabular}

Note: NaN means that no solution was found under that calibration. Shaded cells indicate the parameter values combinations that generate the highest welfare in the table.

Table B.8: Sensitivity analysis of Non-Ricardian welfare under $\overline{\mathcal{D}}=2 \%$ 


\section{B.7.2.3}

Sensitivity analysis under $\overline{\mathcal{D}}=5 \%$

Rule 1: Risky policy asset, but the CB ignores default-risk dynamics

\begin{tabular}{lrrrrr}
\hline \hline & $\gamma_{\tau}=0.100$ & $\gamma_{\tau}=0.125$ & $\gamma_{\tau}=0.150$ & $\gamma_{\tau}=0.175$ & $\gamma_{\tau}=0.200$ \\
\hline$\phi^{\pi}=1.00$ & 417 & -2942 & $\mathrm{NaN}$ & $\mathrm{NaN}$ & $\mathrm{NaN}$ \\
$\phi^{\pi}=1.25$ & $\mathrm{NaN}$ & -1325 & -640 & -445 & -377 \\
$\phi^{\pi}=1.50$ & $\mathrm{NaN}$ & -1317 & -653 & -451 & -371 \\
$\phi^{\pi}=1.75$ & $\mathrm{NaN}$ & -1297 & -653 & -451 & -370 \\
$\phi^{\pi}=2.00$ & $\mathrm{NaN}$ & -1314 & -649 & -451 & -362 \\
$\phi^{\pi}=2.25$ & $\mathrm{NaN}$ & -1183 & -652 & -450 & -334 \\
$\phi^{\pi}=2.50$ & $\mathrm{NaN}$ & -641 & -649 & -437 & -309 \\
$\phi^{\pi}=2.75$ & $\mathrm{NaN}$ & -314 & -560 & -420 & -329 \\
$\phi^{\pi}=3.00$ & $\mathrm{NaN}$ & -490 & -509 & -393 & -239 \\
\hline \hline
\end{tabular}

Rule 2: Risky policy asset, and the CB perfectly tracks default-risk dynamics

\begin{tabular}{lrrrrr}
\hline \hline & $\gamma_{\tau}=0.100$ & $\gamma_{\tau}=0.125$ & $\gamma_{\tau}=0.150$ & $\gamma_{\tau}=0.175$ & $\gamma_{\tau}=0.200$ \\
\hline$\phi^{\pi}=1.00$ & $\mathrm{NaN}$ & $\mathrm{NaN}$ & $\mathrm{NaN}$ & $\mathrm{NaN}$ & $\mathrm{NaN}$ \\
$\phi^{\pi}=1.25$ & $\mathrm{NaN}$ & -1438 & -702 & -482 & -398 \\
$\phi^{\pi}=1.50$ & $\mathrm{NaN}$ & -1411 & -690 & -476 & -345 \\
$\phi^{\pi}=1.75$ & $\mathrm{NaN}$ & -1322 & -642 & -408 & -210 \\
$\phi^{\pi}=2.00$ & $\mathrm{NaN}$ & -1269 & -632 & -415 & -164 \\
$\phi^{\pi}=2.25$ & $\mathrm{NaN}$ & -712 & -570 & -313 & -261 \\
$\phi^{\pi}=2.50$ & $\mathrm{NaN}$ & -658 & -525 & -223 & -218 \\
$\phi^{\pi}=2.75$ & $\mathrm{NaN}$ & -396 & -401 & -229 & -203 \\
$\phi^{\pi}=3.00$ & $\mathrm{NaN}$ & -170 & -407 & -216 & -204 \\
\hline \hline
\end{tabular}

Note: NaN means that no solution was found under that calibration. Shaded cells indicate the parameter values combinations that generate the highest welfare in the table.

Table B.9: Sensitivity analysis of Ricardian welfare under $\overline{\mathcal{D}}=5 \%$ 
Rule 1: Risky policy asset, but the CB ignores default-risk dynamics

\begin{tabular}{lrrrrr}
\hline \hline & $\gamma_{\tau}=0.100$ & $\gamma_{\tau}=0.125$ & $\gamma_{\tau}=0.150$ & $\gamma_{\tau}=0.175$ & $\gamma_{\tau}=0.200$ \\
\hline$\phi^{\pi}=1.00$ & 8670 & -8765 & $\mathrm{NaN}$ & $\mathrm{NaN}$ & $\mathrm{NaN}$ \\
$\phi^{\pi}=1.25$ & $\mathrm{NaN}$ & -3492 & -1412 & -816 & -599 \\
$\phi^{\pi}=1.50$ & $\mathrm{NaN}$ & -3591 & -1520 & -891 & -641 \\
$\phi^{\pi}=1.75$ & $\mathrm{NaN}$ & -3570 & -1541 & -904 & -650 \\
$\phi^{\pi}=2.00$ & $\mathrm{NaN}$ & -3635 & -1538 & -910 & -639 \\
$\phi^{\pi}=2.25$ & $\mathrm{NaN}$ & -3256 & -1549 & -911 & -586 \\
$\phi^{\pi}=2.50$ & $\mathrm{NaN}$ & -1657 & -1544 & -884 & -539 \\
$\phi^{\pi}=2.75$ & $\mathrm{NaN}$ & -694 & -1308 & -847 & -579 \\
$\phi^{\pi}=3.00$ & $\mathrm{NaN}$ & -1215 & -1173 & -783 & -400 \\
\hline \hline
\end{tabular}

Rule 2: Risky policy asset, and the CB perfectly tracks default-risk dynamics

\begin{tabular}{lrrrrr}
\hline & $\gamma_{\tau}=0.100$ & $\gamma_{\tau}=0.125$ & $\gamma_{\tau}=0.150$ & $\gamma_{\tau}=0.175$ & $\gamma_{\tau}=0.200$ \\
\hline$\phi^{\pi}=1.00$ & $\mathrm{NaN}$ & $\mathrm{NaN}$ & $\mathrm{NaN}$ & $\mathrm{NaN}$ & $\mathrm{NaN}$ \\
$\phi^{\pi}=1.25$ & $\mathrm{NaN}$ & -4032 & -1704 & -1010 & -741 \\
$\phi^{\pi}=1.50$ & $\mathrm{NaN}$ & -3953 & -1669 & -993 & -627 \\
$\phi^{\pi}=1.75$ & $\mathrm{NaN}$ & -3688 & -1538 & -829 & -352 \\
$\phi^{\pi}=2.00$ & $\mathrm{NaN}$ & -3528 & -1512 & -845 & -257 \\
$\phi^{\pi}=2.25$ & $\mathrm{NaN}$ & -1875 & -1343 & -604 & -451 \\
$\phi^{\pi}=2.50$ & $\mathrm{NaN}$ & -1715 & -1222 & -393 & -364 \\
$\phi^{\pi}=2.75$ & $\mathrm{NaN}$ & -940 & -888 & -406 & -333 \\
$\phi^{\pi}=3.00$ & $\mathrm{NaN}$ & -270 & -907 & -375 & -334 \\
\hline \hline
\end{tabular}

Note: NaN means that no solution was found under that calibration. Shaded cells indicate the parameter values combinations that generate the highest welfare in the table.

Table B.10: Sensitivity analysis of Non-Ricardian welfare under $\overline{\mathcal{D}}=5 \%$ 


\section{B.8 \\ Endogenous regime-switching DSGE solution strategy}

The third step ${ }^{8}$ of the solution algorithm of this paper's regime-switching dynamic stochastic general equilibrium (RS-DSGE) model employs the method described in Maih (2015) with the help of the MatLab toolbox RISE ${ }^{9}$, developed by the same author. This method embeds switching behavior in perturbation solutions, allowing for the transition probability matrix to be time-varying and determined endogenously, that is, state-to-state probabilities can depend on the state vector of the model. Besides, such a method does not require the existence of a unique steady state across different regimes, differently from methods that first linearize the model to only then impose Markov-switching behavior to some of its parameters - an approach that reduces the capacity of the model of truly reflecting its original non-linearities. Furthermore, compared to so-called "global methods" that discretize the state space into a grid of points, the curse of dimensionality is a much smaller problem here.

The algorithm develops as follows, where we maintain the notation of Maih (2015), but with fewer details.

The problem we solve is

$$
\mathbb{E}_{t} \sum_{r_{t+1}=1}^{h} \pi_{r_{t}, r_{t+1}}\left(I_{t}\right) \tilde{d}_{r_{t}}(v)=0
$$

where $h$ is the regime at time $t, \tilde{d}_{r_{t}}: \Re^{n_{\nu}} \rightarrow \Re^{n_{d}}$ is a $n_{d}$ x 1 vector of functions with argument $\nu, r_{t}$ is the regime at time $t, \pi_{r_{t}, r_{t+1}}\left(I_{t}\right)$ is the transition probability from regime $r_{t}$ to $r_{t+1}$ at the next period, and $I_{t}$ is the information set at time $t$. The vector $\nu$, by its turn, is given by

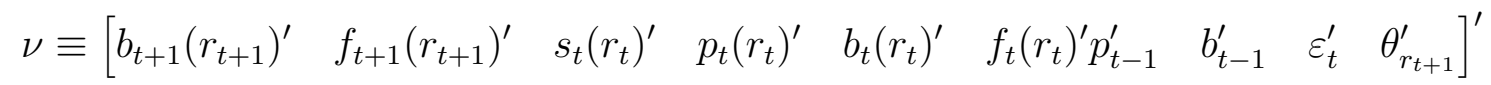

- $s_{t}$ is a vector of static variables, the ones that appear only at time $t$

- $f_{t}$ is a vector of forward-looking variables, the ones that appear at times $t$ and $t+1$

- $p_{t}$ is a vector of predetermined variables, the ones that appear at times $t$ and $t-1$

${ }^{8}$ The first step is the solution of the model as a function of its non-linearities; the second step is the calculation of the fiscal limit distribution using "global methods".

${ }^{9}$ Available on https://github.com/jmaih/RISE_toolbox/ as of August 162020. 
- $b_{t}$ is a vector of both variables, the ones that appear at times $t-1, t$, and $t+1$

- $\varepsilon_{t}$ is a vector of shocks such that $\varepsilon_{t} \sim N\left(0, I_{n_{\varepsilon}}\right)^{10}$

- $\theta_{r_{t+1}}$ is a vector of switching parameters appearing with a lead

where $n_{g}$ is the length of vector $g$. Note that the parameters of the model are implicitly attached to the object $\tilde{d}_{r_{t}}$, so that even the equations in each regime are allowed to differ. Besides, it is required that each transition probability function contains only parameters that are fixed through time, and that input variables have a unique steady state. Both conditions are satisfied in our model. The expected default probability function depends only on stationary exogenous processes and a stationary variable, debt, whose convergence is guaranteed by the tax policy rule. The probability that the peak of the Laffer curve is binding, by its turn, depends only on the shadow tax rate, whose steady state is the same across regimes.

The algorithm assumes that agents may have information about shocks into the future. ${ }^{11}$ The state vector is defined as

$$
z_{t} \equiv\left[\begin{array}{lllllll}
p_{t-1}^{\prime} & b_{t-1}^{\prime} & \sigma & \varepsilon_{t}^{\prime} & \varepsilon_{t+1}^{\prime} & \cdots & \varepsilon_{t+k}^{\prime}
\end{array}\right]^{\prime}
$$

where $\sigma$ is the perturbation parameter.

The general solution to our problem takes the form

$$
y_{t}\left(r_{t}\right) \equiv\left(\begin{array}{c}
s_{t}\left(r_{t}\right) \\
p_{t}\left(r_{t}\right) \\
b_{t}\left(r_{t}\right) \\
f_{t}\left(r_{t}\right)
\end{array}\right)=\mathcal{T}^{r_{t}}\left(z_{t}\right) \equiv\left(\begin{array}{c}
\mathcal{S}^{r_{t}}\left(z_{t}\right) \\
\mathcal{P}^{r_{t}}\left(z_{t}\right) \\
\mathcal{B}^{r_{t}}\left(z_{t}\right) \\
\mathcal{F}^{r_{t}}\left(z_{t}\right)
\end{array}\right)
$$

where $y_{t}\left(r_{t}\right)$ is the vector of all endogenous variables, and $\mathcal{T}^{r_{t}}\left(z_{t}\right)$ is the vector of their respective decision rules.

To help us in obtaining the approximations of the model, we define some selector matrices. First, for all $g \in\{s, p, b, f\}, \lambda_{x} \equiv\left(\begin{array}{c}\lambda_{p} \\ \lambda_{b}\end{array}\right)$ and $\lambda_{b f} \equiv\left(\begin{array}{c}\lambda_{b} \\ \lambda_{f}\end{array}\right)$ select $p-b$ and $b-f$ variables, respectively. Second, for all $g \in z_{t}$, a matrix $m_{g}$ selects $g$-type variables in $z_{t}$.

We express now forward-looking variables as a function of the current state vector by employing the relation $z_{t+1}=h^{r_{t}}\left(z_{t}\right)+u z_{t}$, where

\footnotetext{
${ }^{10}$ Modeling correlated shocks is possible under this solution algorithm by creating auxiliary variables that are linear combinations of the shocks.

${ }^{11}$ This "anticipated shocks" approach has advantages over the "news shocks" approach, for in the first one shocks are actually structural, suffer horizon-discount, and allow for Bayesian model comparison (Maih, 2015).
} 


$$
\begin{aligned}
& h^{r_{t}}\left(z_{t}\right) \equiv\left[\begin{array}{llllll}
\left(\lambda_{x} \mathcal{T}^{r_{t}}\left(z_{t}\right)\right)^{\prime} & \left(m_{\sigma} z_{t}\right)^{\prime} & \left(m_{\varepsilon, 1} z_{t}\right)^{\prime} & \ldots & \left(m_{\varepsilon, k} z_{t}\right)^{\prime} & \left(0_{n_{\varepsilon}} x 1\right)^{\prime}
\end{array}\right] \\
& \text { and } u \equiv\left[\begin{array}{c}
0_{\left(n_{p}+n_{b}+1+k_{n_{\varepsilon}}\right) \times n_{z}} \\
\varepsilon_{t+k+1} m_{\sigma}
\end{array}\right]
\end{aligned}
$$

Following the algorithm, we can express $v$ as a function of the state variables, including the switching parameters, for which we postulate that $\theta_{r_{t+1}}=\bar{\theta}_{r_{t}}+\sigma \hat{\theta}_{r_{t+1}}{ }^{12}$ where we adopt in this paper that $\bar{\theta}_{r_{t}}$ is the steady state of regime 1 (no constraints are binding).

$$
v=\left(\begin{array}{c}
\lambda_{b f} \mathcal{T}^{r_{t+1}}\left(h^{r_{t}}\left(z_{t}\right)+u z_{t}\right) \\
\mathcal{T}^{r_{t}}\left(z_{t}\right) \\
m_{p} z_{t} \\
m_{b} z_{t} \\
m_{\varepsilon, 0} z_{t} \\
\bar{\theta}_{r_{t}}+\hat{\theta}_{r_{t+1}} m_{\sigma} z_{t}
\end{array}\right)
$$

The logic of choosing a regime-specific steady state is that, once the system is at that regime, it will remain at the same point in the absence of further shocks and of regime changes. Maih (2015) makes the case that the ergodic mean is not necessarily an attractor of the system, and that agents may act as to insure against switching to another regime and not to the ergodic mean. In that last case, unconditional forecasts done with the model could miss the level suggested by the recent history of the data. The regime-specific steady state can be computed by making

$$
\tilde{d}_{r_{t}}\left(b_{t}\left(r_{t}\right), f_{t}\left(r_{t}\right), s_{t}\left(r_{t}\right), p_{t}\left(r_{t}\right), b_{t}\left(r_{t}\right), f_{t}\left(r_{t}\right), p_{t}\left(r_{t}\right), b_{t}\left(r_{t}\right), 0, \theta_{r_{t}}\right)=0
$$

By now, we are able to take $1^{\text {st }}$ and $2^{\text {nd }}$ order (for calculating welfare) Taylor approximations of the objective function around our picked reference point. We redirect the reader to sections 3.2 and 3.3 of Maih (2015), where she can find more details of these approximations, and to section 5.2 of the same paper, where she can find more details about the solution technique employed by RISE. The toolbox uses a functional iteration algorithm that, despite the fact that it is not able to find all the solutions, it is still useful for solving large systems. It is important to note that, so far to the best of our knowledge, there is no stability concept in the literature that comprehends solutions of regime-switching models with endogenous (not necessarily smooth) transition probabilities of the like employed in this paper.

\footnotetext{
${ }^{12}$ Maih (2015) shows that this is the expression that results from a first-order approximation of an endogenous auxiliary variable meant for handling the presence of future switching parameters in the model.
} 